\title{
Cesar Enoki
}

\section{GESTÃO DE PROCESSOS DE NEGÓCIO:}

\author{
Uma Contribuição para a Avaliação de Soluções \\ de Business Process Management (BPM) sob a \\ ótica da Estratégia de Operações
}




\title{
Cesar Enoki
}

Cesar Hidetoshi Enoki

\section{GESTÃO DE PROCESSOS DE NEGÓCIO:}

\author{
Uma Contribuição para a Avaliação de Soluções \\ de Business Process Management (BPM) sob a \\ ótica da Estratégia de Operações
}

\author{
Dissertação apresentada à Escola \\ Politécnica da Universidade de São \\ Paulo para obtenção do Título de Mestre \\ em Engenharia. \\ Área de Concentração: \\ Engenharia de Produção
}

Orientador: Prof. Doutor Antonio R. N. Muscat.

São Paulo

2006 
Ficha catalográfica.

Dados Internacionais de Catalogação na Publicação (CIP)

Enoki, Cesar. (Cesar Hidetoshi Enoki)

Gestão de processos de negócio: uma Contribuição para a Avaliação de Soluções de Business Process Management (BPM) sob a ótica da Estratégia de Operações. São Paulo: 2006 $213 p$.

Dissertação (Mestrado). Escola Politécnica da Universidade de São Paulo- Departamento de Engenharia de Produção.

1.Estratégia de Operações 2. Gestão de Processos 4. Objetivos de Desempenho 4. Business Process Management I. Universidade de São Paulo. Escola Politécnica. Departamento de Engenharia de Produção. II.t

É permitida a reprodução total ou parcial deste trabalho, desde que: a) sem fins lucrativos; e b) se atribuam os créditos de autoria. 


\section{PÁGINA DE APROVACẼ̃O}

Escola Politécnica da Universidade de São Paulo

GESTÃO DE PROCESSOS DE NEGÓcIO:

Uma Contribuição para a Avaliação de Soluções de Business Process Management (BPM) sob a ótica da Estratégia de Operações

(Dissertação)

CESAR HIDETOSHI ENOKI

Data:

BANCA EXAMINADORA 


\section{DEDICATÓRIA}

We shall not cease from exploration

And the end of all our exploring

Will be to arrive where we started

And know the place for the first time.

T.S. Eliot

Esta dissertação é dedicada à todos que me apoiaram durante a sua confecção. Aos meus pais por todos estes anos. Aos meus amigos que sempre souberam me ouvir e oferecer algum conselho. 


\section{AGRADECIMENTOS}

Ao Prof. Dr. Antonio Rafael Namur Muscat pela sua amizade, paciência, conhecimento e senso crítico ao longo da orientação acadêmica. Cada vez mais a atuação na pesquisa científica evoca uma profunda reflexão sobre o dinamismo das demandas do mundo empresarial $e$ as infinitas oportunidades ainda não exploradas.

Meus sinceros agradecimentos aos colegas Maurício, Renato e Inácio por compartilharem suas experiências profissionais. E, à todos aqueles que direta ou indiretamente participaram da pesquisa.

Aos Profs. do Departamento de Engenharia de Produção, em especial aos Profs. Fleury, Spínola, Paulino, Miyake, e Hugo pelo interesse e apoio.

Ao Profs. De Sordi e M. Pessoa pelas sugestões e colaborações fundamentais para a concretização do trabalho.

À Cilene por me fazer lembrar que tudo é possível com Amor e muita Fé.

Um agradecimento especial ao Prof. Manuel Meireles por seus admiráveis ideais enquanto educador e contínua fonte de apoio nas horas decisivas.

E, por fim, à Deus por cada dia. 


\section{Resumo}

Em ambientes de negócios, a busca incessante pela competitividade tem demandado uma maior capacidade de lidar com as mudanças. Com o objetivo de atender à esta dinâmica, as empresas buscam soluções de integração dos seus processos com uso intensivo de tecnologia da informação, de modo a prover maior flexibilidade e agilidade nas suas operações. O termo Solução de Business Process Management, ou abreviadamente BPMS (Business Process Management System), diz respeito à plataforma tecnológica para a realização das iniciativas de integração e gestão dos processos de negócio neste contexto. Identifica-se como relevante a discussão sobre os requisitos organizacionais necessários para o uso de tais instrumentos e, especialmente, quanto à adequação das soluções de BPM existentes no mercado sob a ótica da estratégia de operações pela diversidade de alternativas existentes. Assim, esta pesquisa amplia os estudos relacionados com Gestão de Operações no que tange aos aspectos de avaliação de soluções de BPM na ótica do gestor de negócios.

Foi desenvolvido um modelo de avaliação com o uso da técnica AHP (Analytic Hyerarchy Process), que permitiu identificar e relacionar as características funcionais de uma solução BPM com os objetivos de desempenho na visão do gestor do negócio. Tal modelo consubstancia-se em um questionário e uma matriz de priorização dos objetivos de desempenho, possibilitando a obtenção de uma nota de perfil competitivo para cada solução de BPM avaliada. Para a validação do modelo foram utilizados o método Delphi na definição do questionário e o método do estudo de caso na verificação da sua aplicabilidade. $O$ modelo proposto mostrou-se adequado para o entendimento das soluções apresentadas e as diferenças entre as mesmas em termos de capacidades e vocações dentro da perspectiva do gestor do negócio. Além disso, o resultado do estudo de caso pemitiu a classificação das alternativas e a delimitação do universo a ser considerado à priori, o que contribui para uma seleção na visão do gestor do negócio e diminui a percepção de risco do investimento a ser feito. 


\begin{abstract}
In business-oriented environments, the incessant search for competitiveness has demanded a higher ability to deal with changes. In order to follow such dynamics, companies have been searching for solutions of integration of its processes with intensive use of information technology, in a way of providing better flexibility and speed to its operations. The term Business Process Management Solution, or Business Process Management System (BPMS) provides a technological platform for realizing such initiatives.

It seems relevant a discussion about organizational requirements needed to apply such tools and, specially, on BPM solutions adequacy under operations strategy point-of-view. A model for evaluation based on the use of AHP (Analytic Hierarchy Process) was developed to identify the functional characteristics of a BPM solution and link to the performance objectives from the business manager point-of-view. Such model is composed of a questionnaire and a matrix of prioritization of the targeted performance objectives, making possible the attainment of one competitive profile grade for each evaluated solution. The model has been validated with the Delphi method for the questionnaire definition and the method of case study for its applicability. Its application proved to be adequate to better understand the presented solutions and the differences among them in terms of capacity and strengths from the manager view, and, it allows a logical selection delimiting the universe to be evaluated what might diminish the perception of risk of the investment to be made.
\end{abstract}




\section{SUMÁRIO}

Lista de llustrações

Lista de Abreviaturas, siglas e símbolos

Capítulo 1-Definição de objetivos

1.1-O problema da pesquisa

1.2-Objetivo da pesquisa

1.2.1-Objetivo Geral

1.2.2-Objetivos Específicos da Pesquisa

1.3-Características da pesquisa

1.3.1-Mapa Conceitual

1.3.2-Aplicabilidade e Utilidade da Pesquisa

1.3.3-Delimitações e Limitações da Pesquisa

1.4-Aspectos metodológicos relevantes

Capítulo 2-Revisão da Literatura

2.1-Estratégia de Operações

2.2-Objetivos de Desempenho

2.3-Abordagem por Processos

2.4-Modelagem de Processos

2.5-Gestão de Processos e Tecnologia da Informação

2.6-Business Process Management (BPM)

2.6.1-Abordagem BPM nas Organizações

2.6.2-A Solução BPM como Plataforma Tecnológica

2.6.3-Soluções de BPM

2.6.4-O Mercado de BPM segundo Delphi Reports (2002-2004)

2.7-Considerações sobre Avaliação de Soluções de Software.

Capítulo 3-Modelo proposto

3.1-Fundamentos Teóricos do Modelo Proposto

3.1.1-Funcionalidades das soluções de BPM

3.1.2-Objetivos de Desempenho

3.1.3-Vínculo das funcionalidades com os objetivos de desempenho

3.2-Propriedades e Limitações do Modelo Proposto

3.3-Síntese do Modelo Proposto

\section{Capítulo 4-Metodologia}

4.1-Operacionalização da Pesquisa

4.2-Matriz AHP (Analytic Hierarchy Process)

4.3-Delphi Eletrônico

4.3.1-Escolha de Especialistas

4.3.2-Sistemática de operacionalização do Delphi eletrônico

4.3.2.1-Adequação da Lista de Funcionalidades

4.3.2.2-Associação entre Funcionalidade e Macro-Funcionalidades

4.3.2.3-Associação das Macro-Funcionalidades com Objetivos de Desempenho

4.3.3-Tratamento Estatístico das Respostas

4.3.3.1-Grau de Convergência

4.3.3.2-Grau de Concordância

4.3.4-Tratamento dos Comentários

4.3.5-Teste Wilcoxon de sinais ordenados

4.4-Uso do estudo de caso

4.4.1-Protocolo do Estudo de Caso xii

xiii

1

1

3

3

3

4

4

5

6

7

8

iii

8 
Capítulo 5-Resultados Obtidos $\quad 89$

5.1-Refinamento do Instrumento $\quad 89$

5.2-Resultados do Método Delphi 90

5.2.1-Aplicação do Método Delphi $\quad 90$

5.2.2-Etapa Inicial com vistas a validar as funcionalidades $\quad 91$

5.2.3-Etapa de Validação dos Agrupamentos das funcionalidades 94

5.2.4-Etapa de Validação do Relacionamento entre as Macro-Funcionalidades e os Objetivos de Desempenho $\quad 95$

5.3-Estudo de Caso $\quad 97$

5.3.1-Entrevistas com os Fornecedores 100

5.3.2-Entrevistas com os Usuários 104

5.3.3-Diferenças de Percepções entre Fornecedores e Usuários 106

5.4-Aplicação do Modelo 109

5.5- Síntese dos Resultados 119

5.5.1-Refinamento do Instrumento 120

$\begin{array}{ll}\text { 5.5.2-Delphi Eletrônico } & 120\end{array}$

5.5.3-Aplicabilidade do Modelo 121

Capítulo 6-Conclusões e Recomendações 122

6.1-Conclusões $r$

6.2-Recomendações 126

$\begin{array}{lr}\text { Bibliografia } & 127\end{array}$

Apêndices

Apêndice 1 - Questionário de Avaliação: Versão Preliminar 136

Apêndice 2 - Questionário de Avaliação: Versão $2 \quad 138$

Apêndice 3 - Questionário de Avaliação: Versão 3

Apêndice 4 - Questionário de Avaliação: Versão 4

Apêndice 5 - Validação das Funcionalidades 145

Apêndice 6 - Agrupamentos das Funcionalidades 159

Apêndice 7 - Macro-Funcionalidades X Objetivos de Desempenho 176

Apêndice 8 - Macro-Funcionalidades X Objetivos de Desempenho - Matrizes AHP 186

Apêndice 9 - Tabulações do Delphi Eletrônico 191

Anexos

Anexo 1 - Lista de Especialistas $\quad 195$

$\begin{array}{lr}\text { Anexo 2-BPMN } & 202\end{array}$ 


\section{LISTA DE ILUSTRAÇÕES}

Figura 01 - Mapa Conceitual da Pesquisa 5

Figura 02 - Abordagem por Processos $\quad 21$

Figura 03 - Ferramentas de Modelagem segundo Gartner Group 27

$\begin{array}{ll}\text { Figura } 04 \text { - Conjunto de Soluções de Integração } & 29\end{array}$

Figura 05 - BPMS (Foco em T.I.) versus BPM (Foco no Negócio) 31

Figura 06 - Plataforma Tecnológica e a Dinâmica e Complexidade do Negócio $\quad 35$

Figura 07 - Modelo conceitual de uma Solução BPM 41

Figura 08 - Quadrante Mágico - Gartner Group $\quad 44$

Figura 09 - Referencial Teórico das Funcionalidades de uma Solução BPM 54

$\begin{array}{ll}\text { Figura } 10 \text { - Esquema conceitual de Delphi Eletrônico } & 67\end{array}$

Figura 11 - Exemplo do Questionário $\quad 70$

Figura 12 - Exemplo Matriz AHP - Funcionalidades da Solução BPM 72

Figura 13 - Exempo de Lista Ordenada das Macro-Funcionalidades com Objetivos de Desempenho $\quad 74$

Figura 14 - Exemplos para determinação do grau de concordância 82

Figura 15 - Coeficiente de Correlação de Postos de Spearman 83

$\begin{array}{ll}\text { Figura } 16 \text { - Posição Relativa das Soluções Avaliadas } & 100\end{array}$

Figura 17 - Exemplo de Agrupamento de Funcionalidades $\quad 110$

Figura 18 - Matriz Normalizada da Matriz de Valores da Figura $17 \quad 111$

Figura 19 - Razão de Consistência para a Matriz AHP - Desenho de Processos 112

Figura 20 - Matriz AHP de Macro-Funcionalidades versus Objetivos de Desempenho 112

Figura 21 - Matriz Normalizada para o Objetivo de Desempenho Flexibilidade $\quad 113$

Figura 22 - Razão de Consistência para a Matriz AHP - Flexibilidade 113

Figura 23 - Matriz AHP com os Objetivos de Desempenho da Empresa AICl 118

$\begin{array}{ll}\text { Quadro } 01 \text { - Abordagens Organizacionais } & 17\end{array}$

Quadro 02 - Organização Funcional versus por Processos 18

Quadro 03 - Escala da Matriz AHP 63

Quadro 04 - Atividades com vistas ao refinamento do instrumento 89

Quadro 05 - Atividades Referentes à Aplicação do Método Delphi 90

Quadro 06 - Objetivos de Desempenho da Empresa AICl 99

Tabela 01 - Interpretação do valor de rho de Spearman 76

$\begin{array}{ll}\text { Tabela } 02 \text { - Grau de Concordância para a Solução SBPMa } & 107\end{array}$

Tabela 03 - Grau de Concordância para a Solução SBPMc 108

Tabela 04 - Grau de Concordância para a Solução SBPMd 108

$\begin{array}{ll}\text { Tabela } 05 \text { - Tabela de Coeficientes } & 114\end{array}$

Tabela 06 - Quadro Comparativo das Soluções BPM em Relação aos Objetivos de
Desempenho

Tabela 07 - Exemplo de Cálculo do Grupo Gerenciamento de Acesso 116

Tabela 08 - Avaliação das Soluções BPM pelos Fornecedores 117

Tabela 09 - Nota de Perfil Competitivo das Soluções BPM Avaliadas 117

Tabela 10 - Exemplo de Cálculo da Nota do Perfil Competitivo da Solução SBPMd 119 


\title{
LISTA DE ABREVIATURAS, SIGLAS E SÍMBOLOS
}

\author{
A2A - Application to Application \\ AHP - Analytic Hierarchy Process \\ B2B - Business-to-Business \\ BPM - Business Process Management \\ BPMI - Business Process Management Initiative \\ BPML - Business Process Modeling Language \\ BPMN - Business Process Modeling Notation \\ BPMS - Business Process Management System \\ BPR - Business Process Reengineering \\ CRM - Customer Relationship Management \\ EAI - Enterprise Application Integration \\ EDI - Electronic Data Interchange \\ ERP - Enterprise Resource Planning \\ FPNQ - Fundação Programa Nacional de Qualidade \\ $\mathrm{H} 2 \mathrm{H}$ - Human to Human \\ IC - İndice de Consistência \\ IR - Índice Randômico \\ PKI - Performance Key Indicator \\ PNQ - Programa Nacional de Qualidade \\ RC - Razão de Consistência \\ SCM - Supply Chain Management \\ TI - Tecnologia da Informação \\ TNG - Técnica Nominal de Grupo \\ TQM - Total Quality Management \\ WfMC - Workflow Management Coalition
}




\section{Capítulo 1 Definição de objetivos}

\subsection{O problema da pesquisa}

Em ambientes de negócios, a busca de competitividade tem demandado uma maior capacidade de lidar com as mudanças (Smith\&Fingar, 2003; Burlton, 2001). Neste contexto, as organizações se vêem forçadas a adequar seus padrões e procedimentos (Hammer, 2001). Essas transformações têm afetado significativamente a tarefa de gerenciar a operação, refletindo em uma busca intensa da aplicação de tecnologia.

Harrington (1988) ressalta o conceito de agregação de valor através dos processos envolvidos, definindo processo como "uma série de atividades que recebe um insumo, agrega-lhe valor e produz um produto ou uma saída (aplicação de habilidades adicionando valor a um insumo)". Para Hammer\&Stanton apud Usirono (2003), processo é um grupo de tarefas inter-relacionadas e que geram valor para o cliente. Portanto, a gestão orientada no sentido da agregação de valor ocorre ao longo das diversas funções (horizontalmente) nas Organizações, através de seus processos (Santos et al., 2004).

O projeto ou a arquitetura dos processos deve considerar o aumento da complexidade e o nível de concorrência do ambiente, particularmente pela necessidade de integração, atender à dinâmica, prover flexibilidade e inovação (Grover\&Kettinger, 2000; Vernadat, 1996; Aalst, 2000; e Salerno, 1999). Atualmente, as empresas buscam soluções de integração dos processos fundamentadas em tecnologia da informação, de modo a prover tais características à sua operação. 
Uma nova concepção de software para gestão de processos denominada de BPMS (Business Process Management System) tem surgido com a intenção de permitir a integração e adaptação entre os diversos processos de negócios dentro de uma abordagem colaborativa, ou seja, integrando as atividades internas e externas da organização, mesmo baseadas em distintas plataformas tecnológicas (De Sordi et al., 2002).

De acordo com o relatório do Gartner de 2004 (Sinur, 2005), existe mais de uma centena de produtos disponíveis no mercado de BPMS. Embora as características técnicas de cada produto sejam fatores importantes a considerar, não se constatam muitos estudos que busquem avaliar os impactos de tais soluções nos objetivos de desempenho do negócio. A questão que se coloca é como selecionar a melhor alternativa de modo a atender às características de uma operação com um perfil competitivo determinado? Ou seja, é possível avaliar soluções ${ }^{1}$ de BPM (Business Process Management) sob a ótica da estratégia de operações, no sentido de atender a um dado perfil competitivo?

O presente trabalho está associado ao tópico soluções de BPM dentro do tema gestão de processos relacionado à gestão de operações.

A estrutura lógica, inerente à pesquisa, está ligada aos objetivos de desempenho de Operações como elementos necessários para fundamentar uma boa decisão na escolha de uma solução de integração e coordenação de processos. O problema da pesquisa não abrange os requisitos tecnológicos em profundidade, tampouco todo o universo de soluções existentes no mercado, mas tão somente características fundamentais que o gestor de Operações deve considerar na avaliação de soluções de BPM para justificar a escolha. $O$ que está sob foco, na presente pesquisa, é a forma como os gestores de operações devem avaliar soluções de BPM

\footnotetext{
${ }^{1}$ Aqui o termo soluções de BPM (Business Process Management) é utilizado referindo-se à plataforma tecnológica para apoiar as iniciativas de gerenciamento voltado aos processos de negócio (Krafzig et al., 2005).
} 
de modo a obter melhor desempenho de suas operações com o uso das mesmas.

\subsection{Objetivo da pesquisa}

\subsection{1—Objetivo geral}

O objetivo principal da pesquisa é propor um modelo ou template ${ }^{2}$, para avaliar soluções de BPM (Business Process Management), sob a ótica da Estratégia de Operações. Neste sentido o modelo de avaliação privilegia os requisitos ou funcionalidades das soluções de BPM (software) asssociados a aspectos da Estratégia de Operações.

\subsection{2-Objetivos específicos}

Para alcançar o objetivo geral, alguns objetivos específicos serão necessários, tais como:

- validar qualitativamente o Modelo com consultores especialistas e acadêmicos da área por meio do método Delphi Eletrônico; e

- realizar um Estudo de Caso para verificar a aplicabilidade do Modelo de Avaliação.

\footnotetext{
${ }^{2}$ Template na definição de Ruth G. Millikan (on line book: on clear and confused ideas, http://vm.uconn.edu/ wwwphil/millikan.htm, acessado Março/2005), é o conjunto das características básicas e pragmáticas da "substância" na sua forma ideal.
} 


\subsection{Características da pesquisa}

A variedade de soluções tecnológicas impõem novos desafios para o gestor de negócios no tocante à identificação e avaliação de tais soluções. Assim, um template contendo os requisitos básicos pode auxiliar nesta avaliação, não como critério único mas, complementar à uma análise puramente de seleção de software (vide item 2.7), na medida em que permite avaliar as características da solução e o respectivo impacto provável no desempenho do negócio.

A dissertação pode ser enquadrada sinteticamente - quanto ao campo da pesquisa, tema e tópico - da seguinte forma:

$\begin{array}{ll}\text { Campo: Gestão de Operações; } \\ \text { Tema: } & \text { Avaliação de Soluções de Business Process } \\ & \text { Management (BPM) sob a ótica da Estratégia de } \\ & \text { Operações } \\ \text { Tópico: } & \text { BPM (Business Process Management) } \\ \text { Problema: } & \text { Quais quesitos devem constar em um template, } \\ & \text { para avaliar soluções de BPM (Business Process } \\ & \text { Management), que sejam relevantes para a } \\ & \text { Estratégia de Operações? }\end{array}$

1.3.1-Mapa conceitual

O mapa conceitual que orienta a presente pesquisa pode ser visto na figura 01, a seguir: 
Fig. 01: Mapa Conceitual da pesquisa.

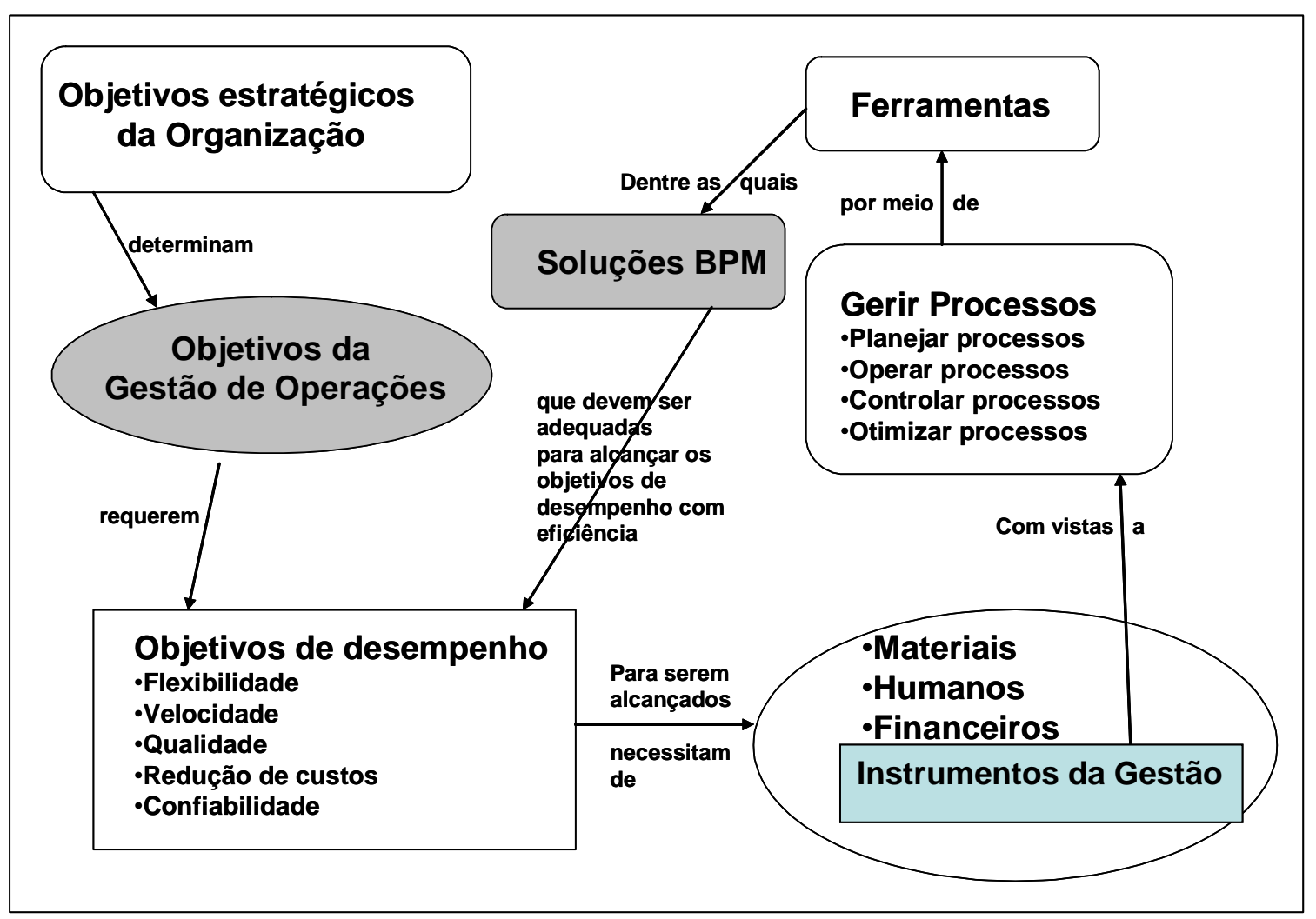

Fonte: Elaborado pelo autor (2006).

\subsection{2-Aplicabilidade e utilidade da pesquisa}

Este trabalho se aplica às empresas de modo geral que buscam a utilização de tecnologia da informação para a gestão dos processos de negócio e implantação de processos flexíveis às mudanças demandadas pelo ambiente competitivo. Esta dissertação irá contribuir com conceitos quanto à aplicabilidade de soluções de BPM (Business Process Management) na ótica da estratégia de operações, com a abrangência e a profundidade que o tema requer.

O tema Gestão de Processos de Negócios ou Business Process Management apresenta-se na literatura com foco principalmente na solução tecnológica, ou seja, na abordagem dos fluxos de informação e integração dos recursos organizacionais por meio de sistemas computadorizados mas, sem fornecer maiores subsídios para a avaliação ou escolha do ponto de 
vista dos objetivos de desempenho da organização. Este tema exige uma visão integrada entre gestores de processos e de estratégia de operações, de maneira a definir adequadamente $\mathrm{o}$ modelo de avaliação e implementação dos requisitos das soluções de BPM na ótica do alinhamento com os objetivos de desempenho do negócio. Embora o conceito de orientação aos processos esteja permeado em diversas áreas, ainda se percebe interesse pelos meios acadêmico e empresarial, especialmente sob o foco da competitividade. Parece ser relevante uma discussão sobre os requisitos organizacionais necessários para o uso de tais instrumentos e, especialmente, quanto à adequação das soluções de BPM existentes no mercado sob a ótica da estratégia de operações. Assim, esta pesquisa amplia os estudos relacionados com Gestão de Operações e, pode chamar a atenção para aspectos de soluções de Integração e Coordenação de Processos.

Embora estes sejam alguns pontos importantes a destacar, cabe lembrar, na visão de Selltiz et al. (1975), que a relação entre a teoria e a pesquisa é sinérgica pois amplia a compreensão dos fatos, ao mesmo tempo que permite a geração de novas teorias.

\subsection{3-Delimitações e limitações da pesquisa}

Uma pesquisa, por maiores que sejam os recursos disponíveis em termos financeiros, humanos e de tempo, estará sempre restrita a alguns delimitadores que condicionarão os elementos deste trabalho. A presente pesquisa se ocupa na definição de alguns requisitos básicos funcionais que uma solução de BPM (Business Process Management) deve possuir. Tais requisitos não devem ser tomados como únicos mas, principalmente, necessários para as organizações que buscam melhorias de desempenho através de soluções integradoras de processos. Assim, esta pesquisa se ocupa em avaliar algumas das soluções de BPM disponíveis no mercado brasileiro com posicionamentos diferentes e, em processos que exigem a 
integração de pessoas e sistemas diversos com o uso de um template desenvolvido neste estudo.

\subsection{Aspectos metodológicos relevantes}

A presente pesquisa deve evidenciar, por meio de um template baseado nos requisitos básicos ou funcionalidades de uma solução de BPM, que pode-se selecionar as soluções mais adequadas à realidade de uma organização.

O método utilizado é o de opinião de especialistas (Malhotra, 2002) para a elaboração de um lista preliminar de funcionalidades; em seguida, utilizou-se a matriz AHP (Analytic Hierarchy Process) para estabelecer o grau de vinculação entre as funcionalidades de uma solução BPM e objetivos de desempenho segundo Slack (1993). O método Delphi foi empregado para avaliar a coerência do modelo proposto e, por fim, através de estudo de caso, se verificou a operacionalização do modelo de avaliação.

O estudo de caso, segundo YIN (1987), é um modo de pesquisa empírica que averigua fenômenos contemporâneos em seu contexto real, quando os limites entre fenômeno e o contexto não estão claramente definidos, e no qual são utilizadas diversas fontes de evidência. Assim, o estudo de caso possibilitará avaliar a coerência do modelo de avaliação e sua respectiva aplicabilidade na prática. 


\section{Capítulo 2 Revisão da Literatura}

Neste capítulo é feita uma revisão da literatura. São apresentados os conceitos da Estratégia de Operações (2.1); os objetivos de desempenho (2.2); a abordagem por processos (2.3); modelagem de processos (2.4); gestão por processos e a tecnologia da informação (2.5); o conceito de Business Process Management (2.6), a solução de BPM nas organizações (2.6.1), a solução de BPM como plataforma tecnológica (2.6.2), as soluções de BPM existentes (2.6.3), uma avaliação do mercado baseado nos relatórios do Delphi Group de 2002 a 2004 (2.6.4) e, algumas considerações sobre avaliação de soluções de software (2.7).

\section{1-Estratégia de operações}

Estratégia, como lembra Ghemawat et al. (2000), é "um termo criado pelos antigos gregos, que significava o comandante-chefe militar." A partir desta concepção, a estratégia é desenvolvida ao longo do tempo, sendo reconhecida como uma ferramenta importante para a condução dos negócios. As estratégias das organizações usualmente objetivam um resultado superior para o negócio.

Zaccarelli (1996) aponta a dificuldade que existe para se conceituar estratégia:

A dificuldade de se ter uma definição rápida e boa de estratégia deve-se à amplitude de seu conceito que impede a condensação em uma única frase. (...)Apresentamos o conceito de estratégia como um guia para decisões sobre ações interativas em problemas de passagem . (...) Estratégia foi definida como um guia para pensar nas decisões sobre ações interativas com reações não previsíveis 
Neste sentido Zaccarelli (1996) define estratégia como:

formulação de caminhos para a busca de vantagens competitivas que aumentem a competitividade da empresa junto aos consumidores, e de diferenciais mercadológicos que melhorem o posicionamento da empresa frente aos concorrentes.

Para Zaccarelli (1996), a estratégia não deve objetivar liquidar com os concorrentes, embora isso possa, eventualmente, acontecer: a empresa deve objetivar ter mais sucesso (ou menos insucesso) do que os concorrentes.

Mintzberg (2000) define estratégia como uma forma de pensar no futuro, integrada no processo decisório, com base em procedimento formalizado e articulador de resultados e em uma programação.

Ansoff (1977) considera a estratégia como um processo de decisão sob desconhecimento parcial voltado para o crescimento e desenvolvimento organizacional. Esse processo tem como produto final a especificação de: produtos, mercados e tecnologias. Ainda chama a atenção para o fato de que é o ambiente quem determina as respostas estratégicas necessárias, e quanto mais dinâmico, maior a necessidade de uma estrutura permanente para a estratégia.

O planejamento estratégico cedeu lugar à moderna estratégia que enfatiza agora as vantagens competitivas. Foi reconhecida então como indispensável a chamada estratégia operacional que está centrada nas operações de compra, produção, distribuição e vendas, para conseguir vantagem competitiva e um conveniente perfil competitivo.

Craig \& Grant (1999) associam a estratégia a um direcionamento de longo prazo em condições de incerteza. Definem gerenciamento estratégico como: elaboração e implementação da estratégia. Afirmam que a estratégia bem sucedida cria vantagem competitiva por meio do uso de recursos e capacidades alinhados com os fatores básicos de sucesso. 
Richard A. D’Aveni (1995), na sua obra "Hipercompetição : estratégias para dominar a dinâmica do mercado", aborda as quatro fontes de vantagem competitiva, às quais ele dá o nome de "vantagens competitivas estáticas":

o custo e qualidade (em seus produtos e serviços ofertados);

o timing (senso de oportunidade) e know-how (conhecimento);

o fortaleza (grandes barreiras à entrada de competidores de forma a manter os concorrentes fora do mercado); e

o reservas financeiras.

Williams et al. (1994) sugere que a estratégia possa ser visualizada em duas orientações básicas: tecnologia e mercado. A orientação para a tecnologia se preocupa com os processos e os produtos. A orientação para o mercado é caracterizada pela busca de oportunidades de mercado e pela satisfação das necessidades dos clientes.

Portanto, deve existir um alinhamento entre a visão do ambiente externo e interno à organização, de modo a prover os recursos que promovam a sua competitividade por meio de investimentos que representem valor ${ }^{3}$ para o mercado (Gerolamo et al., 2002). Para integrar essas duas visões, o conceito de competências essenciais - conjunto de habilidades e tecnologias que permite a uma empresa oferecer um determinado benefício aos clientes, introduzido por Hamel \& Prahalad, (1995) - permite uma visão na qual ao mesmo tempo em que contempla o investimento naqueles fatores que determinam o que a empresa faz de melhor, ou seja, suas competências, também fica atenta àquilo que o mercado exige.

Segundo Day (2001), estar orientado para o mercado é um fator capacitador de estratégias mais eficientes. Tais fatores incluem: cultura,

\footnotetext{
${ }^{3}$ Valor para o Cliente significa atender e/ou exceder as suas expectativas versus o preço ou sacrifício envolvidos. Valor para o acionista significa retorno financeiro sobre o negócio (Rutner, 2000).
} 
monitoramento do mercado, aptidões de relacionamento com o mesmo, modelo de organização e visão estratégica.

Uma empresa orientada para o mercado potencializa o seu desempenho e o valor que entrega para os seus clientes e acionistas. A satisfação do cliente decorrente do aumento de valor possibilita a geração de lealdade, constituindo-se neste ponto um vínculo positivo para a lucratividade da empresa.

Para Gary Hammel apud Day (2001: 211):

a estratégia é sempre o produto de uma interação inesperada e complexa entre idéias, informações, personalidades e desejos. O ritmo de mudança está se acelerando, a concorrência está se intensificando, os clientes estão mais exigentes e novas tecnologias estão solapando estruturas de negócios tradicionais. O Status quo tornou-se insustentável.

Porter, no artigo intitulado O que é Estratégia? (1996), afirma que a escolha da estratégia é um ponto significativo do planejamento ou replanejamento de uma empresa, pois a estratégia é uma das mais importantes bases para garantir o sucesso da empresa. Nesse artigo Porter sustentou que o núcleo da Administração central é tríplice:

o definir a estratégia de posicionamento;

o prover trade-offs ${ }^{4}$;

o promover ajustes entre atividades e funções.

Continuando, Porter afirma que a estratégia competitiva, para ser sustentável, exige trade-offs. Trade-offs ocorrem quando duas ou mais opções são incompatíveis, não são similares; criam a necessidade de escolha por parte do consumidor, e limitam objetivamente o que a empresa oferece. Os trade-offs dificultam o enquadramento dos concorrentes, são penetrantes pontas de lança na competição, sendo essenciais para a

\footnotetext{
${ }^{4}$ Termo não traduzível, por perder seu sentido, tal como acontece com software, layout, etc.. Entretanto, podemos encontrar na literatura uma tradução aproximada pela expressão: "conflito de compromissos".
} 
estratégia: significam uma compensação balanceada, um perde-ganha de produtos ou serviços.

Considerando os trade-offs, Porter (1996) deu uma segunda abordagem ao seu conceito de estratégia:

Não é apenas a criação de uma inigualável e valiosa posição envolvendo um conjunto de múltiplas atividades que difere do conjunto de atividades dos rivais, mas é, também a definição de trade-offs: o que se fará e o que não se fará.

Desta forma a estratégia competitiva ou de operações exige a definição de atividades ou de funções em que a empresa terá uma performance melhor do que as empresas rivais, bem como definir como se relacionam umas atividades com as outras (Muscat \& Fleury, 1993). Significa escolher e combinar atividades. Se constrói base para uma vantagem competitiva pelo modo como as atividades se ajustam e mutuamente se reforçam.

Alguns autores descrevem estratégia de operações por meio de dois conceitos interrelacionados: conteúdo e processo. Enquanto o conteúdo está relacionado aos objetivos de desempenho que constituem a estratégia de operações (focando prioridades e áreas de decisão), o processo está relacionado ao modo que esses elementos são formados (Santos, 2004). E, portanto, a priorização dos objetivos de desempenho, por sua vez, está relacionada com o conceito de trade-off.

\section{2-Objetivos de desempenho}

Skinner (1969) afirma que "a conexão entre manufatura e sucesso corporativo é raramente vista como algo mais que a obtenção de alta eficiência e baixos custos. O ambiente competitivo se tornou mais complexo e, portanto, o conceito requer uma ampliação. Na visão de Nigel Slack 
(1993), a obtenção do sucesso estratégico significa obter competitividade na operação. Esta visão é complementada por Correa \& Gianesi (1994) podendo ser estendida para o setor de serviços. Esta competitividade pode ser traduzida em alguns fatores:

o Fatores Ganhadores de Pedidos: são aqueles que direta e signficativamente contribuem para o ganho de negócios.

o Fatores Qualificadores: podem ou não ser os principais determinantes do sucesso competitivo, mas são importantes para permitir estar presente no ambiente competitivo.

Estes fatores podem ser desdobrados e interpretados como obtenção de vantagens funcionais que definem o perfil competitivo de uma empresa e, que podem ser classificados como:

o vantagem em Qualidade - fazer certo. A dimensão qualidade pode ser entendida como a de adequação às especificações ou como de adequação aos propósitos, ou seja, alinhado com as estratégias do produto e, muitas vezes, alinhado com as estratégias mais globais da empresa;

o vantagem em Velocidade - fazer rápido. Entende-se que o encurtamento do ciclo operacional dentro da cadeia de valor, proporciona redução de despesas, e especulação com estoques possibilitando melhores previsões e atendimento da demanda;

o vantagem em Pontualidade - cumprir prazos. Embora possa ser facilmente confundido com o aspecto da velocidade, ser pontual significa ter uma operação capaz de atender dentro dos prazos estabelecidos, gerando, com isso, maior confiabilidade;

o vantagem em Flexibilidade - capacidade de adaptação. A capacidade de lidar com o risco das incertezas, da falta de informação ou erro de previsão, da variedade, por meio de uma operação robusta no sentido de permitir rápidas adaptações seja de resposta quanto de faixa;

o vantagem em Custo - fazer barato. A equação do lucro pressupõem não somente a redução de custos como da otimização do capital investido. A busca incessante de redução de custos expõem a interdependência com os outros fatores mas, também, reafirma a lógica de obtenção de maior competitividade por meio de melhorias na margem de lucro. 
Hill \& Jones (1998) sugerem as seguintes variáveis para a mensuração do desempenho competitivo:

o Eficiência: Significa que as empresas geram produtos e serviços valiosos a preços que os consumidores estejam dispostos a pagar;

o Qualidade: Refere-se à excelência presente nos seus produtos e serviços, incluindo atributos como: atratividade, ausência de defeitos, confiabilidade e segurança, ou seja, a qualidade percebida pelos seus clientes;

o Inovação: É a capacidade das empresas criarem novas demandas mercadológicas, através de novos produtos e serviços que os seus clientes valorizam; e,

o Velocidade (Capacidade de respostas aos clientes): Consiste na antecipação da identificação das necessidades dos clientes, percebidas através da velocidade dos lançamentos de novos produtos e serviços, pontualidade das entregas e a antecipação de resoluções de problemas, ainda não detectados pelos clientes.

Nas colocações de Albrecht (1992: 34): "Não há nenhum produto destituído de um relacionamento associado entre comprador e provedor". O componente de prestação de serviços é um importante fator da percepção ${ }^{5}$ do cliente sobre a qualidade de um produto. As avaliações de qualidade são derivadas do processo de atendimento e do seu resultado.

Parasuraman et al. (2000) e Trez et al. (2000) argumentam que oferecer produtos de qualidade e preço competitivo são armas fáceis de se copiar. A noção de valor ${ }^{6}$ percebido é dinâmica, portanto, para se agregar valor ao cliente deve-se oferecer serviços de qualidade como forma de se obter vantagens competitivas sustentáveis. Parasuraman et al. (2000) e

\footnotetext{
${ }^{5}$ Segundo Monroe \& Krishnan apud Lima Filho (1999: 29), percepção é o processo de organizar, interpretar, e derivar significado de estímulo por meio dos sentidos. Sensação é o processo de receber estas impressões. Entretanto, necessidades individuais, memória, e experiências passadas também influenciam a percepção.

${ }^{6}$ Valor Extrínseco: como perspectiva utilitarista (benefícios x preço). Valor Intrínseco: relacionado a uma preferência relativística (comparativa, pessoal, situacional). (Lima Filho, 1999; Rutner \& Langley, 2000).
} 
Zeithaml (2000) identificaram cinco dimensões que os clientes utilizam como critérios de julgamento da qualidade de serviços: confiabilidade, responsividade, segurança, empatia e tangibilidade. De todos os fatores, confiabilidade é a dimensão de maior importância relativa e elemento principal da qualidade de serviços.

A obtenção de um determinado desempenho demanda uma avaliação do posicionamento competitivo a ser adotado para o negócio (Zaccarelli, 2000) e, sua respectiva implementação e monitoramento por meio de um sistema de indicadores (Harrington, 1998; Kiyan, 2001; Sink \& Tuttle, 1993). O uso de um sistema de indicadores tem vários objetivos relatados na literatura (Kaplan \& Norton, 1997; Muscat \& Fleury, 1993; Kaydos, 1991), entre eles:

o comunicar a estratégia;

o entender os processos envolvidos;

o definir responsabilidades;

o obter envolvimento e comprometimento das pessoas;

o melhorar o controle e planejamento;

o gerir mudanças e comportamentos;

o identificar problemas e oportunidades;

o diagnosticar problemas;

o explicitar o trabalho realizado (dar visibilidade);

o servir de base para um sistema de remuneração.

Vale ressaltar que a compreensão da realidade organizacional é fator essencial para a manutenção da competitividade. Por meio da informação pode-se ter um domínio das diversas variáveis que regem a dinâmica dos negócios (Spinola \& Pessôa, 1997).

Os objetivos de desempenho devem ser priorizados com base na geração de valor para o cliente e, consequentemente, na identficação dos processos que darão sustentação à dinâmica competitiva (Hayes \& Upton, 
1998). Para que a empresa consiga manter-se constantemente adaptada às mudanças que são demandadas neste ambiente, não basta apenas o controle e a reação, mas também se antecipar às mudanças e adaptar-se mais rápido que a concorrência (Shiba et al, 1997).

Para Slack et al (1999), uma vez que a prioridade de melhoramento tenha sido determinada, uma operação precisa considerar a abordagem ou estratégia que ela deseja para levar adiante o processo de mudança. Uma das razões principais para a mudança é a busca pela flexibilidade organizacional, que corresponde a capacidade de reação das organizações frente aos sobressaltos impostos pelos movimentos de inovação. Kaplan \& Norton (1997) apresentam uma visão, através de indicadores de desempenho, como um caminho para chegar à transformação da estratégia em ação, visando o resultado empresarial.

Mills, Platts \& Gregory (1995) sugerem que as decisões estratégicas podem ser organizadas de acordo com os processos empresarias. Assim, a interdependência entre as diferentes decisões em operações (e também entre as diferentes funções organizacionais) poderia ser considerada por meio da visualização dos processos-chave das operações e no mapeamento das ações necessárias para o suporte do planejamento estratégico, assim como na definição/revisão do sistema de indicadores (Faria et al., 2004). Conclui-se que a visão por processos é fundamental para a gestão estratégica de operações. 


\section{3-A Abordagem por Processos}

Não existe um produto ou serviço oferecido por uma empresa sem um processo para provê-los. Segundo Torres (2002, 51), para gerenciar processos de negócios é necessário um modelo mental da organização, por meio de quatro perspectivas: visão das pessoas, visão dos processos, visão dos recursos e a visão dos clientes. A representação por processos de negócios é de fundamental importância para a gestão organizacional. $\mathrm{O}$ conceito permeia as referências sobre estratégia na medida em que representa o componente que possibilita a tomada de ações (Kaplan \& Norton, 1997; Acur \& Bititci, 2003).

Quadro 01 - Abordagens Organizacionais

\begin{tabular}{|c|c|c|}
\hline \multirow{2}{*}{ DOMÍNIO } & \multicolumn{2}{|c|}{ ABORDAGENS ORGANIZACIONAIS } \\
\cline { 2 - 3 } & ABORDAGEM CLÁSSICA & ABORDAGEM ORGÂNICA \\
\hline Referências & $\begin{array}{c}\text { Teoria Científica (Taylor), Teoria Clássica (Fayol), Teoria de } \\
\text { Sistemas (Bertalanffy), Burocracia (Weber) }\end{array}$ & $\begin{array}{c}\text { Teoria Contingencial (Woodward, Chandler, Staler), } \\
\text { Administração por Objetivos (Drucker), Gestão Estratégica } \\
\text { (Porter), Participativa (Marx, Rousseau, Stuart Mill), Japonesa } \\
\text { (Deming, Ohno) }\end{array}$ \\
\hline Sistemas & Fechados & Abertos \\
\hline Processos & Fragmentados & Totais \\
\hline Estruturas & Verticais & Horizontais \\
\hline Trabalho das Pessoas & Mecânicos & Empowerment (Capacitação) \\
\hline
\end{tabular}

Fonte: Adaptado de Torres (2002).

A teoria e prática organizacional ao longo dos anos nos mostra a evolução de uma abordagem fragmentada para uma visão mais holística de processo (quadro 01). 
Ao compararmos algumas características de uma organização funcional (tradicional) para as organizações centradas em processos (quadro 02), podemos observar também uma mudança de percepção tanto no âmbito do perfil da força de trabalho com múltiplos conhecimentos, habilidades, trabalho em equipe quanto no desenho organizacional focado na criação de valor para o cliente por meio das pessoas (Schiar, 2002).

Quadro 02 - Organização Funcional versus por Processos

\begin{tabular}{|l|l|}
\hline \multicolumn{1}{|c|}{ ORGANIZAÇÃo FUNCIONAL } & \multicolumn{1}{c|}{ ORGANIZAÇÃo POR PROCESSOS } \\
\hline Cliente como uma variável que causa distúrbio & Objetivos ajustados pelas necessidades dos clientes \\
\hline Negação da Incerteza & Legitimação da Incerteza \\
\hline Controle & Auto-Organização \\
\hline Busca do Equilíbrio & Fluxo Constante \\
\hline Sobrevivência contra o ambiente & Convivência com o ambiente \\
\hline Ordem Planejada & Ordem Emergente \\
\hline Trabalho Individual & Trabalho em Equipe \\
\hline Especialização & Múltiplos Conhecimentos \\
\hline
\end{tabular}

Fonte: Adaptado de Schiar (2002).

Sistemas de operações, seja de manufatura como de serviços, são baseados em processos. O conceito de processo, enquanto função, consiste conceitualmente em observar o fluxo do objeto de trabalho (material, serviços ou mesmo idéias) no tempo e no espaço. O conceito de operação consiste, por outro lado, no acompanhamento do fluxo do agente do trabalho no tempo e no espaço (Cassel, 2004). Segundo Shingo (1996), todos os sistemas produtivos podem ser compreendidos como uma rede funcional de processos e operações. De maneira análoga, Correa \& Gianesi. (1994) reforçam a visão de processos em serviços. Podemos encontrar o enfoque em processos em diversas literaturas: BPM (Smith\&Fingar, 2003), Qualidade 
(Deming, 1990); Análise da Cadeia de Valor (Porter, 1980); Em Busca da Excelência (Peters\&Waterman, 1982); Reengenharia (Hammer, 1994); Inovação (Davenport, 1994); A Empresa Orientada ao Cliente (Day, 2001); Gestão do Conhecimento (Davenport\&Prusak, 1998); Cadeia de Suprimentos (Coughlan et al., 2002).

No trabalho de Acur \& Bititci (2003), na prática da integração entre estratégia de operações e gestão por processos ressalta-se a necessidade da visão dos processos que suportam os objetivos empresariais dentro de uma visão cíclica de aprendizagem.

Segundo Grover \& Kettinger (2000) processos devem estar alinhados com a estratégia, pessoas/estrutura, métricas e a arquitetura de T.I. (Tecnologia da Informação).

Assim, como síntese dentro desta abordagem mais orgânica e holística, podemos perceber a importância do conceito de processo.

Segundo Tinnila (1995), processo é um grupo de tarefas logicamente interrelacionados que utilizam recursos da organização para prover determinados resultados face aos objetivos da organização.

Segundo Schaeller (1997), podemos tipificar processos em: processos de produção - produzem produtos ou serviços diretamente; processos baseados em atividades ou projeto - geralmente invisíveis para o cliente final, são executados para administrar, obter, controlar e coordenar recursos; processos de distribuição ou baseados em agentes - aqueles focados na definição de ações ou quais atividades a serem executadas; processos comportamentais ou baseados no cliente - focado nos fluxos de trabalho para fornecer serviços e apoio ao cliente onde tempo é uma variável importante.

Segundo Davenport (1993), processo é, simplesmente, um conjunto de atividades estruturadas e mensuráveis para produzir uma saída 
específica para um determinado cliente ou mercado. Portanto, a ênfase está muito mais no como o trabalho é feito em contraste à pergunta o quê, cujo foco está no produto ou serviço fornecido. Assim, um processo é uma sequência especifica de atividades orientadas à ação através do tempo e lugar, com um começo e fim, e com entradas e saídas claramente identificadas. Harrington (1996) ressalta a agregação de valor, definindo processo como "uma série de atividades que recebe um insumo, agrega-lhe valor e produz um produto ou uma saída (aplicação de habilidades adicionando valor a um insumo)." Para Hammer \& Stanton apud Usirono (2003), processo é um grupo de tarefas inter-relacionadas e que geram valor para o cliente.

Quando o conceito é aplicado à uma organização ou negócio, o termo "processo de negócio" ou business process passa a ser mais utilizado. $\mathrm{Na}$ visão de Camp $(1995,7)$, processos de negócios são aqueles crossfuncionais críticos para o sucesso do negócio, enquanto processos de trabalho são aqueles inteiramente dentro de um único e simples controle. Um processo de negócio consiste em um conjunto de atividades relacionadas que visam atingir um objetivo de negócio, no contexto de uma estrutura organizacional definindo regras e relacionamentos (Workflow Management Coalition, 1999). Segundo Smith\&Fingar (2003, 47), um processo de negócios (Business Process) é o conjunto completo de atividades transacionais colaborativas e dinamicamente coordenadas que entregam valor para os clientes. Ainda segundo os mesmos autores, podemos caracterizar processos de negócios como:

o Complexos e Longos - envolvendo fluxos de materiais, informação e trade-offs;

o Dinâmicos - respondendo às demandas dos clientes e à dinâmica do mercado;

- Amplamente Distribuído - personalizado através das fronteiras dentro e entre negócios, frequentemente executando múltiplas aplicações em plataformas tecnológicas diversas; 
o Longa Duração - uma simples ação, tais como pedidos ou desenvolvimento de produtos pode levar meses ou anos;

o Automatizáveis - atividades rotineiras podem ser realizados pelos computadores todas as vezes em que for possível, principalmente quando se busca velocidade e confiabilidade;

o Dependentes da tecnologia - processos de negócios dependem de sistemas computadorizados que são tanto transacionais quanto colaborativos. Modelos de processos podem, portanto, compreender redes, objetos, fluxos de controle, fluxos de mensagens, regras de negócios, métricas, exceções, transformações e atribuições;

o Dependente do julgamento e apoio da inteligência humana - pessoas executam tarefas que são desestruturadas demais para serem delegadas para o computador ou que requerem a interação humana com clientes;

o Difícil de tornar visível - em muitas empresas, os processos de negócios não são conscientes, nem explícitos. A principal característica de processo de negócio é a necessidade de coordenação.

A abordagem por processos (fig.02) é um dos fundamentos de excelência do Programa Nacional de Qualidade (PNQ) e justifica a definição da prática de gestão ${ }^{7}$ para o exercício do controle e do aprendizado organizacional (FPNQ, 2003).

Fig. 02: Abordagem por Processos.

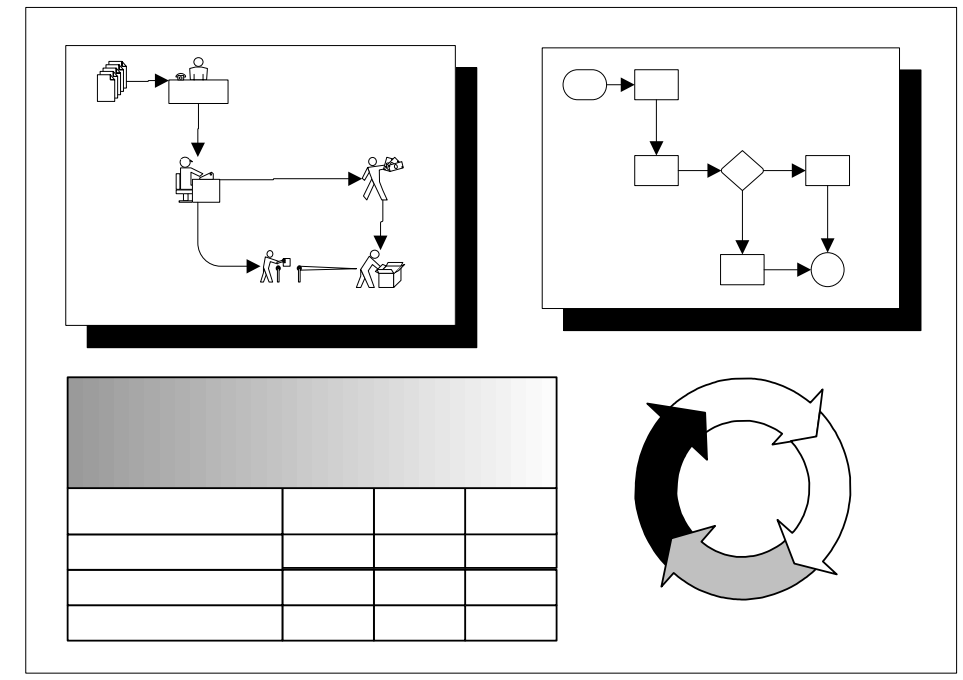

Fonte: Elaborado pelo Autor

${ }^{7}$ O termo compreende: planejamento, projeto, construção, implementação, utilização, monitoramento, identificação de melhorias e realização de ajustes. (De Sordi, 2005). 
Organizações sentem a necessidade de migrar de uma estrutura hieráquica de comando-e-controle para modelos mais horizontais baseados em redes de informações (Applegate et al., 1996).

Enquanto uma estrutura hierárquica é, tipicamente, uma visão fragmentada e estática das responsabilidades e das relações de subordinação, a estrutura por processo é uma visão dinâmica da forma pela qual a organização produz valor. A visão do processo evidencia a seqüência de atividades que são realizadas, cruzando departamentos e níveis hierárquicos, até a saída dos produtos. Tal abordagem implica em uma ênfase relativamente forte sobre a melhoria da forma pela qual o trabalho é feito. A adoção de uma abordagem por processo significa a adoção do ponto de vista do cliente. Uma vez que os processos são a estrutura pela qual uma organização faz o necessário para produzir valor para seus clientes, deve-se oferecer produtos e serviços de que atendam as suas expectativas, empregando processos eficientes e eficazes.

Eficiência de processos pode ser traduzido em termos de capacidade de adaptação à mudanças ou flexibilidade. Conseqüentemente, os processos devem ser medidos em termos de dimensões que tragam valor para o cliente. Essas medidas tornam-se os critérios para a avaliação do valor de uma inovação e para o estabelecimento de programas de melhoria contínua.

Na visão de Burlton (2001), um verdadeiro processo de negócio pode conter etapas lógicas ${ }^{8}$ ou ilógicas e, geralmente, atravessam funções ou unidades organizacionais. As medidas de desempenho são naturalmente desejáveis quando orientados para as partes interessadas e alinhadas com os objetivos estratégicos. E, finalmente, um teste de integridade é verificar

\footnotetext{
${ }^{8}$ Lógica como algo racional, resultado de um senso comum e válido dentro de um determinado contexto.
} 
se o processo entrega um produto/serviço claro para um stakeholder externo ou outro processo interno.

\section{4-Modelagem de Processos}

Modelagem de processos de negócio: do inglês business process modeling, trata de uma linha teórica com base na reengenharia de processos (Davenport, 1994) e, pode contribuir com alguns propósitos, como por exemplo: explicitar o conhecimento; entender como funciona; controlar ou monitorar; tomar decisões; analisar alguns aspectos da organização; simular o comportamento de algumas partes; reprojetar e racionalizar (Correia et al., 2002). Tanto a reengenharia ou Business Process Reengineering (BPR) quanto o Total Quality Management (TQM) necessitam que seus processos sejam desenhados. Embora a reengenharia pura tenha insistido em evitar a busca de melhorias incrementais por apregoar mudanças radicais, muitos autores a consideram parte de uma gestão integrada de processos à longo prazo (Moad, 1994; Bennigson, 1996; Caldwell, 1994). Não há evidências práticas que comprovem a separação entre iniciativas de reengenharia e melhoria contínua. Ou seja, a melhoria contínua pode ser sequenciada depois de uma ação de BPR (Guha et al., 1993; Davenport, 1993). Todos os modelos existentes na literatura são variações do modelo de "Descongelar-Mudar-Congelar" formulado primeiramente por Kurt Lewin (Kanter et al., 1992).

Pode-se considerar que o modelo de processos de negócio está contido no modelo de empresa ou modelagem empresarial sendo em diversas metodologias seu principal elemento constituinte (Amaral \& Rozenfeld, 2001) e pré-requisito para a integração (Vernadat, 1996).

Segundo Schaeller (1997), a modelagem empresarial possibilita visualizar as seguintes perspectivas: Informacional - entidades, atributos, 
domínios e relacionamentos; comportamental - eventos, condições, estados e transições; processos - atividades, artefatos, agentes e relacionamentos e,; organizacional - unidades de organização, regras, recursos e locais.

Segundo Vernadat (1996) "...um modelo de empresa pode ser composto de muitos sub-modelos", sendo que "...o conteúdo de modelo de empresa é qualquer que a empresa considere importante para suas operações". O escopo da modelagem de empresas, propriamente dito, segundo Vernadat (1996) seria basicamente definido pela resposta às perguntas o quê, como, quando, quem e onde. Respondendo o que é ou deve ser feito está-se descrevendo aspectos funcionais da empresa. O que se refere também ao aspecto informacional, ou seja, quais dados são usados ou produzidos e qual seu relacionamento. Como e quando se referem a aspectos do comportamento dinâmico do sistema, integrando ao modelo o importante aspecto do tempo. Por fim, deve-se responder quem é responsável por quais funções, conferindo uma dimensão organizacional ao modelo, mas também qualificando o local no qual as funções são executadas.

A qualidade da modelagem é uma questão importante, na medida em que o desenho do processo passa a ser o pilar básico. Segundo Bi (2004), as seguintes qualidades de uma solução para modelagem de processos são importantes: formalismo - semântica inequívoca; expressividade suficiente; escalabilidade - múltiplos níveis; modularidade - unidades padrões de representação; fácil de usar - amigável.

Aalst et al. (2000) propõem seis diretrizes neste sentido:

1. Aderência - a sintaxe utilizada é completa e coerente e, a semântica mostra que a estrutura e o comportamento do modelo é coerente com o mundo real;

2. Relevância - selecionou um objeto relevante e utilizou uma técnica de modelagem adequada de um modelo mínimo (um dado modelo não deve conter mais informações que o necessário); 
3. Clareza - a terminologia, denominações e visualização são claras e legíveis para os usuários;

4. Comparabilidade - terminologias e convenções utilizadas permitem a comparação de diferentes processos (busca de uma linguagem homogênea);

5. Estruturação Sistemática - utiliza todas as estruturas relevantes para demonstrar adequadamente a realidade (integração de modelos de processos e modelos de informações);

6. Eficiência Econômica - como uma restrição das outras diretrizes. Ou seja, a avaliação do custo $X$ benefício de se obedecer cada uma das diretrizes em um nível viável (por exemplo: em termos de utilidade e tempo).

Pandya (1997) afirma que existem dois modos de representação dos processos de negócios: voltado para os sistemas de informações (implementação de sistemas computacionais) e o voltado para a gestão de valor dos processos (avaliação de desempenho).

Na visão de Kondareddy (1998), modelagem de processos tem a sua origem nos processos de desenvolvimento de softwares. Diferentemente do diagrama de fluxo de dados ou de entidades e relacionamentos, o modelo de processos explicita o papel fundamental das pessoas devendo facilitar o entendimento, análise e comunicação para outros. e, desempenham um papel fundamental em processos de mudanças. A modelagem de processos é pré-requisito essencial na busca de integração e coordenação (Vernadat, 1996).

Uma das técnicas mais comuns é o mapeamento do processo na forma de um fluxograma, que descreve graficamente um processo existente ou um novo processo proposto, identificando cada evento da seqüência de atividades por meio de símbolos, linhas e palavras (Harrington, 1991). Uma das vantagens de se utilizar uma ferramenta gráfica é a facilidade de visualização, tanto da seqüência de atividades, como da forma como as atividades se encaixam. Outra vantagem consiste em disciplinar a forma de raciocínio da equipe. São evidenciadas, também, diferenças entre a forma 
como se supõe que as atividades sejam feitas e como elas realmente são feitas.

Muitos processos não podem ser representados por um simples fluxograma pela sua complexidade. Apesar das definições de processo apresentadas serem muito simples, os processos reais de uma organização geralmente não o são. Assim, para se compreender realmente como funcionam seus processos, com o objetivo de melhorá-los, é necessário adotar ferramentas que possibilitem uma compreensão completa de cada passo e das inter-relações de um processo.

Diversas outras metodologias foram desenvolvidas, tais como: CIMOSA (Computer Integrated Manufacturing Open System Architecture) que propõe uma visão de modelagem na qual a empresa é vista como uma grande coleção de processos de negócio executados por agentes sincronizados por eventos e mensagens (Kosanke, 1995); ARIS (Architecture of Integrated Information Systems) considerada uma tecnologia madura para a modelagem integrada de processos (Green\&Rosemann, 2000); PETRI NETS muito popupar e poderosa para representar e analisar os sistemas que possuem simultaneidade, paralelismo, sincronização e compartilhamento de recursos (Vernadat, 1996); IDEF (Integrated Definition) desenvolvida pela Força Aérea Americana (Grover, 2000; Vernadat, 1996); EKD (Enterprise Knowledge Development) é o estado atual do desenvolvimento de uma metodologia chamada PLANTADA, realizando uma inteligente integração de "componentes organizacionais de uma especificação, como por exemplo, objetivos de um negócio" com os tradicionais modelos de processo e entidade-relacionamento (Pádua, 2000); PERA (Purdue Enterprise Reference Architecture) que abrange todo o ciclo de vida de uma empresa, suportados por um formalismo gráfico bastante simples e de fácil entendimento (Vernadat,1996); GIM (GRAI Integrated Methodology) uma metodologia similar ao CIMOSA; e, outros. Segundo pesquisa do Gartner Group sobre as ferramentas de modelagem e análise 
de processos (fig.03), a solução da IDS Scheer (ARIS) tem se destacado como líder nos últimos anos, cujas características foram também avaliadas pelo Grupo de Produção Integrada da UFRJ (Santos, 2002), não somente no suporte aos métodos de modelagem, quanto nas funcionalidades para a gestão, execução e aplicações dos processos modelados.

Todas as ferramentas trazem em sua essência a integração e visualização dos processos $e$, realizadas com o uso da tecnologia da informação de modo a representar da melhor forma possível toda a complexidade inerente aos processos de negócios mas, nenhuma delas isoladamente consegue representar todas as características de um modelo de negócios real (Torres, 2002). Ressalte-se aqui, portanto, a necessidade de representar os aspectos estáticos (organizacional e informacional) e dinâmicos (comportamental, avaliação e controle) de um dado processo de negócio.

Figura 03 - Ferramentas de Modelagem segundo Gartner Group

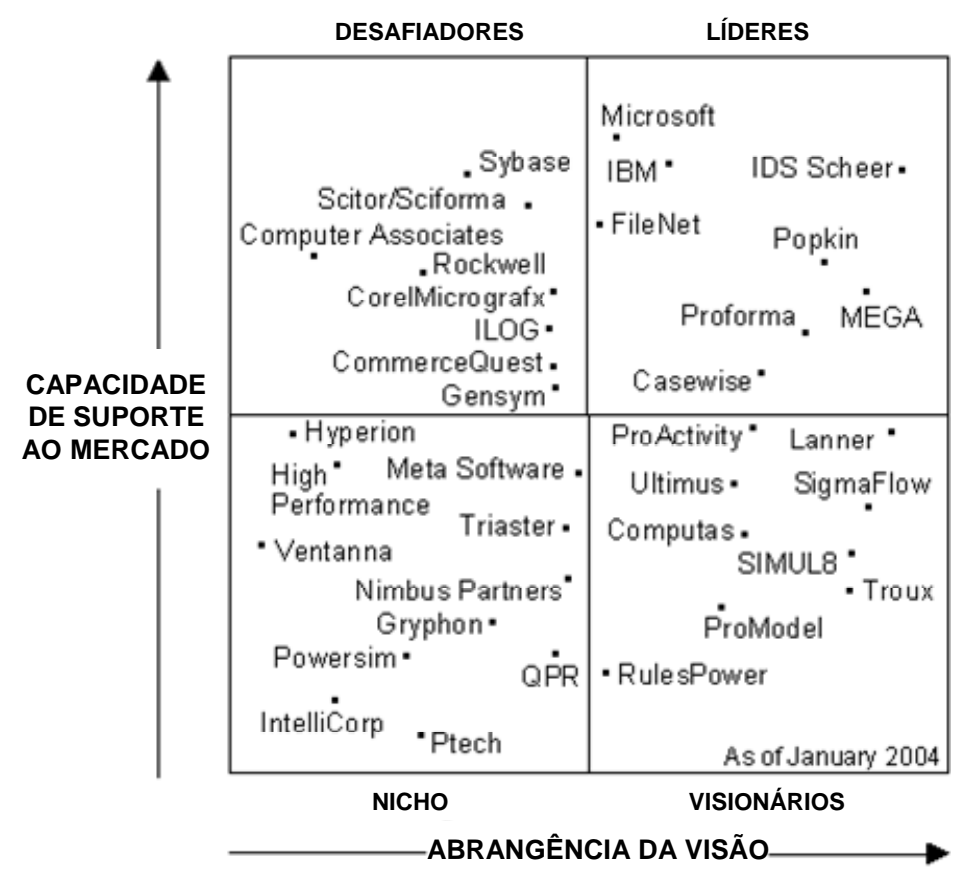

Fonte: Quadrante Mágico Gartner Group, Março/2004. 
Mais recentemente, a Business Process Management Initiative (BPMl.org), uma organização sem fins lucrativos, propõem uma notação padrão abrangente e fácil de utilizar para a especificação dos processos de negócios denominada BPMN (Business Process Modeling Notation) (ver Anexo2).

\section{5-Gestão por Processos e a Tecnologia da Informação}

Com o objetivo de atender à dinâmica competitiva atual, as empresas buscam soluções de integração dos processos fundamentadas em tecnologia da informação, de modo a prover maior flexibilidade e agilidade nas suas operações.

Apesar da Tecnologia de Informação hoje disponível possibilitar novas formas de operação e gerenciamento dos processos das empresas, ela não garante que esses processos sejam realizados da forma mais adequada para atingir os objetivos da empresa (Davenport, 1994). Assim é necessário definir os requisitos dos processos de negócios, analisá-los e então projetálos, incorporando os conhecimentos e tecnologias realmente necessárias para sua realização (Campos\&Santos, 2001).

Davenport apud Smith\&Fingar $(2003,113)$ identifica 9 efeitos ou possibilidades da tecnologia da informação sobre os processos de negócios: automatização; obtenção da informação; permitir a sequenciação de tarefas e atividades; rastreabilidade; melhorar a capacidade análitica; extrapolar as fronteiras físicas da organização; integração das partes ou processos; gestão do conhecimento e possibilitar a desintermediação.

$\mathrm{Na}$ visão de Arif et al. (2005), soluções de TI não devem impor restrições no desenho de processos, pelo contrário, o foco principal são os processos de negócios e a sua integração. Para atender a esta demanda, 
existem diversas soluções tecnológicas disponíveis, entre elas (De Sordi, 2002):

- Integração de aplicações (Applicatio-to-Application) ou Enterprise Application Integration (EAI): que estão focados na integração de componentes (dados e aplicações) entre bases ou ambientes distintos;

o Automação do fluxo de trabalho ou Workflow: é uma categoria de sistemas, que permite a automação do fluxo de trabalho (definição de regras e tratamento de exceções), comumente representando os vários processos internos da organização;

o Gestão integrada ou Enterprise Resource Planning (ERP): são os sistemas que permitem a automação de processos operacionais segundo modelos de trabalho previamente definidos;

o Business-to-Business (B2B): tecnologias focadas nas fronteiras entre parceiros de negócios, usualmente por meio da troca de dados.

Figura 04: Conjunto de Soluções de Integração.

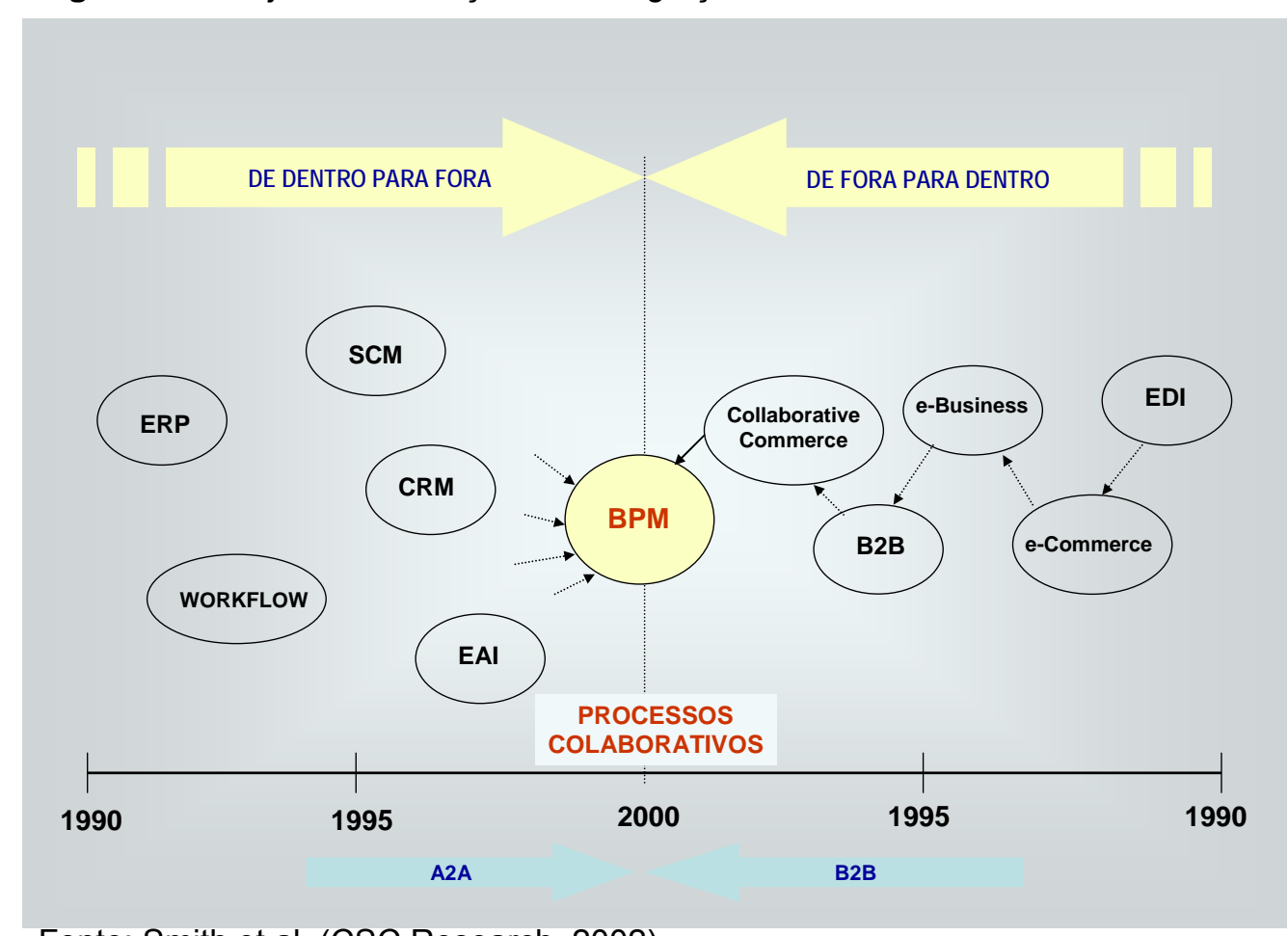

Fonte: Smith et al. (CSC Research, 2002)

A visão de dentro-para-fora (fig.04) representa o conjunto de aplicações cujos processos são embutidos e não podem ser explicitamente gerenciados. Neste ambiente, geralmente, existe uma alta heterogeneidade 
de pessoas e políticas envolvidas o que reforça a necessidade de uma estrutura que suporte as mudanças constantes (Krafzig et al., 2005). A visão de fora-para-dentro é caracterizado por processos padronizados e compartilháveis. Gradualmente, as tecnologias estão convergindo para soluções mais poderosas que permitem uma integração destas duas visões. Ou seja, a concepção de software para gestão de processos denominada de BPMS (Business Process Management System) na intenção de permitir a integração e adaptação entre os diversos processos de negócios dentro de uma abordagem colaborativa, ou seja, integrando as atividades internas e externas da organização, mesmo baseadas em distintas plataformas tecnológicas.

Como resultado do avanço da tecnologia da informação (T.I.) e a evolução das condições do ambiente competitivo, a categorização do impacto estratégico das soluções de T.I. para um determinado negócio devem ser revistas (McFarlan, 1984). Neste contexto, o alinhamento estratégico de T.I. deixa de considerar somente requisitos de custos e serviços dentro de uma abordagem técnica para buscar um papel catalisador e, por vezes, de arquitetura do negócio com base em múltiplos critérios na obtenção de diferenciais competitivos para o negócio ao longo do tempo (Laurindo, 1995).

\section{6-Business Process Management}

O termo Business Process Management, ou abreviadamente BPM, tem sido utilizado no mais variado contexto, desde o tecnológico até a perspectiva do gerenciamento de mudanças. Segundo Krafzig et al. (2005), quando se aborda o conceito dentro do contexto de negócio, frequentemente nos deparamos com as iniciativas voltadas para a qualidade (Seis Sigma, ISO 9000, TQM, etc.) ou da gestão por processos (Activity Based Costing, Value Chain, Balanced Scorecard, etc.). $\mathrm{Na}$ abordagem tecnológica, 
usualmente, encontramos soluções para a modelagem de processos ou gerenciamento de workflow (ver fig.05). Assim, um sistema de gestão de processos de negócio (Business Process Management System) fornece a plataforma tecnológica para a realização das iniciativas de BPM. Este, por sua vez, introduz o conceito de "processamento de processos" e ressalta que não é um conceito limitado a automação de modelos digitalizados mas, promove a descoberta, o desenho e, o detalhamento de processos de negócio, assim como a execução, administração, supervisão e controle sobre os mesmos de modo a assegurar que estejam alinhados com os objetivos do negócio.

Figura 05: BPMS (Foco em T.I.) versus BPM (Foco no Negócio)

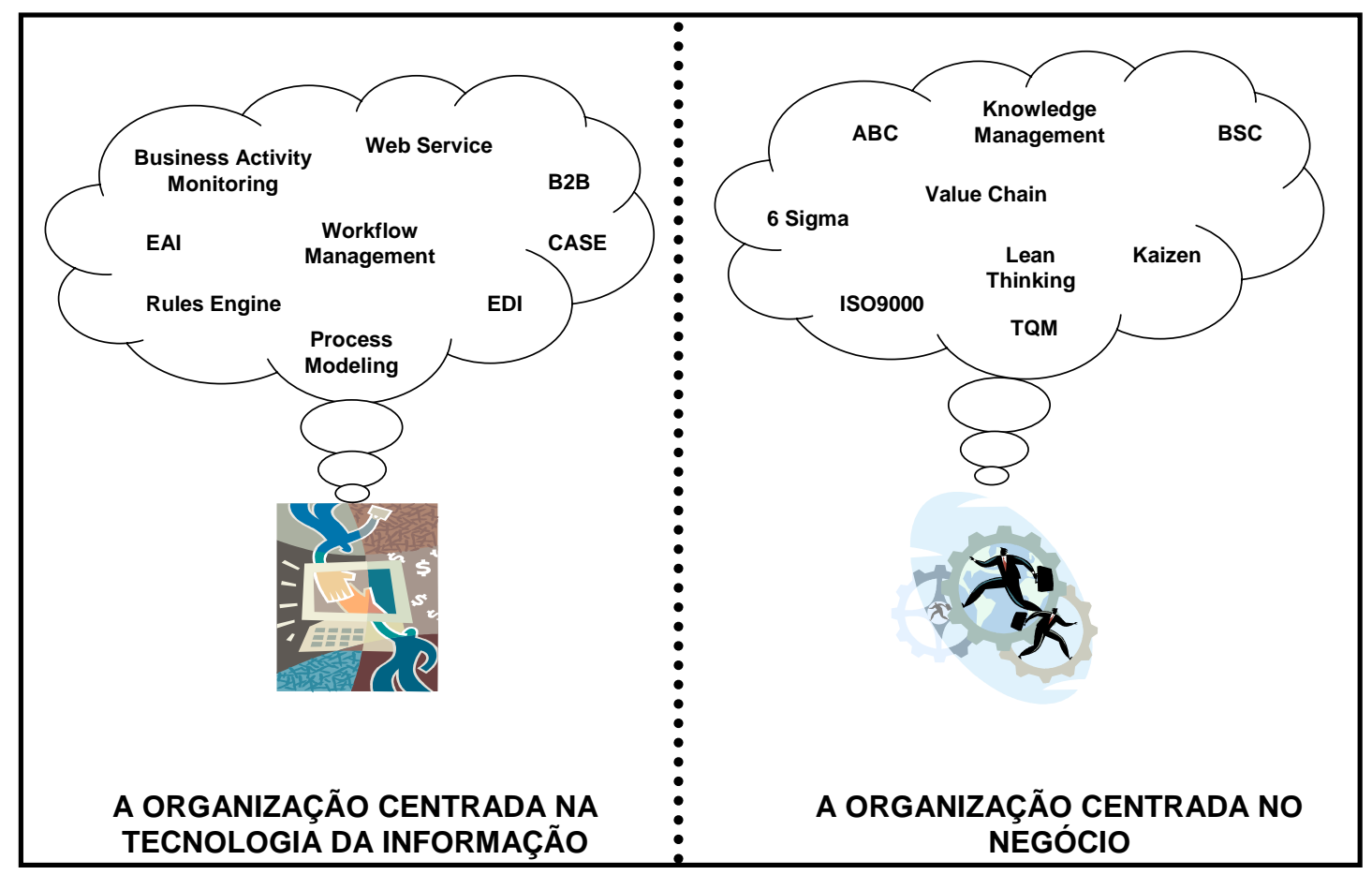

Fonte: Krafzig, 2005.

Nesta pesquisa, assumimos tanto o termo solução de BPM quanto BPMS (Business Process Management System) do ponto de vista da solução tecnológica, embora os conceitos e objetivos em que se baseiam a 
sua utilização sejam intimamente relacionados com a gestão de processos do negócio.

No web site "Business Process Trends", BPM é o alinhamento de processos com as estratégias organizacionais, desenhando e implementando arquiteturas de processos, estabelecendo métricas alinhadas com as metas, educando e organizando os gestores de modo a possibilitar a obtenção de maior eficácia.

Lee\&Dale (1998) definem solução de BPM como uma série de ferramentas e técnicas para o aperfeiçoamento contínuo do desempenho de processos de negócios que classificam como operacional, de suporte e de direção.

Um ponto de vista na capacitação tecnológica, a notícia do site ITWeb 10 afirma que o BPM automatiza e conecta processos através de um processo independente que permite controlar como pessoas e tecnologia interagem.

Talvez, a abordagem tecnológica de Workflow de uma maneira mais ampliada possa ser utilizada para iniciar o entendimento sobre BPM enquanto software. Segundo Grudin (1994) apud Usirono (2003), o conceito de workflow é caracterizado pela troca de informações entre pessoas em tempos distintos. Portanto, a tecnologia workflow permite a integração de informações que são tratadas e disponibilizadas por diversos indivíduos em tempos e locais distintos. O conceito de BPM vem se sobrepor ao de workflow na medida em que foca a integração de processos que reunem diversos elementos como pessoas, tecnologia, equipamentos e facilidades

\footnotetext{
${ }^{9}$ Source: $\mathrm{http}: / /$ www.bptrends.com/resources_glossary.cfm?wordid=1585CF7E-1031-D52237BF07D25D38A070 (acessado Março/2005)

http://www.itweb.co.za/sections/business/2005/0502250815.asp?A=COV\&S=Cover\&T=Secti on\&O=C (acessado Março/2005)
} 
sob a ótica de uma gestão integrada tanto de processos internos como externos à organização.

Na visão da American Productivity \& Quality Center (APQC), Business Process Management pode ser entendido como o gerenciamento de workflow em uma organização.

\subsection{1-A Solução de BPM nas Organizações}

Na década de 90, as empresas viveram a frustração da reengenharia, principalmente por ter falhado em prover agilidade e apoio para as mudanças, além de contar com soluções tecnológicas inadequadas. Ainda, pacotes ERP (Enterprise Resource Planning) e Workflow prometiam mas, no fim, mostraram-ser inflexíves e ainda requerendo customizações para atender as necessidades dos negócios. Em passado recente, novas ferramentas de mapeamento de processos surgiram, possibilitando captar e gerenciar processos organizacionais. Inicialmente, eram voltados para documentar processos existentes e, embora tenham avançado para representar processos de negócios, não preenchiam a lacuna entre os objetivos estratégicos e as demandas tecnológicas para atingí-los. Daqui para frente, processos serão encarados pelas pessoas como informações e pelos computadores como códigos executáveis, ambos ao mesmo tempo. Assim, podemos dizer que soluções de BPM podem lidar com as mudanças, e os desafios da integração e colaboração incorporando funcionalidades para tal realidade e, não somente para processos do tipo entradas-e-saídas mas, para todo tipo de processo (Smith\&Fingar, 2003).

O BPM pode ser interpretado como a reengenharia da reengenharia. Sterling Commerce ${ }^{11}$ afirma sucintamente que O BPM oferece a oportunidade de mudar a forma como os negócios são feitos utilizando uma solução ampla que pode integrar os processos internos e externos.

\footnotetext{
${ }^{11}$ http://www.sterlingcommerce.com/resourcecenter/bpm.html
} 
Assim, por meio de uma implementação eficaz de BPM, pode-se obter os seguintes benefícios:

o Integração dos inúmeros fatores envolvidos em um processo (pessoas, tecnologia, equipamento, facilidades) de modo a assegurar compatibilidade;

o Reagir rapidamente às mudanças do mercado;

o Permite desenvolver novos negócios mais rapidamente;

o Acomoda mais facilmente processos de terceirização ou mesmo de gerenciamento da cadeia de suprimentos;

o Reforçar padrões, políticas e procedimentos através da organização;

- Criar pontos de contato simplificados para um determinado processo e ser capaz de rastrear responsabilidades através do processo;

o Aumentar a capacidade de monitoramento do desempenho, eliminar gargalos, e assegurar que as tarefas estão sendo realizadas;

o Monitorar o status de todos os processos, incluindo que atividades estão aderentes aos padrões, políticas e procedimentos;

o Integrar funcionários de diferentes unidades e locais;

o Encontrar oportunidades para automatizar atividades e eliminar redundâncias;

- Melhorar a execução de processos automatizados e fazer mudanças quando necessário;

o Identificar atividades que não agregam valor;

- Aumentar a produtividade examinando tempos e custos gastos nos processos;

- Mudar a mentalidade para a melhoria contínua;

o Melhorar a imagem da organização para os clientes;

o Alcançar os objetivos organizacionais estratégicos com transparência.

De Sordi (2005), aponta que o ambiente de negócios intensivo (complexo, dinâmico e interativo), resultado da adoção de determinadas práticas administrativas, tais como: a busca de diferenciação, colaboração na cadeia de valor e a terceirização, demanda novas formas de organização e execução do trabalho. Neste contexto, a necessidade de integração urge como principal desafio das soluções de TI. Muito embora a implementação 
eficaz de uma solução de BPM nas organizações demande a preparação de um ambiente para a gestão por processos, a solução tecnológica pode ser adotada mesmo na ausência de uma maior maturidade na prática da abordagem por processos com possibilidades de benefícios por meio de projetos específicos, por exemplo. A maximização deste tipo de investimento poderá ser obtida com o amadurecimento da visão por processo de negócios e no uso adequado da arquitetura tecnológica para tal fim.

Figura 06 - Plataforma Tecnológica e a Dinâmica e Complexidade do Negócio

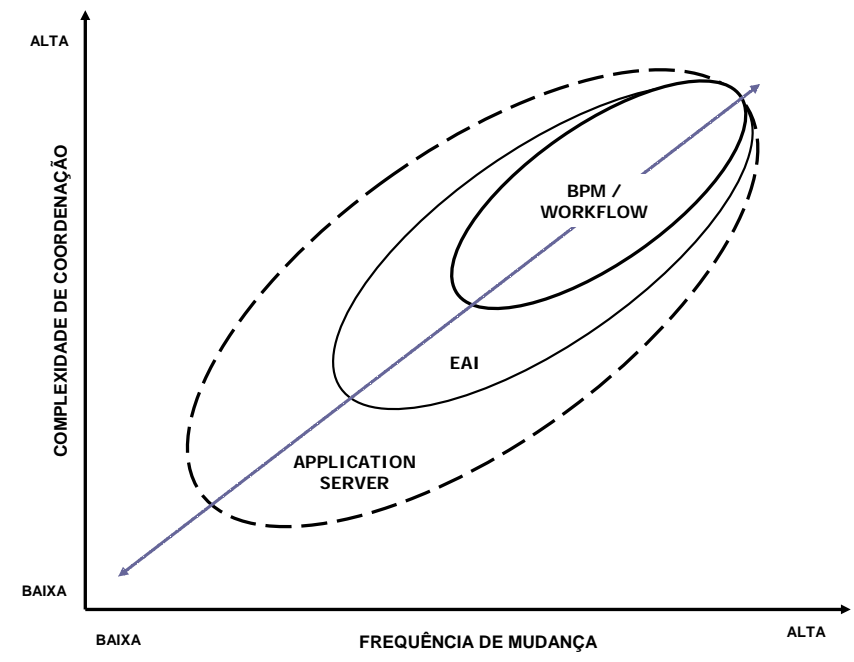

Fonte: Krafzig et al. (2005).

O custo e a complexidade de se implementar uma solução de BPM ainda são expressivos, portanto, alguns aspectos devem ser avaliados previamente (Krafzig et al., 2005):

- A equipe de $\mathrm{TI}$ e responsáveis pelo negócio devem trabalhar juntos, dado que a orientação por processos é base nas duas abordagens;

o Utilizar modelos pré-existentes de processos como ponto de partida, considerando que os mesmos foram obtidos das melhores práticas do mercado; 
- Identificar a tecnologia mais adequada para o negócio, combinando uma análise da dinâmica envolvida (frequência de mudança) e o grau de coordenação exigida entre os processos (vide fig. 06);

o Adotar um modelo de desenvolvimento que apresente a melhor relação de custo versus benefício na evolução e adaptação da solução às necessidades do negócio.

Portanto, a complexidade de coordenação das diversas atividades e processos do negócio e, o grau de mudanças requeridas dentro da dinâmica competitiva, são ao fatores preponderantes que determinarão a maior ou menor necessidade de uma solução de BPM (vide fig. 06).

Adicionalmente, poderíamos acrescentar a necessidade de avaliarmos a aderência de uma dada solução aos objetivos de desempenho desejados para o negócio.

\subsection{2-A Solução de BPM como Plataforma Tecnológica}

Neste trabalho, buscamos elencar um conjunto de funcionalidades que descrevessem de um modo genérico uma solução de BPM na gestão de processos de negócios. Assim, um pacote de BPM deve contemplar (Thompson, 2003; Megard, 2002; Santos, 2002; McDaniel, 2002; Delphi Reports 2002 e 2003):

o Uma ferramenta de modelagem e/ou definição de processos;

o Uma ferramenta e/ou módulo para definição de regras de negócio;

o Um mecanismo e/ou ferramenta para integração com outras soluções de sistemas e bases de dados;

o Um mecanismo para a Execução do processo modelado; 
o Um mecanismo e/ou módulo para interação com os usuários ou participantes do processo;

o Um módulo para o monitoramento dos processos.

\section{- Uma ferramenta de modelagem elou definição de processos:}

Para a modelagem adequada de um processo, é necessário descobrir o real propósito do mesmo para o negócio. Geralmente, exige a participação conjunta de: Analistas de Processos, Participantes do Processo, Gerentes, Donos de Processo e, algumas vezes, de consultores treinados. É interessante que a ferramenta permita implementar a arquitetura dos processos correntes bem como visualizar e identificar melhorias através de uma notação e linguagem gráfica fácil de usar e comum a todos os envolvidos, como por exemplo a notação BPMN (Business Process Modeling Notation) desenvolvido pelo grupo de trabalho chamado BPMI (Business Process Management Initiative). Além disso, a ferramenta deve dispor de flexibilidade para a decomposição ou fragmentação do processo em subconjuntos menores mantendo a coesão ou coerência geral. Os fluxos dos processos podem ser em série ou em paralelo. Algumas técnicas devem estar incorporadas para facilitar o desenho do processo (Megard, 2002):

o Um conjunto de algoritmos para rearranjo dos diagramas em segundos. Eles adaptam o layout automaticamente (usando uma tecnologia chamada "graph layout") colocando os elementos do diagrama na representação mais significativa;

o Representação de processos e sub-processos com a capacidade de quebrar um sub-processo para simplificar uma representação ou expandi-lo em detalhes menores, sem limitação de número de níveis;

- Uma janela para visualizar o processo para apresentar a seleção corrente no seu contexto e mover com rapidez e precisão de uma área para outra;

- Apresentação dos diagramas de diferentes processos compartilhando os mesmos objetos básicos (atividades e 
regras) para reorganizar facilmente diferentes processos movendo partes de um para outro;

- Abrir visões múltiplas em locais diferentes dentro da mesma definição do processo para possibilitar relacionar partes do gráfico que estão muito distantes para serem mostradas em uma visão legível;

o Diferentes visões para desenvolvedores e usuários olhando para o mesmo modelo, filtrando os objetos mostrados em um diagrama para apresentar o nível de detalhe apropriado da situação atual (por exemplo: nós associados à uma regra ou não), facilitando a compreensão ou integridade;

o Capacidade de simulação em gráficos animados de "tokens" fluindo através do gráfico para simular a execução das instâncias do processo. Isto permite uma melhor visualização e rastrear um processo para identificar pontos de melhorias;

o Representação baseada no tempo no qual os nós são representados como segmentos cujo comprimento mostra seus tempos de execução e espera. Através desta visão, o caminho mais longo e o mais curto podem ser identificados, prazos e atrasos ajustados com os resultados esperados. Também, simplificações podem ser determinadas para melhorar as metas de tempo de resposta.

Dependendo da arquitetura desenhada, ou seja, do local onde se coloque uma determinada atividade, podemos ter um impacto diferente em termos de eficiência e custo. Aqui vale ressaltar que uma determinada atividade pode ser interpretada como um processo menor ou até mesmo um componente reutilizável em outros processos.

- Uma ferramenta elou módulo para definição de regras de negócio:

O desenvolvimento baseado em componentes é uma tecnologia que pode ser genericamente definida em três camadas: serviços comuns, a lógica do negócio e apresentação. Assim, a visão tradicional em camadas: dados, aplicação e apresentação é reformulada numa 
solução BPM com a inclusão da camada de processos, onde a lógica do negócio é considerada na definição dos fluxos e no interrelacionamento das atividades, além de uma camada de regras para a definição da interação com os participantes e no tratamento dos eventos e objetos relacionados. A definição das regras do negócio demandam um módulo que avalie automaticamente o estado de cada objeto e execute o método correto baseado neste estado e nas regras associadas, além do gerenciamento por exceções (vide fig.07).

Os objetos ou itens de trabalho (ex.: pedido, ordem de serviço, reclamação, etc.) podem ser obtidos de sistemas e bases legadas e/ou variáveis constituídas por meio de formulários criados e transformados ao longo do processo. Portanto, a lógica de tratamento para questões do tipo: enfileiramento de tarefas, agendamento, priorização, aprovação, tratamento de exceção e direcionamento, são implementadas como regras de negócio. Este tipo de implementação requer, muitas vezes, algum desenvolvimento específico de componentes com o uso de linguagens script, ou seja, a construção de blocos de códigos por um especialista.

A infraestrutura tecnológica requer que todas as definições e regras inerentes atendam aos requisitos básicos de qualquer aplicação baseada em servidores: escalabilidade, confiabilidade e disponibilidade e, seja capaz de administrar os requisitos dos processos de negócio independentemente das considerações sobre a rede de comunicação instalada.

- Um mecanismo elou ferramenta para integração com outras soluções de sistemas e bases de dados:

Ferramentas de Integração das diversas soluções, plataformas de sistemas, bancos de dados, estruturas interna e externa. $\mathrm{O}$ acesso à dados externos por meio de conectores padrões permitem a 
integração com banco de dados e/ou aplicações externas, tais como: soluções de ERP, CRM, SCM, etc.. É recomendável que este tipo de implementação seja realizada com a ajuda de um especialista. Tal integração deve prever a população (obtenção dos dados externos e suas estruturas) das bases da solução BPM, além de permitir a atualização em ambas as direções. Com o uso de uma camada de middleware, é possível a utilização de recursos para a gestão da integração, com o uso de sinalizadores, gerenciamento de filas, alarmes, sincronização de bases de dados, etc., facilitando o uso e manutenção.

\section{- Um mecanismo para a Execução do processo modelado:}

Um modulo de execução (Execution Engine) onde o desenho do processo e as regras do negócio podem ser ativadas e coordenadas, inclusive possibilitando intervenções em tempo real. A execução pode ser instanciada para verificação do fluxo definido e identificação de eventuais gargalos. Processos síncronos e assíncronos podem ser disparados em série ou em paralelo. Este mecanismo requer uma avaliação cuidadosa da arquitetura tecnológica disponível para garantir o desempenho e a escalabilidade desejados. Além disso, existe a possibilidade de registro de todos os eventos ou por meio de parametrizações, de modo a permitir a rastreabilidade e a auditoria do que foi executado.

\section{- Um mecanismo elou módulo para interação com os usuários ou participantes do processo:}

Um módulo para a interação com os usuários, notificando as tarefas a serem realizadas e possibilitando a visualização e priorização dos itens de trabalho. A flexibilidade na visualização e tratamento dos itens de trabalho está relacionado com a configuração do acesso dos 
participantes e regras estabelecidas na modelagem do processo. Em geral, as soluções devem permitir a utilização de meta definições, tais como: grupos, sub-grupos, funções, além do próprio usuário com recurso de login e senha. Este módulo deve ser acessível também via Web e requer um cuidado no dimensionamento da arquitetura de comunicação e disponibilidade dos servidores. A consideração mais importante é identificar como os usuários se encaixam no desenho geral da solução. Melhorias podem ser introduzidas mostrando as atividades precedentes, consequentes e os seus participantes.

Figura 07 - Modelo conceitual de uma Solução BPM

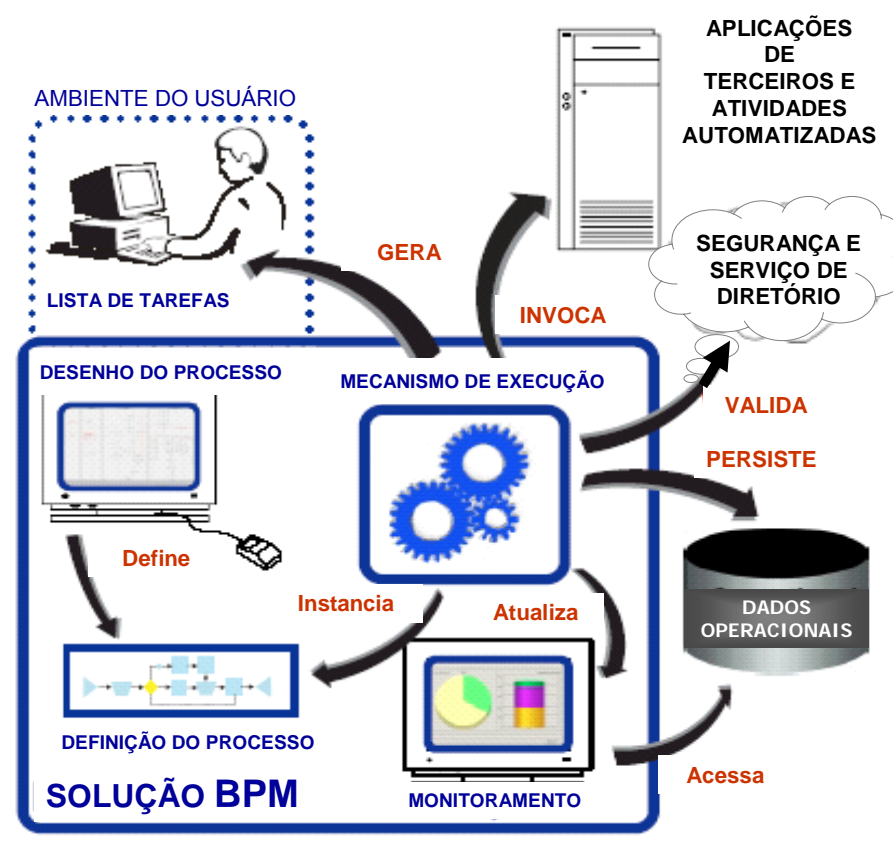

Fonte: Delphi Report (2003)

\section{- Um módulo para o monitoramento dos processos:}

Módulo que permite o monitoramento visual dos processos/atividades, a auditoria, obtenção de indicadores ou métricas e um histórico de $\operatorname{logs}^{12}$ que permitem inclusive a otimização. Durante o monitoramento

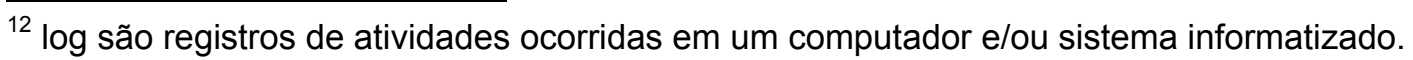


exceções como sobrecargas, atrasos anormais, metas perdidas e falhas de processo devem ser rapidamente transmitidas para os participantes e donos de processo. Informações acerca da instância e instância agregada devem ser reunidas, organizadas e filtradas. 0 usuário deve ser capaz de entender rapidamente o que está ocorrendo e tomar ações corretivas. O monitoramento básico pode ser realizado com o uso de visões tabulares das atividades em execução, mostrando em linhas e colunas: qual atividade, categoria da atividade, instância do processo a que pertence, tipo, participante, ou aplicação em execução, status, tempo, etc.. Melhor do que isso, é a possibilidade de visualização gráfica mostrando o contexto do problema, caminho de execução, atividades precedentes e consequentes, regras de transição, atores, aplicações, tempos envolvidos e distribuição de cargas de trabalho.

A análise de desempenho difere do monitoramento porque este ocorre em tempo real, enquanto o primeiro baseia-se em indicadores coletados da execução das atividades ao longo do tempo. Esta funcionalidade começa com indicadores agregados, em uma abordagem top-down. Assim como no monitoramento, as leituras para análise de desempenho podem ser melhoradas com 0 uso de tecnologia de visualização gráfica capazes de:

- Diagramas de processos expandidos com simbolos, cores, gráficos e medidores mostrando os tempos médios de execução e espera;

o Visões baseadas no tempo para comparar tempos efetivos de espera e execução versus o esperado;

- Gráficos de programação para ver como os recursos são realmente utilizados nas atividades durante vários períodos;

- A capacidade de detalhar a partir do indicador de performance os dados históricos que compõem o mesmo ou a lista de participantes daquela atividade e acompanhar o desempenho de um processo ao longo do tempo. 
E, por fim, reforçar a importância de uma interface eficiente com o usuário para interação com os processos mapeados e tais funcionalidades anteriormente descritas, principalmente, possibilitando identificar o que foi feito antes, o que será feito em seguida e quem fará o trabalho.

$\mathrm{Na}$ visão de Megard (2002), as funcionalidades mais importantes de um BPM são: Definição de Processos, Monitoramento de Atividades e Análise de Performance.

Na visão de Santos (2002), além das funcionalidades já mencionadas, uma solução de BPM deveria permitir a criação de metodologias ou métodos de modelagem com filtros para cada metodologia. Embora interessante, tal requisito foi interpretado pelo autor como além do que uma solução genérica deveria prover e, assim deixado de lado para efeito desta pesquisa.

Uma nota adicional vale ser mencionada no que se refere à sinergia entre o conceito de Web Services (o software como serviço) e BPM, no sentido de componentes de serviços sob demanda. Cada vez mais nos transformamos tanto em consumidores como em fornecedores de atividades, com o desenvolvimento da componentização de sistemas ou partes de sistemas, permitindo reduzir cada vez mais os ciclos de projeto e implementação de soluções de T.I.. A visão nos processos / atividades como elementos centrais de qualquer negócio solicita a capacidade de gerenciamento destes elementos e, uma solução de BPM deve permitir ir além, no sentido de alinhar soluções de TI e negócios num único ambiente.

\subsection{3-Soluções de BPM}

Segundo o relatório Delphi (2001), podemos evidenciar três gerações de soluções BPM: (1) Baseadas na engenharia de software - onde as regras de negócio eram implementadas embutidas em códigos de software; (2) Baseadas na engenharia de negócios - onde a implementação era realizada 
por meio de diversas ferramentas para definição de regras de negócio mas, distantes das soluções de TI; (3) Baseadas na engenharia de valor via Web - onde se permite a definição de atividades e tarefas de maneira mais flexível sob a forma de componentes integráveis ao processo principal. Existe uma clara independência entre o modelo do processo e as regras do negócio.

De acordo com o relatório do Gartner de 2004 (Sinur, 2005), existe mais de uma centena de produtos disponíveis no mercado de BPM. Analisando-os segundo os critérios de grau de integridade de visão, ou seja, capacidade de antecipar necessidades do mercado e reproduzir nas funcionalidades da ferramenta de BPM e, capacidade de execução, no sentido de agir conforme sua visão, podemos classificá-los no quadrante a seguir (fig. 08).

Fig. 08 - Quadrante Mágico - Gartner Group

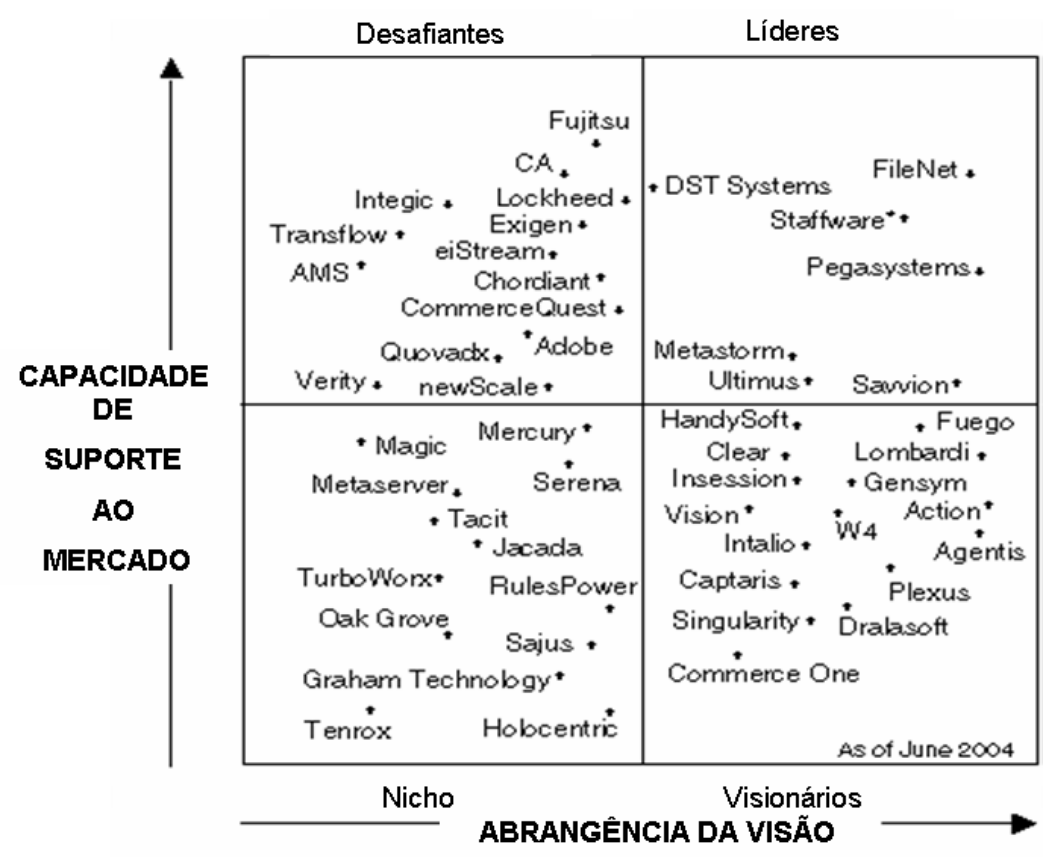

Fonte: Sinur, 2005 (Gartner Group) 
O quadrante dos líderes está mais relacionado com o faturamento, participação no mercado e cujos produtos atendem à uma gama maior de interessados.

Os visionários compreendem bem o mercado e os requisitos dos clientes, mas possuem poucos ativos comprometidos em atender o mercado quando comparados com os líderes.

Desafiadores possuem recursos mas, tem uma compreensão limitada do mercado e uma estratégia de produto menos impactante.

O quadrante das empresas de nicho se limitam a atender bem à um segmento do mercado ou com uma menor amplitude de recursos e funcionalidades.

Muitas soluções existentes no mercado se originaram de categorias distintas (Por Exemplo: Workflow, EAl, Simuladores, Modelagem de Processos) e, que aliada a vasta terminologia empregada com conotações variadas torna a comparação entre eles uma tarefa muito difícil. Do ponto de vista da organização, sugere-se que as soluções tecnológicas para os processos críticos sejam mapeados para uma adequada delimitação das soluções a serem empregadas e das necessidades de integração e coordenação por meio de uma solução BPM (Smith et al., 2002).

Esforços no sentido de buscar um padrão de modelagem são feitos, como a linguagem de modelagem BPML (Business Process Modelling Language), para a definição de processos para os diferentes públicos (Engenheiros de Software, Usuários, Analistas de Negócios) e diversos nichos de negócios (Financeiras, Indústria, Comércio, Telecomunicações) e permitir a execução direta. Na visão dos que apoiam tal iniciativa, um padrão deve suportar não somente qualquer tipo de processo (baseado em produção de bens materiais, baseado em informação, baseado em relacionamentos) como também prover uma linguagem capaz de (Smith et al., 2002): 
o expressar de forma mais natural possível o modo como os participantes trabalham juntos para atingir um objetivo de negócio;

o prover uma semântica rica para expressar a lógica do negócio, suas regras e fluxos de informação;

o permitir restrições na troca de dados, tempos e serviços a serem disponibilizados;

o apoiar profundamente o encadeamento de transações e tratamento de exceções;

o expôr elementos de software como processos explícitos;

o permitir compor componentes de processos existentes como novos processos de valor agregado;

o capacitar a análise, previsão, simulação e monitoramento de processos;

o capacitar processos a reagir a eventos e adaptá-los a novos requisitos em tempo real;

o simplificar a interação entre processos executados em sistemas distintos e através de diferentes domínios de negócios.

Do ponto de vista desta pesquisa, o que se buscou foi uma definição genérica das funcionalidades em níveis de implementação de uma solução BPM para que o mesmo cumpra os seus objetivos de facilitar a gestão integrada de processos com base nas referências bibliográficas citadas (Thompson, 2003; Megard, 2002; Santos, 2002; McDaniel, 2002; Delphi Reports 2002 e 2003).

Outras tendências podem ser identificadas neste mercado:

o Aumento de fusões e aquisições entre os fornecedores de soluções BPM;

o Usuários estão, cada vez mais, adotando processos que necessitam de interfaces $\mathrm{H} 2 \mathrm{H}$ (Humano para Humano);

- Proliferação de templates que possibilitam agilizar a automação de processos, mesmo que não atendam a $100 \%$ das necessidades específicas de cada negócio;

o A obediência às questões regulatórias;

- A busca de maior eficiência, atender às necessidades dos clientes e maior agilidades como direcionadores básicos na adoção de uma solução de BPM, segundo Smith et al. (2002). 


\subsection{4-O Mercado de BPM segundo Delphi Reports (2002-2004)}

O relatório Delphi's Market Milestone Report 2002 combina uma pesquisa conduzida com aproximadamente 10.000 usuários finais (executivos e gerentes de $\mathrm{TI}$ ) e mais de 20 fornecedores de soluções BPM em diversos países. Embora a maioria (83\%) ainda esteja em um estágio inicial de avaliação ou aprendizado, uma grande parcela (54\%) admite que o BPM é um elemento-chave na infraestrutura de TI para processos e aplicações. Implementar uma solução de BPM é para 38\% dos respondentes uma ferramenta de redesenho de processos sobre uma plataforma computacional alinhada com a Internet e Web Services e, iniciariam com os processos internos. Por outro lado, $7 \%$ disseram que se concentrariam nos processos inter-organizacionais. Outras prioridades estariam no nível da integração de dados entre as aplicações (19\%) e fluxo de documentos baseado em regras (14\%). A utilização adequada de uma solução de integração baseada em TI demanda que a organização tenha uma cultura de digitalização, ou seja, que a maioria de seus documentos esteja codificada na forma digital e, notadamente, nos quase $62 \%$ das companhias entrevistas existe um grau de digitalização menor que $25 \%$. Ou seja, existe uma grande oportunidade ou lacuna a ser preenchida nesta área, já que apenas $2.5 \%$ de todos os respondentes afirmam que a maioria de seus processos está digitalizado.

Quando perguntados sobre as possíveis estratégias para aquisição de uma solução de BPM, 36\% responderam que se baseariam na percepção de valor, como uma combinação de preço e serviço, outros $32 \%$ na combinação de disponibilidade e requisitos do negócio. Entre os benefícios esperados, a automação de tarefas repetitivas (30\%); permitir a gestão e monitoramento o desempenho de processos (25\%) e possibilidade de modificar a lógica do processo sem a ajuda de especialistas de TI (20\%).

O relatório Delphi's Market Milestone Report 2003 foi desenvolvido com 500 usuários, em sua maioria engajados em projetos que envolvem 
BPM, de diversas partes do mundo, onde aproximadamente $75 \%$ das respostas são provenientes de empresas americanas. De forma resumida, a prioridade ou maior motivação para a adoção de uma solução BPM está no redesenho dos processos de toda a organização. Para técnicos de TI, o maior benefício esperado seria a capacidade de integrar aplicações internas ou legadas.

Do ponto de vista de padrões para soluções de BPM, existe pouco conhecimento e muitos padrões disponíveis. Entretanto, a possibilidade de intercambiar processos definidos de uma solução para outra evindenciaria um benefício adicional importante para a decisão de implementação. O fato é que tanto a WfMC (Workflow Management Coalition) como a BPMI (Business Process Management Institute) devem buscar a convergência e a coexistência das diversas plataformas e padrões disponíveis.

O relatório Delphi's Market Milestone Report 2004 foi desenvolvido com 900 usuários, em sua maioria engajados em projetos que envolvem BPM, de diversas partes do mundo, onde aproximadamente $75 \%$ das respostas são provenientes de empresas americanas. A anatomia de uma solução de BPM é composto de: Mecanismo de Execução que inclui Integração, Regras de Negócio; Modelagem de Processos; Monitoramento de Atividades; Interface com o Usuário. As empresas buscam, por meio da solução de BPM, ganhos de gerenciamento dos processos e estratégias de negócios, do que simplesmente automatização de processos discretos em detrimentos de outras atividades do negócio. Outro dado importante é que a iniciativa de implementação de soluções de BPM são conduzidas em sua maioria por usuários finais ou os chamados "donos do processo de negócio" (61\% em 2003 e 74\% em 2004). Os motivos pela não adoção de soluções de BPM se devem à falta de um "business case", patrocinadores e acomodação com as soluções já implementadas. Entretanto, ressalta-se a falta de uma cultura ou expertise em processos para avaliar soluções de BPM. 


\section{7-Considerações sobre avaliação de soluções de software}

Na visão de Sommerville (1989), um bom software é aquele que atende às necessidades do usuário, possível de realizar manutenções, confiável, eficiente e que provê interfaces apropriadas para o usuário. A característica dinâmica mais importante de um software é a confiabilidade. Ainda na visão do autor, existem requisitos associados à todo software e, podem ser classificados em:

o Funcionais: serviços esperados pelo usuário. completo, no sentido de que todas as funcionalidades requeridas pelo usuário sejam especificadas e, consistente, no sentido de que tais especificações não sejam contraditórias entre elas;

o Não-Funcionais: restrições ou condições de operação e os padrões a serem obedecidos. Exemplos: velocidade; vamanho; facilidade de uso; confiabilidade; robustez; portabilidade, escalabilidade, custo adequado, manutenibilidade, suporte local.

Qualquer investimento em TI prescinde de alguns cuidados como: escalabilidade, segurança, flexibilidade, robustez e qualidade, além da possibilidade de controle ou administração sobre o seu uso para que o mesmo seja otimizado e preservado. Assim, as premissas ou critérios de seleção de alternativas devem atentar para:

- Escalabilidade: no sentido de possibilitar a expansão ou atualização (upgrades) sem descartar a base já adquirida e instalada;

o Flexibilidade: as soluções de hardware e software adotadas devem, na medida do possível, serem de uso amplo, de padrões consolidados e que permitam customizações e/ou utilizações de forma variada;

- Qualidade: esta dimensão deve ser atestada através de comprovação de origem e certificação técnica, além de referências mercadológicas para minimizar interrupções e manutenções indesejáveis. Para a obtenção de uma solução de software confiável ou de qualidade podemos utilizar o modelo CMM (Capacity Maturity Level), 
referenciados pelas normas NBR ISO/IEC 12207 e ISO/IEC 15504, que sugere a correlação direta com a maturidade e capacidade de processo;

o Confiabilidade: não somente relacionado à qualidade da solução a ser adotada como também da sua origem (fabricante/fornecedor). Referências de mercado quanto à experiência de uso e conectividade com outras tecnologias e padrões existentes complementam este quesito;

o Robustez: uma solução pode ser entendida como robusta quando apresenta tolerância a variações nas suas condições de uso, ou seja, quando provê alto índice de disponibilidade;

o Segurança: a infra-estrutura deve ser projetada para permitir a gestão segura das informações;

o Administração: a gestão eficaz dos recursos de TI prescinde de um centro de competências e de instrumentos que permitam monitorar o desempenho, identificar e solucionar problemas e, principalmente, adequar continuamente com as necessidades da empresa;

o Custos e Riscos versus Benefícios: o conjunto de critérios já citados acima deve ser adequado no sentido de minimização dos custos totais de propriedade e riscos versus maximização de benefícios em termos de como as necessidades de informações são supridas e convertidas em diferenciais para os negócios da companhia (McFarlan, 1981). Comumente tal abordagem permite uma avaliação quantitativa do ponto de vista de retorno financeiro, onde valem as técnicas de avaliação de investimentos em ativos.

$\mathrm{Na}$ visão de Laurindo et al. (2002), dentro de uma perspectiva estratégica, aplicações de TI permitem retorno para os resultados de um negócio desde que a empresa tenha capacidade de explorar de maneira eficaz o seu uso. $O$ autor lembra ainda que eficácia está associada ao atingimento de objetivos e requisitos mais amplos do negócio, enquanto eficiência relaciona-se com o uso dos recursos. Assim, fatores estruturais e organizacionais da empresa precisam ser avaliados dentro de um contexto mais abrangente, onde a visão estratégica é fundamental para o reconhecimento e alinhamento das soluções de TI para a obtenção e manutenção de vantagens competitivas. 
Ainda, no que tange aos benefícios esperados de um investimento de TI os autores de Stategic Choices, Kenneth Primozic, Edward Primozic e Joe Leben apud McNurlin \& Sprague (1998: 53) descrevem dentro de uma perspectiva evolutiva. Ou seja, partindo de uma abordagem de redução de custos e obtenção de maior controle das operações e, evoluindo até uma perspectiva de ganhos estratégicos (eficácia) para o negócio, situação na qual se torna desejável um envolvimento maior da alta direção nas escolhas efetuadas. $O$ fato é que as caraterísticas tecnológicas continuam, de modo geral, a direcionar uma análise comparativa de custos, riscos e benefícios da solução a ser implementada. Entretanto, com a crescente evolução das soluções tecnológicas demandando, por consequência, uma maior participação dos usuários na seleção de alternativas, evidencia-se a necessidade de instrumentos e referenciais do ponto de vista do gestor do negócio, que se constitui no objeto desta pesquisa. 


\section{Capítulo 3 Modelo Proposto}

Neste capítulo é feita uma revisão da literatura, que se desdobra em: fundamentos teóricos do modelo proposto (3.1), citando as funcionalidades de uma solução de BPM (3.1.1), os objetivos de desempenho adotados na pesquisa (3.1.2) e o vínculo das funcionalidades com os objetivos de desempenho (3.1.3); as propriedades e limitações do modelo proposto (3.2) e uma síntese do mesmo (3.3).

\section{1-Fundamentos teóricos do modelo proposto}

O modelo proposto é um template com vistas a avaliar soluções de BPM sob a ótica da gestão da operações e pretende responder à seguinte questão: - Qual a solução BPM mais adequada para apoiar uma dada estratégia competitiva?

Desta forma verifica-se que a questão do modelo proposto contempla o conceito de estratégia competitiva e premissas sob a constituição das soluções BPM. O que o modelo proposto busca avaliar é a aderência de múltiplos quesitos inerentes a uma solução BPM (funcionalidades) a uma dada estratégia competitiva.

Por meio de pesquisa empírica buscou-se estabelecer quais seriam os quesitos ou funcionalidades das soluções BPM existentes no mercado e o grau de maturidade tecnológica de tais quesitos com vistas a estabelecer um 
nível considerado mínimo (ou corrente) e um nível considerado elevado ou ideal.

Quanto à perspectiva de estabelecer as características de determinada estratégia competitiva adotou-se o referencial teórico de Slack (1993) que resume os vários objetivos de desempenho que são comuns à maioria dos autores (Muscat \& Fleury, 1993; Skinner, 1969; Slack et al., 2002; Porter, 1980; Zacarelli, 1996; Corrêa \& Gianesi, 1994; Hill \&J ones,1998; Shiba et al., 1997, Contador, 1996) e, focados nos processos internos da organização cujos desempenhos são objetivamente mensuráveis.

Tendo em mãos as funcionalidades das soluções BPM e as características dos objetivos de desempenho, o modelo proposto busca relacioná-los sob a perspectiva de maior eficiência ou contribuição, relação esta feita por meio de metodologia descrita no capítulo 4 .

\subsection{1-Funcionalidades das soluções BPM}

De acordo com a revisão de literatura já apresentada são considerados os seguintes aspectos quanto às funcionalidades das soluções BPM:

- Uma ferramenta para modelagem e/ou definição de processos (Process Design). Para implementar a arquitetura dos processos correntes bem como visualizar e identificar melhorias através de uma notação e linguagem gráfica fácil de usar e flexível para a decomposição ou fragmentação do processo em subconjuntos menores mantendo a coesão ou coerência geral;

- Um modulo de execução (Execution Engine) onde as regras do negócio podem ser ativadas e coordenadas através da execução de um processo de negócio, inclusive possibilitando intervenções em tempo real. A definição das regras do negócio demandam um módulo que avalie automaticamente o estado de cada objeto e execute o método correto baseado neste estado e nas regras associadas, além do gerenciamento por exceções; 
- Um módulo para a interação com os usuários, que permite definir o perfil de acesso, a lista de tarefas a serem realizadas, além de eventuais parametrizações para facilitar a visualização e a priorização das tarefas a serem executadas;

- Ferramentas de Integração das diversas soluções (Application to Application), plataformas de sistemas, banco de dados (Troca de Dados), sistemas corporativos, estruturas interna e externa;

- Módulo que permite o monitoramento tanto por meio de relatórios quanto visual (em tempo real) dos processos/atividades, exceções como sobrecargas, atrasos anormais, metas perdidas e falhas de processo.

As funcionalidades genéricas anteriores podem ser detalhadas segundo uma estrutura de gestão (Fig.09) da seguinte forma:

Figura 09 - Referencial Teórico das Funcionalidades de uma Solução BPM

\begin{tabular}{|c|c|c|c|c|}
\hline PDCA & \# & $\begin{array}{l}\text { MACRO } \\
\text { FUNÇÃO }\end{array}$ & FUNCIONALIDADES & REFERÊNCIAS \\
\hline \multirow{12}{*}{$\underset{\square}{z}$} & 1 & 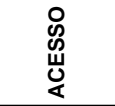 & DEFINIÇÃO E GERENCIAMENTO DE USUÁRIOS, REGRAS E ACESSOS & SANTOS (2002) \\
\hline & 2 & \multirow{6}{*}{ 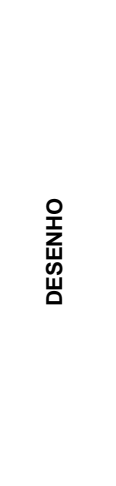 } & MODELAGEM POR MEIO DE INTERFACE GRÁFICA (GUI) E RECURSOS DE OTIMIZAÇÃO DE LAYOUT & $\begin{array}{l}\text { DELPHI REPORT (2002); SMITH\&FINGAR (2003); } \\
\text { SANTOS (2002); SMITH ET AL. (2002) }\end{array}$ \\
\hline & 3 & & $\begin{array}{l}\text { REPRESENTAÇÃO E VISUALIZAÇÃO EM MÚLTIPLOS NIVEEIS COM RECURSOS DE EXPANSÃOE } \\
\text { NAVEGAÇÃA }\end{array}$ & $\begin{array}{l}\text { MEGARD, Patrick (2002); SMITH ET AL. (2002); } \\
\text { SANTOS (2002) }\end{array}$ \\
\hline & 4 & & $\begin{array}{l}\text { DIFERENTES VISÕES PARA DESENVOLVEDORES E ANALISTAS DE NEGÓCIO DE UM MESMO } \\
\text { MODELO COM HELP CONTEXTUAL }\end{array}$ & MEGARD, Patrick (2002); SANTOS (2002) \\
\hline & 5 & & $\begin{array}{l}\text { APRESENTAR DIFERENTES PROCESSOS QUE COMPARTILHEM AS MESMAS ATIVIDADES E REGRAS } \\
\text { PARA FACILMENTE REORGANIZÁ-LOS MOVENDO PARTES DE UM PARA OUTRO }\end{array}$ & $\begin{array}{l}\text { MEGARD, Patrick (2002); SMITH ET AL. (2002); } \\
\text { SANTOS (2002) }\end{array}$ \\
\hline & 6 & & $\begin{array}{l}\text { BIBLIOTECA DE COMPONENTES E MODELOS DE PROCESSOS COM FERRAMENTAS DE BUSCA E } \\
\text { SERVIÇO DE DIRETÓRIO }\end{array}$ & $\begin{array}{l}\text { SANTOS (2002); THOMPSON (2003); DELPHI } \\
\text { REPORT (2002); SMITH ET AL. (2002) }\end{array}$ \\
\hline & 7 & & GERENCIAMENTO DE VERSÕES DOS DESENHOS DE PROCESSOS & SMITH ET AL (2002); SANTOS (2002) \\
\hline & 8 & \multirow{4}{*}{ 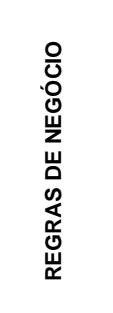 } & $\begin{array}{l}\text { DEFINICCÃO DE REGRAS DO NEGÓCIO DE MODO GRÁFICO E/OU LINGUAGEM DE FÁCIL } \\
\text { ENTENDIMENTO }\end{array}$ & DELPHI REPORT (2002); SMITH\&FINGAR (2003) \\
\hline & 9 & & $\begin{array}{l}\text { MECANISMO DE ENFILEIRAMENTO DE TAREFAS E GERENCIAMENTO DE STATUS DE ESPERAE } \\
\text { FINALIZAÇÃO }\end{array}$ & DELPHI REPORT (2003) \\
\hline & 10 & & PERMITE SALVAR AS VERSÕES DOS DESENHOS E REGRAS ANTERIORES. & DELPHI REPORT (2002) \\
\hline & 11 & & DEFINIÇÃO DE FORMULÁRIOS PARA INTEGRAÇÃO COM INDICADORES E SISTEMAS LEGADOS. & DELPHI REPORT (2002); SMITH ET AL. (2002) \\
\hline & 12 & 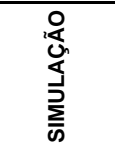 & $\begin{array}{l}\text { CAPACIDADE DE SIMULAÇÃO ONDE ESQUEMAS ANIMADOS DE "TOKENS" FLUEM ATRAVÉS DO } \\
\text { GRÁFICO PARA SIMULAR EXECUÇÕES INSTANCIADAS DO PROCESSO. }\end{array}$ & MEGARD, Patrick (2002); SANTOS (2002) \\
\hline
\end{tabular}




\begin{tabular}{|c|c|c|c|c|}
\hline PDCA & \# & $\begin{array}{l}\text { MACRO } \\
\text { FUNÇÃO }\end{array}$ & FUNCIONALIDADES & REFERÊNCIAS \\
\hline \multirow{7}{*}{ 음 } & 13 & 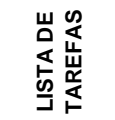 & LISTA DE TAREFAS PERSONALIZÁVEL & $\begin{array}{l}\text { SMITH ET AL (2002); SANTOS (2002); MEGARD } \\
\text { (2002) }\end{array}$ \\
\hline & 14 & \multirow{3}{*}{ 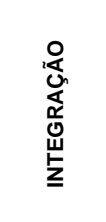 } & GERENCIAMENTO DE FORMULÁRIOS E DOCUMENTOS ATACHADOS & $\begin{array}{l}\text { DELPHI REPORT (2002); SMITH ET AL. (2002); } \\
\text { SANTOS (2002) }\end{array}$ \\
\hline & 15 & & INTEGRAÇÃO COM APLICAÇÕES EXTERNAS (ERP, CRM, SCM, SERVIÇO DE E-MALL, WEB) & $\begin{array}{l}\text { DELPHI REPORT (2002); SMITH ET AL. (2002); } \\
\text { SANTOS (2002) }\end{array}$ \\
\hline & 16 & & INTERFACE COM BANCO DE DADOS. & DELPHI REPORT (2002); SANTOS (2002) \\
\hline & 17 & \multirow{3}{*}{ 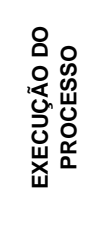 } & EXECUÇÃO DE PROCESSOS EM PARALELO OU CONCORRENTES EM VÁRIOS NIVEIS & DELPHI REPORT (2002); MCDANIEL, Tyler (2001) \\
\hline & 18 & & INTERFACE GRÁFICA PARA INTERVENÇÕES MANUAIS E TRATAMENTO DE EXCEÇÕES & DELPHI REPORT (2002); SMITH ET AL. (2002) \\
\hline & 19 & & $\begin{array}{l}\text { EM TEMPO REAL, O MECANISMO DE EXECUÇÃO PODE REGISTRAR TODOS OS EVENTOS } \\
\text { OCORRIDOS EM UMA BASE DE DADOS COM RECURSO DE EXPORTAÇÂOO PARA POSTERIOR } \\
\text { ANÁLISE. }\end{array}$ & MEGARD, Patrick (2002); SANTOS (2002) \\
\hline \multirow{3}{*}{$\begin{array}{l}\frac{Y}{U} \\
\text { 夏 }\end{array}$} & 20 & \multirow{3}{*}{ 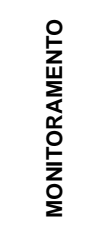 } & REPORT WIZARD (ASSISTENTE INTELIGENTE) E TEMPLATES DE RELATÓRIOS. & $\begin{array}{l}\text { DELPHI REPORT (2002); SMITH ET AL. (2002); } \\
\text { SANTOS (2002) }\end{array}$ \\
\hline & 21 & & MECANISMO PARA IDENTIFICAÇÃO DE GARGALOS E SINALIZADORES NOS PROCESSOS & SMITH ET AL (2002) \\
\hline & 22 & & $\begin{array}{l}\text { POSSUI UM PAINEL DE FÁCIL VISUALIZAÇÃO DE TODAS AS ATIVIDADES DO PROCESSO COM DADOS } \\
\text { DE CATEGORIA, INSTÂNCIAA A QUE PERTENCE, TIPO, PARTIIIPANTE, APLICAÇÃO CORRENTE, } \\
\text { STATUS, ETC. }\end{array}$ & MEGARD, Patrick (2002); SMITH ET AL. (2002) \\
\hline \multirow{2}{*}{ 㫐 } & 23 & \multirow{2}{*}{ 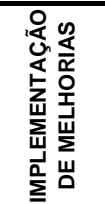 } & INTERVENÇÕES MANUAIS ATRAVÉS DE INTERFACE GRÁFICA & DELPHI REPORT (2002); SMITH ET AL. (2002) \\
\hline & 24 & & $\begin{array}{l}\text { PERMITE ALTERAÇÕES NO PROCESSO EM TEMPO DE EXECUÇÃO PARA DISTRIBUIR A CARGA DE } \\
\text { TRABALHO E/OU REMOVER REDUNDÂNCIAS }\end{array}$ & DELPHI REPORT (2002); SMITH ET AL. (2002) \\
\hline
\end{tabular}

Fonte: Elaborado pelo Autor.

\subsection{2-Objetivos de desempenho}

Os objetivos de desempenho considerados pelo presente modelo são inerentes ao referencial teórico proposto por Slack et al. (1997) e são os seguintes:

- vantagem em Qualidade - fazer certo. A dimensão qualidade pode ser entendida como a de adequação às especificações ou como de adequação aos propósitos, ou seja, alinhado com as estratégias do produto/serviço e, muitas vezes, alinhado com as estratégias mais globais da empresa;

- vantagem em Velocidade - fazer rápido. Entende-se que o encurtamento do ciclo operacional dentro da cadeia de valor, 
proporciona redução de despesas, e especulação com estoques possibilitando melhores previsões e atendimento da demanda;

- vantagem em Confiabilidade- prover acuracidade. Embora possa ser facilmente confundido com o aspecto da pontualidade, ou ter uma operação capaz de atender dentro dos prazos estabelecidos, também se atribui o fornecimento de informações e serviços exatamente como solicitado, gerando, com isso, maior confiabilidade ;

- vantagem em Flexibilidade - capacidade de adaptação. A capacidade de lidar com o risco das incertezas, da falta de informação ou erro de previsão, da variedade, por meio de uma operação robusta no sentido de permitir rápidas adaptações seja de resposta quanto de faixa;

- vantagem em Custo - fazer barato. A equação do lucro pressupõem não somente a redução de custos como da otimização do capital investido. A busca incessante de redução de custos expõem a interdependência com os outros fatores mas, também, reafirma a lógica de obtenção de maior competitividade por meio de melhorias na margem de lucro.

\subsection{3-Vínculo das funcionalidades BPM aos objetivos de desempenho}

O modelo de template proposto parte da premissa que é possível estabelecer um dado grau de contribuição de certa funcionalidade para certo objetivo de desempenho. $O$ estabelecimento do nível desta contribuição foi feito por meio de matriz AHP validada por especialistas em BPM e gestão de operações. Vale ressaltar que esta vinculação foi efetuada tendo como ponto de vista o gestor do negócio. Isto é, não se trata de avaliar a solução de BPM em si, mas os impactos que a utilização deste tipo de ferramenta traz para o negócio. De fato, a capacidade da ferramenta de prover facilidades na modelagem de processos e sua execução é fundamental na obtenção de processos de maior qualidade, especialmente quando avaliados na perspectiva da aprendizagem organizacional. Assim, a despeito da correlação direta entre a maturidade dos processos e os benefícios gerados, busca-se a vinculação levando-se em consideração o nível de contribuição que as funcionalidades de uma solução promovem para um dado objetivo de desempenho assumindo um processo, a priori, bem definido. 
A contribuição de cada macro-funcionalidade para os objetivos de desempenho adota os subsídios do trabalho de Muscat \& Fleury (1993), Sumanth (1984), Contador (1996), Kaplan\&Norton (1997) e Hronec (1994). Nestes trabalhos os autores vinculam um conjunto de indicadores a cada estratégia competitiva - que aqui é entendida com a mesma função do objetivo de desempenho. A análise dos indicadores propostos por estes autores, possibilitou que fosse facilitado o entendimento da maior ou menor contribuição das funcionalidades de uma solução BPM para uma dada estratégia competitiva.

Por exemplo, Muscat \& Fleury (1993) argumentam:

a o objetivo custo pressupõe o uso eficiente da capacidade, isto é, da melhor utilização dos recursos disponíveis pela organização. $O$ presente trabalho considerou que as funcionalidades associadas aos recursos da organização contribuem para o objetivo de desempenho custos. Desta forma, o grau de automação por meio da definição do processo e suas regras, integração com soluções legadas, o balanceamento de carga de trabalho e o monitoramento necessário são exemplos claros de funcionalidades que mais influenciam diretamente nos custos envolvidos;

- o objetivo qualidade centra-se na identificação das necessidades dos clientes, o ajuste do sistema de operações para atender a tais necessidades tanto do ponto de vista de processos gerenciais quanto de processos operacionais. Esta pesquisa considerou que as funcionalidades associadas à identificação das necessidades e ao ajuste do sistema de operações, incluindo capabilidade de processos, estabilidade de processos e qualidade de projetos e de recursos contribuem para o objetivo de desempenho qualidade. Assim, a execução conforme definido, o monitoramento eficaz em 
tempo real e o tratamento de exceções destacam-se no atendimento a este objetivo de desempenho;

- o objetivo flexibilidade relaciona-se à adaptabilidade no reposicionamento das operações em consonância com as demandas do mercado no que tange à: desenvolvimento de novos produtos e serviços; mudanças na faixa de produtos e serviços; mudanças nos volumes envolvidos; e de programação das datas de entrega. Nesta pesquisa identificou-se a capacidade de se adaptar à variação de volumes de transações, a integração e coordenação das partes por meio da própria definição do processo como funcionalidades prioritárias para contribuir com este objetivo de desempenho;

- o objetivo velocidade deve permitir o monitoramento e ganhos de eficiência nos tempos dos ciclos envolvidos: gestão; operação e fornecimento. Assim, a identificação de gargalos, o balanceamento de capacidade e a possibilidade de intervenções na execução são exemplos de ações necessárias para este objetivo de desempenho;

- o objetivo confiabilidade centra-se na acuracidade das operações e informações. Para efeito desta pesquisa as funcionalidades relacionadas com a execução conforme a definição, tratamento de exceções, definição de acesso e monitoramento como as mais relevantes para este objetivo de desempenho. 


\section{2-Propriedades e limitações do modelo proposto}

O modelo proposto possui determinadas propriedades e, é sujeito a diversas limitações:

Propriedade 1: $O$ modelo proposto estrutura-se com base nos objetivos de desempenho de estratégia de operações considerados por Slack (1993);

Propriedade 2: $O$ modelo proposto assume que a lista de funcionalidades que levou em conta são comuns à maioria das soluções de BPM atualmente existentes no mercado ao menos em seu nível de implementação básico, desconsiderando-se portanto quaisquer novas soluções que venham a surgir após esta data.

Propriedade 3: O grau de vinculação ou de contribuição de cada funcionalidade a um dado objetivo de desempenho foi estabelecido inicialmente pelo autor por meio de raciocínio lógico apoiado no método AHP e posteriormente submetido a apreciação de especialistas na área por meio do método Delphi, desconsiderando-se, portanto, quaisquer outras grandezas de atribuição por métodos diferentes.

Limitação 1: O modelo proposto limita-se às soluções BPM mais relevantes e existentes no mercado, de acordo com a lista do Gartner Group (Sinur, 2005);

Limitação 2: O modelo proposto ocupa-se apenas das funcionalidades operacionais, desconsiderando outros requisitos, tais como: linguagem; plataforma, hardware, suporte e modelo de comercialização;

Limitação 3: $O$ modelo proposto refere-se apenas a alguns requisitos das soluções BPM em relação a certos objetivos de desempenho de estratégia de operações desconsiderando outros requisitos, tais como: preço da solução; modelo de implementação e arquitetura tecnológica requerida; 
Limitação 4: O modelo proposto terá avaliada a sua aplicabilidade por meio de um estudo de caso que considera apenas quatro soluções, selecionadas por conveniência e que representam soluções utilizadas por empresas com operações no país, porquanto uma avaliação adequada da eficácia do Modelo proposto exigiria a aplicação em processos de negócios reais e a respectiva investigação do atendimento da solução adotada ao perfil competitivo objetivado inicialmente.

\section{3-Síntese do modelo proposto}

O modelo proposto, sinteticamente, consubstancia-se numa planilha constituída por 20 proposições tipo escala Likert (1-5) com destaque para os diferenciais semânticos 1, 3 e 5 para coleta de opinião do avaliador e cujos resultados serão traduzidos num índice que é a somatória dos valores ponderados da avaliação. A ponderação é estabelecida de acordo com a metodologia proposta neste trabalho. 


\section{Capítulo 4 Metodologia de Pesquisa}

Neste capítulo discute-se a metodologia a adotar. Utilizar-se-á a matriz AHP (Analytic Hierarchy Process) para estabelecer o grau de vinculação entre as funcionalidades de uma solução BPM e objetivos de desempenho segundo Slack. Também será utilizado o método Delphi eletrônico para avaliar a coerência lógica do modelo proposto e, por fim, através de estudo de caso, se verificará a operacionalização do modelo de avaliação.

\section{1-Operacionalização da pesquisa}

Neste item é descrita a operacionalização da pesquisa, isto é, apresenta-se a seqüência das principais etapas da pesquisa que foram cumpridas:

1. Definição das funcionalidades das soluções de BPM;

2. Elaboração do questionário preliminar para avaliar soluções de BPM, tipo escala Likert (1-5), e seu refinamento por meio de entrevistas com especialistas;

3. Utilização do método Delphi eletrônico para busca de consenso de especialistas a respeito de: a) conjunto de funcionalidades das soluções de BPM; b) das relação das funcionalidades listadas com os objetivos de desempenho (Avaliação do grau da relação das funcionalidades listadas com os objetivos de desempenho, segundo Slack, utilizando a matriz AHP)

4. Elaboração do questionário final para avaliar soluções de BPM;

5. Verificação da aplicabilidade do modelo proposto por meio de um estudo de caso (solicitação a fornecedores para avaliação da solução BPM conforme questionário; tabulação dos dados; classificação das soluções segundo objetivos de desempenho prédefinidos; entrevistas com clientes dos fornecedores; análise da concordância entre as afirmações dos fornecedores e seus respectivos clientes); 
6. análise dos dados do estudo de caso e realização de possíveis ajustes;

7. elaboração de conclusões;

8. conclusão da pesquisa redigindo o Relatório Final

\section{2-Matriz AHP}

A metodologia AHP (Analytic Hierarchy Process) oferece uma sistemática onde se pode representar os elementos de qualquer problema em uma estrutura hierárquica, coletar julgamentos, e estabelecer relações com prioridades para melhor entendimento e, eventual, tomada de ação (Saaty, 1980). Esta teoria foi desenvolvida nos E.U.A. na Wharton School of Business, pelo Prof. Dr. Thomas Saaty em 1971 e, permite defrontar-se com um grande número de elementos, controláveis ou não, que abrangem uma situação complexa, agregá-los em grupos, segundo caractetrísticas comuns e estabelecer prioridades (Fig.09).

A estrutura básica de uma estrutura hierárquica é a seguinte:

Fig. 09: Estrutura Matriz AHP

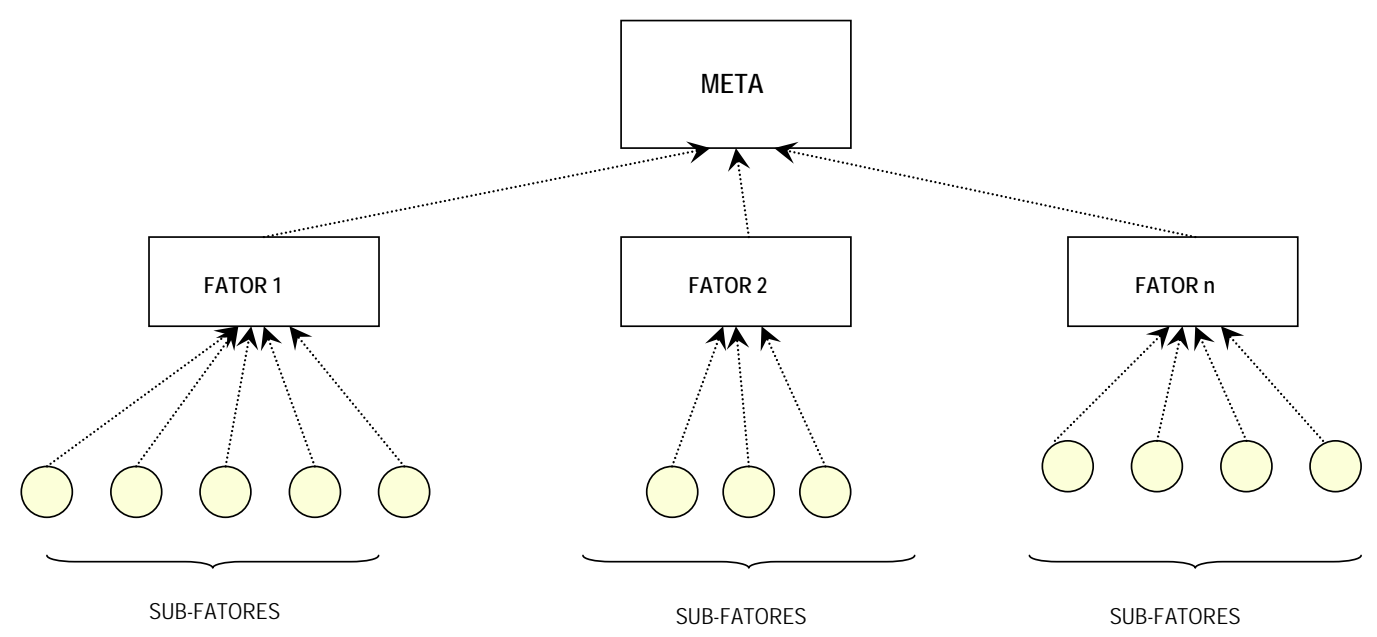

Fonte: Elaborado pelo autor (2005). 
A questão central na estruturação desta hierarquia é identificar com que peso os fatores individuais do nível mais baixo da hierarquia influenciam seu fator máximo, o fator meta ? Desde que esta influência não seja uniforme, chegamos à identificação de sua intensidade ou, como entendemos, às suas prioridades em relação ao seu nível imediatamente superior.

Esta determinação das prioridades dos fatores mais baixos com relação ao objetivo pode reduzir-se a uma seqüência de problemas de prioridade, um para cada nível, e cada um desses problemas de prioridade de uma seqüência de comparações por pares. Essas comparações são feitas por especialistas ou pessoas conhecedoras do assunto em questão, utilizando uma escala de importância, como ilustrado na quadro 03.

Quadro. 03 - Escala Matriz AHP

\begin{tabular}{|c|c|l|}
\hline INTENSIDADE & DEFINIÇÃO & \multicolumn{2}{|c|}{ JUSTIFICATIVA } \\
\hline $\mathbf{1}$ & Igual & Os dois fatores contribuem igualmente para o objetivo \\
$\mathbf{3}$ & Pouco Melhor & O fator é levemente superior em relação ao outro \\
$\mathbf{5}$ & Forte & O fator é de forte importância em relação ao outro \\
$\mathbf{7}$ & Muito Forte & O fator é muito forte em relação ao outro \\
$\mathbf{9}$ & Absoluto & O fator é de importância absoluta \\
$\mathbf{2 , 4 , 6 , 8}$ & & Podem ser utilizados quando a situção necessitar \\
\hline
\end{tabular}

Fonte: Morita (1998)

Embora o método permita utilizar critérios subjetivos, a qualidade do resultado depende da coerência dos julgamentos entre os pares de elementos. A existência de inconsistência pode indicar falha na estruturação do problema ou erro de avaliação (Morita, 1998). A medida da consistência pode ser dada pela Razão de Consistência (RC) obtida pela seguinte equação (Morita, 1998):

$$
R C=\frac{I C}{I R}
$$

IC representa o índice de consistência e, é dada pela fórmula: 


$$
\begin{aligned}
& I C= \frac{\left(\lambda_{\text {máx }}-n\right)}{(n-1)} \\
& \lambda_{\text {máx }}=A \times w, \text { sendo } \mathrm{A} \text { a Matriz de valores e w o autovetor de } \mathrm{A} . \\
& \mathrm{n}=\text { número de fatores }
\end{aligned}
$$

IR é um Índice Randômico e pode ser obtido pela equação:

$$
I R=1,98 \times \frac{(n-2)}{n}
$$

Segundo Saaty (1980), o RC (razão de consistência) deve ser de uma ordem de grandeza menor que $10 \%$.

\section{3-Delphi eletrônico}

O método Delphi busca formar um consenso de especialistas a respeito de uma determinada questão. Surgiu em 1948 na Rand Corporation dos Estados Unidos e de acordo com Wright \& Giovinazzo (2000) o método passou a ser disseminado no começo dos anos 60 e tinha como objetivo original desenvolver uma técnica para aprimorar o uso da opinião de especialistas na previsão tecnológica.

Sackman (1975) define Delphi como uma tentativa de elucidar a opinião de especialistas de maneira sistemática para resultados úteis. Uma outra definição dada por Turoff \& Linstone (1975) diz que Delphi é um método para estruturar um processo de comunicação grupal de maneira que o processo seja efetivo em permitir a um grupo de indivíduos como um todo lidar com um problema complexo.

Segundo Vichas (1982), três elementos se destacam no processo Delphi: (1) O anonimato; (2) feedback controlado; e (3) tratamento estatístico das respostas do grupo. 
O anonimato significa que o grupo de especialistas não sabe quem está participando do projeto ou se sabe de maneira nenhuma eles se comunicam diretamente. O propósito do anonimato é evitar que algumas pessoas, devido a características pessoais, dominem as opiniões. Além disto, quando há especialistas renomados e outros desconhecidos, pode ocorrer de um especialista desconhecido mudar suas opiniões meramente em função da reputação dos especialistas renomados, o que alteraria a representatividade estatística das respostas.

O feedback controlado significa que a cada rodada de questionários os participantes devem conhecer um pouco como os outros responderam. Este processo permite que cada um reflita antes de responder uma próxima rodada de questionários, mudando suas opiniões caso concorde com as opiniões de outros participantes.

O tratamento estatístico das respostas do grupo significa que a opinião de cada participante é avaliada, considerada e inserida em registros computacionais. As questões quantitativas são tabuladas, recebendo um tratamento estatístico simples.

Um dos aspectos importantes do método Delphi é a escolha dos especialistas da área em que se está desenvolvendo a pesquisa. Vichas (1982) argumenta que uma condição essencial do método Delphi é que depende de pessoas que sejam conhecedoras do assunto em pauta. Kayo \& Securato (1997) apontam dois motivos para o uso de especialistas: (1) especialistas constituem um grupo de potenciais inventores ou um grupo de pessoas formadoras de opinião cujas declarações podem refletir previsões confiáveis; e (2) as informações fornecidas por especialistas em um dado assunto tendem a ser de maior qualidade do que as informações de não especialistas. Um dos problemas do método Delphi, é definir critérios que possam indicar e identificar os especialistas a serem consultados. 
O Delphi Eletrônico é uma aplicação do método Delphi aliado a ferramentas da internet que surgiu em 1999 no Programa de Estudo do Futuro da Fundação Instituto de Administração ${ }^{13}$.O método incorpora todas as premissas características de um Delphi tradicional, sendo que os resultados das rodadas são comunicados pela Internet, para que possam ser considerados pelo grupo no preenchimento da rodada seguinte. Para estes autores existe uma seqüência básica de atividades envolvidas na execução de um Delphi Eletrônico:

- O objetivo de pesquisa deve ser claramente definido, especificando o horizonte de tempo e o tipo de resultado desejado. A equipe coordenadora do Delphi deve estruturar um primeiro modelo do questionário;

- As questões devem ser cuidadosamente elaboradas. Em função das necessidades específicas do estudo, diferentes tipos de questões podem ser utilizadas. Nesta fase é importante a interação entre os coordenadores do estudo e especialistas do setor, para assegurar a correção técnica das questões formuladas;

- Enquanto o questionário da primeira rodada é desenvolvido e testado via internet, a equipe coordenadora faz a seleção dos especialistas. A qualidade do resultado depende essencialmente dos participantes do estudo.

- O questionário é disponibilizado via Internet, utilizando um formulário cujos dados das respostas são encaminhados para uma planilha eletrônica como Excel, ou outra planilha adequada para a tabulação das informações.

- Após um prazo determinado pela coordenação, a equipe procede à sua tabulação e análise, e procurando associar os principais argumentos às diferentes tendências das respostas. Após a análise da $1^{\mathrm{a}}$ rodada a coordenação deve decidir sobre a necessidade de incorporação de novas questões à $2^{a}$ rodada, o que é bastante comum;

- A segunda rodada do questionário Delphi apresenta obrigatoriamente os resultados do primeiro questionário, possibilitando que cada respondente reveja sua posição face à previsão e argumentação do grupo, em cada pergunta. Por incluir os resultados da rodada anterior $\mathrm{e}$, ocasionalmente, novas questões, o segundo questionário geralmente é mais extenso que o primeiro. As questões em geral objetivam a convergência de resultados da primeira rodada, e são rediscutidas à luz da argumentação dos especialistas.

- No mínimo, duas rodadas são necessárias para caracterizar o processo Delphi, sendo raros os exemplos de estudos com mais de três rodadas de questionários;

- Os resultados finais são processados a partir do consenso gerado pelo grupo.

O Delphi Eletrônico, assemelha-se ao Delphi tradicional: ambas as abordagens têm um desenho semelhante ao mostrado na figura 10. Pode-se

\footnotetext{
${ }^{13}$ O Programa de Estudo do Futuro (PROFUTURO) é um dos programas desenvolvidos pela Fundação Instituto de Administração (FIA), entidade ligada à Faculdade de Economia, Administração e Contabilidade da Universidade de São Paulo (FEA-USP). Este programa faz uso regular do método Delphi em suas pesquisas e foi pioneiro no desenvolvimento do Delphi Eletrônico.
} 
dizer que o Delphi Eletrônico representa uma evolução no que diz respeito à velocidade de aplicação do método Delphi ao substituir o correio tradicional pelo uso da Internet no envio e devolução dos questionários de pesquisa.

Figura 10 - Esquema conceitual de Delphi Eletrônico.

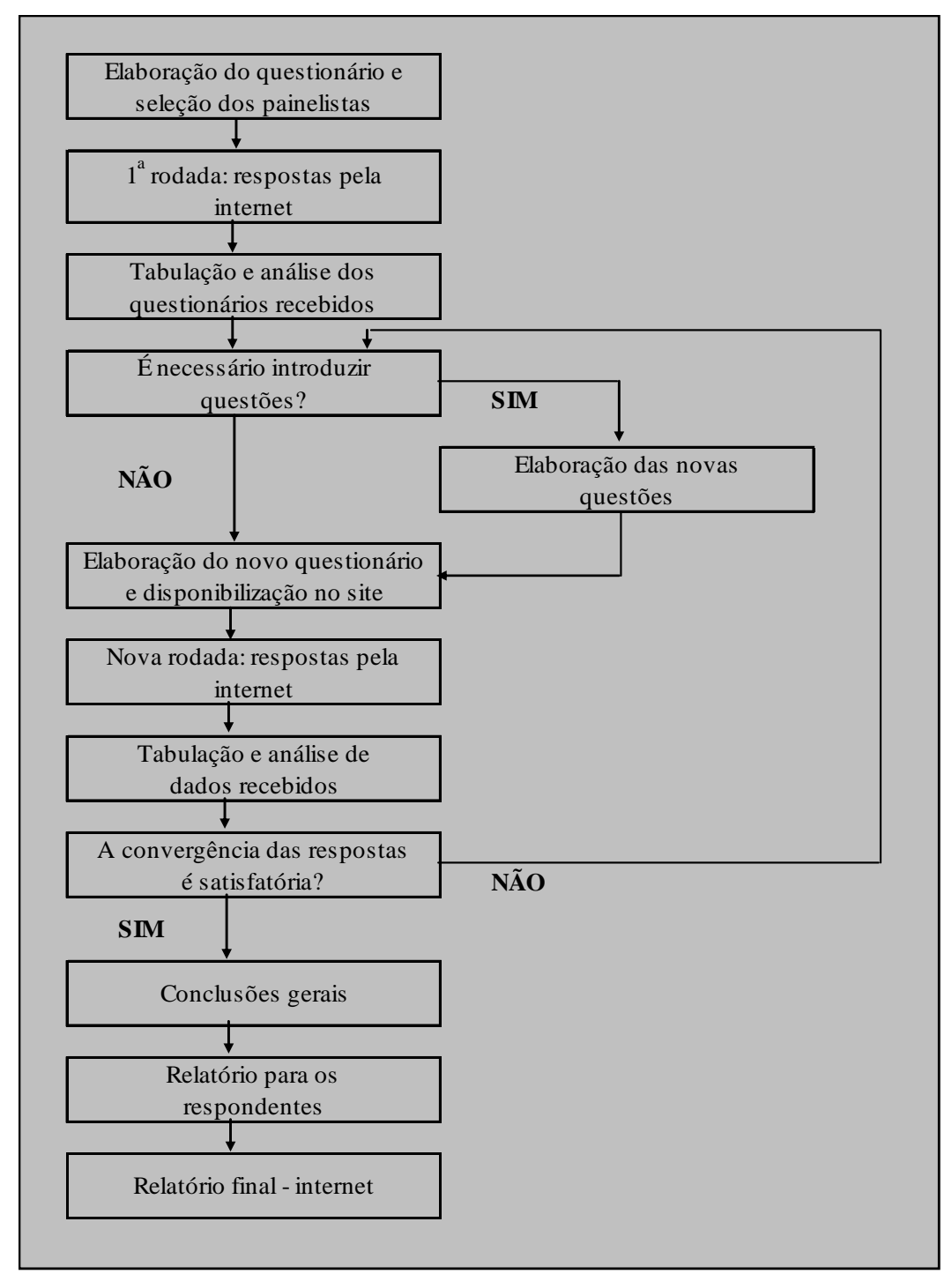

Fonte: Loures (2002)

\subsection{1-Escolha dos especialistas}

Os especialistas foram selecionados da Base de Dados Lattes encontrados com o uso da palavra chave Business Process Management. A lista de tais especialistas encontra-se no Anexo 1. 
Inicialmente cada especialista será convidado a participar do Delphi eletrônico. Serão envidados esforços no sentido de se ter a adesão de pelo menos 20 especialistas, tamanho este suficiente para o tratamento estatístico das respostas por meio de testes não-paramétricos (Siegel, 1979).

A mensagem de convite terá o seguinte teor:

Prezado(a) Colega:

Sou César Enoki, aluno de pós-graduação da Poli-USP e estou desenvolvendo uma pesquisa sobre soluções de BPM e sua relação com os objetivos de desempenho de operações. A busca de consenso de especialistas a respeito do conjunto de funcionalidades das soluções de BPM e das relações das funcionalidades listadas com os objetivos de desempenho será feita por meio do método Delphi eletrônico.

O método Delphi busca formar um consenso de especialistas a respeito de uma determinada questão. O Delphi Eletrônico é uma aplicação do método Delphi aliado a ferramentas da internet, sendo que os resultados das rodadas são comunicados por e-mail, para que possam ser considerados pelo grupo no preenchimento da rodada seguinte.

Basicamente cada especialista, frente a uma dada proposição, terá de expressar seu grau de concordância por meio de uma escala tipo Likert (1-5) podendo também tecer comentários ou justificativas.

Após o recebimento das respostas, as mesmas serão tabuladas e o resultado é enviado aos especialistas, reincidindo-se na questão se um dado nível de convergência não tiver sido atendido.

Todas as respostas são consideradas para análise da questão e os especialistas terão preservados o anonimato.

Assim sendo, faço o convite para que aceite participar desta pesquisa.

Certo da sua valiosa cooperação,

cordialmente

César Enoki

A cada especialista participante do Delphi eletrônico se atribuirá uma designação codificada do tipo Rnn. Por exemplo: Especialista R07.

\subsection{2-Sistemática de operacionalização do Delphi eletrônico}

O Delphi eletrônico da presente pesquisa se ocupará, basicamente, de três aspectos: primeiro: a adequação da lista de funcionalidades e sua respectiva gradação, isto é, se inquirirá aos especialistas qual o grau de concordância quanto aos níveis 1,3 e 5 de implementação da funcionalidade, níveis esses que correspondem, respectivamente aos níveis básico, intermediário e ideal; segundo: adequação da associação especificada entre cada funcionalidade e sua correspondente macro-funcionalidade; e 
terceiro: adequação da associação das macro-funcionalidades com objetivos de desempenho.

\subsubsection{1- Adequação da lista de funcionalidades}

Cada especialista receberá o template em forma de planilha Excel contendo colunas adicionais para que expresse a sua avaliação. Esta será feita mediante uma escala tipo Likert, com o seguinte diferencial semântico: 1)DT: discordo totalmente; 2) D: discordo; 3) I: indiferente; 4) C: concordo e 5) CT: concordo totalmente. Haverá espaço para possíveis comentários dos especialistas.

O especialista ao receber o template para análise receberá as seguintes instruções:

Instruções: Cada uma das funcionalidades listadas à esquerda (de 1.1 até 6.3 ) possui uma gradação de nível de implementação, que vai do básico (nível 1) ao nível máximo ou ideal (nível 5) passando pelo nível intermediário (nível 3). À direita há um campo para sua reposta, por meio de um questionário tipo Likert que requer que aponte com um $\mathbf{X}$ a alternativa que está mais de acordo com o seu entendimento.

Assinale:

- DT (Discordo Totalmente) se entender que a funcionalidade e sua respectiva gradação é totalmente contra o seu entendimento; é recomendável que justifique sua resposta;

- D (Discordo) se entender que a funcionalidade e sua respectiva gradação é parcialmente contrária ao seu entendimento; é recomendável que justifique sua resposta; 
- I (Indiferente) se entender que a funcionalidade e sua respectiva gradação possui aspectos discordantes e concordantes com o mesmo peso;

- C (Concordo) se entender que a funcionalidade e sua respectiva gradação está práticamente de acordo com o seu entendimento;

- CP (Concordo plenamente) se entender que a funcionalidade e sua respectiva gradação está totalmente de acordo com o seu entendimento.

Exemplo parcial de respostas de especialista com a sua avaliação e comentários (ver figura 11).

Fig.11 - Exemplo do Questionário

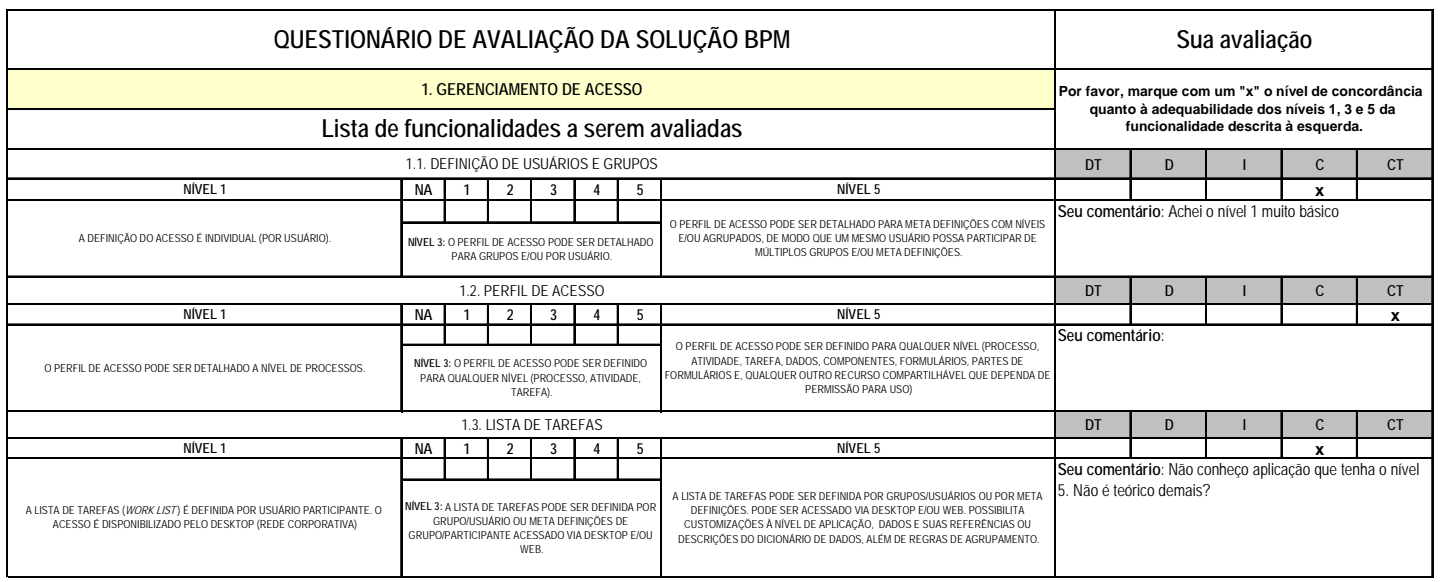

Fonte: Elaborado pelo autor.

As respostas recebidas são tabuladas e submetidas a tratamento estatístico para aferir o grau de convergência. Os comentários ou a justificativas quanto a uma determinada proposição são também tabulados. Por exemplo, no caso acima o respondente teceu os seguintes comentários:

Funcionalidade 1.1- Achei o nível 1 muito básico

Funcionalidade 1.3- Não conheço aplicação que tenha o nível 5. Não é teórico demais? 


\subsubsection{2- Associação entre funcionalidade e macro-funcionalidade}

O grau de adequação da associação entre cada funcionalidade e suas correspondente macro-funcionalidade será também objeto de estudo dos especialistas. Neste caso os especialistas serão chamados a dar seu nível de concordância quanto ao grau de associação das funcionalidades para cada macro funcionalidade, associação essa mostrada por meio de matriz AHP.

O especialista ao receber cada matriz AHP para análise terá as seguintes instruções:

Instruções: São fornecidas seis planilhas Excel, contendo cada uma matriz AHP que relaciona as funcionalidades a uma macro-funcionalidade. A associação é feita por meio de valores de 1 a 9 utilizados na matriz AHP e cuja interpretação está na própria planilha. À direita há um campo para sua reposta, por meio de um questionário tipo Likert que requer que aponte com um $\mathbf{X}$ a alternativa que está mais de acordo com o seu entendimento.

Assinale:

- DT (Discordo Totalmente) se entender que a associação entre as funcionalidades e sua macro-funcionalidade é totalmente contra o seu entendimento; é recomendável que justifique sua resposta;

- D (Discordo) se entender que a associação entre as funcionalidades e sua macro-funcionalidade é parcialmente contrária ao seu entendimento; é recomendável que justifique sua resposta;

- I (Indiferente) se entender que a associação entre as funcionalidades e sua macro-funcionalidade possui aspectos discordantes e concordantes com o mesmo peso; 
- C (Concordo) se entender que a associação entre as funcionalidades e sua macro-funcionalidade está praticamente de acordo com o seu entendimento;

- CP (Concordo plenamente) se entender que a associação entre as funcionalidades e sua macro-funcionalidade está totalmente de acordo com o seu entendimento.

Fig.12 - Exemplo Matriz AHP - Funcionalidades da Solução BPM

\begin{tabular}{|c|c|c|c|c|c|c|c|c|}
\hline $\begin{array}{c}\text { Matriz AHP } \\
\text { Formula de comparação: } \\
\text { A propriedade Y (abaixo) contribui } \\
\text {-Extremamente (9); } \\
\text {-Muito mais (7); } \\
\text {-Mais (5); } \\
\text {-Moderadamente (3); } \\
\text {-Igual (1) } \\
\text { do que a propriedade X (à direita) }\end{array}$ & 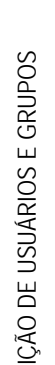 & 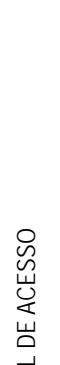 & 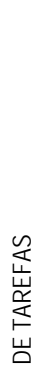 & \multicolumn{5}{|c|}{$\begin{array}{l}\text { Por favor, marque com um } \\
\text { "x" o nível de } \\
\text { concordância quanto ao } \\
\text { grau de associação das } \\
\text { funcionalidades para o } \\
\text { Gerenciamento de } \\
\text { Acesso, na presente } \\
\text { matriz AHP }\end{array}$} \\
\hline DEFINIÇÃO DE USUÁRIOS E GRUPOS & 1,0 & 1,0 & 3,0 & DT & D & I & C & CT \\
\hline PERFIL DE ACESSO & 1,0 & 1,0 & 5,0 & & & & & \\
\hline LISTA DE TAREFAS & 0,3 & 0,2 & 1,0 & & & & $X$ & \\
\hline \multicolumn{9}{|l|}{ Seus comentários: } \\
\hline \multicolumn{9}{|c|}{ ntendo que o peso do perfil de acesso está excessivo em comparação com a lista de tarefas } \\
\hline
\end{tabular}

Fonte: Elaborado pelo autor.

Exemplo de resposta de especialista com a sua avaliação e comentário referente á macro-funcionalidade Gerenciamento de Acesso está na figura 12.

\subsubsection{3- Associação das macro-funcionalidades com objetivos de desempenho}

O grau de adequação da associação entre cada macrofuncionalidade e cada objetivo de desempenho será também objeto de estudo dos especialistas que serão chamados a dar seu nível de concordância quanto ao grau de associação estabelecido. Embora a construção do modelo proposto baseie-se no uso da Matriz AHP, procuramos simplificar a coleta de opiniões por meio do formato em lista ordenada de 1 (maior contribuição) a 6 (menor contribuição). A seguir, com 
base na ordenação consensada pelos especialistas, construiu-se uma associação provável com o uso da Matriz AHP. Vale ressaltar que esta vinculação deve ser feita tendo como ponto de vista o do gestor do negócio. Isto é, não se trata de avaliar a solução de BPM em si, mas os impactos que a utilização deste tipo de ferramenta traz para o negócio. De fato, a capacidade da ferramenta de prover facilidades na modelagem de processos e sua execução é fundamental na obtenção de processos de maior qualidade, especialmente quando avaliados na perspectiva da aprendizagem organizacional. Assim, a despeito da correlação direta entre a maturidade dos processos e os benefícios gerados, busca-se a vinculação levando-se em consideração o nível de contribuição que as funcionalidades de uma solução promovem para um dado objetivo de desempenho assumindo um processo, a priori, bem definido (fig.13).

O especialista ao receber cada conjunto para análise terá as seguintes instruções:

Instruções: São fornecidas cinco grupos de macrofuncionalidades em uma planilha Excel, contendo uma ordem de contribuição de cada macro-funcionalidade com um dado objetivo de desempenho (velocidade, custo, qualidade, flexibilidade e confiabilidade). A ordenação é feita por meio de valores de 1 a 6 , sendo 1 para a Maior e 6 para o menor. À direita há um campo para sua reposta, por meio de um questionário tipo Likert que requer que aponte com um $\mathbf{X}$ a alternativa que está mais de acordo com o seu entendimento.

Assinale:

- DT (Discordo Totalmente) se entender que a ordenação entre as macros-funcionalidades e o objetivo de desempenho é totalmente contra o seu entendimento; é recomendável que justifique sua resposta; 
- D (Discordo) se entender que a ordenação entre as macrofuncionalidades e o objetivo de desempenho é parcialmente contrária ao seu entendimento; é recomendável que justifique sua resposta;

- I (Indiferente) se entender que a ordenação entre as macrofuncionalidades e o objetivo de desempenho possui aspectos discordantes e concordantes com o mesmo peso;

- C (Concordo) se entender que a ordenação entre as macrofuncionalidades e o objetivo de desempenho está praticamente de acordo com o seu entendimento;

- CP (Concordo plenamente) se entender que a ordenação entre as macro-funcionalidades e o objetivo de desempenho está totalmente de acordo com o seu entendimento.

Fig. 13 - Exemplo de Lista Ordenada das Macro-Funcionalidades com objetivos de desempenho
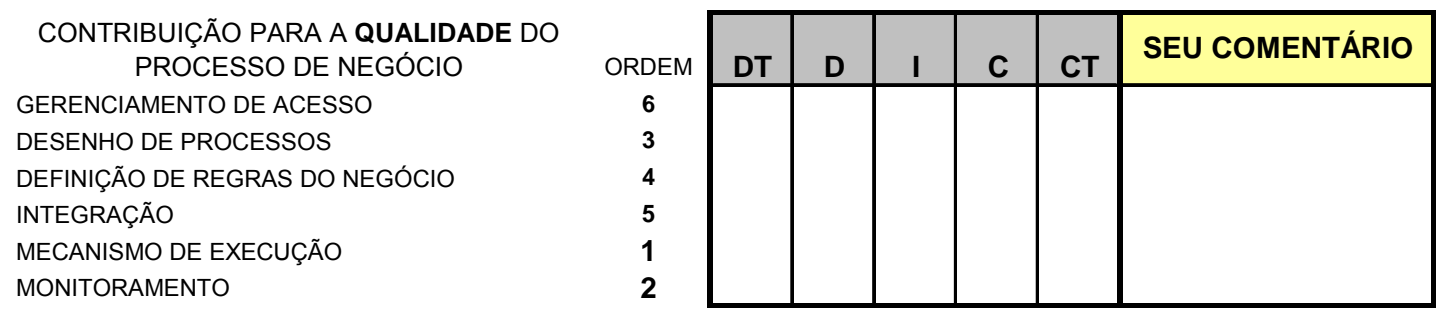

Fonte: Elaborado pelo autor.

\subsection{3-Tratamento estatístico das respostas}

O tratamento estatístico das respostas é feito utilizando testes nãoparamétricos. Prenovost (1999) afirma que os dados provenientes de escala Likert são de natureza estritamente ordinal e lamenta que ainda hoje as variáveis de nível ordinal formem a base de muitos dos dados usados em modelos paramétricos, quando esse tipo de processo de agregação assume 
no mínimo um nível intervalar de mensuração, o que fornece um indicativo pelo uso de testes não paramétricos quando do uso deste tipo de escala.

Siegel (1975) afirma que ao aplicar os testes não-paramétricos não é necessário fazer suposições sobre a distribuição da população. Esse mesmo autor afirma (p.84) que a prova de Wilcoxon pode ser utilizada para averiguar se dois grupos de variáveis diferem significativamente. Motulsky (2003:55) afirma que o teste de Wilcoxon usa-se para comparar dois grupos, e, neste caso ele é chamado Wilcoxon signed rank test. Este teste também responde à questão, por meio do p-value, se a mediana de uma amostra difere significativamente ou não de um dado valor. Se o p-value é pequeno, pode-se concluir que as populações possuem diferentes medianas ou a mediana da população difere do valor testado; se o p-value é grande não há razões para concluir que haja diferença entre as medianas ou entre a mediana da amostra e o valor testado.

O Wilcoxon signed rank test será utilizado para aferir o grau de convergência das respostas conforme mostrado abaixo. Linstone \& Turoff (1975:162) discutem o grau de convergência no contexto do método Delphi de quatro grupos de respondentes comparando a média entre os quartis $3 \mathrm{e}$ 4: investigaram a mudança intervalar nos quartis 3 e 4 . Estes autores utilizaram a correlação por postos de Spearman para investigar se havia diferença significativa ou não entre respostas dadas pelo mesmo grupo.

O coeficiente de correlação por postos de Spearman, de acordo com Siegel (1975) é uma medida de associação que exige que ambas as variáveis se apresentem em escala de mensuração pelo menos ordinal, de modo que os objetos ou indivíduos em estudo possam dispor-se por postos em duas séries ordenadas. Esta estatística por vezes é designada por rho.

A correlação de Spearman se expressa como:

$$
r h o=1-\frac{6 \sum_{i=1}^{N} d_{i}^{2}}{N^{3}-N}
$$


onde $d$ é a amplitude da diferença entre os pares $\mathrm{X}$ e $\mathrm{Y}$.

O coeficiente de correlação Spearman pode ser derivado algebricamente, diz Arsham (2001), da fórmula de correlação de Pearson, fazendo uso da soma de séries. Pearson contém expressões para

$\Sigma X(i), \Sigma Y(i), \Sigma X(i)^{2}$, e $\Sigma Y(i)^{2}$.

No caso de Spearman, os X(i)'s e os Y(i)'s são amplitudes e as somas das amplitudes e das amplitudes ao quadrado são inteiramente determinadas pelo número de casos:

$\Sigma \mathrm{i}=(\mathrm{n}+1) \mathrm{n} / 2, \Sigma \mathrm{i}^{2}=\mathrm{n}(\mathrm{n}+1)(2 \mathrm{n}+1) / 6$.

Desta forma a fórmula de Spearman é igual a:

$\left[12 P-3 n(n+1)^{2}\right] /\left[n\left(n^{2}-1\right)\right]$,

onde $\mathrm{P}$ é a soma dos produtos de cada par de filas $\mathrm{X}(\mathrm{i}) \mathrm{Y}(\mathrm{i})$. Isto se reduz a:

rho $=1-\left(6 \Sigma d^{2}\right) /\left[n\left(n^{2}-1\right)\right]$,

onde d é a diferença de amplitudes entre cada par de X(i) e Y(i).

Uma conseqüência importante disto é que se se incluem listas na fórmula de Pearson, se obtém exatamente o mesmo valor numérico que é obtido incluindo listas na fórmula de Spearman. Arsham (2001) afirma que para interpretar o valor de rho se pode utilizar a tabela 01:

Tabela 01- Interpretação do valor de rho de Spearman. Fonte: Arsham (2001)

\section{Valor de rho Interpretação}

da

$0,00-0,40$

Correlação

$0,41-0,75 \quad$ Justa

$0,76-0,85 \quad$ Boa

0,86-1,00 Excelente

Wright \& Giovinazzo (2000) afirmam que no método Delphi, o tratamento que pode ser dispensado a cada questão depende do tipo da questão. Para estes autores a mediana deve ser utilizada em lugar da média quando os painelistas têm grande variedade de opções. A apresentação 
dos quartis permite uma avaliação do grau de convergência das respostas e concluem: após a última rodada a mediana representará a resposta final do grupo.

\subsubsection{1- Grau de convergência}

A pesquisa requer, ao utilizar o método Delphi que se determine se as respostas convergem ou não para um dado valor. Para tal é necessário determinar o grau de convergência das respostas dadas pelos especialistas. Denomina-se convergência de opinião de dois ou mais sujeitos, de acordo com Siegel (1979) e interpretado em Enoki et al. (2005), a um dado nível de significância, ao valor para o qual tendem as opiniões dos sujeitos no espaço semântico. Por exemplo, ouvidos $n$ sujeitos quanto a determinada proposição, o grau de convergência é expresso pelo valor para o qual os $n$ sujeitos tendem no espaço semântico. O espaço semântico admite variações, cada uma delas distinguindo-se das outras, pelo que se dá ao conjunto das variações o nome de diferencial semântico (Pereira, 1986:2).A presente pesquisa faz uso de escala tipo Likert (1-5) e considera que há a seguinte correspondência quanto ao diferencial semântico:

\begin{tabular}{|c|c|c|c|c|}
\hline DT & D & I & C & CT \\
\hline 1 & 2 & 3 & 4 & 5 \\
\hline
\end{tabular}

Por meio do Wilcoxon signed rank test se verificará para qual diferencial convergem as respostas. O procedimento a adotar para investigar a convergência, segue o exemplo abaixo:

1)-Para cada questão se receberá um conjunto de respostas. Admitase a título de exemplo que para as proposições acima, 20 respondentes tenham dado as seguintes respostas:

\begin{tabular}{|c|r|r|r|}
\hline $\begin{array}{c}\text { Espec } \\
.\end{array}$ & Q-01-r1 & Q-02-r1 & Q-03-r1 \\
\hline E01 & 5 & 5 & 2 \\
\hline E02 & 5 & 4 & 2 \\
\hline E03 & 5 & 4 & 1 \\
\hline E04 & 5 & 5 & 2 \\
\hline
\end{tabular}




\begin{tabular}{|l|r|r|r|}
\hline E05 & 5 & 5 & 2 \\
\hline E06 & 5 & 4 & 1 \\
\hline E07 & 5 & 5 & 2 \\
\hline E08 & 5 & 4 & 2 \\
\hline E09 & 4 & 4 & 2 \\
\hline E10 & 5 & 5 & 1 \\
\hline E11 & 5 & 5 & 2 \\
\hline E12 & 5 & 5 & 1 \\
\hline E13 & 5 & 4 & 3 \\
\hline E14 & 4 & 5 & 1 \\
\hline E15 & 5 & 3 & 2 \\
\hline E16 & 5 & 5 & 3 \\
\hline E17 & 5 & 5 & 1 \\
\hline E18 & 5 & 4 & 2 \\
\hline E19 & 5 & 5 & 1 \\
\hline E20 & 5 & 5 & 2 \\
\hline
\end{tabular}

2)-Por meio de um software estatístico se fará uma análise descritiva dos dados recebidos:

\begin{tabular}{|c|c|c|c|c|}
\hline Variable & $\mathrm{N}$ & Mean & Median & TrMean \\
\hline Q1 & 20 & $4,900 \odot$ & $5,000 \odot$ & 4,9444 \\
\hline Q2 & 20 & 4,550 & $5,00 \odot$ & 4,611 \\
\hline Q3 & 20 & 1,750 & $2, \odot \odot \odot$ & 1,722 \\
\hline Variable & Minimum & Maximum & Q1 & Q3 \\
\hline Q1 & 4, ०००० & $5,0 \odot \odot \odot$ & $5,0 \odot \odot \odot$ & $5, \odot \odot \odot \odot$ \\
\hline Q2 & 3,000 & 5,000 & 4,000 & 5,000 \\
\hline Q3 & $1,00 \odot$ & $3, \odot \odot \odot$ & 1, $\odot \odot \odot$ & $2,0 \odot \odot$ \\
\hline
\end{tabular}

3)-Por meio do Wilcoxon signed rank test se investigará para qual diferencial semântico convergem as respostas:

Wilcoxon signed rank test

Q1

Does the median of Q1 differ significantly from 4.000?

The two-tailed $P$ value is $<0.0001$, considered extremely significant

Does the median of Q1 differ significantly from 5.0००?

The two-tailed $P$ value is 0.5000 , considered not significant.

Q2

Does the median of Q2 differ significantly from 4.000?

The two-tailed $P$ value is 0.0005 , considered extremely significant.

Does the median of $Q 2$ differ significantly from 5.000?

The two-tailed $P$ value is 0.0078 , considered very significant.

Q3

Does the median of $Q 3$ differ significantly from 1.000?

The two-tailed $P$ value is 0.0002 , considered extremely significant.

Does the median of Q3 differ significantly from 2.000? 
The two-tailed $P$ value is 0.1641 , considered not significant.

4)-A análise dos dados, a título de exemplo, pelo teste Wilcoxon de sinais ordenados mostrou que apenas a questão Q2 não obteve convergência. A Q1 convergiu para 5, isto é, convergiu para "concordo totalmente" e a questão Q3 convergiu para 2, isto é, convergiu para " não concordo".

5)-No caso de não convergência há dois caminhos adicionais:

\section{5a) caso da não convergência}

Para buscar a convergência da questão Q2, que está entre 4 (=concordo) e 5 (=concordo totalmente) se formula uma nova proposição que busca investigar até que ponto os especialistas concordam com a resposta de maior grau. A proposição é modificada de forma a incluir o grau de concordância à direita no intervalo obtido anteriormente e se busca uma resposta do tipo sim ou não.

\begin{tabular}{|c|c|c|c|}
\hline Q & Proposição & Sim & Não \\
\hline \multirow{3}{*}{02 r2 } & $\begin{array}{c}\text { Concordo totalmente que o perfil de acesso deve contemplar, } \\
\text { no mínimo, quais processos e quais atividades o usuário } \\
\text { (participante) pode acessar }\end{array}$ & & \\
\cline { 2 - 4 } & Comentário: & \\
\hline
\end{tabular}

A convergência será obtida pelo valor modal das respostas à questão Q2r2.

\section{5b) caso de convergência discordante}

Caso as respostas dos especialistas sejam discordantes, isto é, estejam convergindo para 1 ou para 2 se tomarão as medidas adequadas.

6)-No caso de convergência para 3: indiferente

Caso se observe que as respostas convergem para 3, se fará uma rodada, com procedimento semelhante ao caso da não convergência (caso 5a), buscando uma convergência para 2 (discordante) ou para 4 (concordante). 
7)-Será dado um feedback aos respondentes apenas sobre as questões que tiverem obtido um determinado grau de convergência (seja concordante ou não). O feedback fornecerá:

a) estatísticas descritivas das respostas;

Descriptive Statistics: Q1

Variable Mean

Q1

$\odot, 160$

Variable

Q1
Mean Median

4,750

20

Maximum

5,000
TrMean

4,889

StDev SE

$\odot, 716$

b) um BoxPlot: o BoxPlot é uma técnica utilizada na descrição de variáveis: é uma apresentação gráfica que possui muitas características indicando a presença de possíveis outliers. O boxplot mostra a amplitude dos dados, o que é uma medida de dispersão, incluindo os quartis superior e inferior bem como a mediana. De acordo com Cooper \& Schindler (2004) um outlier ou ponto extremo é um valor muito afastado dos demais dados. No caso de boxplots, o Minitab considera que qualquer valor entre 1.5 e 3 vezes de $50 \%$ da mediana é um possível outlier;

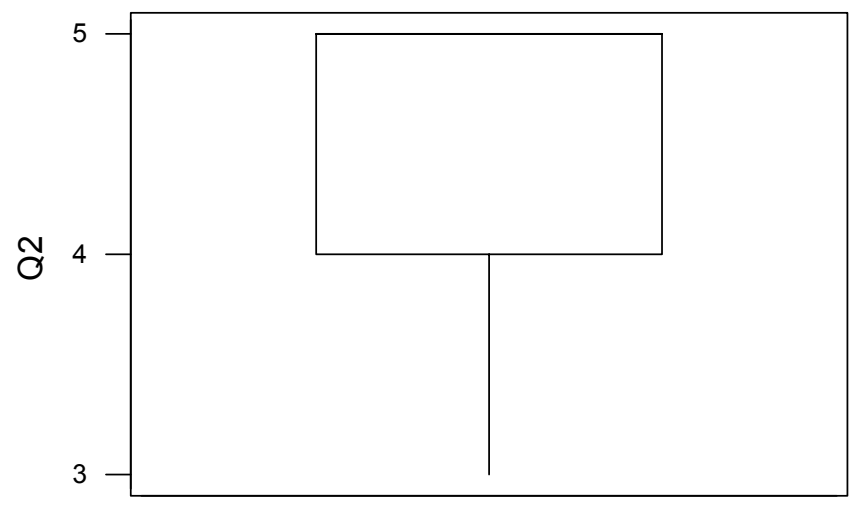


c) um histograma.

Histogram of Q1

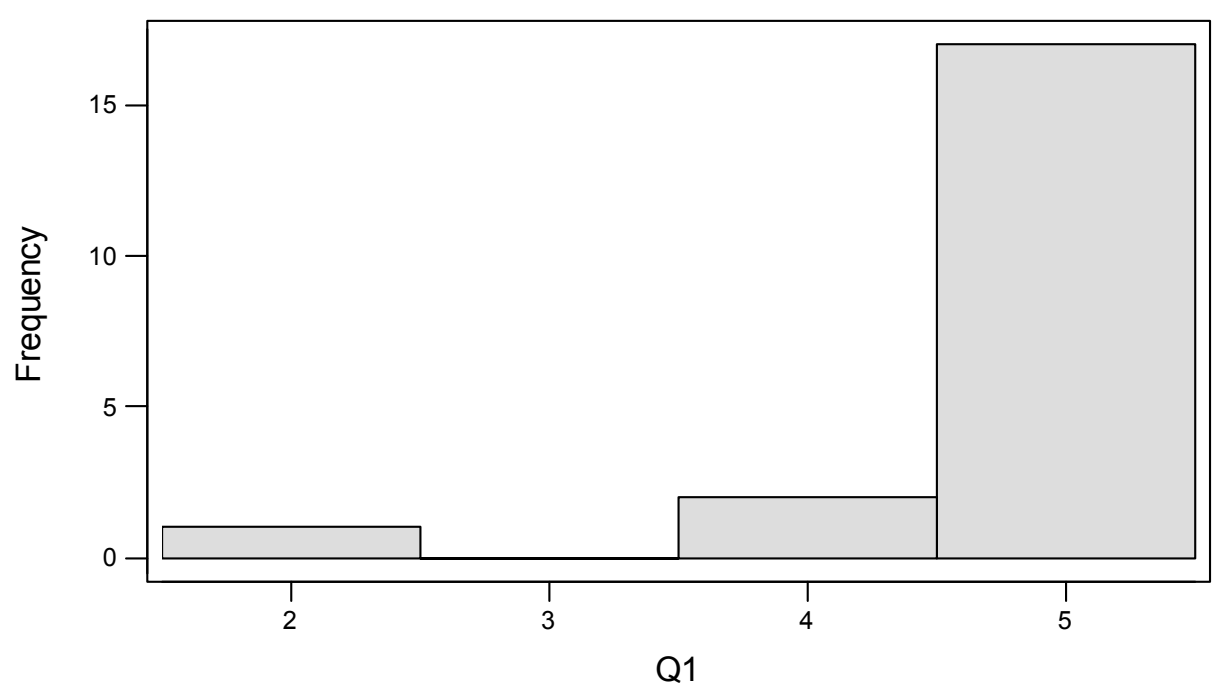

d) sumário dos comentários. O feedback para ser efetivo, no entender de Kayo \& Securato (1997) deve apresentar um sumário dos comentários feitos na rodada, principalmente se persistirem opiniões muito divergentes. A partir do feedback, quando necessário, é solicitado uma reavaliação das respostas anteriores e, persistindo a não convergência pede-se justificativa da posição.

\subsubsection{2- Grau de concordância}

A pesquisa requer que se averigúe também o nível em que respondentes concordam com determinadas proposições. Para determinar o grau de concordância entre respondentes se adota o método que pode ser visto em Yamamoto (2005). Denomina-se grau de concordância de respostas ao valor (entre -1 e 1) que se pode atribuir, a um dado nível de significância, que os postos, de um sujeito, expressando preferência sobre um conjunto de características, aderem aos postos de um outro sujeito expressando preferência sobre o mesmo conjunto de características. Ao 
grau -1 se dá o nome de discordância total e ao grau 1 o nome de concordância total.

Yamamoto (2005) para verificar o nível de concordância existente entre os diversos tipos de respondentes aplicou o teste de correlação por postos de Spearman, conforme Siegel (1975). Por meio do coeficiente de correlação de postos de Spearman $r_{s}$ se determinou o grau de similaridade quanto às preferências dos respondentes. O processo utilizado é mostrado na figura 14, que considera dois sujeitos que exprimem sua preferência a certos quesitos (comodidade, gentileza, etc) por meio de postos a sete itens, sendo que a maior preferência é expressa pelo posto 7 e a menor pelo posto 1. No exemplo 1 há uma concordância total de preferências, dado que os dois sujeitos apresentam a mesma preferência; do exemplo 2 ao exemplo 6 , as diferenças vão aumentando até se observar uma diferença total no exemplo 7. O exemplo 8 mostra o procedimento que se deve ter em caso de atribuição de postos iguais: os postos 3 e 4 foram atribuídos de forma igual, atribuindo-se a média dos valores.

Fig. 14: Exemplos para determinação do grau de condordância.

\begin{tabular}{|c|c|c|c|c|c|c|c|c|c|c|c|c|}
\hline \multirow{3}{*}{$\begin{array}{c}\text { Grau de concordância entre dois sujeitos } \\
\text { Característica }\end{array}$} & \multicolumn{3}{|c|}{ Exemplo 1} & \multicolumn{3}{|c|}{ Exemplo 2 } & \multicolumn{3}{|c|}{ Exemplo 3} & \multicolumn{3}{|c|}{ Exemplo 4} \\
\hline & \multirow{2}{*}{\begin{tabular}{|l|} 
S01 \\
postos \\
\end{tabular}} & \multirow{2}{*}{\begin{tabular}{|l}
$\mathbf{S 0 2}$ \\
postos
\end{tabular}} & \multirow{2}{*}{$d^{2}$} & \multirow{2}{*}{\begin{tabular}{|c|} 
S01 \\
postos \\
\end{tabular}} & \multirow{2}{*}{\begin{tabular}{|l|} 
S02 \\
postos
\end{tabular}} & \multirow{2}{*}{$d^{2}$} & \multirow{2}{*}{\begin{tabular}{|l|} 
S01 \\
postos \\
\end{tabular}} & \multirow{2}{*}{$\begin{array}{l}\mathbf{S} 02 \\
\text { postos }\end{array}$} & \multirow{2}{*}{$d^{2}$} & \multirow{2}{*}{\begin{tabular}{|c|} 
S01 \\
postos \\
\end{tabular}} & \multirow{2}{*}{\begin{tabular}{|l|} 
S02 \\
postos
\end{tabular}} & \multirow{2}{*}{$d^{2}$} \\
\hline & & & & & & & & & & & & \\
\hline comodidade & 7 & 7 & 0,00 & 7 & 7 & 0,00 & 7 & 7 & 0,00 & 7 & 7 & 0,00 \\
\hline gentileza & 6 & 6 & 0,00 & 6 & 6 & 0,00 & 6 & 6 & 0,00 & 6 & 6 & 0,00 \\
\hline variedade & 5 & 5 & 0,00 & 5 & 5 & 0,00 & 5 & 5 & 0,00 & 5 & 5 & 0,00 \\
\hline segurança & 4 & 4 & 0,00 & 4 & 4 & 0,00 & 4 & 4 & 0,00 & 4 & 1 & 9,00 \\
\hline precisão & 3 & 3 & 0,00 & 3 & 3 & 0,00 & 3 & 1 & 4,00 & 3 & 2 & 1,00 \\
\hline agilidade & 2 & 2 & 0,00 & 2 & 1 & 1,00 & 2 & 2 & 0,00 & 2 & 3 & 1,00 \\
\hline maleabilidade & 1 & 1 & 0,00 & 1 & 2 & 1,00 & 1 & 3 & 4,00 & 1 & 4 & 9,00 \\
\hline $6^{*}$ a soma dos quadrados das diferenças= & & & 0,00 & & & 12,00 & & & 48,00 & & & 120,00 \\
\hline coeficiente observado de correlação de postos de Spearman $r_{s}$ & & & 1,00 & & & 0,96 & & & 0,86 & & & 0,64 \\
\hline Grau de concordância entre dois sujeitos & & xemp & & & xemplc & & & xempl & & & $\overline{x e m p l}$ & 08 \\
\hline \multirow{2}{*}{ Característica } & S01 & S02 & \multirow{2}{*}{$d^{2}$} & S01 & S02 & \multirow{2}{*}{$d^{2}$} & S01 & S02 & \multirow{2}{*}{$d^{2}$} & S01 & S02 & \multirow{2}{*}{$d^{2}$} \\
\hline & postos & postos & & postos & postos & & postos & postos & & \begin{tabular}{|l|l|l|l} 
postos \\
\end{tabular} & postos & \\
\hline comodidade & 7 & 7 & 0,00 & 7 & 7 & 0,00 & 7 & 1 & 36,00 & 7 & 3,5 & 12,25 \\
\hline gentileza & 6 & 6 & 0,00 & 6 & 1 & 25,00 & 6 & 2 & 16,00 & 6 & 3,5 & 6,25 \\
\hline variedade & 5 & 1 & 16,00 & 5 & 2 & 9,00 & 5 & 3 & 4,00 & 5 & 5 & 0,00 \\
\hline segurança & 4 & 2 & 4,00 & 4 & 3 & 1,00 & 4 & 4 & 0,00 & 4 & 7 & 9,00 \\
\hline precisão & 3 & 3 & 0,00 & 3 & 4 & 1,00 & 3 & 5 & 4,00 & 3 & 6 & 9,00 \\
\hline agilidade & 2 & 4 & 4,00 & 2 & 5 & 9,00 & 2 & 6 & 16,00 & 2 & 1 & 1,00 \\
\hline maleabilidade & 1 & 5 & 16,00 & 1 & 6 & 25,00 & 1 & 7 & 36,00 & 1 & 2 & 1,00 \\
\hline $6^{*}$ a soma dos quadrados das diferenças $=$ & & & 240,00 & & & 420,00 & & & 672,00 & & & 231,00 \\
\hline coeficiente observado de correlação de postos de Spearman $r_{s}$ & & & 0,29 & & & $-0,25$ & & & $-1,00$ & & & 0,31 \\
\hline
\end{tabular}

Legenda: S01 e S02: preferência dos sujeitos; $d^{2}=$ quadrado da diferença entre os postos.

Fonte: Adaptado de Enoki \& Meireles (2005).

A fórmula para o cálculo do coeficiente de correlação $r_{s}$ é dada por: 
$r_{s}=1-\frac{6 \sum_{i=1}^{N} d_{i}^{2}}{N^{3}-N}$ onde d é a diferença obtida entre os postos dos sujeitos e $\mathrm{N}$ o número de itens em análise.

No caso do exemplo 8, o valor $r_{\mathrm{s}}$ foi assim calculado:

$r_{s}=1-\frac{6 \sum_{i=1}^{N} d_{i}^{2}}{N^{3}-N}=1-\frac{6 * 38,50}{7^{3}-7}=1-\frac{231}{343-7}=1-\frac{231}{336}=1-0,688=0,313$

Para que se possa afirmar a existência ou não de concordância, a um dado nível de significância é necessário que se observe que o valor calculado de $r_{\mathrm{s}}$ seja igual ou maior do que o valor de $r_{\mathrm{s}}$ tabelado conforme mostra a figura 15. Nos exemplos dados acima (figura 2), sendo $\mathrm{N}=7$, o valor crítico de $r_{\mathrm{s}}$ é 0,714 ao nível de significância de 0,05. Pode-se afirmar, desta forma, que os exemplos 1,2, 3 e 7 expressam concordância a tal nível de significância. 0 exemplo 7 , na medida em que mostra sinal negativo, podese afirmar que expressa discordância significativa.

Figura 15: Coeficiente de correlação de postos de Spearman- Valores críticos para $r_{s}$.

\begin{tabular}{|c|c|c|}
\hline \multicolumn{3}{|c|}{ Valores críticos de rs } \\
\hline & \multicolumn{2}{|c|}{$\begin{array}{c}\text { Nivel de significância } \\
\text { (unilateral) }\end{array}$} \\
\hline $\mathbf{N}$ & $\mathbf{0 , 0 5}$ & \multicolumn{1}{c|}{$\mathbf{0 , 0 1}$} \\
\hline $\mathbf{4}$ & 1,000 & \\
\hline $\mathbf{5}$ & 0,900 & 1,000 \\
\hline $\mathbf{6}$ & 0,829 & 0,943 \\
\hline $\mathbf{7}$ & 0,714 & 0,893 \\
\hline $\mathbf{8}$ & 0,643 & 0,833 \\
\hline $\mathbf{9}$ & 0,600 & 0,783 \\
\hline $\mathbf{1 0}$ & 0,564 & 0,746 \\
\hline $\mathbf{1 2}$ & 0,506 & 0,712 \\
\hline $\mathbf{1 4}$ & 0,456 & 0,645 \\
\hline $\mathbf{1 6}$ & 0,425 & 0,601 \\
\hline $\mathbf{1 8}$ & 0,399 & 0,564 \\
\hline $\mathbf{2 0}$ & 0,377 & 0,534 \\
\hline $\mathbf{2 2}$ & 0,359 & 0,508 \\
\hline $\mathbf{2 4}$ & 0,343 & 0,485 \\
\hline $\mathbf{2 6}$ & 0,329 & 0,465 \\
\hline $\mathbf{2 8}$ & 0,317 & 0,448 \\
\hline $\mathbf{3 0}$ & 0,306 & 0,432 \\
\hline
\end{tabular}

Fonte: Siegel (1979:315) 


\subsection{4-Tratamento dos comentários}

Os comentários sobre uma determinada questão serão listados e será feita uma síntese das recomendações ou sugestões dos mesmos. Caso se observe uma convergência discordante tais comentários serão levados em conta. Todos os comentários serão disponibilizados nos respectivos Apêndices (5, 6 e 7).

\subsection{5- Teste Wilcoxon de sinais ordenados}

Segundo Triola (1999:323), o teste de Wilcoxon de sinais ordenados tende a dar conclusões que refletem melhor a natureza dos dados. Admitese que a população de diferenças (obtidas a partir dos pares de dados) tenha distribuição aproximadamente simétrica (metade esquerda do histograma é aproximadamente igual ao histograma da metade direita). Ao contrário do teste $\mathrm{t}$ de Student não exige que os dados tenham distribuição normal. Triola (p.324) discorre sobre a realização deste teste por meio do Minitab e afirma que quando o valor do p-value é inferior ao nível de significância $(\alpha=0,05)$ deve-se rejeitar a hipótese nula de não diferença, isto é: quando o $p$-value $>0,05$ pode-se aceitar que há diferença significativa. Nos exemplos abaixo, realizados com o Minitab, observou-se, para as respostas Q2 que os respondentes não convergem nem para 4,0 nem para 5,0: p-values, respectivamente iguais a 0,008 e 0,014 < $\alpha=0,05$.

No outro exemplo, referente a Q1, o $p$-value observado $=0,181>$ $\alpha=0,05$, o que significa que não se observa diferença significativa. 


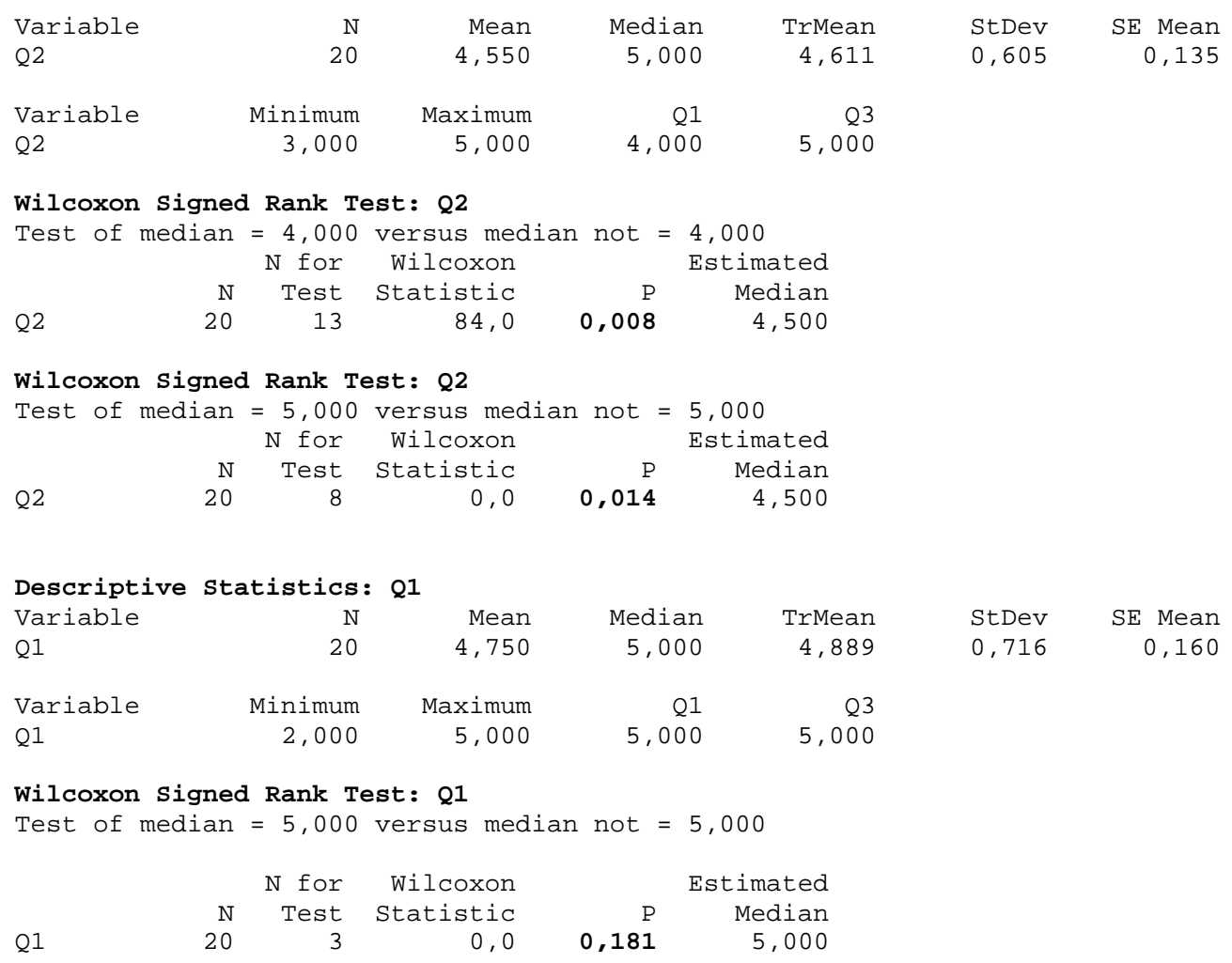

\subsection{Estudo de caso}

O estudo de caso caracteriza-se, em geral, pela análise profunda e exaustiva de um objeto, pressupondo-se, a fortiori, que a investigação possibilite a compreensão da generalidade do mesmo ou o estabelecimento de bases para uma investigação posterior, mais sistemática e precisa (Gil, 1991). O propósito desse tipo de pesquisa é o de proporcionar uma visão global do problema ou identificar possíveis fatores que o influenciam ou são por ele influenciados (Gil, 2000).

Segundo Becker (1999), o termo "estudo de caso" originou-se da pesquisa médica e psicológica, conquanto com a exploração intensiva de um caso individual procura-se explicar a dinâmica e a patologia de uma enfermidade. "O ensino da Medicina, especialmente das chamadas cadeiras clínicas, é realizado através de casos concretos (pacientes) em fase cuja 
sintomatologia o estudante deve procurar diagnosticar e recomendar a terapia que Ihe pareça adequada" (Figueiredo \& Hamburger, 1970: vii).

De acordo com Laville \& Dionne (1999:156): "se o estudo de caso incide (...) sobre um caso particular, examinando em profundidade, toda forma de generalização não é por isso excluída. Com efeito, um pesquisador seleciona um caso, na medida em que este Ihe pareça típico, representativo de outros casos análogos. As conclusões gerais que ele tirará deverão, contudo, ser marcadas pela prudência, devendo o pesquisador fazer prova de rigor e transparência no momento de enunciá-las."

A despeito dessas objeções, Gil (2000:123) ressalta que o estudo de caso constitui modalidade adequada para pesquisas com diferentes escopos, como: “a) explorar situações da vida real cujos limites não estão claramente definidos; b) preservar o caráter unitário do objeto estudado; c) descrever a situação do contexto em que está feita determinada investigação; d) formular hipóteses ou desenvolver teorias; e, e) explicar as variáveis causais de determinado fenômeno em situações muito complexas que não possibilitem a utilização de levantamentos e experimentos."

O estudo de caso referente à presente pesquisa constitirá na aplicação do template para avaliar quatro soluções de BPM (Business Process Management).

\subsubsection{Protocolo do estudo de caso}

A utilização do estudo de casos como método de pesquisa na área da administração, segundo Donaire (1997) requer o uso de protocolo do estudo:

A utilização de um protocolo para o estudo de casos constitui-se numa peça fundamental que transcende seu papel de instrumento de coleta de dados. O protocolo contém, além do conteúdo comum de um instrumento de coleta, o procedimento e as regras que serão obedecidas durante a sua utilização.

A existência de um protocolo, é uma das melhores maneiras de aumentarmos a confiabilidade do estudo de casos e de gerar uma pesquisa de boa qualidade. Na circunstância de serem utilizados múltiplos casos é essencial a existência de um protocolo. 
O protocolo deve incluir as seguintes seções:

a) Visão sobre o projeto do estudo de caso: objetivos, recursos, pessoal envolvido, resultados esperados e leituras relevantes sobre o assunto;

b) Procedimentos de campo: credenciais e acesso aos locais de pesquisa e informações gerais de como proceder;

c) Questões de estudo de casos, identificando quais as questões relevantes que o pesquisador deve efetuar e quais as fontes de informação potenciais para responder a cada uma delas. Neste caso, duas características devem ser enfatizadas: I) as questões em essência devem ser usadas para que o pesquisador lembre das informações de que necessita e o por quê delas; II)—cada questão deve ser acompanhada por uma lista das prováveis fontes de evidência, que podem incluir entrevistas pessoais, análise de arquivos e documentos ou observação.

d) Guia para o relatório do estudo de casos: esboço, formato, audiência, especificação da informação bibliográfica e outros documentos. Isto é muito importante, pois contrariamente ao que ocorre com outros tipos de pesquisa, o relatório da cada caso deve ser feito concomitantemente com a coleta de dados.

Na presente pesquisa o estudo de caso se consistiu na aplicação do template a quatro soluções de BPM. O protocolo, considerará o seguinte modelo:

\begin{tabular}{|l|l|}
\hline Visão do Projeto \\
\hline Objetivos & $\begin{array}{l}\text { Demonstrar a aplicabilidade do template proposto para avaliar soluções } \\
\text { de BPM (Business Process Management), sob a ótica da Estratégia de } \\
\text { Operações. }\end{array}$ \\
\hline Recursos & $\begin{array}{l}\text { Inobservância de dispêndios ou de recursos financeiros na medida em } \\
\text { que o estudo baseia-se em entrevistas com os fornecedores e seus } \\
\text { respectivos clientes }\end{array}$ \\
\hline $\begin{array}{l}\text { Pessoal } \\
\text { envolvido }\end{array}$ & $\begin{array}{l}\text { As pessoas envolvidas neste projeto são: a) pessoal técnico e comercial } \\
\text { de fornecedores de soluções BPM (simplesmente designados por } \\
\text { fornecedores); b) process owner de clientes de tais fornecedores (aqui } \\
\text { designados por usuários) }\end{array}$ \\
\hline $\begin{array}{l}\text { Resultados } \\
\text { Esperados }\end{array}$ & $\begin{array}{l}\text { Verificação de que o template proposto para avaliar soluções de BPM } \\
\text { (Business Process Management), sob a ótica da Estratégia de } \\
\text { Operações é eficaz. }\end{array}$ \\
\hline $\begin{array}{l}\text { Leituras } \\
\text { relevantes }\end{array}$ & \begin{tabular}{l} 
Ver Referências Bibliográficas \\
\hline
\end{tabular}
\end{tabular}




\begin{tabular}{|l|l|}
\hline Procedimentos de Campo \\
\hline $\begin{array}{l}\text { Locais de } \\
\text { pesquisa }\end{array}$ & A pesquisa será feita nos escritórios dos fornecedores e usuários \\
\hline $\begin{array}{l}\text { Procedimentos } \\
\text { gerais }\end{array}$ & Deslocamento até aos escritórios e entrevista pessoal e telefônica \\
\hline
\end{tabular}

\begin{tabular}{|l|l|}
\hline Questões do Estudo de Caso \\
\hline $\begin{array}{l}\text { Questão } \\
\text { Relevante }\end{array}$ & $\begin{array}{l}\text { O template proposto é aplicável para avaliar soluções de BPM (Business } \\
\text { Process Management), que sejam relevantes para a Estratégia de } \\
\text { Operações? }\end{array}$ \\
\hline $\begin{array}{l}\text { Fontes de } \\
\text { Informação }\end{array}$ & Percepção e opinião dos fornecedores e usuários de soluções BPM \\
\hline
\end{tabular}

\begin{tabular}{|l|l|}
\hline Aspectos do processo de Avaliação \\
\hline Foram realizadas as seguintes operações: \\
\hline Operação 1 & $\begin{array}{l}\text { Entrevista com o fornecedor da solução SBPMa. Resultados a serem } \\
\text { alcançados: a) Questionário de avaliação preenchido; b) grau de } \\
\text { compreensão do questionário; c) recomendações e sugestões para o } \\
\text { questionário }\end{array}$ \\
\hline Operação 2 & $\begin{array}{l}\text { Entrevista com o fornecedor da solução SBPMb. Resultados a serem } \\
\text { alcançados: a) Questionário de avaliação preenchido; b) grau de } \\
\text { compreensão do questionário; c) recomendações e sugestões para o } \\
\text { questionário }\end{array}$ \\
\hline
\end{tabular}




\section{Capítulo 5 Resultados obtidos}

Neste capítulo são discutidos os resultados observados. No item 5.1 descreve-se os resultados inerentes ao refinamento do instrumento; no item seguinte são apresentados os resultados referentes ao Método Delphi que buscou a validação do instrumento e, por fim são apresentados os resultados do estudo de caso com vistas a mostrar a aplicabilidade do instrumento aqui proposto.

\section{1-Refinamento do instrumento}

Neste item são descritas as atividades realizadas e os resultados obtidos por meio delas com vistas a refinar o modelo de instrumento proposto, partindo-se de uma versão inicial. As atividades e os resultados encontram-se descritos no quadro 04.

Quadro 04 - Atividades com vistas ao refinamento do instrumento

\begin{tabular}{|l|l|}
\hline Aspectos do processo de refinamento do instrumento \\
\hline $\begin{array}{l}\text { Foram realizadas as seguintes atividades com vistas a refinar o instrumento que foi, } \\
\text { posteriormente, objeto de validação pelo Método Delphi: }\end{array}$ \\
\hline Atividade 1 & $\begin{array}{l}\text { Data: 13/05/2005 Elaboração preliminar do instrumento com base em } \\
\text { referencial teórico conforme Apêndice 1 }\end{array}$ \\
\hline Atividade 2 & $\begin{array}{l}\text { Data: 20/05/2005 Primeira entrevista com os especialistas Mauricio } \\
\text { M.R.S e Verner R. para obter subsídios para a reelaboração do } \\
\text { instrumento }\end{array}$ \\
\hline Atividade 3 & $\begin{array}{l}\text { Data 19/05/2005: Redefinição do instrumento considerando os subsídios } \\
\text { da entrevista, com especificação dos diferenciais semânticos 1 e 5, } \\
\text { conforme Apêndice 2. }\end{array}$ \\
\hline Atividade 4 & $\begin{array}{l}\text { Data: 21/07/2005 Submissão do modelo ao Prof. Doutor Paulino } \\
\text { Francischini e recolhimento de sugestões }\end{array}$ \\
\hline Atividade 5 & $\begin{array}{l}\text { Data 29/07/2005 Redefinição do instrumento acatando integralmente as } \\
\text { recomendações do Prof. Doutor Paulino Francischini com a introdução } \\
\text { do diferencial semântico 3, conforme Apêndice 3 }\end{array}$ \\
\hline Atividade 6 & $\begin{array}{l}\text { Data 14/08/2005 Segunda entrevista com os especialistas Mauricio } \\
\text { M.R.S e Verner R. para apreciação do modelo. }\end{array}$ \\
\hline Atividade 7 & $\begin{array}{l}\text { Data 15/08/2005 Redefinição do instrumento levando em conta as as } \\
\text { recomendações dos especialistas, melhorando o conteúdo dos } \\
\text { diferenciais semânticos 1, 3 e 5, conforme Apêndice 4 }\end{array}$ \\
\hline
\end{tabular}




\section{2-Resultados do Método Delphi}

Neste item são descritos os resultados provenientes da utilização do Método Delphi, rodada a rodada. Inicialmente é feita uma descrição sintética das atividades realizadas para a aplicação de tal método.

\subsection{1-Aplicação do Método Delphi}

O quadro 05 mostra o conjunto de atividades realizadas para aplicação do Método Delphi com vistas a validar o instrumento e o método de sua concepção.

Quadro 05 - Atividades referentes à aplicação do Método Delphi

\begin{tabular}{|c|c|}
\hline de & \\
\hline $\begin{array}{l}\text { Foram realiz } \\
\text { presente pes }\end{array}$ & $\begin{array}{l}\text { Is seguintes atividades com vistas a validar o instrumento objeto da } \\
\text { segundo o método Delphi }\end{array}$ \\
\hline Atividade 1 & $\begin{array}{l}\text { Data: } 15 / 07 / 2005 \text { Seleção dos especialistas a serem convidados, com } \\
\text { base em pesquisas de trabalhos publicados nas áreas de Engenharia de } \\
\text { Processos e BPM }\end{array}$ \\
\hline Atividade 2 & Data: 2/08/2005 Submissão de e-mail-convite conforme item 4.3.1 \\
\hline Atividade 3 & $\begin{array}{l}\text { Data: De 2/08/2005 a 31/08/2005: Recebimento de confirmações de } \\
\text { participações }\end{array}$ \\
\hline Atividade 4 & $\begin{array}{l}\text { Data: De 01/09/2005 a 12/09/2005: Envio da Lista de Funcionalidades } \\
\text { para Avaliação dos Especialistas - Fase I - 1. Rodada }\end{array}$ \\
\hline Atividade 5 & $\begin{array}{l}\text { Data: De 19/09/2005 a 25/09/2005: Feedback sobre Resultados e } \\
\text { Comentários da Fase I - 1. Rodada }\end{array}$ \\
\hline Atividade 6 & $\begin{array}{l}\text { Data: De 26/09/2005 a 30/09/2005: Envio da Lista de Agrupamento das } \\
\text { Funcionalidades para Avaliação dos Especialistas - Fase II - 1. Rodada }\end{array}$ \\
\hline Atividade 7 & $\begin{array}{l}\text { Data: De 15/10/2005 a 21/10/2005: Feedback sobre Resultados e } \\
\text { Comentários da Fase II - 1.Rodada. Envio para nova Avaliação dos } \\
\text { Especialistas - Fase II - 2.Rodada }\end{array}$ \\
\hline Atividade 8 & $\begin{array}{l}\text { Data: De 22/10/2005 a 29/10/2005: Feedback sobre Resultados da Fase } \\
\text { II - 2.Rodada. Envio de Agrupamentos não consensados para nova } \\
\text { Avaliação dos Especialistas - Fase II - 3.Rodada }\end{array}$ \\
\hline Atividade 9 & $\begin{array}{l}\text { Data: De 01/11/2005 a 06/11/2005: Conclusão da Fase II e } \\
\text { Desenvolvimento do Material para a Fase Final }\end{array}$ \\
\hline Atividade 10 & $\begin{array}{l}\text { Data: De 12/11/2005 a 05/12/2005: Envio de Lista de Macro- } \\
\text { Funcionalidades e seu relacionamento com Objetivos de Desempenho } \\
\text { para Avaliação dos Especialistas - Fase III - 1.Rodada }\end{array}$ \\
\hline Atividade 11 & $\begin{array}{l}\text { Data: De 05/12/2005 a 11/12/2005: Feedback sobre Resultados e } \\
\text { Comentários da Fase III - 1.Rodada e nova lista para Avaliação - Fase } \\
\text { III - 2.Rodada }\end{array}$ \\
\hline Atividade 12 & $\begin{array}{l}\text { Data: De 12/12/2005 a 19/12/2005: Conclusão da Fase III e Feedback } \\
\text { Final para os Especialistas. }\end{array}$ \\
\hline
\end{tabular}




\subsection{2-Etapa inicial com vistas a validar as funcionalidades}

Nesta etapa inicial, denominada de Fase I, foi enviada a lista de funcionalidades (Apêndice 4), refinada preliminarmente com especialistas consultores em BPM. Os resultados desta etapa foram tabulados com a utilização do software MiniTab e, são apresentados, no Apêndice 5, um resumo das estatísticas descritivas e, para cada item um gráfico boxplot e um histograma, além do teste de Wilcoxon e os comentários dos 34 avaliadores participantes.

De modo geral, houve convergência para os diferenciais semânticos C-Concordo e CT-Concordo Totalmente, não se fazendo necessárias rodadas adicionais com os especialistas. Ou seja, a lista de funcionalidades descritas em seu nível de abstração foi interpretada adequadamente e, permitiu um julgamento por parte dos especialistas. A seguir, apresentamos algumas considerações com base nos comentários dos especialistas:

Gerenciamento de Acesso - a utilização de meta-definições, como por exemplo: cargo, função, grupo e sub-grupo, permitem uma flexibilidade na definição de processos e suas regras de negócio, na medida em que "isolam"14 o usuário-participante da modelagem do processo em si, facilitando a respectiva manutenção. Foi declarado que o acesso ao nível de dados deve ser administrado por componentes de serviços (transações ou sistemas transacionais) que fazem parte dos fluxos do processo modelado e, que a definição de acesso dos usuários-participantes deve ser efetuado na camada de processos/atividades. Assim, a própria visualização de itens de trabalho (conjunto de dados operacionais) deve ser definido por meio de formulários ou componentes de serviços. O acesso e interação do usuárioparticipante dentro do processo modelado pode ser viabilizado em ambiente de rede corporativa (desktop) e/ou com o uso de solução web (internet);

\footnotetext{
${ }^{14}$ Isolamento no sentido de despersonificar a definição de usuário-participante com um determinado processo em questão.
} 
Desenho de Processos - parece não haver dúvidas quanto à facilidade e necessidade de ferramentas com recursos de visualização gráfica para o desenho de processos. Muito embora existam diversas metodologias e técnicas de modelagem, não houve a preocupação em avaliarmos qual deveria ser adotada, uma vez que existem iniciativas de padronização (BPMN) e, também, porque as soluções de BPM existentes oferecem recursos suficientes para este propósito. Na prática, o desenho ou redesenho de um processo, em si, não é a atividade mais crítica. Daí, termos considerado como pouco relevantes a possibilidade de acolher diversas metodologias e/ou a portabilidade de desenhos dentre as soluções. Recursos adicionais como simulação ou gerenciamento de projetos devem ser considerados em contextos específicos, na medida em que exigem parâmetros adicionais nem sempre previsíveis e/ou determináveis à priori. Cada vez mais, o uso de templates de processos baseado em melhores práticas ou práticas mais usuais permitem uma maior velocidade na definição dos fluxos e aprendizado;

Regras de Negócio - a camada de regras de negócio em uma solução BPM permite preencher eventuais lacunas na modelagem de processos, do ponto de vista do desenho em si. Muito embora algumas soluções forneçam funcionalidades gráficas e intuitivas na definição de regras, o uso de especialistas e programação com linguagem de script ainda se fazem necessárias. Dados provenientes de sistemas legados ou dos próprios processos modelados podem ser manipulados por meio de formulários ou como simples variáveis. Não existe a obrigatoriedade de integração com banco de dados, embora isto seja possível. Ao mesmo tempo em que se exige um cuidado na gestão de dados, ressalta-se que este não deve ser o foco principal de uma solução BPM, mas sim o uso de componentes ou transações apropriadas que preservem a integridade referencial das mesmas. O uso de imagens, documentos digitalizados ou arquivos anexos tornam-se um atrativo a mais, embora a gestão adequada 
dos mesmos exija a robustez de soluções próprias de software GED (Gestão Eletrônica de documentos);

Integração - um dos méritos no uso de uma solução BPM reside na possibilidade de integrar e coordenar atividades/processos em ambientes heterogêneos, isto é, que onde se apresenta uma certa complexidade no uso de soluções de software e plataformas distintas. Assim, possuir conectividade ao nível de dados e com outras aplicações corporativas de mercado é de extrema importância. A existência de um middleware (camada intermediária) que reúna os componentes de serviços ou conectores com banco de dados e aplicações de mercado (ERP, CRM, EDI, etc.) e permita a gestão das integrações é a situação ideal apontada;

Mecanismo de Execução - a execução conforme o desenho do processo deve ser fácil e intuitiva para o usuário. Naturalmente, a interatividade requer cuidado quando levamos em consideração as transações e regras de negócio implementadas. A adaptabilidade às mudanças decorrentes da própria dinâmica do negócio e do ciclo de aprendizagem demanda um mecanismo que permita a implementação de versões e sua rastreabilidade. Além disso, a possibilidade de intervenções na execução mediante monitoramento em tempo real, fazem de uma solução BPM um instrumento eficaz para garantir a execução das tarefas. Muito embora a portabilidade e a escalabilidade sejam fatores técnicos de arquitetura, a solução deve permitir o crescimento sem maiores impactos no meio físico disponível (hardware);

Monitoramento - a visualização de gargalos ou eventuais problemas na execução de tarefas para rápidas intervenções e a definição e uso de indicadores para avaliar o desempenho em tempo real são funcionalidades desejáveis. É claro, no entanto, que toda solução BPM deve permitir a extração de relatórios operacionais seja por meio de funcionalidades nativas, seja por meio de aplicações de terceiros com acesso às bases de dados constituídas na execução dos processos. 


\subsection{3-Etapa de Validação dos Agrupamentos das funcionalidades}

Para a validação dos respectivos agrupamentos das funcionalidades e o grau de contribuição de cada uma por meio da matriz AHP, foram necessárias 3 (três) rodadas com os especialistas para a obtenção de uma convergência adequada.

Da $1^{\text {a }}$ rodada participaram 21 especialistas, cujas avaliações foram coletadas no período de 26/09/05 a 30/09/05; da $2^{a}$ rodada também participaram 21 especialistas, cujas avaliações foram coletadas no período de 15/10/05 a 21/10/05; e, da $3^{a}$ rodada participaram 18 especialistas, cujas avaliações foram coletadas no período de 22/10/05 a 29/10/05. Os resultados apresentam-se tabuladas no Apêndice 6. Algumas considerações sobre os resultados encontram-se, a seguir:

- Gerenciamento de Acesso - houve o entendimento e consenso quanto a possibilidade de utilizar meta-definições (cargo, função, grupo) para usuários-participantes, no entanto, indicouse a importância da funcionalidade de definição do perfil de acesso em detrimento dos demais. Apesar de eventuais facilidades na funcionalidade Lista de Tarefas impactar o uso eficiente das interfaces homem-máquina, podemos pressupor que isto pode ser também viabilizado por meio da definição/uso de transações legadas e/ou formulários;

- Desenho de Processos - além da possibilidade de desenhar eficientemente os processos, a visualização foi entendida como parte importante e integrante de tal funcionalidade;

- Definição de Regras do Negócio - regras complementam o desenho do processo, na medida em que permitem estabelecer o tratamento dinâmico dos fluxos e as interações com o usuário-participante e aplicações externas. O enfileiramento de tarefas e tratamento dos itens de trabalho podem ser definidos por meio de customizações nos sistemas transacionais e/ou definições de formulários. Provavelmente, em função desta opção, alguns especialistas não promoveram esta funcionalidade como fundamental;

- Integração - a maioria identifica o mérito de uma solução BPM por meio desta funcionalidade, na medida em que torna-se possível coordenar uma diversidade de aplicações sem maiores impactos de mudanças radicais nos chamados 
sistemas legados. Acessar bancos de dados é encarado como uma funcionalidade básica e, de certa forma, de domínio na maioria das soluções de software. Talvez, a criação e uso de uma biblioteca de componentes e conectores para facilitar as integrações e, além disso, a existência de uma camada que possibilite a gestão de tais integrações é encarado como a situação ideal, especialmente para a manutenção das mesmas;

- Mecanismo de Execução - é interessante notar que muitos relacionam a eficiência da execução com o grau de automatização. Embora, isto possa ser aplicável em alguns casos, devemos lembrar que processos de negócios reais estão sujeitos à mudanças constantes e, além disso, o ciclo de aprendizagem e grau de maturidade dos processos são variáveis importantes. Assim, a intervenção e tratamento de exceções deveria ser avaliado sob o prisma da flexibilidade e adaptabilidade. Ou seja, a importância da eficácia da interação entre a solução tecnológica com o usuário ou gestor do negócio. Porém, podemos notar por meio de algumas considerações, que existirá uma importância relativa de algumas funcionalidades em detrimento de outras dependendo do negócio em questão. Ou seja, que pode existir uma maior ou menor contribuição de algumas funcionalidades dependendo das necessidades e objetivos do gestor do negócio naquele momento. O mesmo podendo ser extrapolado para outros agrupamentos aqui avaliados;

- Monitoramento - parece claro que o monitoramento, em si, é importante para qualquer negócio. Entretanto, visualizar a execução e obter alguns indicadores de desempenho em tempo real parecem mais interessantes, enquanto que relatórios operacionais é encarado como uma funcionalidade básica.

\subsection{4-Etapa de Validação do Relacionamento entre as Macro- Funcionalidades e os Objetivos de Desempenho}

Nesta etapa participaram 14 especialistas no período de 12/11/2005 a 18/12/2005, cujas avaliações foram tabuladas com a utilização do software MiniTab e, são apresentados, no Apêndice 07, um resumo das estatísticas descritivas e, para cada item um gráfico boxplot e um histograma, além do teste de Wilcoxon e os respectivos comentários. 
Pôde-se perceber uma certa dificuldade na convergência de opiniões entre os especialistas, pois colocar-se na posição do usuário para avaliar o impacto em cada aspecto de desempenho (Objetivos de Desempenho) do negócio, dadas as características funcionais da solução de BPM, é muito influenciada pela experiência individual e contexto de referência utilizado por cada um.

Dada tal dificuldade em obter uma única lista consensada para cada objetivo de desempenho, optou-se pela adoção da técnica de grupo nominal (Meireles, 2001) com base nas sugestões dos especialistas (Vide Apêndice 07) para identificar uma lista ordenada pelo grau de importância ou contribuição de cada Macro-Funcionalidade para um dado Objetivo de Desempenho. Em seguida, passou-se a obter um consenso, essencialmente, sobre os pesos relativos de cada Macro-Funcionalidade para o respectivo Objetivo de Desempenho. A partir daí, elaboraram-se as matrizes AHP respeitando as sequências e pesos sugeridos e a razão de consistência (RC) indicado por Saaty (1980) e apresentadas no Apêndice 08. 


\section{3-Estudo de caso}

Neste item é feita a descrição do estudo de caso que se constituiu na aplicação do instrumento para avaliar quatro soluções BPM (Business Process Management). Basicamente as etapas deste estudo estão configuradas no protocolo abaixo que atende às premissas propostas em Donaire (1997).

\begin{tabular}{|l|l|}
\hline Visão do Projeto \\
\hline Objetivos & $\begin{array}{l}\text { Demonstrar a aplicabilidade do template proposto para avaliar soluções } \\
\text { de BPM (Business Process Management), sob a ótica da Estratégia de } \\
\text { Operações e Serviços. }\end{array}$ \\
\hline Recursos & $\begin{array}{l}\text { Inobservância de dispêndios ou de recursos financeiros na medida em } \\
\text { que o estudo baseia-se em entrevistas com os fornecedores e seus } \\
\text { respectivos clientes }\end{array}$ \\
\hline $\begin{array}{l}\text { Pessoal } \\
\text { envolvido }\end{array}$ & $\begin{array}{l}\text { As pessoas envolvidas neste projeto são: a) pessoal técnico e comercial } \\
\text { de fornecedores de soluções BPM (simplesmente designados por } \\
\text { fornecedores); b) process owner de clientes de tais fornecedores (aqui } \\
\text { designados por usuários) }\end{array}$ \\
\hline $\begin{array}{l}\text { Resultados } \\
\text { Esperados }\end{array}$ & $\begin{array}{l}\text { Verificação de que o template proposto para avaliar soluções de BPM } \\
\text { (Business Process Management), sob a ótica da Estratégia de de } \\
\text { Operações e Serviços é eficaz. }\end{array}$ \\
\hline $\begin{array}{l}\text { Leituras } \\
\text { relevantes }\end{array}$ & Ver Referências Bibliográficas \\
\hline
\end{tabular}

\begin{tabular}{|l|l|}
\hline Procedimentos de Campo \\
\hline $\begin{array}{l}\text { Locais de } \\
\text { pesquisa }\end{array}$ & A pesquisa foi feita nos escritórios dos fornecedores e usuários \\
\hline $\begin{array}{l}\text { Procedimentos } \\
\text { gerais }\end{array}$ & Deslocamento até aos escritórios e entrevista pessoal e telefônica \\
\hline
\end{tabular}

\begin{tabular}{|l|l|}
\hline Questões do Estudo de Caso \\
\hline $\begin{array}{l}\text { Questão } \\
\text { Relevante }\end{array}$ & $\begin{array}{l}\text { O template proposto é aplicável para avaliar soluções de BPM (Business } \\
\text { Process Management), que sejam relevantes para a Estratégia de } \\
\text { Operações e Serviços? }\end{array}$ \\
\hline $\begin{array}{l}\text { Fontes de } \\
\text { Informação }\end{array}$ & Percepção e opinião dos fornecedores e usuários de soluções BPM \\
\hline
\end{tabular}

\begin{tabular}{|l|l|}
\hline Aspectos do processo de Avaliação \\
\hline Foram realizadas as seguintes operações: \\
\hline Operação 1 & $\begin{array}{l}\text { Data: 29/09/2005 Duração: das 09:00 às 11:30 horas. Entrevistado: } \\
\text { Gerente Técnico da solução SBPMa. Resultado alcançado: a) } \\
\text { Questionário de avaliação preenchido conforme Apêndice 11; b) grau de } \\
\text { compreensão do questionário; c) recomendações e sugestões }\end{array}$ \\
\hline
\end{tabular}




\begin{tabular}{|c|c|}
\hline Operação 2 & $\begin{array}{l}\text { Data: 04/10/2005 Duração: das } 09: 00 \text { às } 11: 00 \text { horas. Entrevistado: } \\
\text { Gerente Técnico da solução SBPMb. Resultado alcançado: a) } \\
\text { Questionário de avaliação preenchido conforme Apêndice 12; b) grau de } \\
\text { compreensão do questionário; c) recomendações e sugestões para o } \\
\text { questionário }\end{array}$ \\
\hline Operação 3 & $\begin{array}{l}\text { Data: 07/10/2005 Duração: das } 09: 00 \text { às } 11: 45 \text { horas. Entrevistado: } \\
\text { Analista Senior da solução SBPMc. Resultado alcançado: a) } \\
\text { Questionário de avaliação preenchido conforme Apêndice } 13 \text {; b) grau de } \\
\text { compreensão do questionário; c) recomendações e sugestões para o } \\
\text { questionário }\end{array}$ \\
\hline Operação 4 & $\begin{array}{l}\text { Data: } 28 / 10 / 2005 \text { Duração: das } 15: 00 \text { às } 18: 00 \text { horas. Entrevistado: } \\
\text { Analista Senior da solução SBPMd. Resultado alcançado: a) } \\
\text { Questionário de avaliação preenchido conforme Apêndice 14; b) grau de } \\
\text { compreensão do questionário; c) recomendações e sugestões para o } \\
\text { questionário }\end{array}$ \\
\hline Operação 5 & $\begin{array}{l}\text { Data: 19/10/2005 Duração: das } 14: 30 \text { às } 16: 00 \text { horas. Entrevistado: } \\
\text { Gerente de Processos de empresa usuária da solução SBPMc. } \\
\text { Resultado alcançado: a) apreciação da avaliação do fornecedor da } \\
\text { solução SBPMc; b) grau de compreensão do questionário; c) } \\
\text { recomendações e sugestões para o questionário }\end{array}$ \\
\hline Operação 6 & $\begin{array}{l}\text { Data: } 21 / 10 / 2005 \text { Duração: das } 10: 00 \text { às } 11: 00 \text { horas. Entrevistado: } \\
\text { process owner de empresa usuária da solução SBPMa. Resultado } \\
\text { alcançado: a) apreciação da avaliação do fornecedor da solução SBPMa; } \\
\text { b) grau de compreensão do questionário; c) recomendações e sugestões } \\
\text { para o questionário }\end{array}$ \\
\hline Operação 7 & $\begin{array}{l}\text { Data: 04/11/2005 Duração: das } 09: 30 \text { às } 11: 40 \text { horas. Entrevistado: } \\
\text { Analista Senior de empresa usuária da solução SBPMd. Resultado } \\
\text { alcançado: a) apreciação da avaliação do fornecedor da solução SBPMd; } \\
\text { b) grau de compreensão do questionário; c) recomendações e sugestões } \\
\text { para o questionário }\end{array}$ \\
\hline
\end{tabular}

A empresa AICl Ltda em setembro de 2005 tinha em seus planos a aquisição de uma solução BPM e concordou que uma avaliação prévia de potenciais fornecedores fosse feita usando-se o modelo proposto.

A AICl Ltda é uma multinacional.japonesa que atua na produção e comercialização de especialidades químicas.para diversos segmentos da indústria: farmacêutica, cosméticos, alimentos e bebidas, com um faturamento anual ao redor de US\$ 300 milhões e cerca de 1.200 funcionários. Dentre as características do negócio em que atua, podemos ressaltar:

o Existência de diversas aplicações (sistemas legados), entre elas: ERP, CRM, Gestão de Documentos e Gestão da Qualidade; 
o Processos operacionais complexos que envolvem atividades de: importação, exportação, produção, armazenamento, desenvolvimento de Projetos para clientes, além do faturamento e distribuição;

o Participação intensiva das pessoas nos processos envolvidos.

Face a uma pesquisa de satisfação dos clientes realizada anualmente, a AICI Ltda busca um melhor desempenho de suas operações privilegiando qualidade e responsividade. Por meio de entrevistas semiestruturadas e uso da matriz AHP com os principais executivos da empresa, foi possível identificar as seguintes prioridades (Quadro 06):

Quadro 06: Objetivos de Desempenho da Empresa AICI

\begin{tabular}{|l|c|c|}
\hline $\begin{array}{c}\text { Objetivos de } \\
\text { Desempenho da } \\
\text { Empresa AICl. }\end{array}$ & IMPORTÂNCIA \\
\hline Flexibilidade & $6 \%$ & $\mathbf{5}$ \\
\hline Qualidade & $34 \%$ & $\mathbf{1}$ \\
\hline Custo & $11 \%$ & $\mathbf{4}$ \\
\hline Velocidade & $31 \%$ & $\mathbf{2}$ \\
\hline Confiabilidade & $17 \%$ & $\mathbf{3}$ \\
\hline
\end{tabular}

Fonte: Elaborado pelo Autor (2005).

O pesquisador, para o fim específico de avaliar solução BPM, entrou em contacto com quatro fornecedores e agendou entrevistas. Os fornecedores estavam cientes de que as declarações sobre as propriedades das suas soluções, em caso de aquisição da mesma por parte da AICI Ltda, deveriam ser atendidas. Cabe observar, deste modo, que o questionário foi utilizado como guia e preenchido pelo próprio pesquisador na presença do responsável técnico do produto e considerando potencial negociação futura. Esta condição removeu qualquer viés no sentido de exacerbar a avaliação 
por parte do fornecedor, na medida em que ele estava ciente de que o nível declarado das funcionalidades teria que ser comprovado em algum momento.

Figura 16: Posição Relativa das Soluções Avaliadas

\begin{tabular}{|c|c|}
\hline DESAFIANTES & LÍDERES \\
& C \\
\hline NICHO & VISIONÁRIOS \\
\hline D & \\
\hline
\end{tabular}

Fonte: Elaborado pelo Autor. Legenda: A, B, C, $D=$ Solução BPM respectivamente do fornecedor $A, B$, C, D.

Cada fornecedor indicou um usuário da sua solução, usuário esse que foi posteriormente entrevistado no sentido de ratificar ou retificar a avalição do fornecedor (vide Fig. 16).

\subsection{1-Entrevistas com os fornecedores}

A entrevista com os fornecedores tinha por objetivo: a) obter questionário de avaliação preenchido conforme Apêndice 4; b) verificar o grau de compreensão do questionário, isto é, se o respondente entendia perfeitamente a descrição de cada funcionalidade; e c) obter recomendações e sugestões para o questionário. 
A tabulação do preenchimento dos questionários pelos quatro fornecedores pode ser vista no Apêndice 10; a análise dos valores tabulados encontra-se no item 5.4- Aplicação do modelo.

De forma geral o questionário foi considerado adequado pelos fornecedores nos quesitos completude e clareza. Foram feitas ligeiras alterações no tocante a alguns termos técnicos e corrigidos alguns erros de digitação.

As recomendações e as sugestões formuladas pelos fornecedores de forma geral referiam-se a especificidades da própria solução que não eram contempladas pelo questionário e, dadas as suas características também não seriam objeto de avaliação, considerando que o modelo de template proposto não pode alcançar particularidades de cada software.

Por exemplo, em um caso, o fornecedor recomendou que o questionário contemplasse a necessidade de se descrever as habilidades e competências do usuário-participante além de grupos e funções; noutro caso o fornecedor sugeriu que o questionário considerasse aspectos de infraestrutura e ambiente nativo (plataforma Windows ou Unix, por exemplo) ou outras características de cunho tecnológico. Considerando que as recomendações e as sugestões fugiam ao escopo do modelo proposto, não foram levadas em consideração. 


\section{Perfil dos Fornecedores e Anotações das entrevistas}

Das entrevistas com os fornecedores, abaixo são relatados alguns aspectos relevantes.

Fornecedor SBPMa: Empresa multinacional americana e líder em soluções de integração de processos de negócios. Iniciou suas atividades em 1994 como provedor de solução de EAl (Enterprise Application Integration). Possui mais de uma centena de clientes nos mais variados segmentos, com detaque para: indústria de telecomunicações, petróleo e financeira. No mercado brasileiro possui um grande cliente no segmento de telecomunicações que, é considerado uma referência internacional para a empresa. Ao longo da apresentação do produto e entrevista, todas as funcionalidades foram entendidas $e$, na maioria, receberam pontuação máxima. A solução SBPMa é forte na integração incluindo tratamento semântico (vocabulário), no tratamento de exceções e escalabilidade. Não possui recursos para gestão de documentos, embora permita uma documentação on-line básica e, sua solução de monitoramento é apresentada como uma camada à parte da solução BPM em si, com possibilidades de interação via Web. Utiliza tecnologia de mensagens Java (JMS) ou WebSphere MQ, o que pode ser traduzido como possibilidade de independência e pouco impacto em infra-estruturas existentes. Quando questionados sobre as questões levantadas foram unânimes em expressar que todos os aspectos básicos da sua solução foram abordados e muito próximos do nível ideal (pontuação 5). Ficou claro para o entrevistador que o questionário deveria servir somente de guia para que pudéssemos explorar adequadamente o nível de implementação por meio de perguntas soltas sobre cada funcionalidade e, evitar qualquer viés nas respostas dadas.

Fornecedor SBPMb: Empresa multinacional americana e líder em soluções de BPM. Iniciou suas atividades em 1994 como provedor de soluções de Workflow e, atualmente, oferece seu produto em mais de 15 
países e cerca de 1500 clientes em diversos segmentos de mercado. É um importante parceiro da Microsoft e, portanto, sua solução é nativa neste ambiente. Oferece uma gama de treinamentos e suporte técnico para o uso adequado da solução por meio da Internet. Sua solução permite uma modelagem colaborativa, ou seja, de maneira distribuída e incorpora explicitamente o gerenciamento de versões dos processos. A definição de acesso pode refletir o organograma da empresa de maneira gráfica. $O$ mesmo conceito gráfico é extendido para a definição de regras de negócio e de formulários. Seu módulo de monitoramento é fornecido como solução à parte e, portanto, não é seu ponto forte. Após a apresentação, o fornecedor expressou surpresa pelas questões colocadas e exatidão nos pontos abordados.

Fornecedor SBPMc: Também, empresa multinacional americana e líder em soluções de BPM. Suas atividades remontam à 2001 como provedor de soluções de Workflow e, atualmente, oferece seu produto por meio de parcerias em diversos países e segmentos de mercado. É uma solução ideal para ambientes Unix e oferece boa conectividade pela parceria com uma empresa local especializada em integração de aplicações (EAI). A definição de processos e simulação é feita em módulo à parte e depois integrada à solução de BPM, propriamente dita. Podemos dizer que é uma solução resultante de diversas outras e que, portanto, necessita de forte apoio técnico para sua implementação.

Fornecedor SBPMd: Fornecedor local, iniciou suas atividades com soluções de EAI em 2001 e, atualmente, oferece soluções de BPM para diversas empresas do ramo segurador. Portanto, podemos conceituá-la como uma empresa de nicho dentro da referência do Gartner Group. A solução necessita de especialista para uma implementação adequada, uma vez que a definição de regras de negócio ou até mesmo os formulários exigem alguma programação ou codificação. Para a definição dos processos utiliza uma simbologia bastante simples e similar à um fluxograma básico, além de permitir cadastrar novas simbologias ou objetos. É possível definir e 
utilizar dados como variáveis dos processos ou referenciados à um banco de dados centralizado. Possui alguma facilidade de integração com bases externas e outras aplicações mas, de maneira geral, as mesmas são tratadas caso a caso. Relatórios são possíveis por meio de aplicativos de terceiros, como o Crystal Reports. Incorpora a facilidade de gerenciar aprovações, principalmente como recurso de workflow.

\subsection{2-Entrevistas com os usuários}

As entrevistas com os clientes de cada solução tinha por objetivo: a) obter questionário de avaliação preenchido conforme Apêndice 4; b) verificar o grau de compreensão do questionário, isto é, se o respondente entendia perfeitamente a descrição de cada funcionalidade por meio do seu relato e,; c) avaliar o grau de concordância com as respostas dos fornecedores.

A tabulação do preenchimento dos questionários foi possível para três clientes, todos relacionados com a indústria de telecomunicações, e pode ser vista no Apêndice 10; a análise dos valores tabulados encontra-se no item 5.3.3—Diferenças de Percepções entre Fornecedores e Usuários.

De forma geral o questionário foi considerado adequado pelos clientes (usuários) nos quesitos completude e clareza. Entretanto, como a participação e/ou uso da solução foi particularizada, algumas funcionalidades não puderam ser avaliadas de maneira confiável.

A seleção e implementação das soluções BPM de cada caso relatado pelo cliente/usuário possui critérios coincidentes:

- todos os casos buscavam integração e coordenação de serviços com uso intensivo de interfaces homem-máquina;

- objetivavam redução de custos e maior confiabilidade nas tarefas realizadas;

- definição de escopos menores no início para avaliar retorno financeiro da implementação em prazos curtos (01 ano). 
Não houveram recomendações e sugestões para o questionário aplicado, uma vez que as entrevistas com os usuários focavam principalmente a avaliação do nível de implementação ou utilização das funcionalidades da solução adotada.

Usuário da Solução SBPMa: Empresa brasileira de telecomunicações com forte atuação em serviços de telefonia fixa no Distrito Federal e nos estados do Acre, Rondônia, Tocantins, Mato Grosso, Mato Grosso do Sul, Goiás, Paraná, Santa Catarina e Rio Grande do Sul desde 1998. Os motivadores para a adoção de uma solução BPM foram: a falta de conhecimento explícito sobre os processos; a existência de diferentes sistemas legados herméticos e,; a falta de homogeneidade na definição de meta dados. Buscavam uma solução robusta que proporcionasse maior velocidade no lançamento de novos produtos e serviços. A solução de BPM adotada foi selecionada pelas referências de outras empresas, escalabilidade e confiabilidade nas interfaces. De uma realidade, no início, de aproximadamente 10.000 eventos/dia, atualmente, a solução permite administrar mais de 1.800 .000 eventos/dia, representando mais de 250 workflows distintos com índices de reaproveitamento de $50 \%$ dos processos mapeados. A aplicação do questionário foi de extrema utilidade para compreender o conhecimento do usuário quanto às funcionalidades da solução e como cada módulo foi implementado no caso em questão.

Usuário da Solução SBPMc: Empresa brasileira de telecomunicações com forte atuação em serviços de telefonia fixa em S.Paulo. A definição pelo uso de solução BPM originou-se no alto índice de reclamações por parte de clientes corporativos. Os problemas identificados foram essencialmente relacionados com falhas na integração e coordenação de atividades. Assim, com o auxílio de consultorias especializadas e pesquisas de mercado, identificaram algumas alternativas e optaram por aquela que se dispôs a realizar um teste piloto. Os objetivos iniciais focavam na busca de maior confiabilidade e integridade. Ao longo da implantação 
enfrentaram diversos desafios, entre eles: as mudanças de definição e escopo e a necessidade de aprendizagem do time envolvido. Entretanto, a grande lição veio ao subestimarem a infra-estrutura necessária para acolher a solução e o respectivo impacto nos sistemas legados. Assim, para evitar impactos negativos no desempenho da solução sugere-se o envolvimento do pessoal técnico de TI. Como resultado deste projeto, foi obtido uma redução das reclamações em mais de $30 \%$, uma maior produtividade na venda de produtos e serviços com confiabilidade e retorno financeiro do investimento realizado em prazo menor que 01 ano, conforme era esperado.

Usuário da Solução SBPMd: Empresa brasileira de prestação de serviços de seguros para empresas de telefonia móvel. Praticamente a empresa e o negócio foram viabilizados com o desenvolvimento e implementação da solução de BPM adotada. Portanto, a solução cobre os processos de: vendas, cobrança, administração de sinistros e entrega de aparelhos para substituição. Os fatores principais para a seleção foram: custo e flexibilidade nas customizações necessárias. O objetivo básico era de prover uma ferramenta de atendimento aos clientes em geral deste tipo de seguro. Durante a implementação foi identificado como ponto crítico o desenvolvimento das transações, já que não haviam sistemas legados para a operação do negócio. A empresa selecionada forneceu toda a mão-deobra para auxiliar na definição dos processos, telas e relatórios necessários. Algumas funcionalidades não foram utilizados nesta implantação, tais como o módulo de integração e o uso de indicadores de desempenho. Portanto, tais funcionalidades não puderam ser avaliados de maneira confiável pelo usuário entrevistado.

\subsection{3-Diferenças de percepções entre fornecedores e usuários}

Uma análise da concordância quanto aos valores dos fornecedores $(F)$ e respectivos usuários $(C)$ é feita abaixo. De acordo com Yamamoto 
(2005), denomina-se grau de concordância de respostas ao valor (entre -1 e 1) que se pode atribuir, a um dado nível de significância, que os postos, de um sujeito, expressando preferência sobre um conjunto de características, aderem aos postos de um outro sujeito expressando preferência sobre o mesmo conjunto de características. Ao grau -1 se dá o nome de discordância total e ao grau 1 o nome de concordância total.

Tabela 02: Grau de Concordância para a Solução SBPMa

\begin{tabular}{|c|c|c|c|c|c|}
\hline Grau de concordância & \multicolumn{2}{|c|}{ Avaliação } & \multicolumn{3}{|c|}{ Postos } \\
\hline \multirow{2}{*}{ Característica } & $\mathbf{F}$ & C & $F$ & C & \multirow{2}{*}{$d^{2}$} \\
\hline & Fornecedor & Usuário & postos & postos & \\
\hline Q1.1 & 5 & 5 & 14 & 15,5 & 2,25 \\
\hline Q1.2 & 4 & 4 & 4,5 & 6 & 2,25 \\
\hline Q1.3 & 4 & 5 & 4,5 & 15,5 & 121,00 \\
\hline Q2.1 & 3 & 4 & 1 & 6 & 25,00 \\
\hline Q2.2 & 5 & 4 & 14 & 6 & 64,00 \\
\hline Q2.3 & 4 & 4 & 4,5 & 6 & 2,25 \\
\hline Q2.4 & 5 & 5 & 14 & 15,5 & 2,25 \\
\hline Q3.1 & 5 & 4 & 14 & 6 & 64,00 \\
\hline Q3.2 & 5 & 5 & 14 & 15,5 & 2,25 \\
\hline Q3.3 & 5 & 5 & 14 & 15,5 & 2,25 \\
\hline Q4.1 & 5 & 5 & 14 & 15,5 & 2,25 \\
\hline $\mathrm{Q} 4.2$ & 5 & 4 & 14 & 6 & 64,00 \\
\hline Q4.3 & 5 & 5 & 14 & 15,5 & 2,25 \\
\hline Q5.1 & 5 & 5 & 14 & 15,5 & 2,25 \\
\hline Q5.2 & 4 & 4 & 4,5 & 6 & 2,25 \\
\hline Q5.3 & 4 & 5 & 4,5 & 15,5 & 121,00 \\
\hline Q5.4 & 5 & 5 & 14 & 15,5 & 2,25 \\
\hline Q6.1 & 5 & 3 & 14 & 1 & 169,00 \\
\hline Q6.2 & 5 & 4 & 14 & 6 & 64,00 \\
\hline Q6.3 & 4 & 4 & 4,5 & 6 & 2,25 \\
\hline \multicolumn{5}{|c|}{$6^{*}$ a soma dos quadrados das diferenças $=$} & 4314,00 \\
\hline \multicolumn{5}{|c|}{ coeficiente observado de correlação de postos de Spearman $r_{s}$} & 0,46 \\
\hline
\end{tabular}

Fonte: Elaborado pelo Autor

Para $n=20$ o valor de $r_{s}$ crítico é 0,377 ao nível de significância 0,05. Neste caso, pode-se afirmar que se observou concordância entre as respostas ao modelo dadas pelo fornecedor da SBPMa e respectivo usuário.

Para $n=20$ o valor de $r_{s}$ crítico é 0,377 ao nível de significância 0,05 . Neste caso, pode-se afirmar que se observou concordância entre as respostas ao modelo dadas pelo fornecedor da SBPMc e respectivo usuário. 
Tabela 03: Grau de Concordância para a Solução SBPMc

\begin{tabular}{|c|c|c|c|c|c|}
\hline Grau de concordância & \multicolumn{2}{|c|}{ Avaliação } & \multicolumn{3}{|c|}{ Postos } \\
\hline \multirow{2}{*}{ Característica } & $F$ & C & $F$ & C & \multirow{2}{*}{$d^{2}$} \\
\hline & Fornecedor & Usuário & postos & postos & \\
\hline Q1.1 & 5 & 4 & \begin{tabular}{|l|}
14,5 \\
\end{tabular} & 13,5 & 1,00 \\
\hline Q1.2 & 4 & 3 & 5 & 4 & 1,00 \\
\hline Q1.3 & 4 & 4 & 5 & 13,5 & 72,25 \\
\hline Q2.1 & 3 & 3 & 1 & 4 & 9,00 \\
\hline Q2.2 & 4 & 4 & 5 & 13,5 & 72,25 \\
\hline Q2.3 & 4 & 3 & 5 & 4 & 1,00 \\
\hline Q2.4 & 5 & 4 & 14,5 & 13,5 & 1,00 \\
\hline Q3.1 & 5 & 4 & 14,5 & 13,5 & 1,00 \\
\hline Q3.2 & 5 & 5 & 14,5 & 13,5 & 1,00 \\
\hline Q3.3 & 5 & 5 & 14,5 & 13,5 & 1,00 \\
\hline Q4.1 & 5 & 4 & 14,5 & 13,5 & 1,00 \\
\hline Q4.2 & 5 & 4 & \begin{tabular}{|l|}
14,5 \\
\end{tabular} & \begin{tabular}{|l|}
13,5 \\
\end{tabular} & 1,00 \\
\hline Q4.3 & 5 & 5 & \begin{tabular}{|l|}
14,5 \\
\end{tabular} & 13,5 & 1,00 \\
\hline Q5.1 & 5 & 5 & \begin{tabular}{|l|}
14,5 \\
\end{tabular} & \begin{tabular}{|l|}
13,5 \\
\end{tabular} & 1,00 \\
\hline Q5.2 & 4 & 3 & 5 & 4 & 1,00 \\
\hline Q5.3 & 5 & 2 & 14,5 & 1 & 182,25 \\
\hline Q5.4 & 5 & 5 & 14,5 & 13,5 & 1,00 \\
\hline Q6.1 & 5 & 3 & \begin{tabular}{|l|}
14,5 \\
\end{tabular} & 4 & 110,25 \\
\hline Q6.2 & 4 & 4 & 5 & 13,5 & 72,25 \\
\hline Q6.3 & 4 & 4 & 5 & 13,5 & 72,25 \\
\hline \multicolumn{5}{|c|}{$6^{*}$ a soma dos quadrados das diferenças $=$} & 3621,00 \\
\hline \multicolumn{5}{|c|}{ coeficiente observado de correlação de postos de Spearman $r_{s}$} & \\
\hline
\end{tabular}

Fonte: Elaborado pelo Autor

Tabela 04: Grau de Concordância para a Solução SBPMd

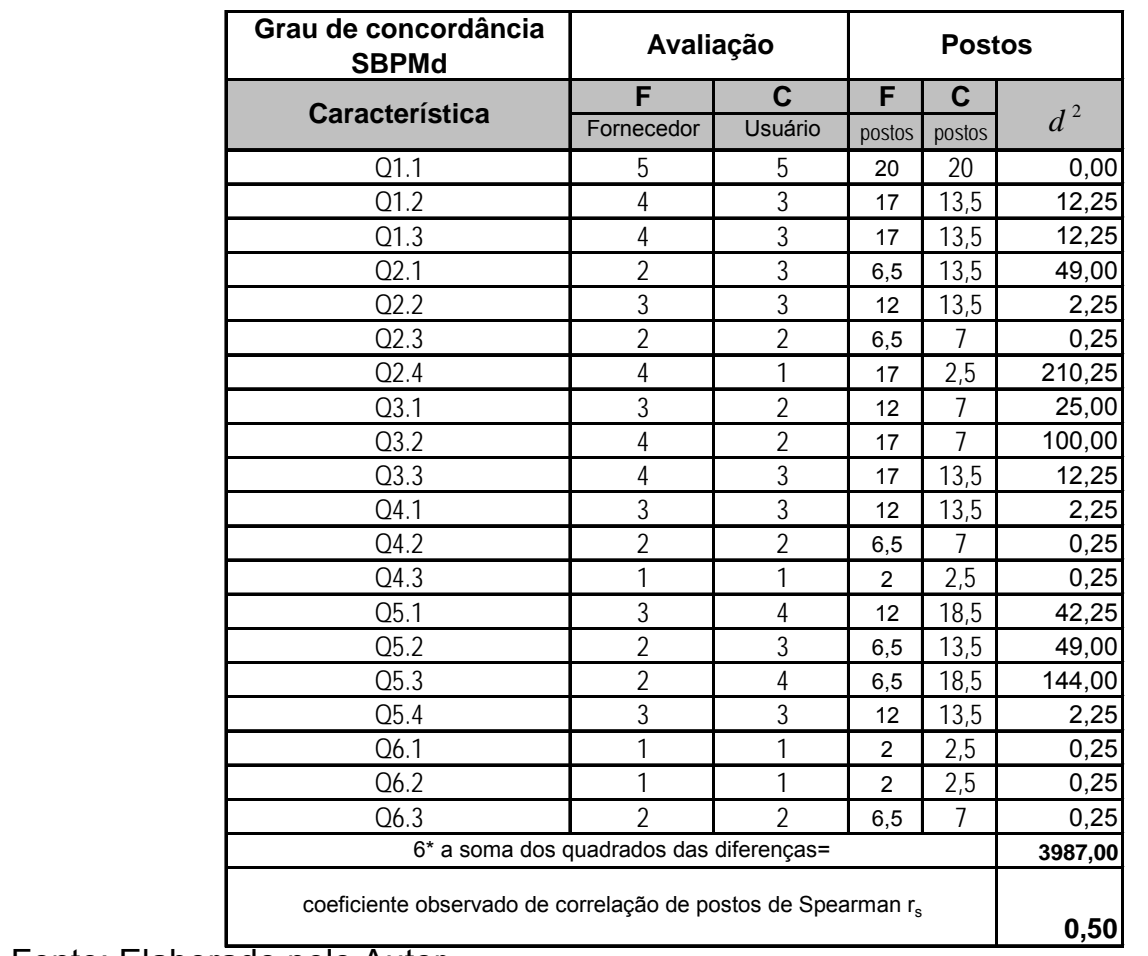

Fonte: Elaborado pelo Autor 
Para $n=20$ o valor de $r_{s}$ crítico é 0,377 ao nível de significância 0,05. Neste caso, pode-se afirmar que se observou concordância entre as respostas ao modelo dadas pelo fornecedor da SBPMd e respectivo usuário.

Embora, os valores do coeficiente de correlação de postos de Spearman obtidos confirmem a concordância de opiniões entre fornecedores e usuários, podemos notar uma certa dificuldade na avaliação de algumas funcionalidades por parte dos usuários, uma vez que, ou não foram implementados ou não tiveram contato com os mesmos.

\section{4-Aplicação do modelo}

É feita, agora, uma aplicação do modelo proposto buscando avaliar qual solução BPM é a mais indicada considerando os objetivos de desempenho definidos pelos executivos da empresa AICI Ltda.

Deve-se ter em conta que, inicialmente, o modelo proposto parte das funcionalidades e seus respectivos agrupamentos por meio do uso de matriz AHP como pode ser visto exemplo na figura $16 \mathrm{e}$, com maoires detalhes no Apêndice 6.

Inicialmente foi construída a matriz AHP que reproduz a comparação, par a par, de cada funcionalidade do grupo Desenho de Processos (fig. 17). Cada célula dessa matriz contém um valor que varia de 1 a 9 e expressa o grau de contribuição da respectiva funcionalidade em relação à outra para o agrupamento. Por exemplo a célula referente ao cruzamento Mecanismo de Desenho x Documentação contém o valor 3 que significa que o Mecanismo de Desenho contribui moderadamente para o agrupamento Desenho de Processos em relação a Documentação. 
Figura 17: Exemplo de agrupamento de funcionalidades

\begin{tabular}{|c|c|c|c|c|c|}
\hline & $\begin{array}{l}\text { Formula de comparação: } \\
\text { A propriedade Y (abaixo) contribui } \\
\text {-Extremamente (9); } \\
\text {-Muito mais (7); } \\
\text {-Mais (5); } \\
\text {-Moderadamente (3); } \\
\text {-Igual (1) } \\
\text { do que a propriedade X (à direita) } \\
\text { para a característica Desenho de } \\
\text { Processos }\end{array}$ & 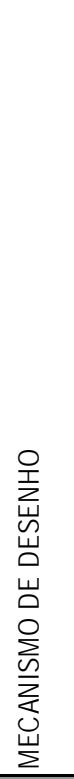 & 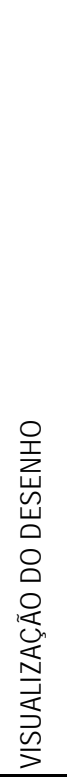 & 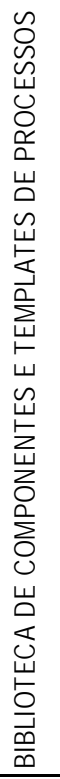 & 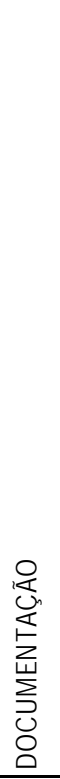 \\
\hline 1 & MECANISMO DE DESENHO & 1,0 & 1,0 & 3,0 & 3,0 \\
\hline 2 & VISUALIZAÇÃO DO DESENHO & 1,0 & 1,0 & 1,0 & 3,0 \\
\hline 3 & BIBLIOTECA DE COMPONENTES E TEMPLATES DE PROCESSOS & 0,3 & 1,0 & 1,0 & 1,0 \\
\hline \multirow[t]{2}{*}{4} & DOCUMENTAÇÃO & 0,3 & 0,3 & 1,0 & 1,0 \\
\hline & & 2,7 & 3,3 & 6,0 & 8,0 \\
\hline
\end{tabular}

Fonte: Elaborado pelo autor. Legenda: A última linha expressa a somatória dos valores de cada coluna.

Matrizes semelhantes foram elaboradas para cada um dos agrupamentos: 1) Gerenciamento de Acesso; 2) Desenho de Processos; 3) Regras de Negócio; 4) Integração; 5) Mecanismo de Execução; e 6) Monitoramento.

Com base na matriz da figura 17 é contruída uma outra normalizada. Esta matriz normalizada nada mais é do que a matriz original na qual o valor de cada célula foi dividido pela somatória de cada coluna (Ver figura 18).

A média da linha expressa a importância relativa de cada funcionalidade para o agrupamento. No exemplo da figura 18 o mecanismo de desenho contribui com 38,75\% para o grupo Desenho de Processos e isso significa que ocupa o posto 1 em relação às demais funcionalidades, ou seja: é a que tem maior contribuição. O valor 0,3875 é utilizado como 
coeficiente representado o peso ou importância da funcionalidade, e tal peso é utilizado na tabela 05.

Figura 18: Matriz normalizada da Matriz de Valores exibida na figura 17

\begin{tabular}{|c|c|c|c|c|c|c|}
\hline $\begin{array}{c}\text { Formula de comparação: } \\
\text { A propriedade Y (abaixo) contribui } \\
\text {-Extremamente (9); } \\
\text {-Muito mais (7); } \\
\text {-Mais (5); } \\
\text {-Moderadamente (3); } \\
\text {-Igual (1) } \\
\text { do que a propriedade X (à direita) } \\
\text { para a característica Desenho de } \\
\text { Processos }\end{array}$ & 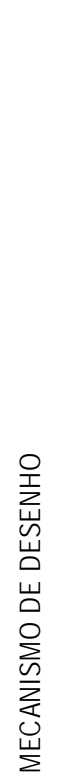 & 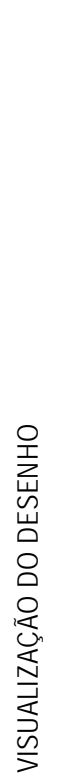 & 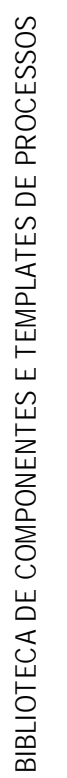 & 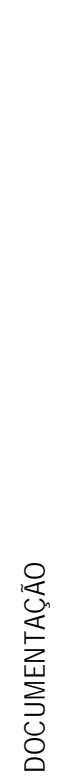 & 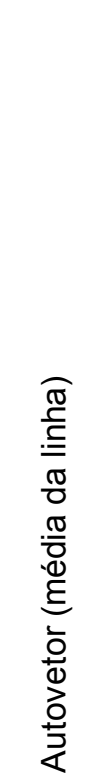 & 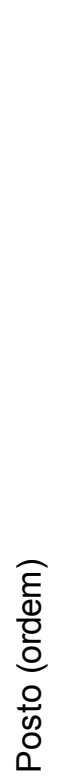 \\
\hline MECANISMO DE DESENHO & 0,4 & 0,3 & 0,5 & 0,4 & 0,3875 & 1 \\
\hline VISUALIZAÇÃO DO DESENHO & 0,4 & 0,3 & 0,2 & 0,4 & 0,3042 & 2 \\
\hline BIBLIOTECA DE COMPONENTES E TEMPLATES DE PROCESSOS & 0,1 & 0,3 & 0,2 & 0,1 & 0,1792 & 3 \\
\hline DOCUMENTAÇÃO & 0,1 & 0,1 & 0,2 & 0,1 & 0,1292 & 4 \\
\hline
\end{tabular}

Fonte: Elaborado pelo Autor (2005).

Tendo por base as matrizes mostradas nas figuras 17 e 18 é obtida uma terceira matriz (ver figura 19) que apresenta a avaliação da Razão de Consistência (RC). De acordo com Saaty (1980) o valor de RC deve ser menor do que 0,10. No exemplo mostrado, o valor RC é igual a 0,0523756. Caso não se observe uma Razão de Consistência adequada todo o processo deve ser refeito, começando-se por rever a matriz original de valores (ver fig. 17).

Ao final desta etapa tem-se um conjunto de matrizes semelhantes à mostrada na figura 19 para cada um dos agrupamentos: 1) Gerenciamento de Acesso; 2) Desenho de Processos; 3) Regras de Negócio; 4) Integração; 5) Mecanismo de Execução; e 6) Monitoramento. 
Figura 19: Razão de Consistência para a Matriz AHP - Desenho de Processos:

\begin{tabular}{|c|c|c|c|c|c|c|c|c|}
\hline & $\begin{array}{c}\text { Formula de comparação: } \\
\text { A propriedade Y (abaixo) contribui } \\
\text {-Extremamente (9); } \\
\text {-Muito mais (7); } \\
\text {-Mais (5); } \\
\text {-Moderadamente (3); } \\
\text {-Igual (1) } \\
\text { do que a propriedade X (à direita) } \\
\text { para a característica Desenho de } \\
\text { Processos }\end{array}$ & 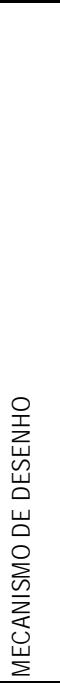 & 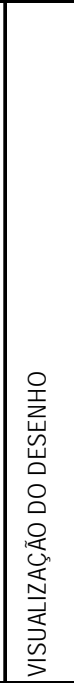 & 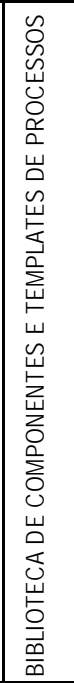 & 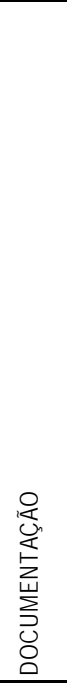 & 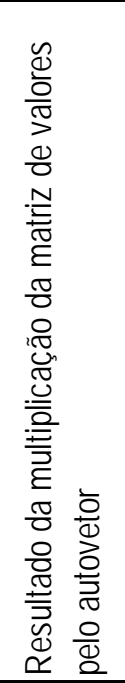 & & 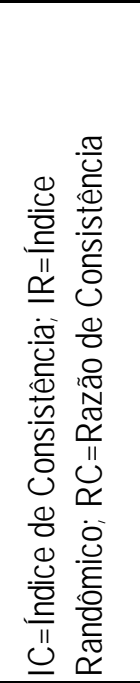 \\
\hline 1 & MECANISMO DE DESENHO & 1,0 & 1,0 & 3,0 & 3,0 & 1,6167 & IC= & 0,0518519 \\
\hline 2 & VISUALIZAÇÃO DO DESENHO & 1,0 & 1,0 & 1,0 & 3,0 & 1,2583 & $\mathrm{R}=$ & 0,99 \\
\hline 3 & BIBLIOTECA DE COMPONENTES E TEMPLATES DE PROCESSOS & 0,3 & 1,0 & 1,0 & 1,0 & 0,7417 & $\mathrm{RC}=$ & 0,0523756 \\
\hline 4 & DOCUMENTAÇÃO & 0,3 & 0,3 & 1,0 & 1,0 & 0,5389 & & \\
\hline & & 2,7 & 3,3 & 6,0 & 8,0 & 4,1556 & $=\mathrm{La}$ & náximo \\
\hline
\end{tabular}

Fonte: Elaborado pelo Autor (2005).

Figura 20: Matriz AHP de Macro-Funcionalidades versus Objetivos de Desempenho

\begin{tabular}{|c|c|c|c|c|c|c|}
\hline $\begin{array}{c}\text { Formula de comparação: } \\
\text { A propriedade Y (abaixo) contribui } \\
\text {-Extremamente (9); } \\
\text {-Muito mais (7); } \\
\text {-Mais (5); } \\
\text {-Moderadamente (3); } \\
\text {-lgual (1) } \\
\text { do que a propriedade X (à direita) } \\
\text { para a dimensão competitiva } \\
\text { Flexibilidade }\end{array}$ & 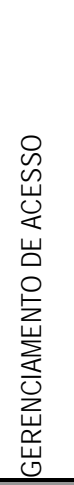 & 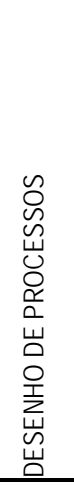 & 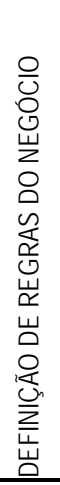 & 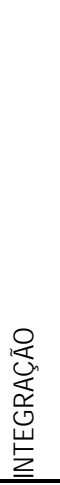 & 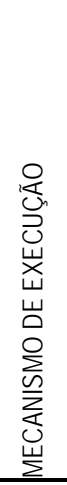 & 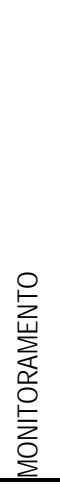 \\
\hline GERENCIAMENTO DE ACESSO & 1,0 & 0,2 & 0,2 & 0,3 & 0,2 & 3,0 \\
\hline DESENHO DE PROCESSOS & 5,0 & 1,0 & 1,0 & 3,0 & 1,0 & 5,0 \\
\hline DEFINIÇÃO DE REGRAS DO NEGÓCIO & 5,0 & 1,0 & 1,0 & 1,0 & 0,3 & 3,0 \\
\hline INTEGRAÇÃO & 3,0 & 0,3 & 1,0 & 1,0 & 0,3 & 3,0 \\
\hline MECANISMO DE EXECUÇÃO & 5,0 & 1,0 & 3,0 & 3,0 & 1,0 & 5,0 \\
\hline MONITORAMENTO & 0,3 & 0,2 & 0,3 & 0,3 & 0,2 & 1,0 \\
\hline
\end{tabular}

Fonte: Elaborado pelo Autor (2005). 
Figura 21: Matriz Normalizada para o Objetivo de Desempenho Flexibilidade

\begin{tabular}{|c|c|c|c|c|c|c|c|}
\hline $\begin{array}{c}\text { Formula de comparação: } \\
\text { A propriedade Y (abaixo) contribui } \\
\text {-Extremamente (9); } \\
\text {-Muito mais (7); } \\
\text {-Mais (5); } \\
\text {-Moderadamente (3); } \\
\text {-lgual (1) } \\
\text { do que a propriedade X (à direita) } \\
\text { para a dimensão competitiva } \\
\text { Flexibilidade }\end{array}$ & 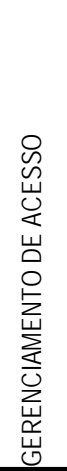 & 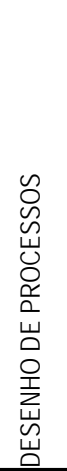 & 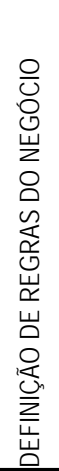 & 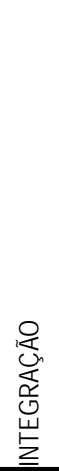 & 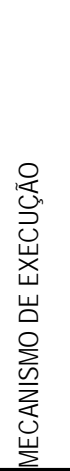 & 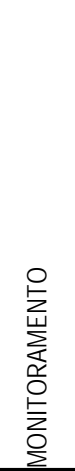 & \\
\hline GERENCIAMENTO DE ACESSO & 0,1 & 0,1 & 0,0 & 0,0 & 0,1 & 0,2 & 0,0649 \\
\hline DESENHO DE PROCESSOS & 0,3 & 0,3 & 0,2 & 0,3 & 0,3 & 0,3 & 0,2670 \\
\hline DEFINIÇÃO DE REGRAS DO NEGÓCIO & 0,3 & 0,3 & 0,2 & 0,1 & 0,1 & 0,2 & 0,1756 \\
\hline INTEGRAÇÃO & 0,2 & 0,1 & 0,2 & 0,1 & 0,1 & 0,2 & 0,1286 \\
\hline MECANISMO DE EXECUÇÃO & 0,3 & 0,3 & 0,5 & 0,3 & 0,3 & 0,3 & 0,3180 \\
\hline MONITORAMENTO & 0,0 & 0,1 & 0,1 & 0,0 & 0,1 & 0,1 & 0,0459 \\
\hline
\end{tabular}

Fonte: Elaborado pelo Autor (2005).

Figura 22: Razão de Consistência para a Matriz AHP - Flexibilidade

\begin{tabular}{|c|c|c|c|c|c|c|c|c|c|}
\hline $\begin{array}{c}\text { Formula de comparação: } \\
\text { A propriedade Y (abaixo) contribui } \\
\text {-Extremamente (9); } \\
\text {-Muito mais (7); } \\
\text {-Mais (5); } \\
\text {-Moderadamente (3); } \\
\text {-Igual (1) } \\
\text { do que a propriedade X (à direita) } \\
\text { para a dimensão competitiva Flexibilidade }\end{array}$ & 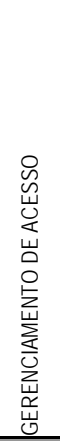 & 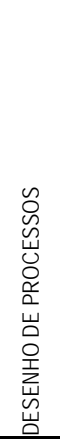 & 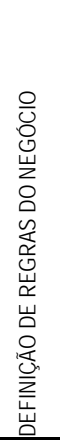 & 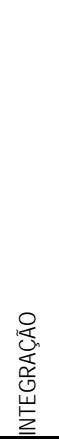 & 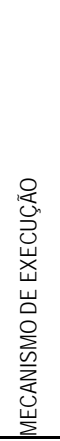 & 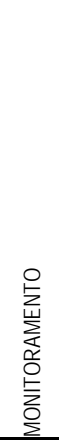 & 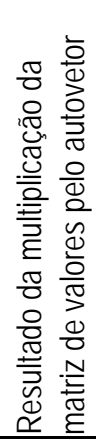 & & 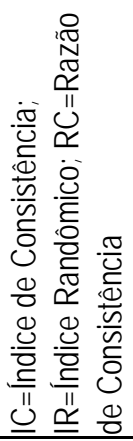 \\
\hline GERENCIAMENTO DE ACESSO & 1,0 & 0,2 & 0,2 & 0,3 & 0,2 & 3,0 & 0,3977 & $I C=$ & 0,081466 \\
\hline DESENHO DE PROCESSOS & 5,0 & 1,0 & 1,0 & 3,0 & 1,0 & 5,0 & 1,7006 & $\mathrm{IR}=$ & 1,32 \\
\hline 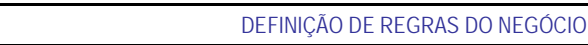 & 5,0 & 1,0 & 1,0 & 1,0 & 0,3 & 3,0 & 1,1396 & $\mathrm{RC}=$ & 0,061717 \\
\hline INTEGRAÇÃO & 3,0 & 0,3 & 1,0 & 1,0 & 0,3 & 3,0 & 0,8317 & & \\
\hline MECANISMO DE EXECUÇÃO & 5,0 & 1,0 & 3,0 & 3,0 & 1,0 & 5,0 & 2,0518 & & \\
\hline MONITORAMENTO & 0,3 & 0,2 & 0,3 & 0,3 & 0,2 & 1,0 & 0,2860 & & \\
\hline & 19,3 & 3,7 & 6,5 & 8,7 & 3,1 & 20,0 & 6,4073 & \multicolumn{2}{|c|}{$=$ Lambda máximo } \\
\hline
\end{tabular}

Fonte: Elaborado pelo Autor (2005). 
Após se ter as matrizes de funcionalidades e seus respectivos agrupamentos, por um processo semelhante se avalia cada agrupamento em relação a um dado objetivo de desempenho (ver figuras $20,21,22$ )

As figuras 20, 21, 22 mostram a matriz AHP relacionando as MacroFuncionalidades com o Objetivo de Desempenho Flexibilidade. Matrizes semelhantes foram elaboradas para cada um dos objetivos de desempenho: 1) Qualidade; 2) Custo; 3) Velocidade; 4) Flexibilidade e 5) Confiabilidade. Os valores correspondentes ao autovetor de cada matriz de agrupamento $x$ objetivos de desempenho são introduzidos como linhas de cada agrupamento na tabela 05 . Esta tabela deve ser entendida como uma tabela de coeficientes mostrando a importância relativa, de forma hierárquica, de cada funcionalidade em relação aos objetivos de desempenho. Assim, podemos identificar que para o objetivo Flexibilidade a macro-funcionalidade do Mecanismo de Execução é o mais relevante (0,3180); para o objetivo Qualidade o Desenho de Processos (0,3214); para o objetivo Custo a Definição de Regras do Negócio $(0,3092)$ e a Integração $(0,3092)$; para o objetivo Velocidade o Desenho de Processos $(0,3084)$ e,; para o objetivo Confiabilidade o Mecanismo de Execução (0,3901).

Tabela 05: Tabela de Coeficientes

\begin{tabular}{|c|c|c|c|c|c|c|}
\hline & $\begin{array}{c}\text { COEFICIENTE } \\
\mathrm{S} \\
\end{array}$ & FLEXIBILIDADE & QUALIDADE & CUSTO & VELOCIDADE & CONFIABILIDADE \\
\hline GERENCIAMENTO DE ACESSO & & 0,0649 & 0,0451 & 0,0488 & 0,0464 & 0,0896 \\
\hline DEFINIÇÃO DE USUÁRIOS E GRUPOS & 0,2605 & & & & & \\
\hline PERFIL DE ACESSO & 0,6333 & & & & & \\
\hline LISTA DE TAREFAS & 0,1062 & & & & & \\
\hline DESENHO DE PROCESSOS & & 0,2670 & 0,3214 & 0,1420 & 0,3084 & 0,1948 \\
\hline MECANISMO DE DESENHO & 0,3875 & & & & & \\
\hline VISUALIZAÇÃO DO DESENHO & 0,3042 & & & & & \\
\hline BIBLIOTECA DE TEMPLATES E COMPONENTES & 0,1792 & & & & & \\
\hline DOCUMENTAÇÃO & 0,1292 & & & & & \\
\hline DEFINIÇÃO DE REGRAS DO NEGÓCIO & & 0,1756 & 0,1443 & 0,3092 & 0,2529 & 0,1591 \\
\hline DEFINIÇÃO DE REGRAS DO NEGÓCIO & 0,6333 & & & & & \\
\hline MECANISMO DE ENFILEIRAMENTO DE TAREFAS & 0,1062 & & & & & \\
\hline DEFINIÇÃO DE FORMULÁRIOS E META DADOS & 0,2605 & & & & & \\
\hline INTEGRAÇÃOO & & 0,1286 & 0,0637 & 0,3092 & 0,0954 & 0,1155 \\
\hline INTERFACE COM BANCO DE DADOS & 0,1578 & & & & & \\
\hline INTERFACE COM APLICAÇÕES EXTERNAS & 0,1867 & & & & & \\
\hline MIDDLEWARE & 0,6555 & & & & & \\
\hline MECANISMO DE EXECUÇẤO & & 0,3180 & 0,2672 & 0,1420 & 0,2015 & 0,3901 \\
\hline EXECUÇÃO DE PROCESSOS & 0,5193 & & & & & \\
\hline REGISTRO DE EVENTOS & 0,2009 & & & & & \\
\hline INTERVENÇÕES E TRATAMENTO DE EXCEÇÕES & 0,0789 & & & & & \\
\hline PORTABILIDADE E ESCALABILIDADE & 0,2009 & & & & & \\
\hline MONITORAMENTO & & 0,0459 & 0,1582 & 0,0488 & 0,0954 & 0,0509 \\
\hline RELATÓRIOS OPERACIONAIS & 0,1429 & & & & & \\
\hline VISUALIZAÇÃO DA EXECUÇÃO & 0,4286 & & & & & \\
\hline INDICADORES DE DESEMPENHO & 0,4286 & & & & & \\
\hline
\end{tabular}

Fonte: Elaborado pelo Autor. 
Na tabela 05, a primeira coluna de coeficientes mostra o peso de cada funcionalidade para o respectivo agrupamento. Por exemplo, o valor 0,2605 (primeiro valor da coluna coeficientes) significa que a funcionalidade Definição de usuários e grupos contribui $26,05 \%$ para o grupo Gerenciamento de acesso. O último valor da mesma coluna indica que Indicadores de desempenho contribuem com $42,86 \%$ para o grupo Monitoramento.

O valor 0,0649 (primeiro valor da coluna Flexibilidade) indica que 0 grupo Gerenciamento de acesso contribui com 6,49\% para o objetivo de desempenho Flexibilidade. Desta forma observa-se que o grupo Mecanismo de Execução é o que mais contribui (com $31,80 \%$ ) para o objetivo de desempenho Flexibilidade.

Com base na tabela 05, pode-se obter numa nota do perfil competitivo de cada solução BPM em cada um dos objetivos de desempenho, além de uma nota global (Vide tabela 06 ).

Tabela 06: Quadro Comparativo das Soluções de BPM em Relação aos Objetivos de Desempenho

\begin{tabular}{|c|c|c|c|c|c|}
\hline SOLUÇÕES BPM & \multirow{2}{*}{ FLEXIBILIDADE } & \multirow{2}{*}{ QUALIDADE } & CUSTO & \multirow{2}{*}{ VELOCIDADE } & CONFIABILIDADE \\
\hline SBPMd & 2,6757 & 2,5504 & 2,5333 & 2,6671 & 2,7239 \\
\hline SBPMb & 3,9765 & 3,7213 & 4,0491 & 3,9186 & 4,0421 \\
\hline SBPMc & 4,4094 & 4,3729 & 4,7149 & 4,4553 & 4,5667 \\
\hline SBPMa & 4,5886 & 4,5174 & 4,7678 & 4,5741 & 4,6169 \\
\hline
\end{tabular}

Fonte: Elaborado pelo Autor (2006).

A tabela 06 foi estruturada tendo em conta a avaliação de cada solução BPM do ponto de vista do fornecedor. Ou seja: a tabela 06 expressa o resultado da multiplicação da tabela 05 pela avaliação de cada solução como é mostrada na tabela 07.

A Tabela 07 mostra o resultado da avaliação do Questionário aplicado aos quatro fornecedores. Por exemplo, a coluna SBPMd exprime as notas de cada funcionalidade da solução do fornecedor SBPMd. No caso, a 
funcionalidade Q1.1 (definição de usuários e grupos) obteve nota 5. Essa nota 5 é multiplicada pelo coeficiente da tabela 05 (no caso 0,2605). Processo semelhante é feito com as questões Q1.2 e Q1.3 referentes ao grupo Gerenciamento de acesso.

Tabela 07: Exemplo de Cálculo do Grupo Gerenciamento de Acesso

\begin{tabular}{|c|c|c|c|c|}
\hline & $\begin{array}{l}\text { Coeficientes do } \\
\text { Gerenciamento } \\
\text { de Acesso }\end{array}$ & $\begin{array}{l}\text { Avaliação do } \\
\text { Fornecedor }\end{array}$ & $\begin{array}{l}\text { Resultado } \\
\text { da } \\
\text { multiplicação }\end{array}$ & $\begin{array}{l}\text { Peso do objetivo de } \\
\text { desempenho } \\
\text { Flexibilidade }\end{array}$ \\
\hline Q1.1 & 0,2605 & 5 & 1,3025 & \multirow{3}{*}{0,0649} \\
\hline Q1.2 & 0,6333 & 4 & 2,5332 & \\
\hline Q1.3 & 0,1062 & 4 & 0,4248 & \\
\hline \multicolumn{3}{|c|}{ Soma dos resultados da multiplicação= } & 4,2605 & 0,2765 \\
\hline
\end{tabular}

Fonte: Elaborado pelo Autor.

A tabela 07 mostra um exemplo da cálculo mostrando a contribuição do grupo Gerenciamento de Acesso para o objetivo de desempenho Flexibilidade. O procedimento consistiu em multiplicar os primeiros três coeficientes da tabela $05(0,2605 ; 0,6333 ; 0,1062)$ respectivamente pelos resultados da avaliação mostrados na tabela $08(5 ; 4 ; 4)$ e pelo coeficiente para a flexibilidade $(0,0649)$. Procedimentos semelhantes, no que se refere à flexibilidade são realizados para os demais grupos: 2) Desenho de Processos; 3) Regras de Negócio; 4) Integração; 5) Mecanismo de Execução; e 6) Monitoramento. A soma dos resultados obtidos (0,2765 + ...........) dá o contribuição da solução BPM do fornecedor SBPMd para o objetivo de desempenho Flexibilidade. No presente caso tal resultado é 2,6757 como pode ser visto na tabela 06 .

Procedimentos semelhantes foram realizados para os demais objetivos de desempenho. 
Tabela 08: Avaliação das Soluções de BPM pelos Fornecedores

\begin{tabular}{|r|c|c|c|c|c|}
\hline Q & QUESTIONÁRIO & SBPMd & SBPMb & SBPMC & SBPMa \\
\hline $\mathbf{1}$ & Q1.1 & 5 & 5 & 5 & 5 \\
\hline $\mathbf{2}$ & Q1.2 & 4 & 5 & 4 & 4 \\
\hline $\mathbf{3}$ & Q1.3 & 4 & 4 & 4 & 4 \\
\hline $\mathbf{4}$ & Q2.1 & 2 & 4 & 3 & 3 \\
\hline $\mathbf{5}$ & Q2.2 & 3 & 3 & 4 & 5 \\
\hline $\mathbf{6}$ & Q2.3 & 2 & 2 & 4 & 4 \\
\hline $\mathbf{7}$ & Q2.4 & 4 & 4 & 5 & 5 \\
\hline $\mathbf{8}$ & Q3.1 & 3 & 5 & 5 & 5 \\
\hline $\mathbf{9}$ & Q3.2 & 4 & 5 & 5 & 5 \\
\hline $\mathbf{1 0}$ & Q3.3 & 4 & 5 & 5 & 5 \\
\hline $\mathbf{1 1}$ & Q4.1 & 3 & 5 & 5 & 5 \\
\hline $\mathbf{1 2}$ & Q4.2 & 2 & 4 & 5 & 5 \\
\hline $\mathbf{1 3}$ & Q4.3 & 1 & 3 & 5 & 5 \\
\hline $\mathbf{1 4}$ & Q5.1 & 3 & 5 & 5 & 5 \\
\hline $\mathbf{1 5}$ & Q5.2 & 2 & 2 & 4 & 4 \\
\hline $\mathbf{1 6}$ & Q5.3 & 2 & 5 & 5 & 4 \\
\hline $\mathbf{1 7}$ & Q5.4 & 3 & 4 & 5 & 5 \\
\hline $\mathbf{1 8}$ & Q6.1 & 1 & 1 & 5 & 5 \\
\hline $\mathbf{1 9}$ & Q6.2 & 1 & 3 & 4 & 5 \\
\hline $\mathbf{2 0}$ & Q6.3 & 2 & 2 & 4 & 4 \\
\hline
\end{tabular}

Fonte: Elaborado pelo Autor.

Tabela 09: Nota de Perfil Competitivo das Soluções de BPM Avaliadas

\begin{tabular}{|c|c|c|c|c|c|c|}
\hline SOLUÇÕES BPM & FLEXIBILIDADE & QUALIDADE & CUSTO & VELOCIDADE & CONFIABILIDADE & $\begin{array}{c}\text { Nota Perfil } \\
\text { Competitivo }\end{array}$ \\
\hline SBPMa & 4,5886 & 4,5174 & 4,7678 & 4,5741 & 4,6169 & $91,70 \%$ \\
\hline SBPMc & 4,4094 & 4,3729 & 4,7149 & 4,4553 & 4,5667 & $89,45 \%$ \\
\hline SBPMb & 3,9765 & 3,7213 & 4,0491 & 3,9186 & 4,0421 & $77,82 \%$ \\
\hline SBPMd & 2,6757 & 2,5504 & 2,5333 & 2,6671 & 2,7239 & $52,45 \%$ \\
\hline
\end{tabular}

Fonte: Elaborado pelo Autor.

A tabela 09 reproduz a tabela 06 mas, chama a atenção para a última coluna, intitulada Nota Perfil Competitivo. Como se pode ver na tabela 09 cada fornecedor de solução BPM descrito na primeira coluna, teve sua solução avaliada ponderadamente quanto aos diversos objetivos de desempenho. Pode-se afirmar que a solução que mais contribui para o objetivo de desempenho Flexibilidade é a do fornecedor SBPMa $(4,5886)$ e a que menos contribui é a do fornecedor SBPMd $(2,6757)$. Os valores obtidos 
teoricamente vão de 1 a 5, expressando a mesma avaliação da escala tipo Likert aplicada.

A solução do fornecedor SBPMa, como se pode ver na tabela 09 destaca-se por ter atingido a maior avaliação dentre os demais para qualquer objetivo de desempenho. Se excluirmos qualquer outro quesito, como custo de aquisição, custo de manutenção, infra-estrutura tecnológica requerida, pode-se afirmar que a solução do fornecedor SBPMa é, das investigadas a melhor. Esta afirmativa, entretanto pode não ser verdadeira se se utilizar outras formas de decisão por multi-critérios como podem ser vistas em Shimizu (2001).

Figura 23: Matriz AHP com os Objetivos de Desempenho da Empresa AICI

\begin{tabular}{|c|c|c|c|c|c|c|c|}
\hline $\begin{array}{c}\text { Objetivos de } \\
\text { Desempenho da } \\
\text { Empresa AICl. }\end{array}$ & $\begin{array}{l}\frac{0}{0} \\
\frac{\pi}{0} \\
\frac{0}{0} \\
\frac{0}{x} \\
\frac{0}{4}\end{array}$ & $\begin{array}{l}\frac{0}{0} \\
\frac{\pi}{0} \\
\frac{0}{0} \\
\frac{\pi}{0}\end{array}$ & 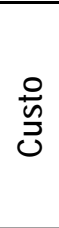 & $\begin{array}{l}\frac{0}{0} \\
\frac{\pi}{0} \\
\frac{0}{0} \\
\frac{0}{0}\end{array}$ & 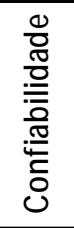 & $\begin{array}{l}\text { Peso } \\
\text { relativo }\end{array}$ & $\begin{array}{l}\text { IMPORTÂNCIA } \\
\text { RELATIVA }\end{array}$ \\
\hline Flexibilidade & 0,1 & 0,1 & 0,0 & 0,1 & 0,0 & 0,06 & 5 \\
\hline Qualidade & 0,3 & 0,3 & 0,3 & 0,3 & 0,4 & 0,34 & 1 \\
\hline Custo & 0,2 & 0,1 & 0,1 & 0,1 & 0,0 & 0,11 & 4 \\
\hline Velocidade & 0,2 & 0,3 & 0,3 & 0,3 & 0,4 & 0,31 & 2 \\
\hline Confiabilidade & 0,2 & 0,1 & 0,3 & 0,1 & 0,1 & 0,17 & 3 \\
\hline
\end{tabular}

Fonte: Elaborado pelo Autor.

Entretanto a melhor solução, no contexto puramente de avaliação das funcionalidades, é aquela que obtém um maior valor ponderado tendo em conta os objetivos de desempenho específicos do avaliador (ou adquirente). Neste caso, o próprio avaliador deve ter uma matriz de importância relativa dos seus objetivos de desempenho. No presente trabalho considerou-se, no estudo de caso, a matriz mostrada na figura 23. 
A nota do Perfil competitivo, mostrada na tabela 09 é o resultante da multiplicação dos pesos relativos mostrados na figura 23 pelos respectivos valores da tabela 05. Ou seja. No caso da solução do fornecedor SBPMd a nota total é a soma das multiplicações mostradas na tabela 10 dividida por 5 (para que o número resultante seja de 0 a 1)

Tabela 10: Exemplo de Cálculo da Nota do Perfil Competitivo da Solução SBPMd

\begin{tabular}{|c|c|c|c|c|c|c|}
\hline & Flexibilidade & Qualidade & Custo & Velocidade & Confiabilidade & \multirow{3}{*}{$\begin{array}{l}\text { Nota do } \\
\text { Perfil } \\
\text { competi } \\
\text { tivo }\end{array}$} \\
\hline $\begin{array}{l}\text { Fornecedor } \\
\text { SBPMd }\end{array}$ & 2,6757 & 2,5504 & 2,5333 & 2,6671 & 2,7239 & \\
\hline $\begin{array}{l}\text { Pesos } \\
\text { relativos }\end{array}$ & 0,06 & 0,34 & 0,11 & 0,31 & 0,17 & \\
\hline Multiplicação & 0,1605 & 0,8671 & 0,2787 & 0,8268 & 0,4631 & 2,5962 \\
\hline & & & & & Nota final= & $52 \%$ \\
\hline
\end{tabular}

Fonte: Elaborado pelo Autor.

Com este procedimento é possível ordenar as soluções em relação aos objetivos de desempenho. Deste modo, torna-se possível uma classificação prévia das alternativas investigadas e mais alinhadas com os objetivos do negócio.

\section{5-Síntese dos resultados}

O objetivo principal da pesquisa é propor um template para avaliar soluções BPM que privilegie os objetivos de desempenho. Para tal: a) elaborou-se uma lista inicial de funcionalidades e validou-se tal lista com especialistas (item 5.1); b) validou-se qualitativamente a lista preliminar com pesquisadores-especialistas da área por meio do método Delphi Eletrônico (item 5.2); e c) foi realizado um Estudo de Caso para verificar a aplicabilidade do modelo proposto (item 5.3). 


\subsection{1-Refinamento do instrumento}

Para o desenvolvimento de um template sob a forma de um questionário foram desenvolvidas as seguintes etapas, a seguir:

1. Levantamento das funcionalidades por meio da revisão bibliográfica e com visão em gestão de processos;

2. Discussão e entendimento da lista preliminar com especialistas em Business Process Management (BPM);

3. Avaliação do nível de abstração a ser utilizado nas descrições para permitir um entendimento comum para especialistas e usuários, ditos gestores de negócios;

4. Definição de níveis de implementação possíveis para cada funcionalidade;

5. Revisão final com especialistas.

O resultado deste refinamento apresenta-se no Apêndice 4 sob a forma de um questionário com três níveis semânticos em uma escala tipo Likert de 5 pontos.

\subsection{2-Delphi Eletrônico}

Para a validação do questionário, dos agrupamentos das funcionalidades e o relacionamento com os objetivos de desempenho selecionados foi utilizado o método delphi eletrônico e a matriz AHP com especialistas ao longo de 03 (três) meses de pesquisa.

O uso deste método possibilitou que a lista de funcionalidades do modelo proposto fosse avaliado por 34 especialistas e sugestões e comentários foram coletados, proporcionando uma maior segurança na aplicação do mesmo. A seguir, os respectivos agrupamentos com o uso da matriz AHP resultou em uma estrutura hierárquica das funcionalidades. Neste ponto, notou-se que algumas prioridades podem se alterar dependendo do negócio. Assim, pode-se recomendar que a construção destes relacionamentos seja revalidado pelo gestor do negócio. Da mesma 
maneira, o grau de contribuição de cada agrupamento com os objetivos de desempenho devem ser reavaliados antes de sua aplicação.

\subsection{3-Aplicabilidade do modelo}

O modelo de avaliação pode ser descrito nos seguintes instrumentos:

1. Questionário de Avaliação de uma Solução BPM;

2. Matriz AHP de Agrupamento das Funcionalidades;

3. Matriz AHP de Relacionamento com os Objetivos de Desempenho;

4. Matriz AHP dos Objetivos de Desempenho e prioridades para o gestor do negócio;

5. Tabela de Coeficientes resultantes;

6. Tabela com as Notas do Perfil Competitivo.

O uso deste modelo mostrou-se adequado para o entendimento das soluções apresentadas e as diferenças entre as mesmas. Além disso, o uso da avaliação construído por meio de matriz AHP, resultou em uma nota de perfil competitivo com base nos objetivos de desempenho adotados. A classificação das alternativas foi aderente com ranking apresentado pelas pesquisas do Gartner Group (quadrante mágico) e, permite uma seleção mais racional, uma vez que delimita à priori o universo a ser avaliado. 


\section{Capítulo 6 -Conclusões e recomendações}

Neste capítulo são tecidas as conclusões da presente pesquisa tendo em vista que o objetivo principal da mesma é a proposta de um modelo ou template, para avaliar soluções de BPM (Business Process Management), sob a ótica da Estratégia de Operações incluindo: a) a validação qualitativa do Modelo com consultores especialistas e acadêmicos da área por meio do método Delphi Eletrônico; e b) realização de um Estudo de Caso para verificar a aplicabilidade de tal modelo.

\section{1-Conclusões}

O template proposto para avaliar soluções BPM que privilegie específicos objetivos de desempenho foi validado qualitativamente por especialistas da área por meio do método Delphi Eletrônico e o Estudo de Caso verificou a aplicabilidade do modelo.

Inicialmente o modelo proposto se ocupou de estruturar as soluções BPM hierarquicamente considerando diversas funcionalidades como mostra a tabela 05. Chama-se a atenção para o fato de que as funcionalidades constituem descrições das soluções, num nível adequado de abstração, sem considerar características específicas de cada solução. Tais funcionalidades foram consensadas por 34 especialistas via método Delphi Eletrônico.

Após a definição de cada funcionalidade foi feita a validação dos agrupamentos das funcionalidades, numa segunda fase do Delphi Eletrônico, que consumiu três rodadas para obtenção do consenso de 21 especialistas. O resultado deste trabalho pode ser visto no Apêndice 6 . Cabe ressaltar: 
a no agrupamento Gerenciamento de Acesso a definição do Perfil de Acesso obteve o maior nível de importância relativa;

a no agrupamento Desenho de Processos a funcionalidade de Desenho e a sua respectiva Visualização foram os itens mais relevantes;

a no agrupamento de Regras do Negócio a funcionalidade para a Definição das Regras foi a mais votada, embora a Definição de Formulários também tenha sido discutida como sendo também importante;

- no agrupamento de Integração não houve dúvida quanto à importância de uma Camada de Gestão da Integração (middleware); a Interface com banco de Dados foi considerada uma funcionalidade básica;

a no agrupamento Mecanismo de Execução a funcionalidade de Execução do Desenho do processo foi considerada a mais importante. Embora não tenha sido comentado pelos especialistas a funcionalidade Portabilidade e Escalabilidade foi identificada como essencial para determinados negócios na prática; e

a no agrupamento Monitoramento tanto a Visualização da Execução quanto a Definição e Uso de Indicadores de Desempenho tiveram o mesmo grau de importância dado pelos especialistas.

Alguns especialistas nesta fase comentaram que alguns dos agrupamentos podem ter prioridade diferenciada daquela sugerida no modelo. Por exemplo, a) Regras do Negócio; b) Integração; e c) Execução são agrupamentos de funcionalidades onde o peso relativo de cada funcionalidade, dependendo da necessidade do negócio, pode ser conveniente que seja alterado. 
A fase seguinte do Delphi Eletrônico buscou a validação do relacionamento entre o agrupamento das funcionalidades e os objetivos de desempenho. Participaram desta fase 14 especialistas. Nesta fase buscouse, basicamente, identificar os pesos de contribuição de cada macrofuncionalidade para um dado objetivo de desempenho. O Apêndice 8 mostra o resultado obtido. Os especialistas votaram numa seqüência inicialmente fornecida e o resultado foi considerado indiferente, isto é,. para os especialistas a lista apresentada era aceitável. Entretanto 12 dos 14 especialistas sugeriram mudanças de ordem. Com base em tais sugestões foi elaborado uma nova ordem de prioridades considerando a pontuação obtida por meio da Técnica de grupo nominal (TGN).

Neste momento o modelo dispunha de um conjunto de macrofuncionalidades ordenadas pela sua contribuição para uma dado objetivo de desempenho. Obedecendo a cada uma destas seqüências foram montadas Matrizes AHP correspondentes com vistas a obter os pesos relativos (ver apêndice 7). Tais pesos relativos proporcionaram o surgimento da matriz de coeficientes (tabela 05) que é a base do modelo de avaliação proposto.

A partir das matrizes acima obteve-se um conjunto de seqüências com pesos relativos. Estes pesos foram validados em mais duas rodadas que contou apenas com a participação de nove especialistas. De forma geral observou-se consenso com poucas sugestões de mudanças. O resultado final encontra-se no Apêndice 8.

No decorrer do processo Delphi Eletrônico verificou-se uma substancial queda de participação dos especialistas. Alguns fatores podem ser apontados como explicativos de tal comportamento: o primeiro e, certamente, o principal foi a falta de tempo (justificativa dada por $40 \%$ dos desistentes); o segundo fator deveu-se ao longo tempo da pesquisa (mais de três meses) e, por fim, alguns desistentes tiverem motivos de força maior. Ressalte-se que apenas $15 \%$ não apresentaram justificativa para o abandono a despeito de terem sido instados a se pronunciar. 
O estudo de caso envolvendo tanto fornecedores quanto usuários das soluções BPM mostrou que o modelo é aplicável. Obviamente a aplicação do modelo exige um entendimento prévio e razoável sobre o que é uma solução BPM: entendimento das funcionalidade básicas e, principalmente o propósito da adoção deste tipo de solução.

Constatou-se, no estudo de caso, que os usuários das soluções BPM não possuíam um objetivo amplo para tal adoção: as soluções BPM foram escolhidas para atender a um dado objetivo específico dentro de parâmetros econômicos. Dois dos respondentes se surpreenderam com contribuições não esperadas da solução para outros problemas inicialmente não considerados. Por exemplo, um usuário obteve ganho de velocidade no lançamento de novos produtos algo que não tinha sido inicialmente cogitado como objetivo a ser alcançado; um outro se surpreendeu com o conhecimento explícito dos processos existentes.

O modelo proposto não substitui nem esgota outras formas para avaliar e selecionar solução BPM, mas contribui para que o gestor do negócio tenha uma percepção mais clara da adequabilidade da solução BPM para os objetivos de desempenho do negócio.

Este trabalho além da própria aplicação para proporcionar ao gestor uma visão da solução mais adequada, fornece também ao mesmo uma percepção maior das capacidades e vocações de cada uma das soluções, dentro da perspectiva do gestor do negócio, que deve diminuir a percepção de risco do investimento a ser feito. 


\section{2-Recomendações}

Considerando o tema abordado é forçoso reconhecer que há um grande campo de trabalho a ser desenvolvido. Algumas sugestões para pesquisas futuras podem ser apresentadas:

a) podem ser identificadas outras dimensões que não sejam apenas os objetivos de desempenho listados neste trabalho;

b) podem ser feitas pesquisas envolvendo a aplicação do presente modelo com vistas a estabelecer um rating de soluções BPM sobre diferentes óticas;

c) o embasamento do presente trabalho parte do pressuposto de um específico grau tecnológico existente que sofre uma obsolescência rápida, pelo que outras pesquisas considerando os avanços observados nas soluções BPM podem ser realizadas;

d) investigar os impactos sociais na implantação de soluções BPM; e

e) propor modelos semelhantes para avaliar outros softwares. 


\section{Bibliografia}

AALST, W. V. D., OBERWEIS, A., DESEL, J.. Business Process Management : Models, Techniques, Springer-Verlag, NY, 2000.

ACUR, N.; BITITCl, U.. Managing Strategy Through Business Process. Production Planning \& Control, v.14, n.4, pp.309-326, June, 2003.

ADESOLA, S., BAINES, T.. Developing and Evaluating a Methodology for Business Process Improvement. Business Process Management Journal, Vol.II, N.1, pg. 37-46, 2000.

ALBRECHT, K.. A única coisa que importa: trazendo o poder do cliente para o centro de sua empresa. São Paulo: Pioneira. 1992.

AMARAL, D. C., ROZENFELD, H. Gerenciamento de Conhecimentos Explícitos Sobre o Processo de Desenvolvimento de Produto. In: $3^{\circ}$ Congresso Brasileiro de Gestão de Desenvolvimento de Produto, Florianópolis, 2001.

ANSOFF, H. I.- Estratégia empresarial. São Paulo, Atlas, 1977.

APPLEGATE, L. M., McFARLAN, W.F., McKENNEY, J.L.. Corporate Information Systems Management. R.D. Irwin, Homewood, IL 60430, 1996.

ARIF, M., KULONDA, J., JONES, J., PROCTOR, M.. Enterprise information systems: technology first or process first?. Business Process Management Journal, vol.11, n.01, pps 05-21, 2005.

BARBALHO, S. C. M., ROZENFELD H., AMARAL, C. D.. Análise da Abrangência de Metodologias de Modelagem de Empresas. In: Anais do XXVI Congresso Enanpad. Rio de Janeiro: Anpad; 2002.

BECKER, H. S. Métodos de pesquisa em Ciências Sociais. 4. ed. São Paulo : HUCITEC, 1999.

BENNIGSON, L.A.. Our Balkanized Organizations. Strategy and Leadership, MarApr 1996, pp: 38-41.

BI, H.H.. Graphical and Logical Formalism for Business Process Modeling and Verification. Thesis submitted to the University of Arizona, 2004.

BIAZZO, S.. Approaches to Business Process Analysis: A Review. Busienss Process Management Journal, vol.6, n.2, pp. 99-112, 2000.

BURLTON, R.T.. Business Process Management. Sams Publishing, USA, 2001.

CALDWELL, B.. Missteps, Miscues. Information Week, June 20, 1994, pp: 50-60.

CAMP, R.C.. Business Process Benchmarking. ASQC Quality Press, USA, 1995.

CAMPOS, R.; SANTOS, L. R. -Modelagem de Processos e Definição de Requisitos para Sistemas de Informações para a Previsão de Demanda. In: Anais dos Trabalhos XXV Enanpad. Rio de Janeiro: Anpad, 2001. 
CASSEL, R.A.; KLIPEL, M.; ANTUNES JR., A.A.V.. Considerações críticas acerca da relação do Mecanismo da Função Produção e a simulação computacional - um estudo de caso. In: Anais dos Trabalhos XXIV Encontro Nacional de Engenharia de Produção: Enegep, Florianópolis, 2004.

CONTADOR, J. C. Modelo para Aumentar a Competitividade Industrial: a transição para a gestão participativa. São Paulo: Edgard Blucher, 1996.

COOPER, D.R.; SCHINDLER, P.S.. Métodos de PEsquisa em Administração. Bookman, Porto Alegre/RS, 2004

CORREA, H. L.; GIANESI, I. G. N.. Administração Estratégica de Serviços. São Paulo: ATLAS, 1994.

CORREIA, K. S.A., LEAL, F., ALMEIDA, D. A.. Mapeamento de Processo: Uma Abordagem para Análise de Processo de Negócio. Enegep 2002.

COUGHLAN, A.T., ANDERSON, E., STERN, L.W., EL-ANSARY, A.I.. Canais de Marketing e Distribuição. Porto Alegre, Bookman, 2002.

CRAIG, J., GRANT, R.. Gerenciamento Estratégico. São Paulo, Littera Mundi, 1999.

CURTIS, B. et al.. Process Modeling. Communication of the ACM, v.35, n.9, September, 1992.

D'AVENI, R. A. Hipercompetição: estratégias para dominar a dinâmica do mercado. Rio de Janeiro: Campus, 1995.

DAVENPORT, T. H. Reengenharia de Processos: como inovar a empresa através da Tecnologia de Informação. Rio de Janeiro, Editora Campus, 1994.

DAVENPORT, T. H., PRUSAK, L.. Conhecimento Empresarial: como as organizações gerenciam o seu capital intelectual. Rio de Janeiro: Campus, 1998.

DAVENPORT, T.H.. Process Innovation: Reengineering Work through Information Technology, Harvard Business School Press, Boston, 1993.

DAY, G.S.. A Empresa Orientada Para o Mercado. Porto Alegre, Bookman, 2001.

De SORDI, J.O. Conectividade entre Organizações: Análise do Potencial dos Ambientes Especializados na Integração entre Sistemas de Informação em Colaborar com a Gestão de Operações. SIMPOI 2005, FGV - EAESP, 2005.

De SORDI, J.O., TORRES, N.A.. Business Process Management (BPM): uma nova solução de software para integração de cadeias colaborativas. In: Anais do XXVI Congresso Enanpad. Rio de Janeiro: Anpad; 2002.

De SORDI, J.O.. Funcionalidades requeridas às soluções de business process management system (BPMS) sob a óptica da gestão do conhecimento. XI SIMPEP - Bauru, SP, 2004. 
DELPHI Group. BPM2002: Market Milestone Report. Boston, MA, USA, 2002.

DELPHI Group. BPM2003: Market Milestone Report. Boston, MA, USA, 2003.

DELPHI Group. Third Generation BPM: The Last Mile for E-Business, the First Step for Web Services. Boston, MA, USA, 2001.

DEMING, W. E. Qualidade: A revolução da Administração. Rio de Janeiro: Editora Marques Saraiva, 1990

DONAIRE, D.-A utilização do estudo de casos como método de pesquisa na área da administração. São Paulo: FEA/USP- IMES/SCS, 1998 (paper).

ENOKI, C.H., YAMAMOTO, E. Y, MEIRELES, M., MAIRETTO, M. Convergência e Concordância. In: Anais do II Simpósio de Excelência em Gestão e Tecnologia. Resende, 2005.

FARIA, A.R.; COSTA, S.E.G.; LIMA, E.P.. Metodologia para Operacionalizar a Estratégia de Operações em Empresas Prestadoras de Serviços aplicando a Abordagem por Processos de Cambridge. In Anais do XXIV Encontro Nacional de Engenharia de Produção, Florianópolis: ENEGEP, 2004.

FIGUEIREDO, O.; HAMBURGER, P. L. Casos de administração mercadológica: uma coletânea. Rio de Janeiro : FGV, 1970.

FPNQ - FUNDAÇÃO PARA O PRÊMIO NACIONAL DA QUALIDADE. Critérios de excelência, São Paulo: FPNQ, 2003.

GEROLAMO M.C., ESPOSTO K.F., CARPINETTI L.C.R.. Modelo para identificação de ações de melhorias de desempenho alinhadas à estratégia, Anais do XXII ENEGEP, Curitiba, 2002.

GHEMAWAT, P., PISANO, G. P. Construindo e Sustentando o Sucesso. In: GHEMAWAT, P. A Estratégia e o Cenário dos Negócios: textos e casos. Porto Alegre: Bookman, 2000.

GHOSHAL, S.. Changing the Role of Top Management: Beyond Structure to Processes. Harvard Business Review, Jan-Feb 1995, pp: 86-96.

GIL, A. C. Técnicas de pesquisa em economia. São Paulo : Atlas, 1991.

GIL, A. C.-Técnicas de pesquisa em economia e elaboração de monografias. São Paulo: Atlas, 2000.

GOLD, B.. Technology, Productivity and Economic Analysis. OMEGA v.1, n.1, 1973.

GONÇALVES FILHO C, GUERRA R.S, MOURA A.. Mensuração de Satisfação, Qualidade, Lealdade, Valor e Expectativa em Instituições de Ensino Superior: um estudo do modelo ACSI através de Equações Estruturais. In: Anais do XXVII Congresso Enanpad. Rio de Janeiro: Anpad; 2003 
GREEN, P., ROSEMANN, M. Integrated process modeling: an ontological evaluation. In: Information Systems. Great Britain, U.K. :v.25, n. 2, 2000, pp. 7387.

GROVER, V., KETTINGER, W.R.. Process Think: Winning Perspectives for Business Change in the Information Age, Idea Group Inc. Hershey, 2000.

GUHA S., KETTINGER W.J., TENG, J.T.C.. Business Process Reengineering Building a Comprehensive Methodology. Information Systems Management, Summer 1993, pp: 82-91.

HAMEL, G.; PRAHALAD, C. K. Competindo pelo futuro: estratégias inovadoras para obter o controle do seu setor e criar os mercados de amanhã. Rio de Janeiro: Campus, 1995.

HAMMER, M., CHAMPY, J. Reengenharia: revolucionando a empresa. Campus. Rio de Janeiro, 1994.

HAMMER, M.. Agenda - o que as empresas devem fazer para dominar esta década. Rio de Janeiro: Campus, 2001.

HARRINGTON, H. J.. Performance improvement: was W. Edwards Deming wrong? The TQM Magazine. Vol. 10. № 4, 1998

HARRINGTON, H.J.. Aperfeiçoando Processos Empresariais. Makron Books, S.Paulo, 1996.

HAYES, R. H.; WHEELWRIGHT, S. C. Restoring our competitive edge: competing through manufacturing. New York: John Wiley \& Sons, 1984. 427p.

HAYES, R.H.; UPTON, D.M.. Operations Based Strategy. California Management Review, v.40, n.4, summer, 1998.

HILL, C. W. L.,JONES, G. R.. Strategic Management Theory: An Integration Approach. Boston, MA: Houghton Mifflin Company, 1998.

HRONEC, S. M. Sinais Vitais: usando medidas de desempenho da qualidade, tempo e custo para traçar a rota para o futuro da empresa. São Paulo: Makron Books, 1994.

HUNT, D.. Process Mapping., Wiley, New York, 1996.

HUPLIC, V.. Knowledge And Business Process Management, Idea Group Pub., 2002.

JURAN, J. M. A qualidade desde o projeto: os novos passos para o planejamento da qualidade em produtos e serviços. São Paulo: Pioneira, 1992.

KANTER, R.M., STEIN, B.A., JICK, T.D.. The Challenge of Organizational Change: How Companies Experience It and Leaders Guide It. The Free Press, NY, USA, 1992. 
KAPLAN, R. S.; NORTON, D. P. A estratégia em ação: balanced scorecard. São Paulo: Campus, 1997.

KAYDOS, W.. Measuring, Managing and Maximizing Performance. Portland Productivity Press, 1991.

KAYO, E.K., SECURATO, J.R.. Método Delphi: Fundamentos, Críticas e Vieses. Caderno de Pesquisa em Administração, São Paulo, v.1, n.4, pp. 51-61, 1997.

KIYAN, F.M.. Proposta para Desenvolvimento de Indicadores de Desempenho como Suporte Estratégico. Tese apresentada à UFSCAR, 2001.

KONDAREDDY, S. From Business Process Reengineering to Integrated Process Management: An Exploratory of Issues. Thesis submitted to the Faculty of Purdue University, 1998.

KOSANKE, K. CIMOSA Overview and Status. Computer in industry, v.27, 1995, pp. 101-109.

KRAFZIG, D., BANKE, K., SLAMA, D.. Enterprise SOA. Prentice Hall - PTR, NJ, USA, 2005.

KWAN, M.L.M.. Process Oriented Knowledge Management. Thesis submitted to the Boston University, 1999.

LAURINDO, F. J. B. Estudo sobre o Impacto da Estruturação da Tecnologia da Informação na Organização e Administração de Empresas. São Paulo: POLIUSP, 1995 (Dissertação de Mestrado em Engenharia de Produção).

LAURINDO, F. J. B., CARVALHO, M.M., PESSÔA, M.S.P., SHIMIZU, T.. Selecionando uma Aplicação de Tecnologia da Informação com Enfoque na Eficácia: Um Estudo de Caso de um Sistema para PCP. Gestão \& Produção, v.9,n.3, pp.377-396, Dez.2002.

LAVILLE, C.; DIONNE, J.-A construção do saber: manual de metodologia da pesquisa em ciências humanas. Porto Alegre : Artes Médicas, 1999.

LEE, R., DALE, B. Policy deployment: an examination of the theory. International journal of Quality. Vol. 15. No. 5., 1998.

LEPINKSON, H.A.. SOMA - Sistema Orgânico de Manufatura Autônoma: Uma Nova Abordagem Distribuída para o Gerenciamento do Chão de Fábrica. UFSC, Tese de Doutorado em Engenharia Mecânica, Florianópolis, 1998.

LIMA FILHO, D. O.. Valor Percebido e o Comportamento do Consumidor de Supermercado: um estudo exploratório em uma média cidade brasileira. FGV, São Paulo, (Tese de Doutorado em Administração), 1999..

LINSTONE, H.A., TUROFF, M.. The Delphi Method. Addison-Wesley, 1975.

MALHOTRA, N.K.. Pesquisa de Marketing: Uma Orientação Aplicada. Ed. Bookman, Porto Alegre, RS, 2002. 
McDANIEL, T.. Ten Pillars of Business Process Management. eAl Journal, November, 2001.

McFARLAN, W.E... Information Technology Changes the Way You Compete. In Strategy: Harvard Business Review Book, 1984.

McFARLAN, W.E.. Portfolio Approach to Information Systems. Harvard Business Review, Set/Out. 1981.

McNURLIN, B.C., SPRAGUE, R.H.. Information Systems Management In Practice. Prentice Hall, NJ, 1998.

MEGARD, Patrick. Business Process Management: Don't Neglect the User !. eAl Journal, March, 2002.

MEIRELES, M.M.. Ferramentas Administrativas para Identificar, Observar e Analisar Problemas. Vilipress, São Paulo, 2001.

MILLS, J.; PLATTS, K.; GREGORY, M. - A framework for the design of manufacturing strategy processes - a contingency approach. International Journal of Operations \& Production Management, v. 15, n. 4,p. 17-49, 1995.

MINTZBERG, H.. Safári de estratégia: um roteiro pela selva do planejamento estratégico. Porto Alegre: Bookman, 2000

MOAD, J.. After Reengineering: Taking Care of Business. Datamation, Oct 15 1994, pp: 40-44.

MORITA, H.. Revisão do Método de Análise Hierárquica - AHP. Dissertação de Mestrado, Engenharia de Produção, USP, 1998.

MOTULSKY, H. InStat. San Diego (CA): GraphPad Software, 2003.

MUSCAT, A. R. N.; FLEURY, A. C. C. Indicadores de qualidade e produtividade na indústria brasileira. Revista Indicadores da Qualidade e da Produtividade. P. 83-107, 1993.

NONAKA, I. e TAKEUCHI, H. Criação de Conhecimento na Empresa: como as empresas japonesas geram a dinâmica da inovação. São Paulo: Campus, 1997.

OLIVEIRA JR., M. M. Administração do Conhecimento em Redes Corporativas Globais: Um Estudo de Caso na Indústria de Propaganda. São Paulo: USP, 2000. (Tese de Doutorado).

PÁDUA, S.I.D. Investigação do processo de desenvolvimento de Software a partir da Modelagem Organizacional, enfatizando regras do negócio. Dissertação (Mestrado) São Carlos. Escola de Engenharia de São Carlos, Universidade de São Paulo. 2000.

PAIM, R.. Engenharia de Processos: Conceitos e Práticas, Eng.Produção; UFRJ, RJ, 2001. 
PANDYA, K. et. al.. Towards the Manufacturing Enterprise of the Future International. Journal of Operations \& Production Management, v.17, n.5, pp. 502$521,1997$.

PARASURAMAN, A. and GREWAL, Dhruv. Serving Customers and Consumers Effectively in the Twenty-First Century: A Conceptual Framework and Overview, Journal of the Academy of Marketing Science, vol.28, n.1, pages 9-16, 2000.

PEREIRA, C.A.A. O diferencial semântico. São Paulo: Ática, 1986

PETERS, T. ; WATERMAN, R. Em busca da excelência. São Paulo: Harper \& Row, 1983

PORTER, M. E. What is Strategy. Harvard Business Review, Nov-Dec, pp. 61-78, 1996.

PORTER, M. E.. Competitive Strategy. New York, NY: Free Press, 1980.

PRENOVOST LK. Books reviews: statistical models for ordinal variables. Structural Equation Modeling, (6) 2, p.212-215, 1999.

RACCA, Felix. Why BPM will succeed where BPR didn't. www.bpmg.org. http://www.bpmg.org/downloads/Articles/BPRvsBPM\%20_1_.pdf acessado em 26/Março/2005.

RUTNER, S. M., LANGLEY Jr., C. J.. Logistics Value: Definition, Process and Measurement. International Journal of Logistics Management, vol. 11, n.2, pp. 7381, 2000.

SAATY, T.L.. The Analytic Hierarchy Process and Health Care Problems In: International Conference on Systems Science in Health Care. Montreal, 1980.

SACKMAN, H.. Delphi critique: Expert Opínion, Forecasting, and Group Process. Lexington, Massachusets: Lexington Book, 1975.

SALERNO, M. S.. Projeto de Organizações Integradas e Flexíveis: Processos, Grupos e Gestão Democrática via Espaços de Comunicação-Negociação, Atlas, S.Paulo, 1999.

SANTOS L.C., VARVAKIS G., GHOR C.F.. Por que a estratégia de operações de serviços deveria ser diferente? Em busca de um modelo conceitual, Anais do XXIV ENEGEP, Florianópolis, 2004.

SANTOS, R.P.C.. Engenharia de Processos: Análise do Referencial TeóricoConceitual, Instrumentos, Aplicações e Casos. Tese submetida à UFRJ, Rio de Janeiro, 2002.

SCHAELLER, R.V.. Software Engineering Methods, Models, and Tools to Support Business Process Reengineering. Thesis submitted to the University of Houston Clear Lake, 1997. 
SCHEER A.G.. Aris Methods v6. IDS SCHEER AG, Set. Saarbrücken, Alemanha, 2001.

SCHIAR, L.B.H.P; DOMINGUES, J.. Organizações Voltadas para Processos: Um Paralelo com as Organizações Funcionais. In: Anais do XXII Encontro Nacional de Engenharia de Produção. Curitiba: Enegep; 2002.

SELLTIZ; JAHODA; DEUTSCH; COOK. Métodos de pesquisa nas relações sociais. São Paulo: EDUSP, 1975.

SHIBA, S; GRAHAM, A., WALDEN, D. TQM: quatro revoluções na gestão da qualidade. Artes Médicas. Porto Alegre: 1997.

SHIMIZU, T.. Decisão nas Organizações. São Paulo: Atlas, 2001.

SHINGO, S.. Sistema Toyota de Produção - do ponto de Vista da Engenharia de Produção. Ed. Bookman, Porto Alegre, 1996.

SIEGEL, S. Estatística não-paramétrica. São Paulo: McGraw-Hill, 1979.

SINK, S.D.; TUTTLE, T.C.. Planejamento e Medição para a Performance. Ed. Qualitymark, RJ, 1993.

SINUR, J.. Magic Quadrant for Pure-Play BPM, Gartner, June/2004, http://mediaproducts.gartner.com/reprints/filenet/121570.html acessado em Março/2005.

SKINNER, W.. Manufacturing - missing link in corporate strategy. Harvard Business Review, mai-jun, p.135-145, 1969.

SLACK, N., CHAMBERS, S., JOHNSTON, R.; Administração da Produção, Editora Atlas, 2 ed., SP, 2002.

SLACK, N.. Vantagem Competitiva em Manufatura, São Paulo: Editora Atlas, 1993.

SLACK, N.; CHAMBERS, S.; HARLAND, C.; HARRISON, A.; JOHNSTON, R. Administração da produção. Edição Compacta. Revisão técnica de Henrique Corrêa e Irineu Gianesi . Atlas : São Paulo, 1999.

SMITH, H., FINGAR, P... Business Process Management: Third Wave, Meghan Kiffer, 2003.

SMITH, H.; NEAL, D.; FERRARA, L. ;HAYDEN, F..The Emergence of Business Process Management. Report by CSC's Research Services, 2002.

SOMMERVILLE, Ian. Software Engineering. Addison-Wesley, 1989.

SPINOLA, M.M.; PESSÔA, M.S.P.. Tecnologia da Informação. In Gestão de Operações, Ed. Edgard Blucher, São Paulo, 1997.

SUMANTH, D.J.. The Need for Productivity Measurements in Companies I Organizations. Cap. 7, 1984. 
THOMPSON, M.. Requirements for Effective BPM. UK, Butler Group, 2003.

TINNILA, M.. Strategic Perspectives to Business Process Redesign. Business Process Reengineering \& Management Journal, Vol.1, N.1, pg. 44-50, 1995.

TORRES, J.B. Um Modelo Dinâmico de Apoio à Gestão Organizacional Baseado na Modelagem de Processos Utilizando Componentes de Software. Tese Doutorado, UFSC, 2002.

TREZ, G.; LUCE, F. B.. Os serviços ao cliente como estratégia de marketing. Enampad. 2000.

TRIOLA, M. Introdução á estatística. Rio de janeiro: LTC, 1999.

TSENG, Y.J.. A Model for Supplier Selection and Tasks Assignment. Journal of American Academy of Business, Cambridge, March, 2005.

USIRONO, C.H.. Tecnologia Workflow: O Impacto de sua Utilização nos Processos de Negócio. Dissertação de Mestrado, FEA/USP, 2003.

VERNADAT, F. B.. Enterprise Modeling and Integration: Principles and Applications, Chapman\&Hall, London, 1996.

VICHAS, R.P.. Complete Handbook of Profitable Marketing Research Techniques. Englewood Cliffs: Prentice Hall, 1982.

WILLIAMS, F.P.; D'SOUZA, D.E.; ROSENFELDT, M.E.; KASSAEE, M. Manufacturing strategy, bussiness strategy and firm performance in a mature industry. Journal of Operations Management, v.13, n.1, jul., pp.19-33, 1994.

WORKFLOW MANAGEMENT COALITION. The Workflow Management Coalition - Terminology and Glossary, document number WfMC TC-1011, issue 3.0, Fevereiro, 1999.

WRIGHT, J.T.C., GIOVINAZZO, R.A.. Delphi - Uma Ferramenta de Apoio ao Planejamento Prospectivo. Caderno de Pesquisas em Administração, v.01,n.12, São Paulo, 2000.

YAMAMOTO, EY. Disfunção competitiva: uma contribuição à gestão da estratégia de serviços das clínicas oftalmológicas. São Paulo: UNIFESP/EPM, 2005 (tese de doutorado)

YIN, R.. Case study research: sesing and methods. London: Sage, 1987

ZACARELLI, S. B. Estratégia moderna nas empresas. São Paulo: Zarco. 1996.

ZACCARELLI, S. B. A estratégia e o sucesso nas empresas. São Paulo: Saraiva, 2000.

ZEITHAML, V. A.. Service Quality, Profitability, and the Economic Worth of Customers: What We Know and What We Need to Learn, Journal of the Academy of Science, vol.28,No1, pages-67-85, 2000. 


\title{
-Apêndices
}

\section{Apêndice 1 Questionário de Avaliação - Versão Preliminar}

\author{
O questionário de avaliação da solução BPM (template) versão
} preliminar elaborado com base da revisão da literatura.

\begin{tabular}{|c|c|c|}
\hline & & \\
\hline & $\begin{array}{l}\text { FACIIIDADE DE DESENHO ATRAVÉS DE INTERFACE GRÁFICA (GUI) COM } \\
\text { TECNOLOGIA "DRAG-AND-DROP". }\end{array}$ & DELPHI REPORT (2002); SMITH\&FINGAR (2003) \\
\hline & $\begin{array}{l}\text { OFERECE UM CONJUNTO DE ICONES REPRESENTATIVO DAS DIVERSAS } \\
\text { SITUAÇOEES ENCONTRADAS EM PROCESSOS REAIS. }\end{array}$ & AUTOR \\
\hline & $\begin{array}{l}\text { REGRAS DE NEGÓCIO PODEM SER DEFINIDAS GRAFICAMENTE E } \\
\text { COMPLEMENTADAS COM UMA LLNGUAGEM DE FÁCLLL ENTENDIMENTO. }\end{array}$ & DELPHI REPORT (2002); SMITH\&FINGAR (2003) \\
\hline & $\begin{array}{l}\text { TECNOLOGIA "GRAPH LAYOUT" QUE PERMITE ORGANIZAR E OTIMIZAR A } \\
\text { VISUALIZAÇAAO DO DESENHO DO PROCESSO. }\end{array}$ & MEGARD, Patrick (2002) \\
\hline & $\begin{array}{l}\text { CAPACIDADE DE REPRESENTAR TANTO ATIVIDADES MANUAIS (WORK ITEMS) } \\
\text { COMO AUTOMATICAS (INVOKED APPLICATIONS). }\end{array}$ & DELPHI REPORT (2003) \\
\hline & PERMITE A REUTILIZACÃ̃O DE SUBPROCESSOS JÁ DESENHADOS. & THOMPSON, Michael (2003) \\
\hline & $\begin{array}{l}\text { REPRESENTACÃ̃O DE PROCESSOS E SUBPROCESSOS COM A POSSIBLIDADE DE } \\
\text { SINTETIZAR SUBPROCESSOS PARA SIMPLIFICAR A VISUALIZAÇÃO OU EXPANDIR } \\
\text { EM DETALHES SEM LIMITE DE NIVEIS }\end{array}$ & MEGARD, Patrick (2002) \\
\hline \multirow[t]{6}{*}{ DESENHO DE PROCESSOS } & $\begin{array}{l}\text { APRESENTAR DIFERENTES PROCESSOS QUE COMPARTLHAM AS MESMAS } \\
\text { ATIVIDADES EREGRAS PARA FACLMENTE REORGANIZÁ-LOS MOVENDO PARTES } \\
\text { DE UM PARA OUTRO }\end{array}$ & MEGARD, Patrick (2002) \\
\hline & $\begin{array}{l}\text { MÚLTIPLAS VISÕES ABERTAS EM DIFERENTES LOCAI DENTRO DA MESMA } \\
\text { DEFIIICÃO DE PROCESSO PARA VISUALIZAR PARTES QUE ESTÃO DISTANTES } \\
\text { DEMAIS PARA SEREM MOSTRADAS EM UMA UUNIICA VISÃO }\end{array}$ & MEGARD, Patrick (2002) \\
\hline & 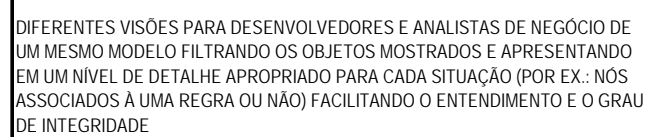 & MEGARD, Patrick (2002) \\
\hline & $\begin{array}{l}\text { CAPACIDADE DE SIMULAÇ̃̃o ONDE ESQUEMAS ANIMADOS DE "TOKENS" FLUEM } \\
\text { ATRAVÉS DO GRÁFICO PARA SIMULAR EXECUÇÕES INSTANCIADAS DO } \\
\text { PROCESSO. }\end{array}$ & MEGARD, Patrick (2002) \\
\hline & $\begin{array}{l}\text { REPRESENTAČ̃O DO TEMPO CUJOS COMPRIMENTOS DOS NÓS MOSTRAM } \\
\text { SIMBOLICAMENTE OS TEMPOS DE EXECUÇÃAO OU ESPERA. }\end{array}$ & MEGARD, Patrick (2002) \\
\hline & POSSUI TEMPLATES PARA FACLLITAR O DESENHO DE PROCESSOS. & DELPHI REPORT (2002) \\
\hline
\end{tabular}




\begin{tabular}{|c|c|c|}
\hline \multirow{3}{*}{ MONITORAMENTO DE PROCESSOS } & $\begin{array}{l}\text { POSSUI UM PAINEL DE FÁCIL VISUALIZAÇÃO DE TODAS AS ATIVIDADES DO } \\
\text { PROCESSO COM DADOS DE CATEGORIA, INSTÂNCIA QUE PERTENCE, TIPO, } \\
\text { PARTICIPANTE, APLICAÇÃO CORRENTE, STATUS, ETC. }\end{array}$ & MEGARD, Patrick (2002) \\
\hline & $\begin{array}{l}\text { AUXILIA NA IDENTIFICAÇÃO DAS CARGAS DE TRABALHO E NA EVOLUÇÃO DAS } \\
\text { MESMAS DE ACORDO COM O PARTICIPANTE. VISÕES DO TEMPO SÃO POSSÍVEIS, } \\
\text { INCLUINDO O TEMPO RESTANTE PARA A FINALIZACCÃO DAS ATIVIDADES. } \\
\text { POSSIBILITA REALOCAR TAREFAS PARA RECURSOS MAIS DISPONIIVEIS EM } \\
\text { TEMPO REAL. }\end{array}$ & MEGARD, Patrick (2002) \\
\hline & REPORT WIZARD E TEMPLATES DE RELATÓRIOS. & DELPHI REPORT (2002) \\
\hline \multirow{9}{*}{ EXECUÇÃO DO PROCESSO } & $\begin{array}{l}\text { PERMITE ALTERAÇÕES NO PROCESSO EM TEMPO DE EXECUÇÃO PARA } \\
\text { CORRIGR ERROS. }\end{array}$ & DELPHI REPORT (2002) \\
\hline & $\begin{array}{l}\text { PERMITE BALANCEAR A CARGA DE TRABALHO DA MANEIRA MAIS EFICIENTE } \\
\text { POSSIVELL, QUER SEJA ALTERANDO O DESENHO DO PROCESSO OU OS } \\
\text { RECURSOS (PARTICIPANTES) E ATIVIDADES. }\end{array}$ & DELPHI REPORT (2002) \\
\hline & PERMITE SALVAR AS VERSÕES DOS DESENHOS E REGRAS ANTERIORES. & DELPHI REPORT (2002) \\
\hline & INTERFACE GRÁFICA PARA INTERVENÇÕES MANUAIS. & DELPHI REPORT (2002) \\
\hline & FACILIDADE DE ATACHAR DOCUMENTOS. & DELPHI REPORT (2002) \\
\hline & $\begin{array}{l}\text { PERMITE DEFINIR FORMULÁRIOS COM CAPACIDADE DE MAPEAMENTO XML PARA } \\
\text { INTEGRAÇÃO COM PKI'S E DE SISTEMAS LEGADOS. }\end{array}$ & DELPHI REPORT (2002) \\
\hline & $\begin{array}{l}\text { PERMITE EXECUÇÕES PARALELAS OU CONCORRENTES DE PROCESSOS, } \\
\text { INDEPENDENTEMENTE DO SUCESSO OU NÃO DE UM DELES. }\end{array}$ & MCDANIEL, Tyler (2001) \\
\hline & $\begin{array}{l}\text { PROVE MECANISMOS DE ENFILEIRAMENTO DE TAREFAS E STATUS DE ESPERA } \\
\text { PARA PERMITIR A FINALIZAÇÃO DAS TRANSAÇÕES DEPENDENTES E DEFINIR } \\
\text { REGRAS BASEADAS NO TEMPO E/OU CONTEXTO. }\end{array}$ & DELPHI REPORT (2003) \\
\hline & $\begin{array}{l}\text { PROVÊ MECANISMO DE ROLL BACK DOS DADOS EM CASO DE FALHAS EM } \\
\text { PROCESSOS AUTOMATIZADOS. }\end{array}$ & DELPHI REPORT (2003) \\
\hline \multirow{3}{*}{ AUTOMAÇÃO DE PROCESSO } & $\begin{array}{l}\text { PROVÊ SERVIÇO DE NOTIFICAÇÃO / MENSAGENS (TIPO E-MAIL PROATIVO) OU } \\
\text { API'S. }\end{array}$ & DELPHI REPORT (2002) \\
\hline & $\begin{array}{l}\text { SUPORTE À PROCESSAMENTO EM VÁRIOS NIVEIS (SUBPROCESSOS INVOCANDO } \\
\text { OUTROS SUBPROCESSOS EM SEQUEENCIA). }\end{array}$ & DELPHI REPORT (2002) \\
\hline & $\begin{array}{l}\text { PERMITE INVOCAR EXECUÇÃO DE PROCESSOS EXTERNOS ENQUANTO } \\
\text { AGUARDA O ESTADO E OS DADOS PARA TAIS CHAMADAS. }\end{array}$ & DELPHI REPORT (2002) \\
\hline \multirow{3}{*}{ FERRAMENTAS DE INTEGRAÇÃO } & $\begin{array}{l}\text { EXISTE UMA SEPARAÇÃO ENTRE A LÓGICA DO PROCESSO E A LÓGICA DO } \\
\text { NEGÓCIO. OU SEJA, OFERECE FERRAMENTAS DIFERENTES DE DESENHO E } \\
\text { VISUALIZAÇẪO DEPENDENDO DO USUÁRIO. }\end{array}$ & DELPHI REPORT (2002) \\
\hline & PARCERIAS COM FORNECEDORES DE EAI'S. & DELPHI REPORT (2002) \\
\hline & INTERFACE COM BANCO DE DADOS (ODBC / ADO). & DELPHI REPORT (2002) \\
\hline \multirow{3}{*}{ MELHORIA DE DESEMPENHO } & $\begin{array}{l}\text { EM TEMPO REAL, O MECANISMO DE EXECUÇÃO PODE REGISTRAR TODOS OS } \\
\text { EVENTOS OCORRIDOS EM UMA BASE DE DADOS PARA POSTERIOR ANÁLISE. }\end{array}$ & MEGARD, Patrick (2002) \\
\hline & $\begin{array}{l}\text { PERMITE VISUALIZAÇÕES ESQUEMÁTICAS COMPARANDO TEMPOS EFETIVOS } \\
\text { VERSUS ESPERADO, RECURSOS EFETIVAMENTE USTILIZADOS E DIVERSOS } \\
\text { GRÁFICOS MOSTRANDO A EVOLUÇÃO. }\end{array}$ & MEGARD, Patrick (2002) \\
\hline & $\begin{array}{l}\text { LISTA DE ATIVIDADES POR PARTICIPANTE E SEU DETALHAMENTO PARA } \\
\text { VISUALIZAR TODO O PROCESSO À QUE UMA DETERMINADA ATIVIDADE } \\
\text { PERTENCE E OUTROS PARTICIPANTES DA MESMA. }\end{array}$ & MEGARD, Patrick (2002) \\
\hline
\end{tabular}




\section{Apêndice 2 \\ Questionário de Avaliação - Versão 2}

O questionário de avaliação da solução BPM (template) versão 2 resultado de um primeiro refinamento com especialistas.

\begin{tabular}{|c|c|c|c|}
\hline MACRO FUNCÕES & REQUISITOS FUNCIONAIS BÁSICOS & NÍVEL BÁSICO & NIVEL IDEAL \\
\hline GERENCIAMENTO DE ACESSO & $\begin{array}{l}\text { DEFINIC̄̃̃O E GERENCIAMENTO DE USUÁRIOS, REGRAS E } \\
\text { ACESSOS }\end{array}$ & 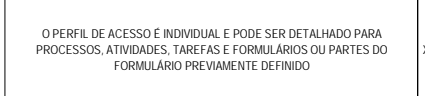 & 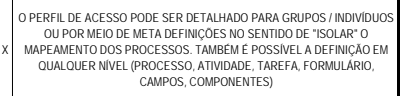 \\
\hline \multirow{6}{*}{ DESENHO DE PROCESSOS } & DIAGRAMAÇÃo ATRAVÉS DE INTERFACE GRÁFICA (GUI) & 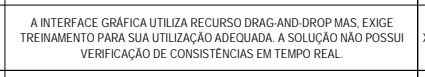 & 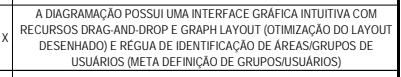 \\
\hline & NIVEIS DE REPRESENTAÇÃO DO PROCESSO & EXISTE UM LIMTTE PARA A QUANTIDADE DE NVEIS $(<=3)$ & NäO EXISTE LMMTE DE NVEEIS \\
\hline & VISUALIZAÇÃO DOS PROCESSOS E SUB-PROCESSOS & $\begin{array}{l}\text { A VISUALIZAÇ̄̃O SOMENTEE ÉPOSSIVEL DO PROCESSO EM QUESTÃO COM } \\
\text { RECURSO DE PAGINAÇ,̄O DA TELA }\end{array}$ & 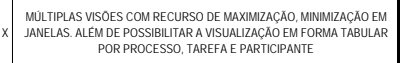 \\
\hline & $\begin{array}{l}\text { UTIUIZACÃ̃ DE TEMPLATES EOU PROCESSOS } \\
\text { ANTERIORMENTE DEFIIDOS }\end{array}$ & $\begin{array}{c}\text { PEMTE O RECURSO DE COPARR OU COLAR MAS, NÃO POSSUI UMA BIBLLTECA } \\
\text { DE TEMPLATES DE PROCESSOS PREVIAMENTE DEFINIOOS }\end{array}$ & 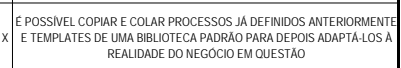 \\
\hline & DOCUMENTAÇÃo & 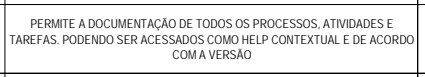 & 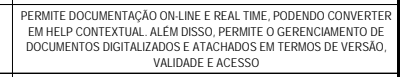 \\
\hline & GERENCIAMENTO DE VERSŐES & $\begin{array}{l}\text { A FERRAMENTA Não PERMITE MANTER VÁRRAS VERSŐ́ES DOS MESMOS } \\
\text { PROCESSOS }\end{array}$ & $\begin{array}{c}\text { A DIAGRAMAÇ̄̃o CRIADA PODE SER SALVA PARA DAR LUGAR A NOVAS } \\
\text { VERSÓES }\end{array}$ \\
\hline \multirow{3}{*}{ REGRAS DO NEGÓCIO } & DEFIIICĀ̃O DE REGRAS DO NEGÓCIO & $\begin{array}{l}\text { A DEFFIICĀÕO DAS REGRAS DO NEGÓCIO NECESSITA DO SUPORTE DE } \\
\text { ESPECIALISTA }\end{array}$ & 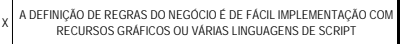 \\
\hline & MECANISMO DE ENFILERAMENTO DE TAREFAS & $\begin{array}{c}\text { ATIVDADES OU TAREFAS PREVIAMENTE DEFINDAS PODEM SER ENCADEADAS } \\
\text { SOMENTE EM SEQUUNCIIA (WORKFLOW) }\end{array}$ & 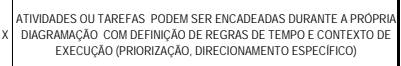 \\
\hline & DEFINIÇÃO DE FORMULARIOS E META DADOS & $\begin{array}{l}\text { A FERRAMENTA PERMTE DEFINIR FoRMULARIOS MAS, NÃO PERMMTE DEFIIIR } \\
\text { REGRAS DE PREEENCHMENTO }\end{array}$ & 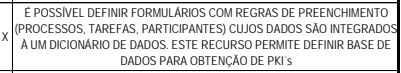 \\
\hline SIMULAÇÃO & SIMULAÇÃO DE PROCESSOS & $\begin{array}{l}\text { PERMTE EXECUTAR ODESENHO DO PROCESSO EM AMBIENTE DE TESTE COMO } \\
\text { RECURSO DE SIMULACĀO }\end{array}$ & 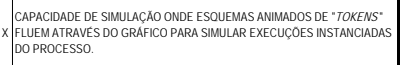 \\
\hline LISTA DE TAREFAS & LISTA DE TAREFAS PERSONALIZAVELL & $\begin{array}{l}\text { A CAIIX DE ENTRADA DE CADA PARTICIPANTEE EADRR̃O E SÓ PODE SER } \\
\text { ACESSADO ATRAVES DAREDE CORPORATIVA (DESKTOP) }\end{array}$ & $\begin{array}{c}\text { A CAIXA DE ENTRADA DE CADA PARTICIPANTEE E PERSONALIZAVELL E PODE } \\
\text { SER ACESSADO VIA WEB }\end{array}$ \\
\hline \multirow{3}{*}{ INTEGRAÇÃo } & INTERFACE POR MEIO DE FORMULÁRIOS & $\begin{array}{l}\text { PERMITE COLETAR DADOS EXTERNOS ATRAVÉS DO PREENCHIMENTO DE } \\
\text { FORMULARIOS }\end{array}$ & $\begin{array}{c}\text { DADOS PODEM SER COLETADOS VIA PREENCHIMENTO DE FORMULARIOS } \\
\text { EIOU OBTIDOS DOS SISTEMAS LEGADOS }\end{array}$ \\
\hline & INTERFACE PADRÃO COM APLCAÇ̄ẼES EXTERNAS & 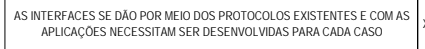 & $\begin{array}{l}\text { EXISTEM INTERFACES POR MEIO DE PROTOCOLOS EXISTENTES E COM AS } \\
\text { PRINCIPAIS APLICACGOES DO MERCADO (ERP, CRM, etC.) }\end{array}$ \\
\hline & INTERFACE COM BASE DE DADOS & 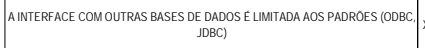 & $\begin{array}{l}\text { CAPACIDADE DE ACESSAR DIVERSAS EASES DE DAAOS POR MEIO DO } \\
\text { MECANISMO OOBC, JOBC ENATIVO }\end{array}$ \\
\hline \multirow{3}{*}{ EXECUÇÃO DO PROCESSO } & $\begin{array}{l}\text { EXECUČ̃̃o DE PROCEESOS EM PARALELO OU } \\
\text { CONCORRENTES EM VARRIOS NIVESS }\end{array}$ & 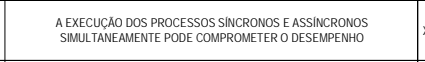 & 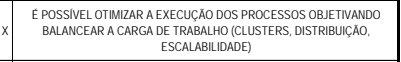 \\
\hline & GERENCIAMENTO DE MENSAGENS & 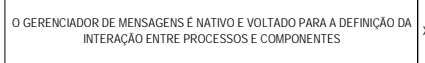 & 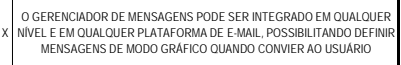 \\
\hline & REGISTRO DE TODOS OS EVENTOS EM BASE DE DADOS & OREGISTRO DE EVENTOS E TRANSAÇ̋ÉSE É PADRÃO & $\begin{array}{l}\text { ÉPOSSIVEL PARAMEERRZZR OREGGISRO DOS EVENTOS DE UM DADO } \\
\text { PROCESSO OU PROCESSOS PARA ANALLSE POSTERIOR }\end{array}$ \\
\hline \multirow{3}{*}{ MONITORAMENTO } & REPORT WIZARD E TEMPLATES DE RELATÓRIOS. & $\begin{array}{l}\text { RELATORRIO SOMENTE Săo POSSIVIVIS COM O USO DE APLLATINOS DE } \\
\text { TERCEROS (CRYSTAL REPORTS) }\end{array}$ & 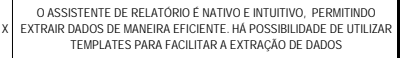 \\
\hline & MECANISMO DE COMMITT EROLL BACK & $\begin{array}{l}\text { OMECANISMO DE COMMITT EROLL BACK SOMENTEE EOSSSIVEL EM } \\
\text { PROCESSOS AUTOMATIZADOS }\end{array}$ & $\begin{array}{c}x \\
x\end{array} \begin{array}{c}\text { PROVÉMECANISMO DE COMMITT EROLL BACK DOS DADOS EM QUALQQER } \\
\text { PROCESSO SINCRONO }\end{array}$ \\
\hline & VISUALIZAÇÃ̃o DA EXECUÇĀo & A VISUALLZZAÇ̄̃o Só É POSSIVEL ATRAVÉS DE RELATÓRIOS (OLAP) & 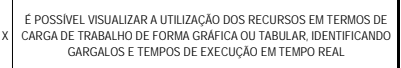 \\
\hline IMPLEMENTAÇÃO DE MELHORIAS & $\begin{array}{l}\text { |NTERVENÇ̃̃ES MANUAIS ATRAVÉS DE INTERFACE } \\
\text { GRÁFICA }\end{array}$ & AINTERVENCĀõo MANUAL SÓ PERMTE LIMPAR E RESTARTAR & 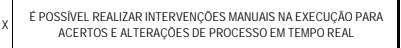 \\
\hline
\end{tabular}




\section{Apêndice 3 Questionário de Avaliação - Versão 3}

O questionário de avaliação da solução BPM (template) versão 3 resultado de um segundo refinamento com especialistas. 
QUESTIONÁRIO DE AVALIAÇÃO DA SOLUÇÃO BPM

\begin{tabular}{|c|c|c|c|c|c|c|c|}
\hline \multicolumn{8}{|c|}{ 1. GERENCIAMENTO DE ACESSO } \\
\hline \multicolumn{8}{|c|}{ 1.1. DEFINIÇÃO DE USUÁRIOS E GRUPOS } \\
\hline NÍVEL 1 & $\mathrm{NA}$ & 1 & 2 & 3 & 4 & 5 & NÍVEL 5 \\
\hline A DEFFIIÇC̃̃O DO ACESSO É É NDIVIDUAL (POR USUÁRIO). & \multicolumn{6}{|c|}{$\begin{array}{l}\text { NIVELL 3: O PERFIL DE ACESSO PODE SER DETALLHADO } \\
\text { PARA GRUPOS EIOU POR USUARIO. }\end{array}$} & 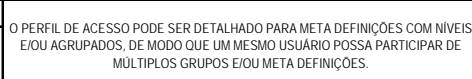 \\
\hline \multicolumn{8}{|c|}{ 1.2. PERFIL DE ACESSO } \\
\hline NÍVEL 1 & $\mathrm{NA}$ & 1 & 2 & 3 & 4 & 5 & NIVEL 5 \\
\hline OPERFLL DE ACESSO PODE SER DETALHADO Å NIVEL DE PROCESSOS. & \multicolumn{6}{|c|}{$\begin{array}{l}\text { NIVEL 3: O PERFFL DE ACESSO PODE SER DEFINDO } \\
\text { PARA QUALQUER NIVELL (PROCESSO, ATIVIDADE, } \\
\text { TAREFA). }\end{array}$} & 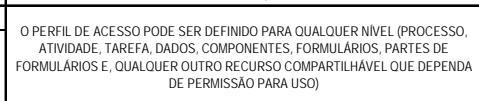 \\
\hline \multicolumn{8}{|c|}{ 1.3. LISTA DE TAREFAS } \\
\hline NÍVEL 1 & NA & 1 & 2 & 3 & 4 & 5 & NIVEL 5 \\
\hline $\begin{array}{l}\text { A LLSTA DE TAREFAS (WORK LIST) É DEFFIIDA POR USUÁRIO PARTICIPANTE. } \\
\text { ACESSO É DISPONIBILZADO PELO DESKTOP (REDE CORPORATINA) }\end{array}$ & \multicolumn{6}{|c|}{ 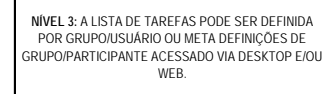 } & 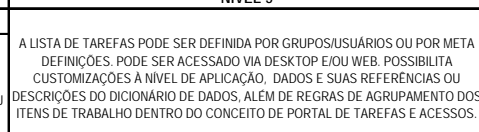 \\
\hline \multicolumn{8}{|c|}{ 2. DESENHO DE PROCESSOS } \\
\hline \multicolumn{8}{|c|}{ 2.1. MECANISMO DE DESENHO } \\
\hline NÍVEL 1 & NA & 1 & 2 & 3 & 4 & 5 & NÍVEL 5 \\
\hline UTILZA INTERFACE GRÁFICA COM RECURSO DRAG-AND-DROP. & \multicolumn{6}{|c|}{ 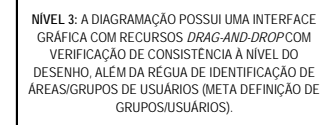 } & 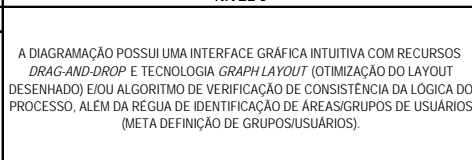 \\
\hline \multicolumn{8}{|c|}{ 2.2. VISUALIZAÇÃO DO DESENHO } \\
\hline NÍVEL 1 & $\mathrm{NA}$ & 1 & 2 & 3 & 4 & 5 & NÍVEL 5 \\
\hline $\begin{array}{l}\text { VISUALIZAÇÃO SOMENTE DE UM PROCESSO EM TELA COM RECURSO DE } \\
\text { PAGINAÇĀ̃o. }\end{array}$ & \multicolumn{6}{|c|}{ 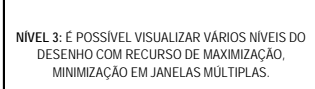 } & 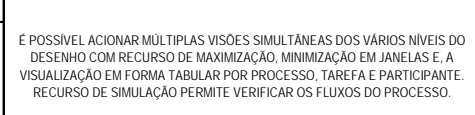 \\
\hline \multicolumn{8}{|c|}{ 2.3. BIBLIOTECA DE COMPONENTES E TEMPLATES DE PROCESSOS } \\
\hline NÍVEL 1 & $\mathrm{NA}$ & 1 & 2 & 3 & 4 & 5 & NÍVEL 5 \\
\hline 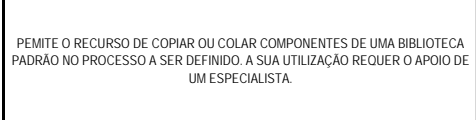 & \multicolumn{6}{|c|}{ 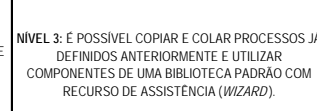 } & 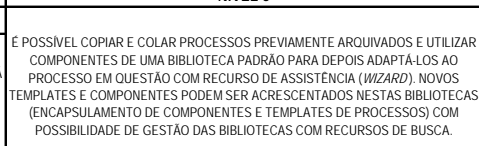 \\
\hline \multicolumn{8}{|c|}{ 2.4. DOCUMENTAÇÃO } \\
\hline NÍVEL 1 & NA & 1 & 2 & 3 & 4 & 5 & NIVEL 5 \\
\hline $\begin{array}{l}\text { PERMITE A DOCUMENTACÃO DE TODAS AS VERSŐ̈ES DOS PROCESSOS PODENDO } \\
\text { SER ACESSADOS NO DESKTOP COMO HELP CONTEXTUAL. }\end{array}$ & \multicolumn{6}{|c|}{ 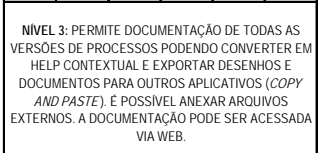 } & 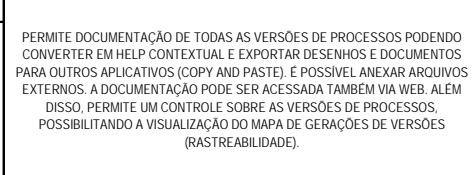 \\
\hline \multicolumn{8}{|c|}{ 3. REGRAS DO NEGÓCIO } \\
\hline \multicolumn{8}{|c|}{ 3.1. DEFINIÇÃO DE REGRAS DO NEGÓCIO } \\
\hline NIVEL 1 & NA & 1 & 2 & 3 & 4 & 5 & NIVEL 5 \\
\hline $\begin{array}{l}\text { ADEFINIÇ̃̃ DAS REGRAS DO NEGǴCIO NECESSITA DO SUPORTE DE ESPECIALISTA } \\
\text { ESUPORTA ALGUMAS LINGUAGENS DE SCRIPT. }\end{array}$ & $\begin{array}{l}\text { NIVEL 3: } \\
\text { SER IMP } \\
\text { ASSIST }\end{array}$ & $\begin{array}{l}\text { DEFII } \\
\text { EMEI } \\
\text { ENTE } \\
\text { L }\end{array}$ & $\begin{array}{l}\text { AOD DE } \\
\text { ADAC } \\
\text { AARD } \\
\text { UAGE }\end{array}$ & $\begin{array}{l}\text { GRAS } \\
\text { GEAU } \\
\text { RECOR } \\
\text { DESC }\end{array}$ & $\begin{array}{l}\text { INEG } \\
\text { NSGR } \\
\text { IMAIC } \\
\text { T. }\end{array}$ & $\begin{array}{l}\text { IO PODE } \\
\text { IOOSE } \\
\text { IADAS }\end{array}$ & 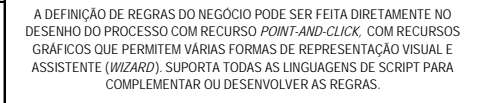 \\
\hline \multicolumn{8}{|c|}{ 3.2. MECANISMO DE ENFILEIRAMENTO DE TAREFAS E ITENS DE TRABALHO } \\
\hline NIVEL 1 & NA & 1 & 2 & 3 & 4 & 5 & NIVEL 5 \\
\hline $\begin{array}{l}\text { ATMIIDADES OU TAREFAS OBEEDECEM Ȧ SEQUUNNCIA ESTABELECIDA NO DESENHO } \\
\text { DO PROCESSO. }\end{array}$ & $\begin{array}{c}\text { NIVEL 3: } \\
\text { PLOEM } \\
\text { DIAC } \\
\text { BASEA }\end{array}$ & $\begin{array}{l}\text { S } \\
\text { EAMA } \\
\text { RAS } \\
\text { ASEL } \\
\text { NOLL }\end{array}$ & 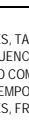 & 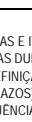 & 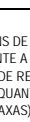 & & 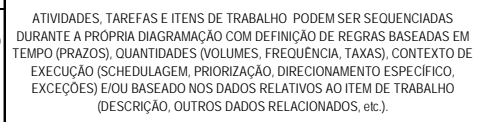 \\
\hline & DEFINIC & ÃO D & FOR & JLÁR & SEN & ETA DA & ADOS \\
\hline NÍVEL 1 & NA & 1 & 2 & 3 & 4 & 5 & NIVEL 5 \\
\hline $\begin{array}{l}\text { A FERRAMENTA PERMTIT DEFINIR FORMULARRIOS EVARIAVEIS ESPECCFFICAS MAS, } \\
\text { NECESSITA DA AJUAA DE UM ESPECIALISTA. }\end{array}$ & $\begin{array}{r}\text { NIVEL 3: } \\
\text { DF } \\
\text { FOR } \\
\text { INTEGR }\end{array}$ & $\begin{array}{l}\text { OSSU } \\
\text { OSG-AN } \\
\text { ADAR } \\
\text { DOSA }\end{array}$ & $\begin{array}{l}\text { TERF } \\
\text { TROP } \\
\text { PEDA } \\
\text { MBAN }\end{array}$ & $\begin{array}{l}\text { GRAF } \\
\text { RAAD } \\
\text { RAUE } \\
\text { SEDA }\end{array}$ & $\begin{array}{l}\text { ICOM } \\
\text { NCEÁC } \\
\text { NEM } \\
\text { SREL }\end{array}$ & $\begin{array}{l}\text { ECURSO } \\
\text { EAR } \\
\text { TIONAL. }\end{array}$ & 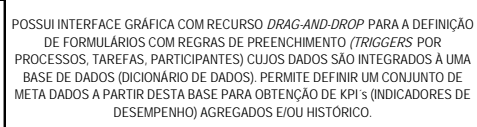 \\
\hline
\end{tabular}




\begin{tabular}{|c|c|c|c|c|c|c|c|}
\hline \multicolumn{8}{|c|}{ 4. INTEGRAÇÃO } \\
\hline \multicolumn{8}{|c|}{ 4.1. INTERFACE COM BANCO DE DADOS } \\
\hline NÍvEL 1 & NA & 1 & 2 & 3 & 4 & 5 & \multirow[b]{2}{*}{ 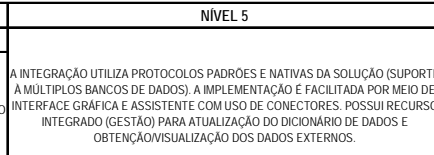 } \\
\hline $\begin{array}{l}\text { AS IITERFACES SE DR̃O POR MEIO DOS PROTOCOLOS EXITENTES AOS BANCO DE } \\
\text { DADOS. A IMPLEMENTACĞO NECESSITA DA AUUDA DE UM ESPECIALLSTA. }\end{array}$ & \multicolumn{6}{|c|}{ 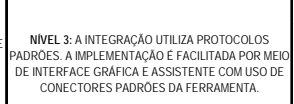 } & \\
\hline \multicolumn{8}{|c|}{ 4.2. INTERFACE COM APLICAÇÕES EXTERNAS } \\
\hline NIVEL 1 & NA & 1 & 2 & 3 & 4 & 5 & NIVEL 5 \\
\hline $\begin{array}{l}\text { AS INTERFACES COM AS APLICACŌES DO MERCADO NECESSTTAM SER } \\
\text { DESENVOLVDAS PARA CADA CASO COM A AJUDA DE UM ESPECIALISTA }\end{array}$ & \multicolumn{6}{|c|}{ 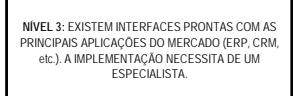 } & 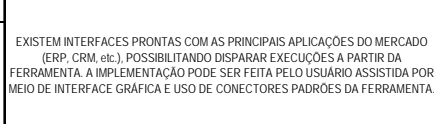 \\
\hline \multicolumn{8}{|c|}{ 4.3. INTERFACE DE CAMADA INTERMEDIÁRIA (MIDDLEWARE) } \\
\hline NIVEL 1 & NA & 1 & 2 & 3 & 4 & 5 & \multirow{2}{*}{ 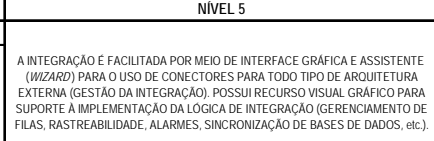 } \\
\hline 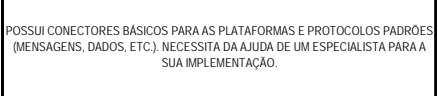 & \multicolumn{6}{|c|}{ 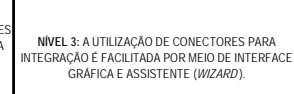 } & \\
\hline \multicolumn{8}{|c|}{ 5. MECANISMO DE EXECUÇÃO } \\
\hline \multicolumn{8}{|c|}{ 5.1. EXECUÇÃO DE PROCESSOS } \\
\hline NIVEL 1 & NA & 1 & 2 & 3 & 4 & 5 & \multirow{2}{*}{ 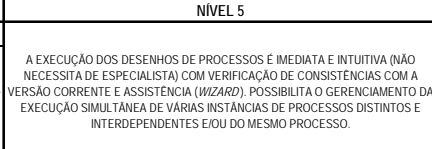 } \\
\hline 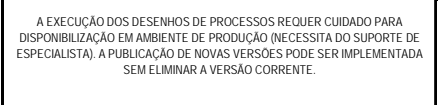 & \multicolumn{6}{|c|}{ 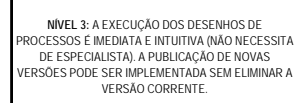 } & \\
\hline \multicolumn{8}{|c|}{ 5.2. REGISTRO DE EVENTOS } \\
\hline NIVEL 1 & NA & 1 & 2 & 3 & 4 & 5 & NIVEL 5 \\
\hline 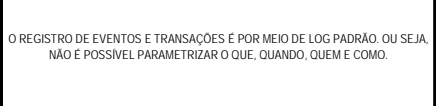 & \multicolumn{6}{|c|}{ 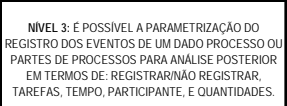 } & 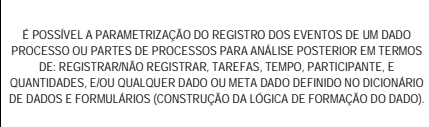 \\
\hline \multicolumn{8}{|c|}{ 5.3. INTERVENÇÕES E TRATAMENTO DE EXCEÇC̄ES } \\
\hline \multirow{2}{*}{ IALLISTA } & $\mathrm{NA}$ & 1 & 2 & 3 & 4 & 5 & NIVEL 5 \\
\hline & $\begin{array}{r}\text { NIVE } \\
\text { MAN } \\
\text { PAA } \\
\text { PARFA } \\
\text { AUXILIO }\end{array}$ & $\begin{array}{l}\text { IN INA } \\
\text { IPAN } \\
\text { ERQUA } \\
\text { ENTE }\end{array}$ & 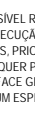 & $\begin{array}{l}\text { PAAA } \\
\text { IDADES } \\
\text { OAESS } \\
\text { FiCAM } \\
\text { FALLIST }\end{array}$ & 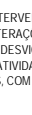 & $\begin{array}{l}\text { ÕES } \\
\text { SDE } \\
\text { DEE } \\
\text { ECMO } \\
\text { UDA DE }\end{array}$ & 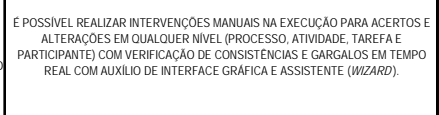 \\
\hline \multicolumn{8}{|c|}{ 5.4. PORTABILIDADE E ESCALABIDADE } \\
\hline NÍVEL 1 & NA & 1 & 2 & 3 & 4 & 5 & NIVEL 5 \\
\hline 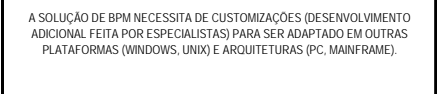 & $\begin{array}{r}\text { ESCA } \\
\text { ENTRE } \\
\text { SAAON }\end{array}$ & $\begin{array}{l}\text { VEL 3: } \\
\text { BILLIDA } \\
\text { NTO, C } \\
\text { CESSA }\end{array}$ & $\begin{array}{l}\text { EDENTY } \\
\text { ETOMZZ } \\
\text { TAPAR } \\
\text { PLATAF }\end{array}$ & 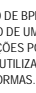 & $\begin{array}{l}\text { PLATA } \\
\text { PLSPE } \\
\text { ESPE } \\
O E M\end{array}$ & & 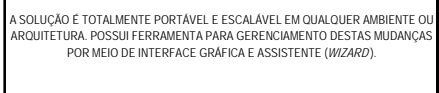 \\
\hline \multicolumn{8}{|c|}{ 6. MONITORAMENTO } \\
\hline \multicolumn{8}{|c|}{ 6.1. RELATÓRIOS OPERACIONAIS } \\
\hline NIVEL 1 & NA & 1 & 2 & 3 & 4 & 5 & NÍVEL 5 \\
\hline $\begin{array}{l}\text { RELATÓRIO SOMENTE SÃO POSSIVEIS COM O USO DE APLCATIVOS DE TERCEIROS } \\
\text { (CRYSTAL REPORTS) }\end{array}$ & \begin{tabular}{|c|c|c|} 
NivEL \\
PERN \\
BAN
\end{tabular} & $\begin{array}{l}\text { INDOE } \\
\text { ODED }\end{array}$ & $\begin{array}{l}\text { TRAR } \\
\text { OOS } B L\end{array}$ & LOSRII & $\begin{array}{l}\text { ISTRA } \\
\text { ELLGS }\end{array}$ & & 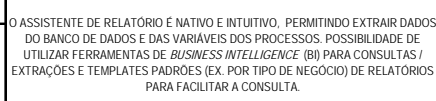 \\
\hline \multicolumn{8}{|c|}{ 6.2. VISUALIZAÇÃO DA EXECUÇÃO } \\
\hline NIVEL 1 & $\mathrm{NA}$ & 1 & 2 & 3 & 4 & 5 & NÍVEL 5 \\
\hline 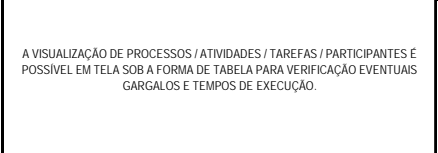 & $\begin{array}{r}\text { NIVE } \\
\text { QUALC } \\
\text { GRUPO } \\
\text { CO } \\
\text { LIGADE } \\
\text { FO } \\
\text { EVEN }\end{array}$ & $\begin{array}{l}\text { ER NIV } \\
\text { ARTICI } \\
\text { AUXIL } \\
\text { AGA.P } \\
\text { MADE } \\
\text { AAIS GA }\end{array}$ & 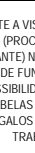 & 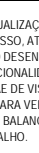 & 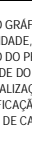 & & 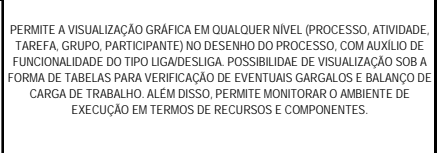 \\
\hline \multicolumn{8}{|c|}{ 6.3. INDICADORES DE DESEMPENHO } \\
\hline $\begin{array}{l}\text { NIVEL } 1 \\
\end{array}$ & \begin{tabular}{|l|}
$\mathrm{NA}$ \\
\end{tabular} & 1 & 2 & 3 & 4 & 5 & NIVEL 5 \\
\hline 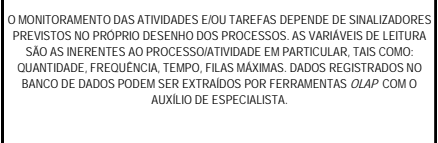 & $\begin{aligned} \text { NIV } \\
\text { INDIC } \\
\text { VARIAV } \\
\text { DEBAS } \\
\text { FORMU } \\
\text { REA } \\
\text { USUAR }\end{aligned}$ & 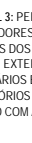 & 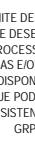 & 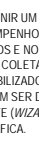 & 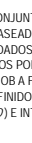 & $\begin{array}{l}\text { DE } \\
\text { SNAS } \\
\text { BTIDOS } \\
\text { MEIODE } \\
\text { RMADE } \\
\text { PELO } \\
\text { RFACE }\end{array}$ & 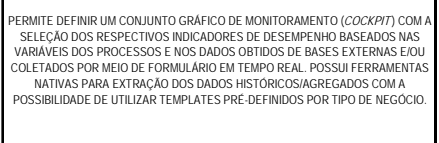 \\
\hline
\end{tabular}




\section{Apêndice 4 Questionário de Avaliação - Versão 4}

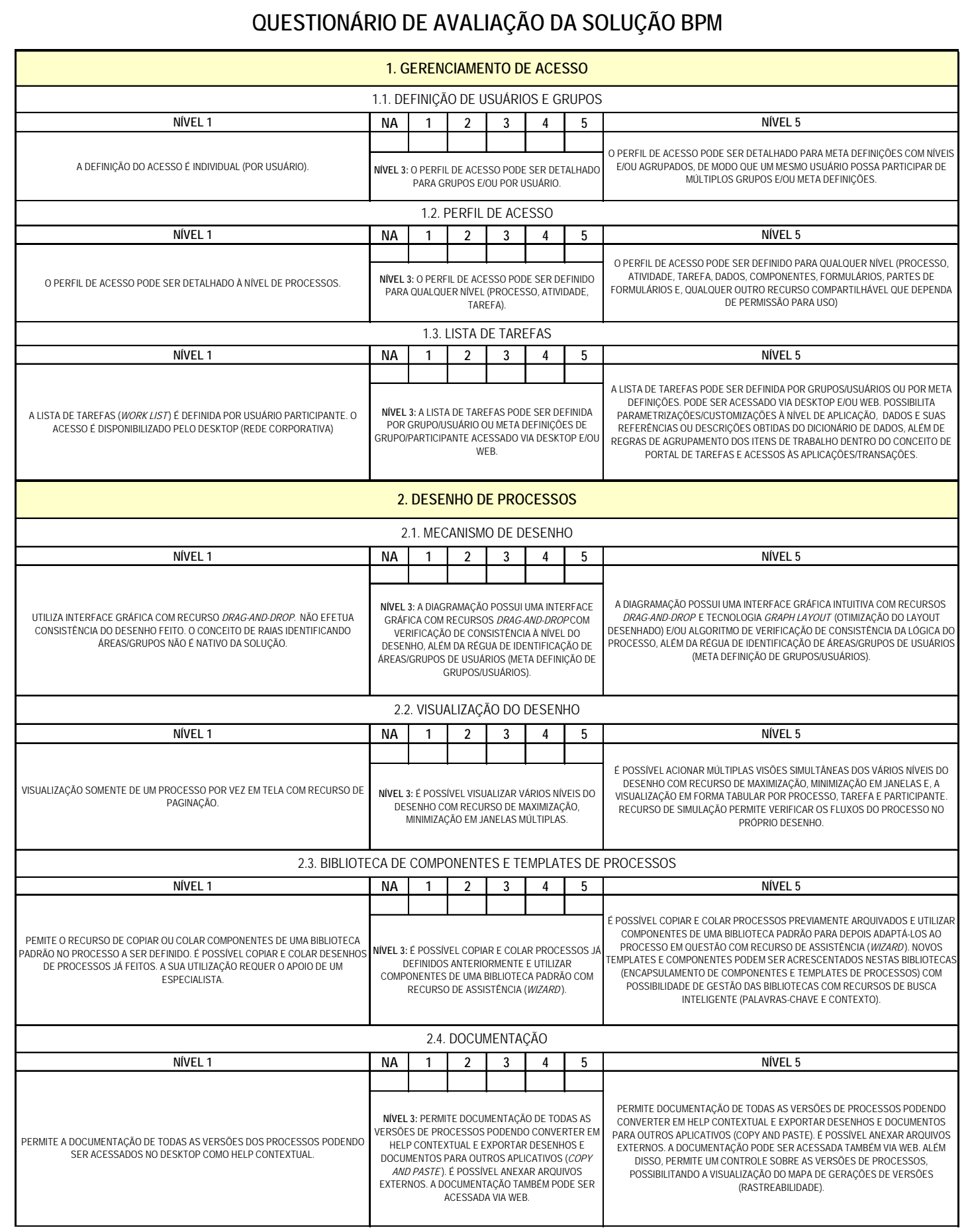




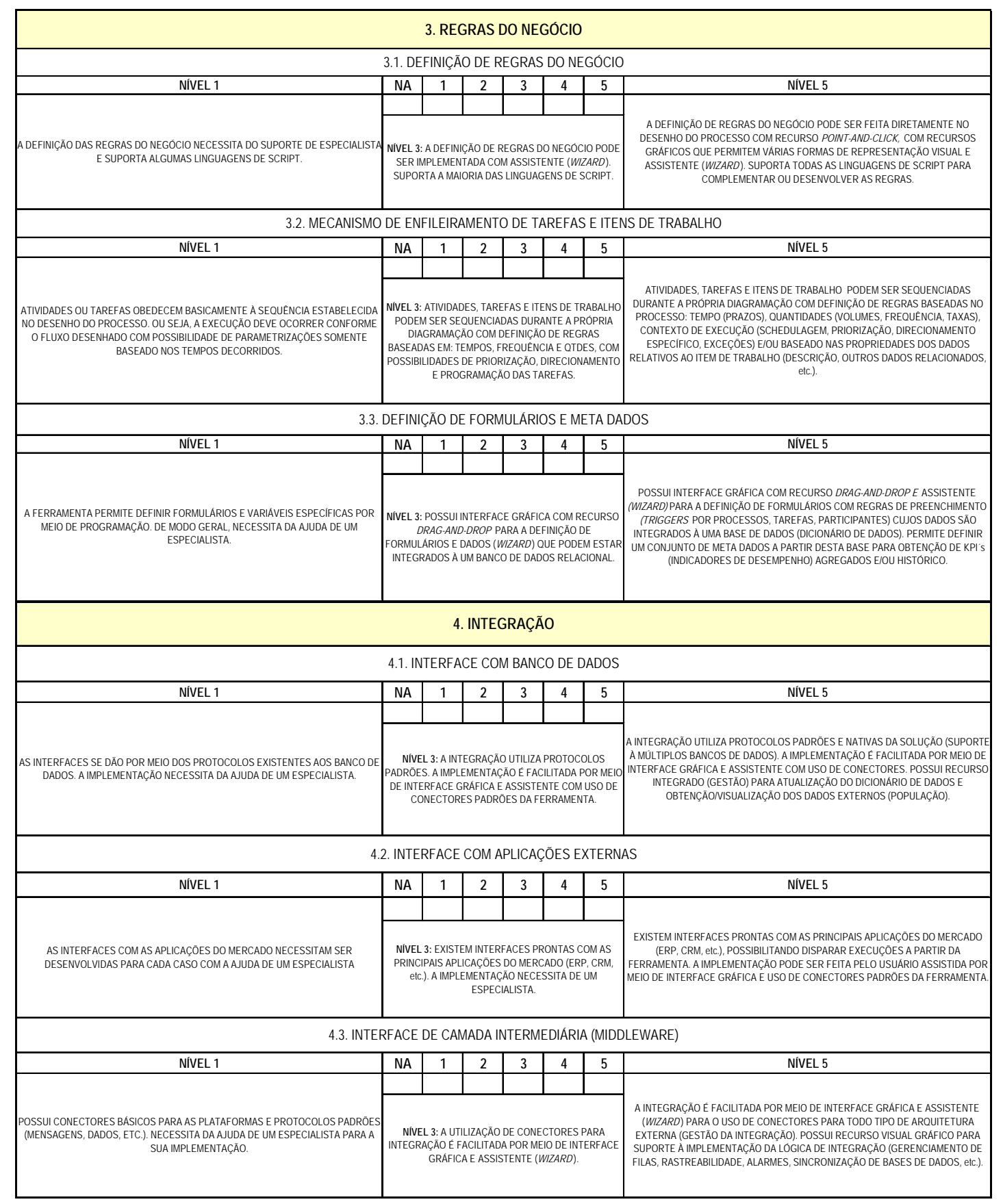




\begin{tabular}{|c|c|c|c|c|c|c|c|}
\hline \multicolumn{8}{|c|}{ 5. MECANISMO DE EXECUÇÃO } \\
\hline \multicolumn{8}{|c|}{ 5.1. EXECUÇÃO DE PROCESSOS } \\
\hline NÍVEL 1 & NA & 1 & 2 & 3 & 4 & 5 & NÍVEL 5 \\
\hline 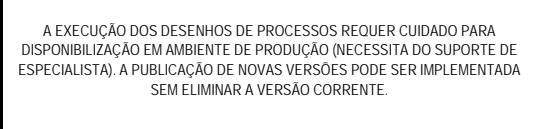 & \multicolumn{6}{|c|}{ 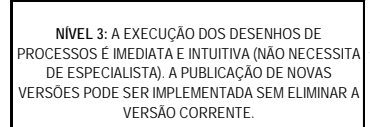 } & 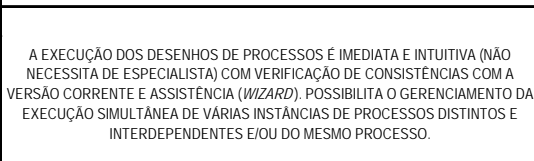 \\
\hline \multicolumn{8}{|c|}{ 5.2. REGISTRO DE EVENTOS } \\
\hline NÍVEL 1 & NA & 1 & 2 & 3 & 4 & 5 & NÍVEL 5 \\
\hline $\begin{array}{l}\text { O REGISTRO DE EVENTOS E TRANSACÖES É EOR MEIO DE LOG PADRÃO. OU SEJA, } \\
\text { NÃO É POSSIVEL PARAMETRIZAR O QUE, QUANDO, QUEM E COMO. }\end{array}$ & \multicolumn{6}{|c|}{ 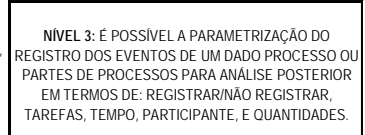 } & 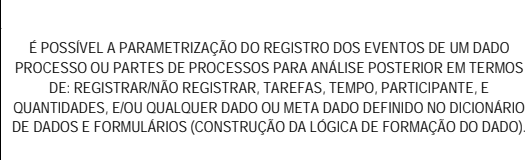 \\
\hline \multicolumn{8}{|c|}{ 5.3. INTERVENÇÕES E TRATAMENTO DE EXCEÇÕES } \\
\hline NÍVEL 1 & NA & 1 & 2 & 3 & 4 & 5 & NÍVEL 5 \\
\hline $\begin{array}{l}\text { A INTERVENČ̃̃O MANUAL SOMENTE PODE SER REALLZADA PELO ESPECIALISTA } \\
\text { DIRETAMENTE NAS BASES DE DADOS E FILAS DE TAREFAS. }\end{array}$ & \multicolumn{6}{|c|}{ 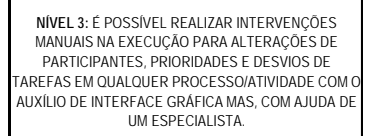 } & 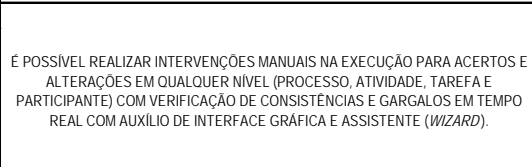 \\
\hline \multicolumn{8}{|c|}{ 5.4. PORTABILIDADE E ESCALABIDADE } \\
\hline NÍVEL 1 & NA & 1 & 2 & 3 & 4 & 5 & NÍVEL 5 \\
\hline $\begin{array}{l}\text { A SOLUÇÃO NECESSITA DE CUSTOMIZACCÕES (DESENVOLVIMENTO ADICIONAL EEITA } \\
\text { POR ESPECIALISTAS) PARA SER ADAPTADO EM OUTRAS PLATAFORMAS (WINDOWS, } \\
\text { UNIX) E ARQUITETURAS (PC, MAINFRAME). }\end{array}$ & \multicolumn{6}{|c|}{ 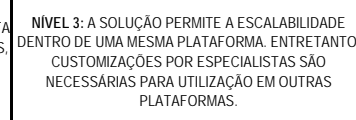 } & $\begin{array}{c}\text { A SOLUČ̃̃ É TOTALMENTE PORTÁVEL E ESCALÁEEL EM QUALQUER AMBIENTE OU } \\
\text { ARQUITETTRA. POSSUU FERRAMENTA PAR GERENIMENTO DESTAS MDDANÇAS } \\
\text { POR MEIO DE INTERFACE GRÁFICA ESSISTENTE (WIZARD). }\end{array}$ \\
\hline \multicolumn{8}{|c|}{ 6. MONITORAMENTO } \\
\hline \multicolumn{8}{|c|}{ 6.1. RELATÓRIOS OPERACIONAIS } \\
\hline NÍVEL 1 & NA & 1 & 2 & 3 & 4 & 5 & NÍVEL 5 \\
\hline $\begin{array}{c}\text { RELATÓRIO SOMENTE SÃO POSSIVEIS COM O USO DE APLICATIVOS DE TERCEIROS } \\
\text { (CRYSTAL REPORTS) }\end{array}$ & \multicolumn{6}{|c|}{$\begin{array}{l}\text { SIVEL 3: O ASSISTENTE DE RELATÓRIO É NATIVO, } \\
\text { PERMITINDO EXTRAIR DADOS REGISTRADOS NO } \\
\text { BANCO DE DADOS (BUSINESS INTELLIGENCE). }\end{array}$} & 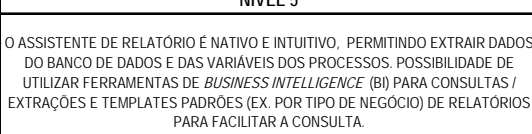 \\
\hline \multicolumn{8}{|c|}{ 6.2. VISUALIZAÇÃO DA EXECUÇÃO } \\
\hline NÍVEL 1 & NA & 1 & 2 & 3 & 4 & 5 & NÍVEL 5 \\
\hline $\begin{array}{l}\text { A VISUALLIZACÃ̃O DE PROCESSOS / ATIVIDADES / TAREFAS / PARTICIPANTES } \\
\text { SOMENTE É POSSIVEL EM MEDIANTE CUSTOMIZACÃO (POR EX.: USO DE } \\
\text { FORMULÁRIOS, RELATÓRIOS). }\end{array}$ & $\begin{array}{r}\text { NIVEL } \\
\text { QUALQ } \\
\text { GRUPO, } \\
\text { CO } \\
\text { LIGAIDE } \\
\text { VISUU } \\
\text { VERIFIC }\end{array}$ & 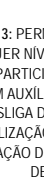 & $\begin{array}{l}\text { (PROC } \\
\text { NTE) } \\
\text { DE FU } \\
\text { ORM } \\
\text { OBA } \\
\text { OBA } \\
\text { VENT } \\
\text { ARGA }\end{array}$ & $\begin{array}{l}\text { SO, A } \\
\text { SESEI } \\
\text { ONAL } \\
\text { ATIVA. } \\
\text { RMAD } \\
\text { S GAR } \\
\text { TRAB }\end{array}$ & $\begin{array}{l}\text { DADE } \\
\text { DOP } \\
\text { DE DO } \\
\text { SSIBIL } \\
\text { ABELA } \\
\text { LOSE } \\
\text { OO. }\end{array}$ & $\begin{array}{l}\text { AEM } \\
\text { REFA, } \\
\text { CESSO, } \\
\text { ES } \\
\text { DE DE } \\
\text { ARA } \\
\text { AANÇO }\end{array}$ & 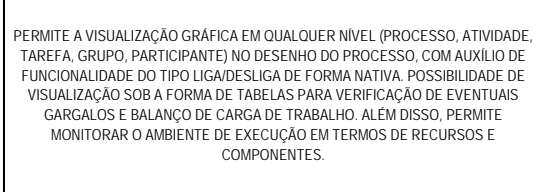 \\
\hline & 6.3 .1 & NDICA & ORE & DE D & EMP & $\mathrm{HHO}$ & \\
\hline NÍVEL 1 & NA & 1 & 2 & 3 & 4 & 5 & NÍVEL 5 \\
\hline 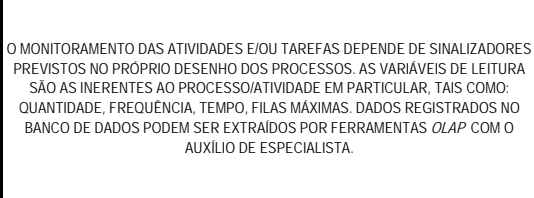 & $\begin{array}{l}\text { NIVE } \\
\text { INDIC } \\
\text { VARIÁV } \\
\text { DEBAE } \\
\text { FORMUL } \\
\text { RELA } \\
\text { USUARR }\end{array}$ & $\begin{array}{l}\text { L 3: PE } \\
\text { DORES } \\
\text { IS DOS } \\
\text { SEXTE } \\
\text { ARIOS } \\
\text { ORIOS } \\
\text { OCOM }\end{array}$ & $\begin{array}{l}\text { ITE DE } \\
\text { EDES } \\
\text { OCCES } \\
\text { AS EIC } \\
\text { DISPOI } \\
\text { JE POL } \\
\text { SISTE } \\
\text { GR }\end{array}$ & $\begin{array}{l}\text { IIR UM } \\
\text { PENHC } \\
\text { SENC } \\
\text { COLET } \\
\text { ILIZAD } \\
\text { USER } \\
\text { EWIZ } \\
\text { IWCA. }\end{array}$ & $\begin{array}{l}\text { ONJUN } \\
\text { ASEAD } \\
\text { AADO } \\
\text { OS PO } \\
\text { OB A } \\
\text { INIDC } \\
\text { INID }\end{array}$ & $\begin{array}{l}\text { DE } \\
\text { NAS } \\
\text { TADOS } \\
\text { IEIO DE } \\
\text { MADEE } \\
\text { ELO } \\
\text { EACE }\end{array}$ & 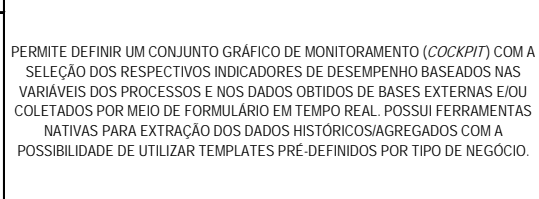 \\
\hline
\end{tabular}




\section{Apêndice 5 \\ Validação das Funcionalidades - Versão \\ 1.Rodada}

Participaram desta $1^{\text {a }}$ rodada da Fase I (Funcionalidades de uma Solução de BPM) 34 especialistas, cujas avaliações foram coletadas no período de 01/09/05 a 25/09/05. A tabulação dos dados foi realizada por meio do software MiniTab e, são apresentadas a seguir um resumo das estatísticas descritivas e, para cada funcionalidade um gráfico boxplot e um histograma.

\section{a) Estatísticas Descritivas para cada Funcionalidade avaliada:}

\begin{tabular}{|c|c|c|c|c|c|c|}
\hline Variable & $\bar{N}$ & Mean & Median & TrMean & $\overline{\text { StDev }}$ & SE Mean \\
\hline Q11 & 34 & 4,471 & 5,000 & 4,533 & 0,662 & 0,114 \\
\hline Q12 & 34 & 4,529 & 5,000 & 4,600 & 0,662 & 0,114 \\
\hline Q13 & 34 & 4,353 & 5,000 & 4,433 & 0,812 & 0,139 \\
\hline Q21 & 34 & 4,412 & 5,000 & 4,533 & 0,925 & 0,159 \\
\hline Q22 & 34 & 4,176 & 4,000 & 4,200 & 0,758 & 0,130 \\
\hline Q23 & 34 & 4,441 & 5,000 & 4,500 & 0,660 & 0,113 \\
\hline Q24 & 34 & 4,471 & 5,000 & 4,533 & 0,662 & 0,114 \\
\hline Q31 & 34 & 4,176 & 4,000 & 4,300 & 0,936 & 0,161 \\
\hline Q32 & 34 & 4,353 & 5,000 & 4,433 & 0,849 & 0,146 \\
\hline Q33 & 34 & 4,324 & 4,500 & 4,400 & 0,806 & 0,138 \\
\hline Q41 & 34 & 4,471 & 5,000 & 4,600 & 0,896 & 0,154 \\
\hline Q42 & 34 & 4,471 & 5,000 & 4,533 & 0,662 & 0,114 \\
\hline Q43 & 34 & 4,500 & 5,000 & 4,600 & 0,788 & 0,135 \\
\hline Q51 & 34 & 4,206 & 4,500 & 4,300 & 1,008 & 0,173 \\
\hline Q52 & 34 & 4,176 & 4,000 & 4,233 & 0,797 & 0,137 \\
\hline Q53 & 34 & 3,912 & 4,000 & 3,967 & 1,083 & 0,186 \\
\hline Q54 & 34 & 4,588 & 5,000 & 4,667 & 0,743 & 0,127 \\
\hline Q61 & 34 & 4,6765 & 5,0000 & 4,7333 & 0,5349 & 0,0917 \\
\hline Q62 & 34 & 4,500 & 5,000 & 4,567 & 0,663 & 0,114 \\
\hline Q63 & 34 & 4,382 & 4,500 & 4,433 & 0,697 & 0,120 \\
\hline
\end{tabular}


b) Avaliação individual de cada funcionalidade apresentada:

\section{Item 1.1 - Definição de Usuários e Grupos}
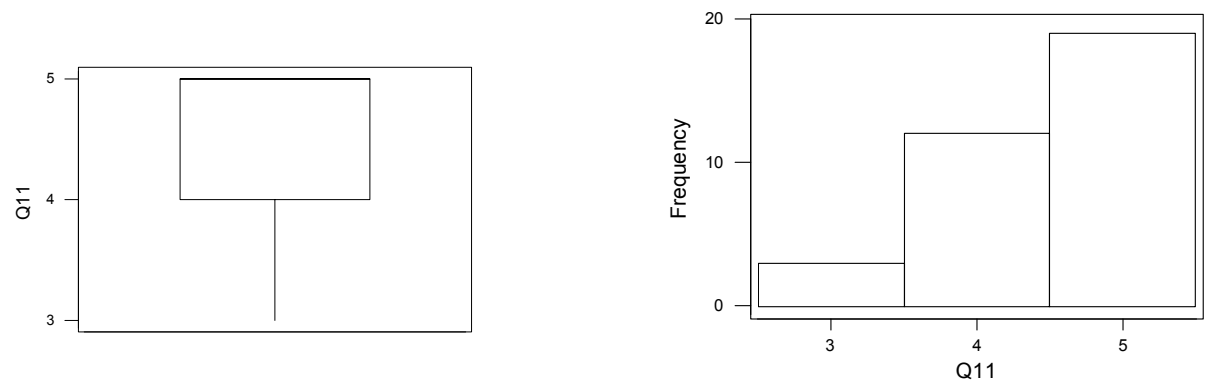

Wilcoxon Signed Rank Test: Q11

\begin{tabular}{|c|c|c|c|c|c|}
\hline & & $\mathrm{N}$ for & Wilcoxon & & timated \\
\hline & $\mathrm{N}$ & Test & Statistic & $\mathbf{P}$ & Median \\
\hline Q11 & 34 & 34 & 304,0 & 0,918 & 4,500 \\
\hline
\end{tabular}

Os comentários dos especialistas na sua forma integral podem ser vistos no Apêndice 5. Em síntese afirmaram que :

- Esta é a forma que dá mais flexibilidade, pois um usuário pode ter diversos papéis em uma organização. Neste caso, seria interessante que o perfil de acesso permitisse saber usuário / papel.

o Modelagem de alta complexidade com necessidade de discussões, padronização e integração.

o O uso de meta definições permite "isolar" o desenho do processo. Mas, exige uma camada de definição de cada usuário com tais meta definições.

o No nível 5 deve ficar claro que um mesmo usuário participando de múltiplos grupos pode ter níveis de acesso diferenciados 
Item 1.2 - Perfil de Acesso
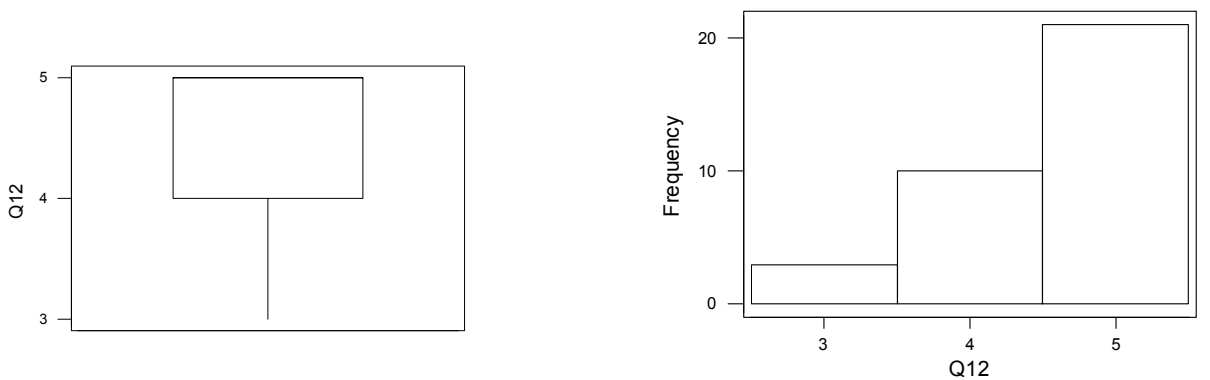

Wilcoxon Signed Rank Test: Q12

Test of median $=4,500$ versus median not $=4,500$

\begin{tabular}{|c|c|c|c|c|c|}
\hline & & for & Wilcoxon & & timated \\
\hline & $\mathrm{N}$ & Test & Statistic & $\mathbf{P}$ & Median \\
\hline र12 & 34 & 34 & 336,0 & 0,516 & 4,50 \\
\hline
\end{tabular}

Comentários dos Especialistas:

o Ter segurança e controle sobre os acessos. Tentar fazer isso de forma inteligente e ágil.

o Da mesma forma, quanto mais opções houver, melhor.

o Também, com o uso de meta definições, a manutenção fica facilitada.

o O acesso no nível de dados deve ser do componente ou serviço. A pessoa (interação manual) ou o processo em si (interação automática) deve ter suas atividades/tarefas associadas para 0 andamento do fluxo do processo.

\section{Item 1.3 - Lista de Tarefas}
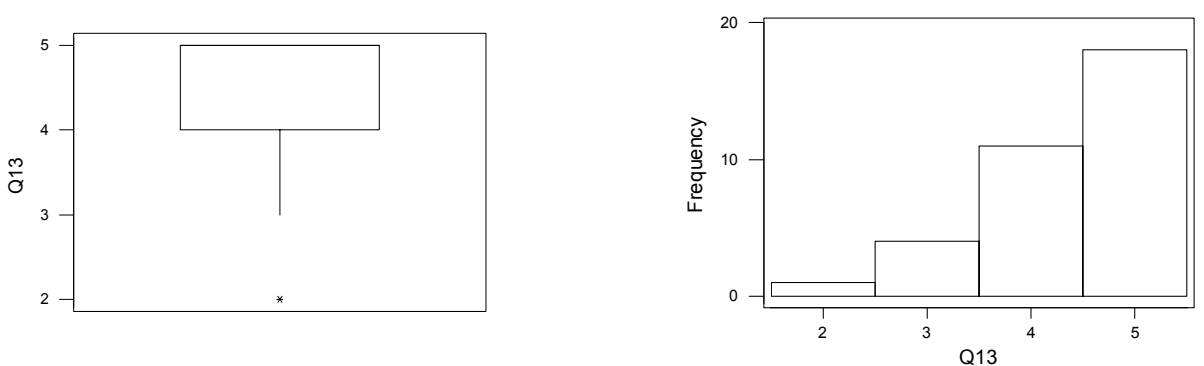

Wilcoxon Signed Rank Test: Q13

$$
\begin{aligned}
\text { Test of median } & =4,500 \text { versus median not }=4,500 \\
& \mathrm{~N} \text { for Wilcoxon }
\end{aligned}
$$


$\begin{array}{rrrrrr} & \mathrm{N} & \text { Test } & \text { Statistic } & \mathbf{P} & \text { Median } \\ \text { Q13 } & 34 & 34 & 270,0 & \mathbf{0 , 6 4 4} & 4,500\end{array}$

Comentários dos Especialistas:

o Tenho dúvidas em relação ao acesso WEB. Será que ele não deveria estar em todos os níveis?

o Da mesma forma, quanto mais opções houver, melhor.

- O BPM deve ter regras de negócio para associar a lista de tarefas compatível com as ações esperadas na interação (manual / automática). Conforme comentário acima, a customização no nível de dados deve ser projetado no componente ou serviço a ser chamado.

\section{Item 2.1 - Mecanismo de Desenho}
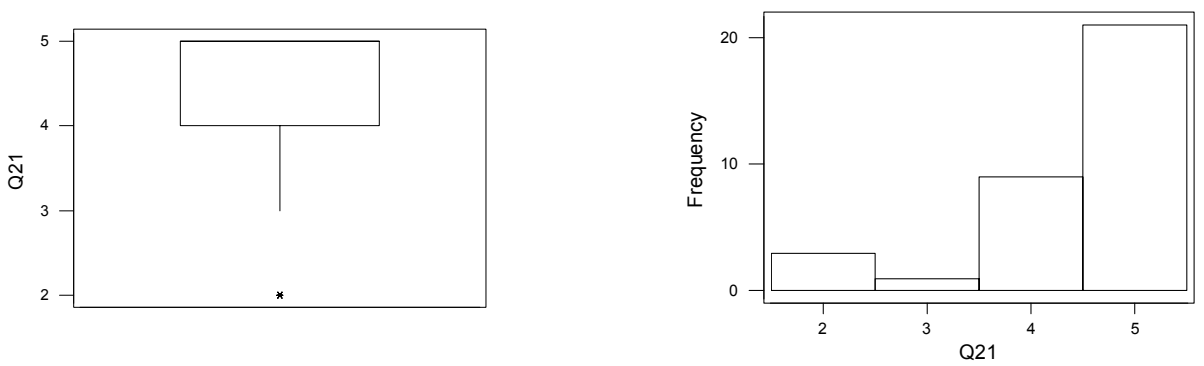

Wilcoxon Signed Rank Test: Q21

$$
\begin{aligned}
& \text { Test of median }=4,500 \text { versus median not }=4,500 \\
& \begin{array}{rrrrrr} 
& & \text { N for } & \text { Wilcoxon } & & \text { Estimated } \\
\text { Q21 } & N & \text { Test } & \text { Statistic } & \mathbf{P} & \text { Median } \\
& 34 & 34 & 325,5 & \mathbf{0 , 6 3 8} & 4,500
\end{array}
\end{aligned}
$$

Comentários dos Especialistas:

- Idealmente a ferramenta gráfica deve ligar automaticamente e fornecer acesso à documentação dos elementos do processo também

- Da mesma forma, quanto mais opções houver, melhor.

o Não acho que as 'raias' sejam itens a serem considerados em níveis máximos (5). Na verdade, ela é uma opção de linguagem e não de recurso de interface de ferramenta de BPM.

- A solução de BPM deve permitir o uso de mais de um método de modelagem (Ex: Aris, Zachman, etc.).

o BPM é um conceito de Arquitetura, portanto, quanto mais intiuitivo e mais what you see is what you get (real e projetado) melhor o cumprimento do seu propósito de existir. 
Item 2.2 - Visualização do Desenho
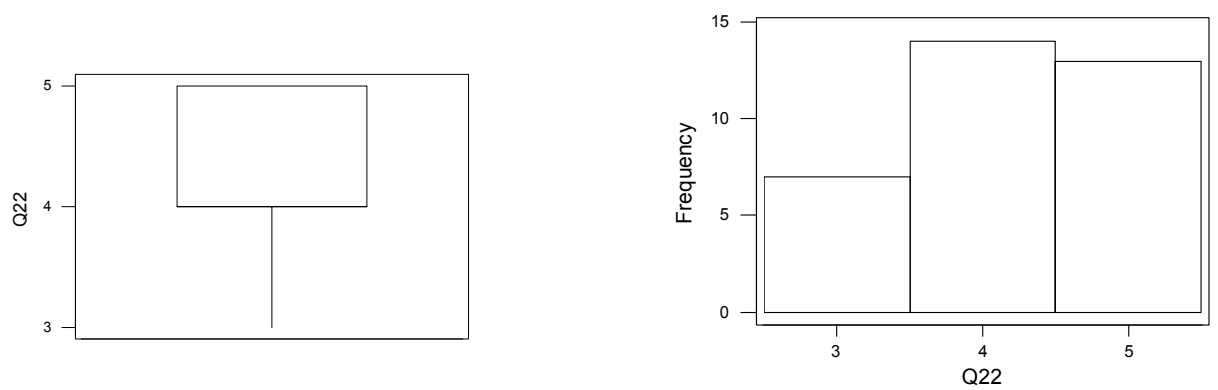

Wilcoxon Signed Rank Test: Q22

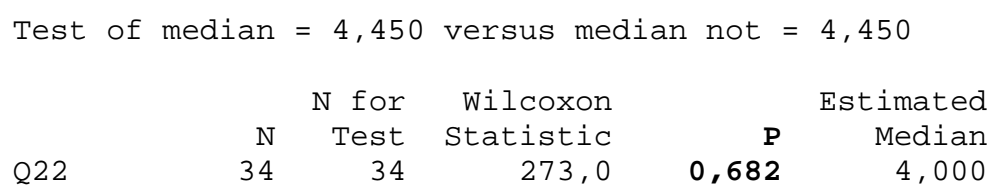

Comentários dos Especialistas:

o Perigo com a poluição visual.

o O recurso de simulação somente para verificar o fluxo do processo ? Recurso de Gerenciamento de Projetos (Caminho crítico, Gantt, etc.) e/ou exportação para aplicativos externos.

o Com certeza, é necessário facilitar a visualização e compreensão do processo desenhado (processo / subprocessos / processos paralelos).

\section{Item 2.3 - Biblioteca de Componentes e Templates de Processos}
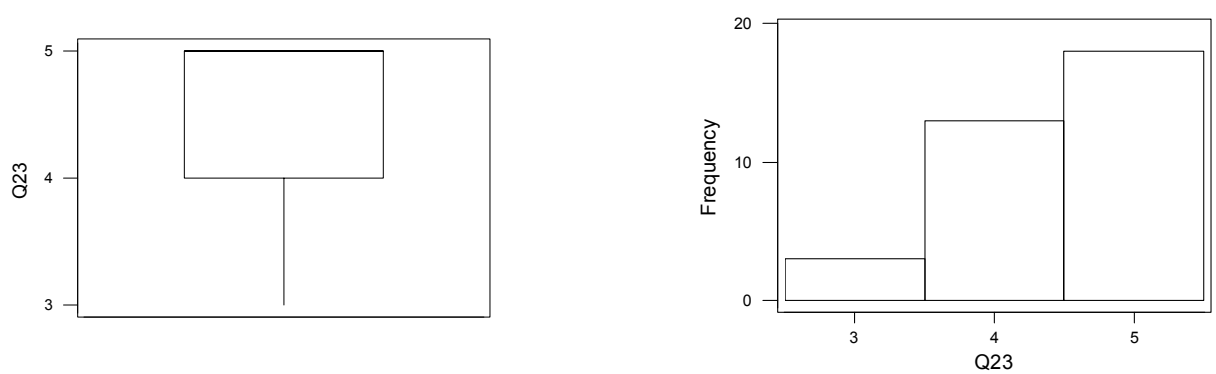

Wilcoxon Signed Rank Test: Q23

Test of median $=4,500$ versus median not $=4,500$

$\begin{array}{rrrrrr} & & \text { N for } & \text { Wilcoxon } & & \text { Estimated } \\ \text { Q23 } & \text { N } & \text { Test } & \text { Statistic } & \text { P } & \text { Median } \\ & 34 & 34 & 288,0 & \mathbf{0 , 8 7 8} & 4,500\end{array}$

Comentários dos Especialistas: 
o Perigo com o não entendimento que o usário possa cometer.

- Aqui o especialista é necessário em todos os níveis.

o Até o momento não vi solução BPM que possibilite uma gestão dos componentes já utilizados nos processos, o que é diferente de buscar componentes numa biblioteca para utilizar no processo. Ou seja, responder a seguinte pergunta: em que processos eu utilizo o componente $\mathrm{X}$ ?

\section{Item 2.4 - Documentação}
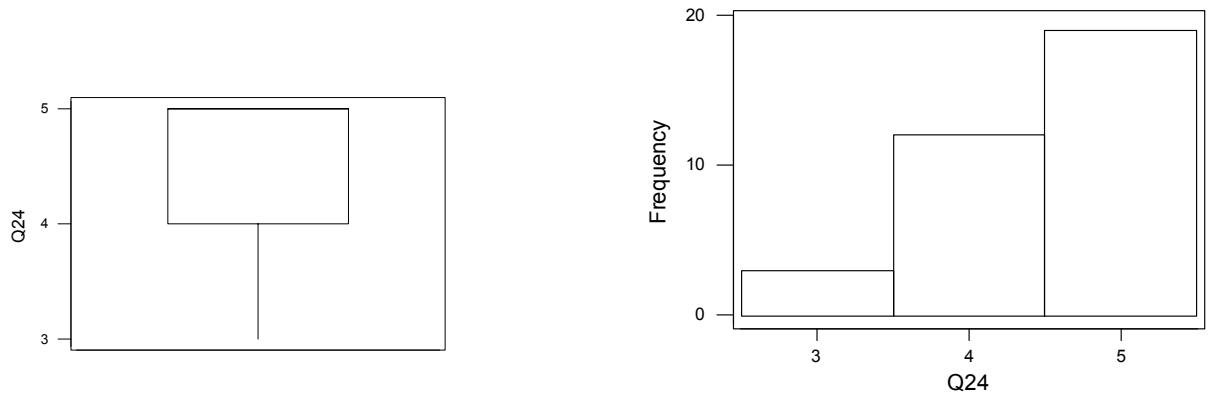

Wilcoxon Signed Rank Test: Q24

\begin{tabular}{|c|c|c|c|c|c|}
\hline & & $\mathrm{N}$ for & Wilcoxon & & timated \\
\hline & $\mathrm{N}$ & Test & Statistic & $\mathbf{P}$ & Median \\
\hline Q24 & 34 & 34 & 304,0 & 0,918 & 4,500 \\
\hline
\end{tabular}

\section{Item 3.1 - Definição de Regras do Negócio}
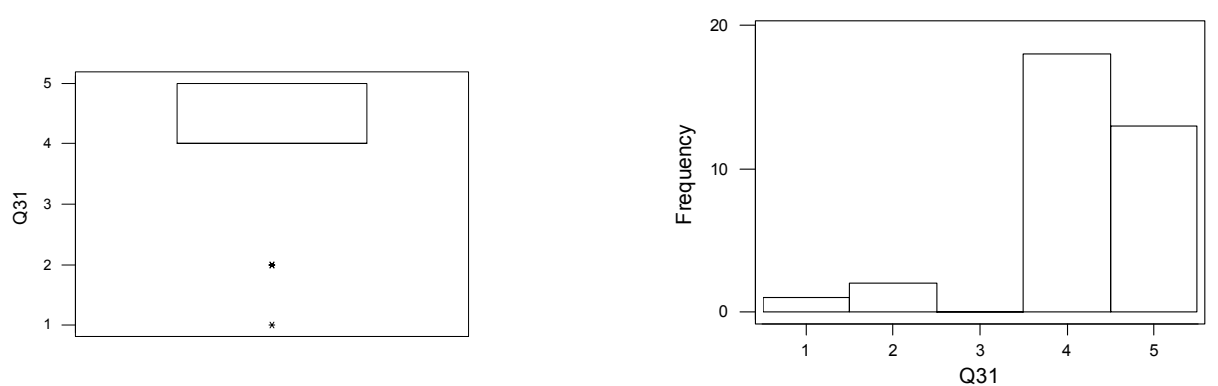

Wilcoxon Signed Rank Test: Q31

$$
\begin{aligned}
\text { Test of median } & =4,450 \text { versus median not }=4,450 \\
& N \text { for Wilcoxon }
\end{aligned}
$$




$\begin{array}{rrrrrr} & \mathrm{N} & \text { Test } & \text { Statistic } & \mathbf{P} & \text { Median } \\ \text { Q31 } & 34 & 34 & 325,0 & \mathbf{0 , 6 4 4} & 4,50 \odot\end{array}$

Comentários dos Especialistas:

- Será que não precisariamos de especialistas em todos os niveis, pelo menos estar disponivel? Talvez no nivel mais complexo seria um tutor, help inteligente.

o Há uma vastidão de linguagens de script...as mais interessantes são o JavaScript, Python e para quem ainda não entrou no Software Livre, VBScript.

o Muito boa esta funcionalidade.

o Situação ideal!!!

Item 3.2 - Mecanismo de Enfileiramento de Tarefas e Itens de Trabalho
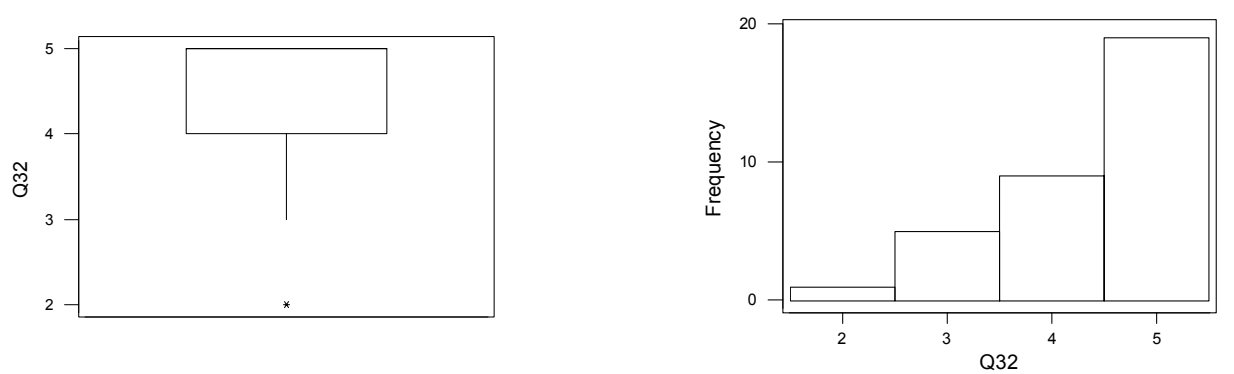

Wilcoxon Signed Rank Test: Q32

\begin{tabular}{|c|c|c|c|c|c|}
\hline & & $\mathrm{N}$ for & Wilcoxon & & timated \\
\hline & $\mathrm{N}$ & Test & Statistic & $\mathbf{P}$ & Median \\
\hline Q32 & 34 & 34 & 275,5 & 0,713 & 4,500 \\
\hline
\end{tabular}

Comentários dos Especialistas:

o Acredito que é melhor "travar".

o Agrupamento de itens de trabalho exige a definição de regras. Por exemplo: entrega de mercadoria no varejo (despacho) exige um procedimento de roteirização e carga, geralmente, lidando com mais de uma Nota Fiscal.

o Poder visualizar "algo mais" do que simplesmente o item de trabalho facilita a priorização e a execução por parte do usuário.

- Esta capacidade pode ser até desenhada no processo, porém, tornaria o processo confuso e pior, misturaria regra de negócio com regra de execução. $O$ ideal é que esta capacidade fique no nível de parametrização da própria atividade/tarefa. 


\section{Item 3.3 - Definição de Formulários e Meta Dados}
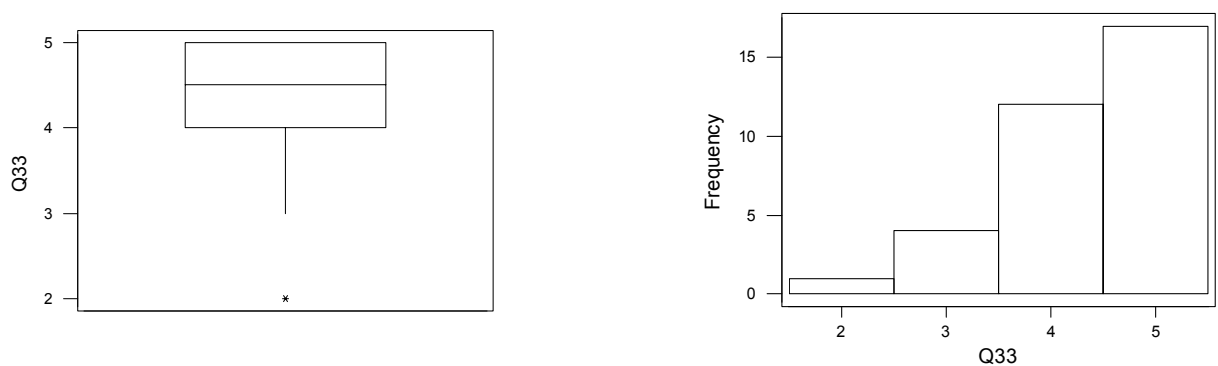

Wilcoxon Signed Rank Test: Q33

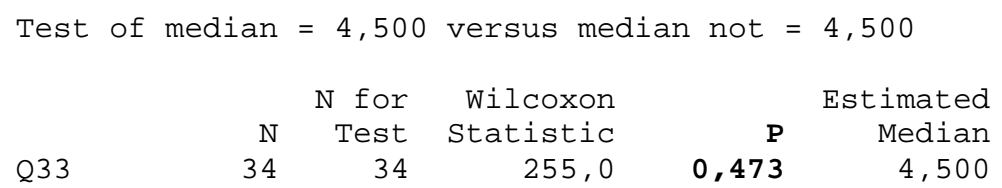

Comentários dos Especialistas:

o Computação pessoal, desde que o conteúdo não se perca.

o Deve existir uma integração com Banco de Dados.

o É o futuro, ou seja, ingeligência de processos empacotados como serviços.

o Formulários são parte básica de soluções de Workflow.

Item 4.1 - Interface com Banco de Dados
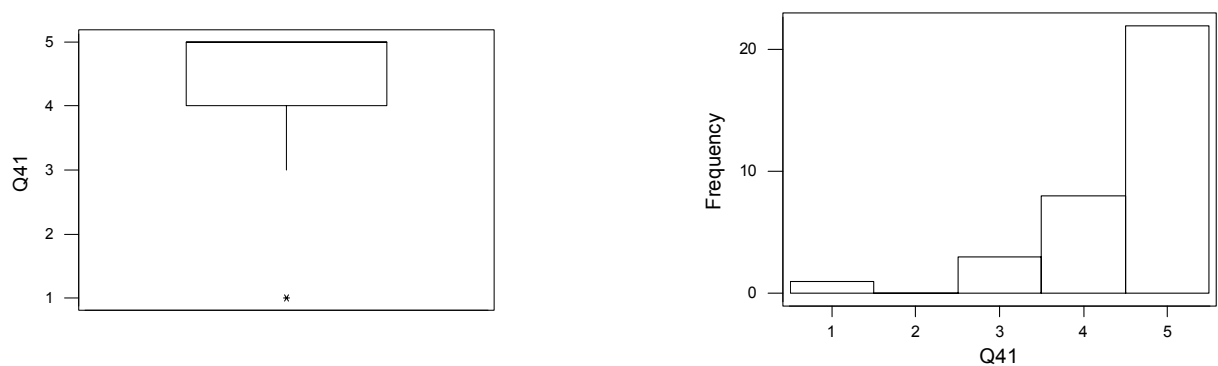

Wilcoxon Signed Rank Test: Q41

$$
\begin{aligned}
\text { Test of median } & =4,500 \text { versus median not }=4,500 \\
& N \text { for Wilcoxon }
\end{aligned}
$$




$\begin{array}{rrrrrr} & \mathrm{N} & \text { Test } & \text { Statistic } & \mathbf{P} & \text { Median } \\ \text { Q41 } & 34 & 34 & 341,0 & \mathbf{0 , 4 6 2} & 4,50 \odot\end{array}$

Comentários dos Especialistas:

o Interface com Bancos de Dados é uma funcionalidade básica.

o "Popular" um Banco de Dados da solução com dados externos.

o Este é o grande perigo de uma solução BPM que quer se tornar uma ferramenta de desenvolvimento. $O$ acesso ao Banco de Dados deveria ser deixado ao componente/método de acesso/API, que garantam a integridade referencial dos dados.

\section{Item 4.2 - Interface com Aplicações Externas}
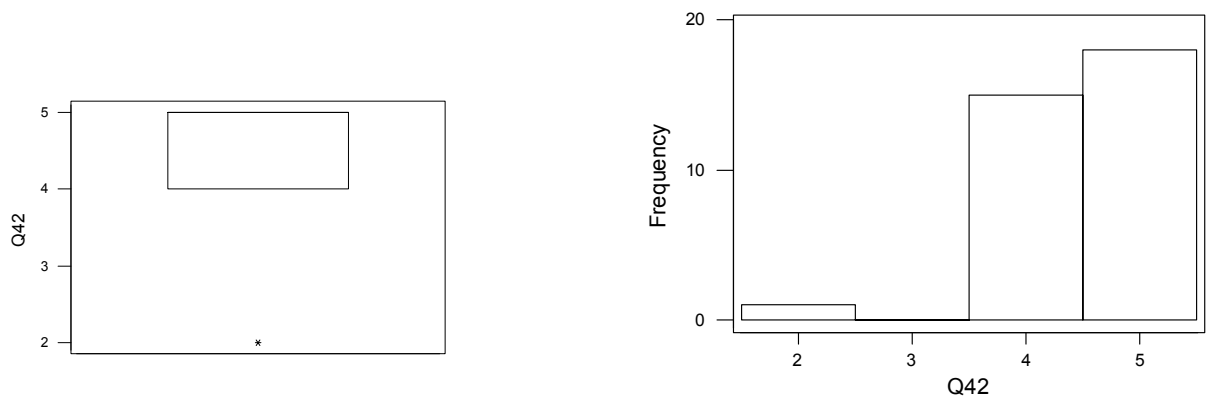

Wilcoxon Signed Rank Test: Q42

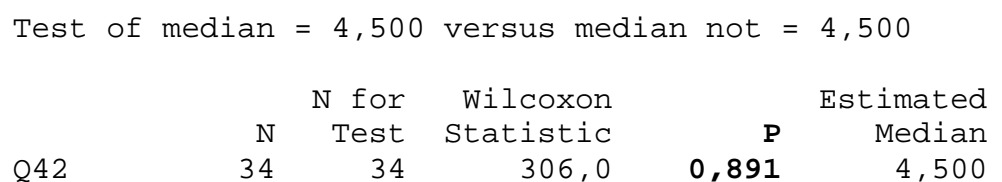

Comentários dos Especialistas:

o através de um sistema corporativo, é mais seguro.

o a existência de uma API bem documentada, além de conectores prontos é vital, especialmente para conectar a sistemas legados e/ou feitos pela própria empresa e/ou fornecedores desconhecidos.

o Perfeito!!!

o Deve existir, pelo menos, a possibilidade de conexão com as principais aplicações existentes no mercado. 
Item 4.3 - Interface de Camada Intermediária (Middleware)
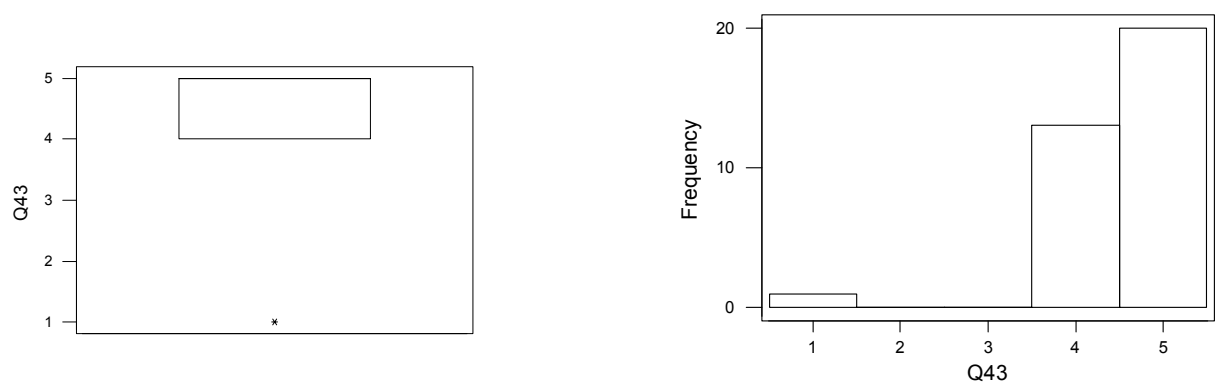

Wilcoxon Signed Rank Test: Q43

\begin{tabular}{|c|c|c|c|c|c|}
\hline & & $\mathrm{N}$ for & Wilcoxon & & stimated \\
\hline & N & Test & Statistic & $\mathbf{P}$ & Median \\
\hline Q43 & 34 & 34 & 340,0 & 0,473 & 4,500 \\
\hline
\end{tabular}

Comentários dos Especialistas:

- Um Middleware permite a gestão de conectores e integrações.

o Ótimo!!! Cada um faz o que sabe fazer melhor!!!

\section{Item 5.1 - Execução de Processos}
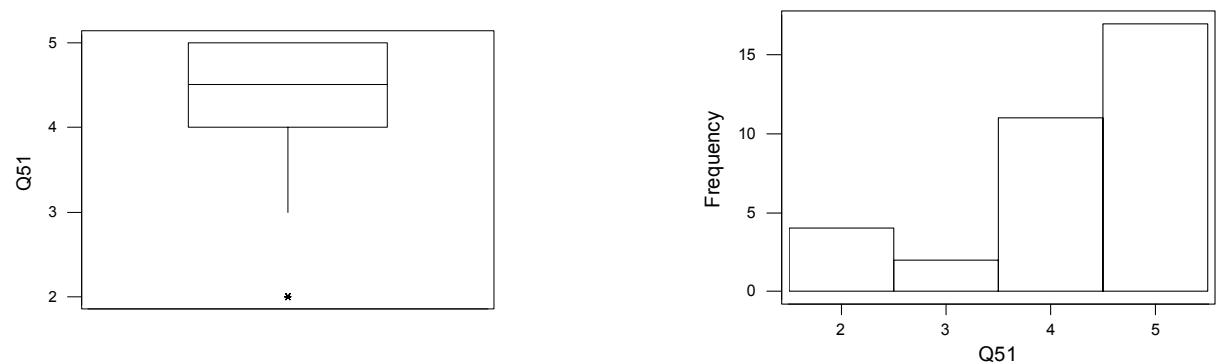

Wilcoxon Signed Rank Test: Q51

\begin{tabular}{|c|c|c|c|c|c|}
\hline & & $\mathrm{N}$ for & Wilcoxon & & timated \\
\hline & $\mathrm{N}$ & Test & Statistic & $\mathbf{P}$ & Median \\
\hline Q51 & 34 & 34 & 340,0 & 0,473 & $4,50 \odot$ \\
\hline
\end{tabular}


Comentários dos Especialistas:

o Não acredito que mesmo que a ferramenta seja de muito fácil manejo, seja possível a implementação direta por usuário sem suporte técnico.

o Não consigo ver como um usuário final pode executar uma nova versão sem ajuda de especialista.

o Esta é uma funcionalidade obrigatória de uma solução BPM para ser considerada como tal.

\section{Item 5.2 - Registro de Eventos}
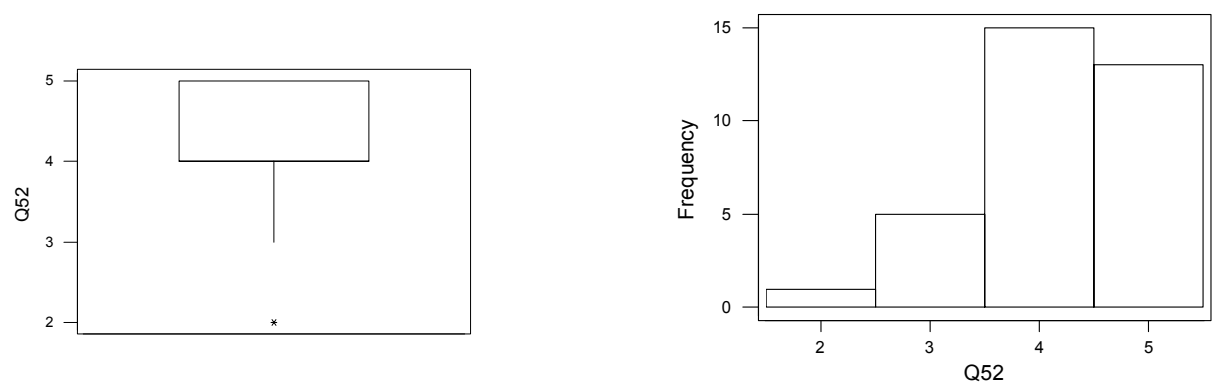

Wilcoxon Signed Rank Test: Q52

$$
\begin{array}{lrrrrr}
\text { Test of median }= & 4,450 & \text { versus median not }=4,450 \\
& & \text { N for } & \text { Wilcoxon } & & \text { Estimated } \\
\text { Q52 } & \text { N } & \text { Test } & \text { Statistic } & \mathbf{P} & \text { Median } \\
& 34 & 34 & 286,0 & \mathbf{0 , 8 5 1} & 4,00
\end{array}
$$

Comentários dos Especialistas:

o pode complicar um pouco...

- Logs são interessantes também para auditorias de segurança e estatísticas, tanto de uso quanto de avaliação de tempos de execução e outros indicadores.

o BPM deveria se focar em registrar indicadores que auxiliam a melhorar o desempenho do negócio. Este é o valor agregado de uma boa implementação BPM!!! 
Item 5.3 - Intervenções e Tratamento de Exceções
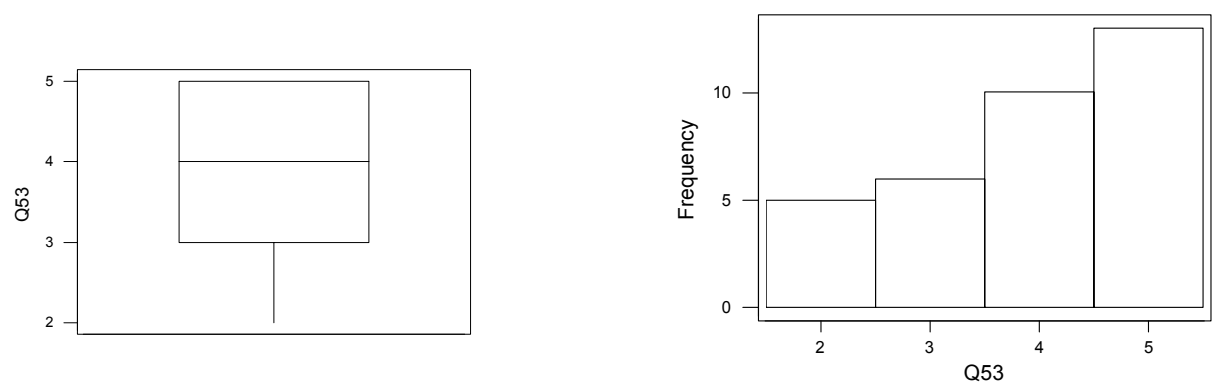

Wilcoxon Signed Rank Test: Q53

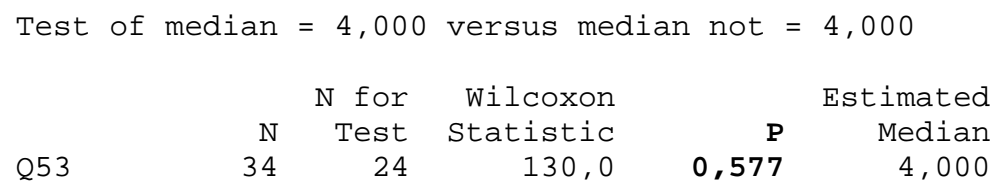

Comentários dos Especialistas:

o é melhor restringir...

o Talvez as intervenções manuais devam ser feitas com registro de log.

o Por mais facilitada que seja a interface da ferramenta não vejo como ser possível a intervenção manual no processo em qualquer nível de execução.

o As intervenções devem ser feitas por meio de uma visualização dos "gargalos".

Item 5.4 - Portabilidade e Escalabilidade
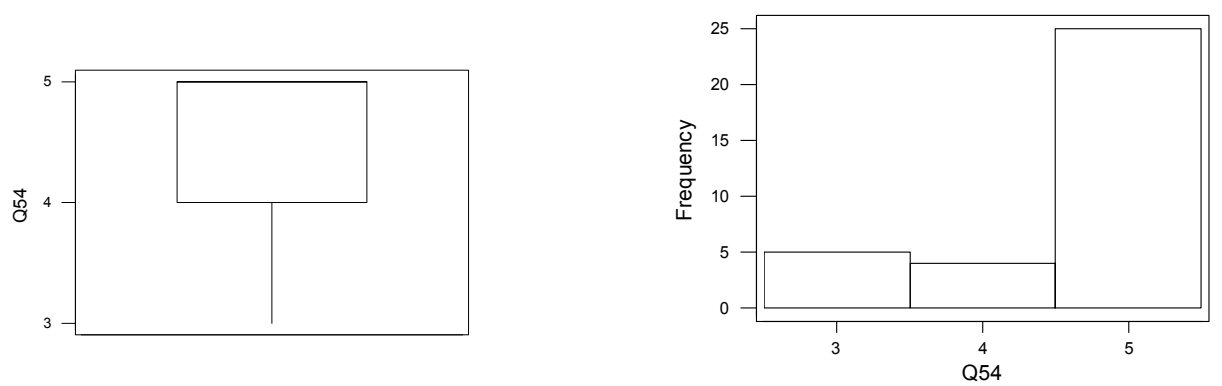

Wilcoxon Signed Rank Test: Q54

Test of median $=4,950$ versus median not $=4,950$ 


\begin{tabular}{|c|c|c|c|c|c|}
\hline & & for & Wilcoxon & & timated \\
\hline & $\mathrm{N}$ & Test & Statistic & $\mathbf{P}$ & Median \\
\hline Q54 & 34 & 34 & 325,0 & 0,644 & 5,000 \\
\hline
\end{tabular}

Comentários dos Especialistas:

- A questão, na maioria das vezes, recai sobre a questão da manutenção e/ou suporte técnico.

- Em geral, cada solução de BPM tem uma plataforma mais adequada pelo sua origem.

\section{Item 6.1 - Relatórios Operacionais}
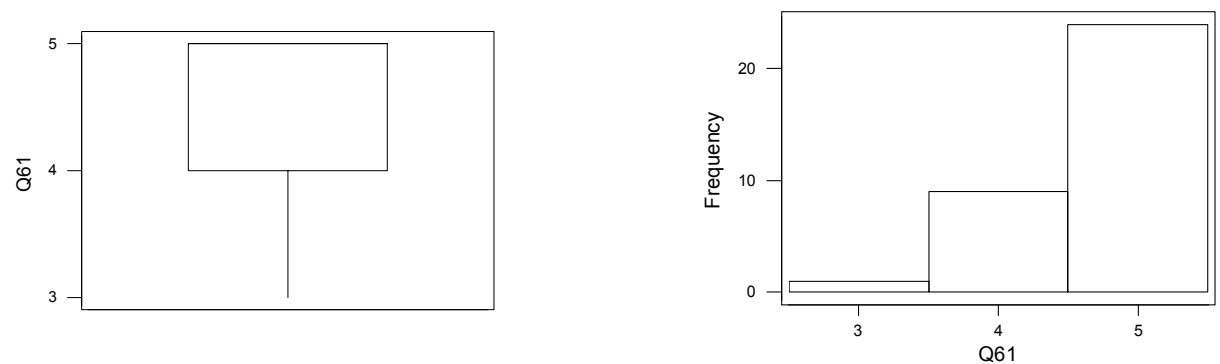

Wilcoxon Signed Rank Test: Q61

$$
\begin{aligned}
& \text { Test of median }=4,950 \text { versus median not }=4,950 \\
& \mathrm{~N} \text { for Wilcoxon } \\
& \text { Test Statistic } \\
& \text { Q61 } \\
& \begin{array}{lrr}
34 & 34 & 300,0
\end{array} \\
& \mathbf{P} \quad \text { Median }
\end{aligned}
$$

Comentários dos Especialistas:

o É necessário diferenciar o que são relatórios próprios dos processos e de qualquer outro relatório que utilizam dados gerados dentro dos processos.

\section{Item 6.2 - Visualização da Execução}
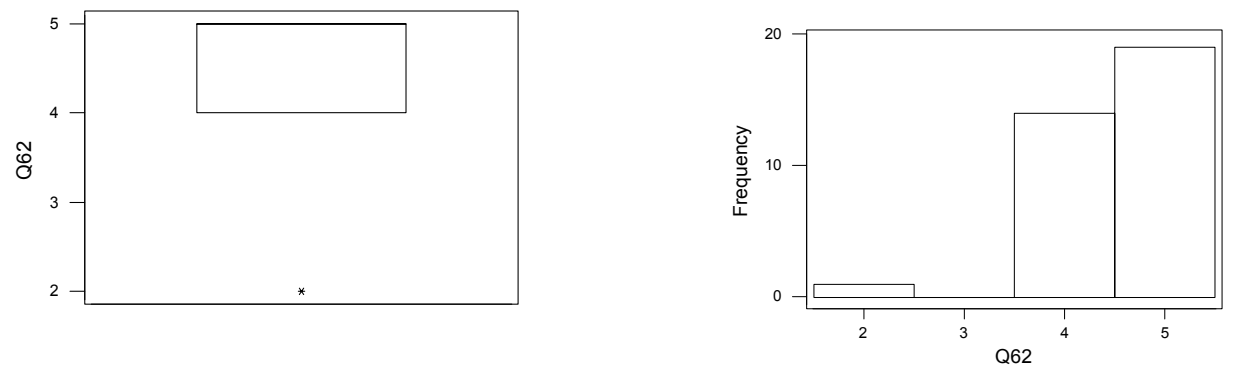
Wilcoxon Signed Rank Test: Q62

\begin{tabular}{|c|c|c|c|c|c|}
\hline & & $\mathrm{N}$ for & Wilcoxon & & timated \\
\hline & $\mathrm{N}$ & Test & Statistic & $\mathbf{P}$ & Median \\
\hline Q62 & 34 & 34 & 323,0 & 0,669 & 4,500 \\
\hline
\end{tabular}

Comentários dos Especialistas:

o A possibilidade de enxergar gargalos é importante.

\section{Item 6.3 - Indicadores de Desempenho}
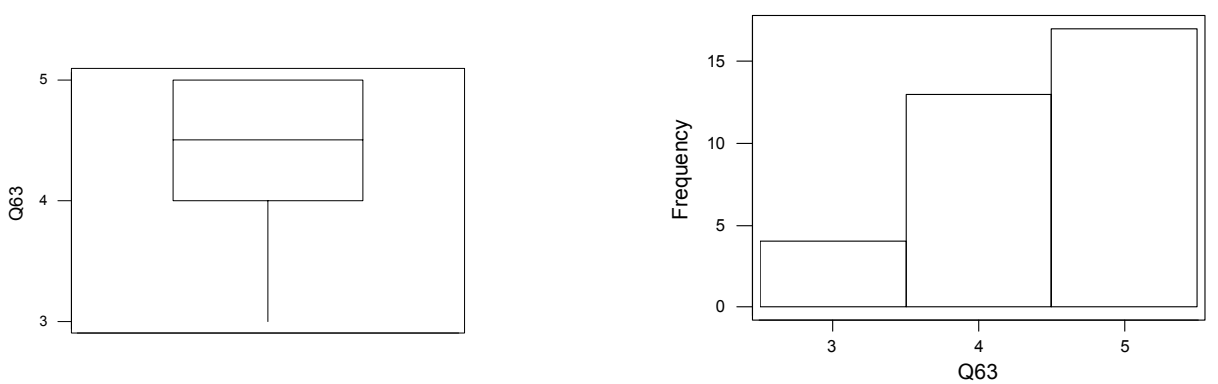

Wilcoxon Signed Rank Test: Q63

\begin{tabular}{|c|c|c|c|c|c|}
\hline & & $\mathrm{N}$ for & Wilcoxon & & timated \\
\hline & $\mathrm{N}$ & Test & Statistic & $\mathbf{P}$ & Median \\
\hline Q63 & 34 & 34 & 263,5 & 0,567 & 4,500 \\
\hline
\end{tabular}

Comentários dos Especialistas:

o é melhor restringir...

- Tanto os indicadores inerentes aos processos quanto aqueles criados por meio de formulários ou variáveis adicionais devem ser possíveis de registrar em um banco de dados.

o Considero isto como o painel que informa a velociada, RPM, indicadores de verificação em tempo real do nível de combustível, freio, temperatura etc. dos carros atuais. O que quero dizer é que com o tempo cockpit será um item obrigatório. Acredito que niguém hoje compraria um carro sem o painel!!! E, também, não paga mais por ter o painel!!! 


\section{Apêndice 6 Agrupamentos das Funcionalidades - Versão 1.Rodada}

Participaram desta $1^{\text {a }}$ rodada da Fase II (Agrupamento das Funcionalidades de uma Solução de BPM) 21 especialistas, cujas avaliações foram coletadas no período de 26/09/05 a 30/09/05. A tabulação dos dados foi realizada por meio do software MiniTab e, são apresentadas a seguir um resumo das estatísticas descritivas e, para cada funcionalidade um gráfico boxplot e um histograma.

a) Estatísticas Descritivas para cada Agrupamento avaliado:

\begin{tabular}{|lrrrrrr|}
\hline Variable & $\mathbf{N}$ & Mean & Median & TrMean & StDev & SE Mean \\
\hline M1 & 21 & 3,571 & $4,00 \odot$ & 3,632 & 1,165 & 0,254 \\
\hline M2 & 21 & 3,857 & $4,00 \odot$ & 3,895 & 1,062 & 0,232 \\
\hline M3 & 21 & 3,429 & $4,00 \odot$ & 3,421 & 1,028 & 0,224 \\
\hline M4 & 21 & 4,429 & $5,00 \odot$ & 4,474 & 0,676 & 0,148 \\
\hline M5 & 21 & 3,143 & $3,00 \odot$ & 3,105 & 1,014 & 0,221 \\
\hline M6 & 21 & 4,286 & $4,00 \odot$ & 4,368 & 0,845 & 0,184 \\
\hline
\end{tabular}


b) Avaliação individual de cada Macro-Funcionalidade apresentada:

Item 1 - Gerenciamento de Acesso

Matriz AHP apresentada:

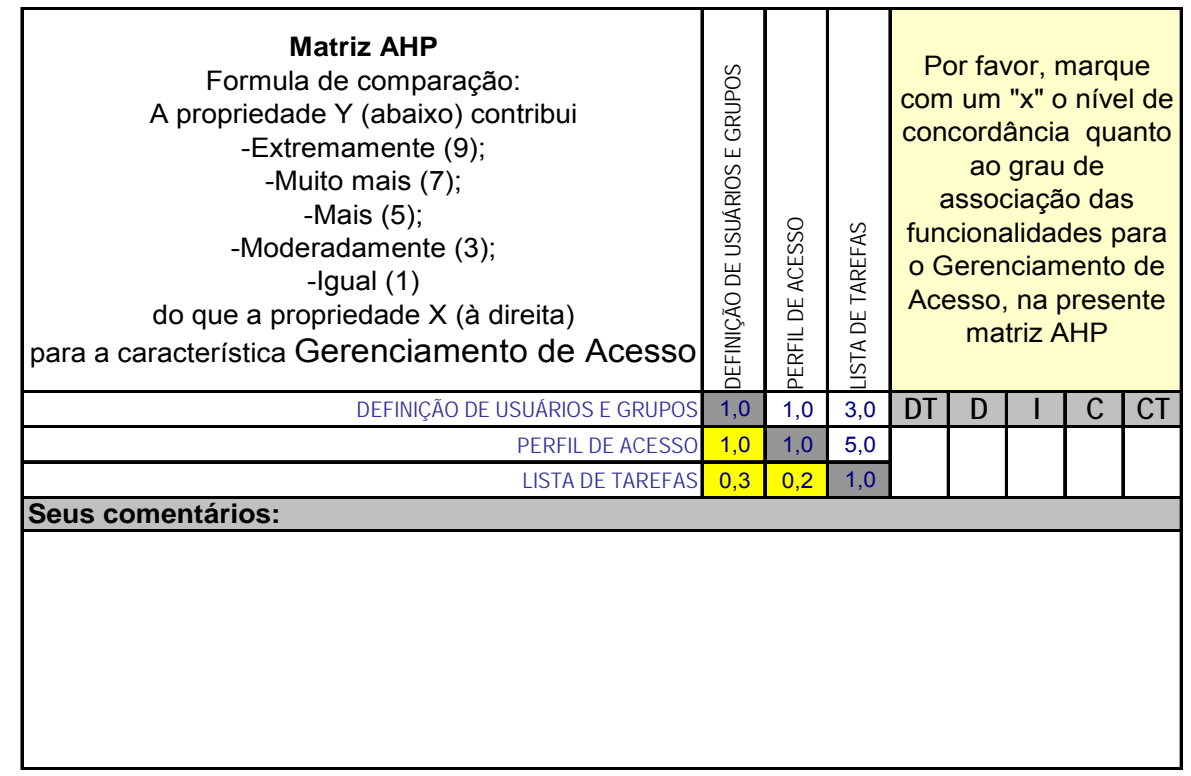

A Avaliação dos Especialistas:
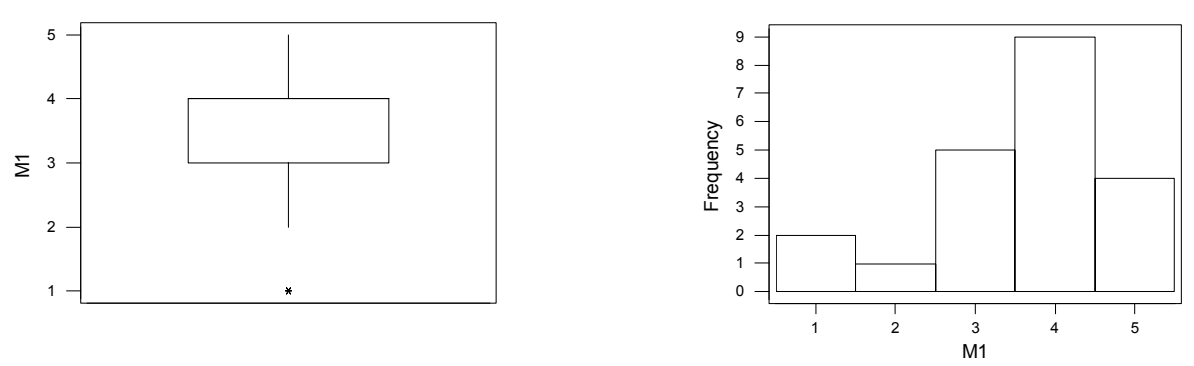

Wilcoxon Signed Rank Test: M1
Test of median $=3,950$ versus median not $=3,950$
M1 N Test Statistic $\mathbf{P}$ Median
$\begin{array}{llllll}\text { M1 } & 21 & 21 & 111,0 & \mathbf{0 , 8 8 9} & 3,500\end{array}$

Comentários dos Especialistas:

o Se entendi a Matriz, o Perfil de Acesso contribui muito mais do que todos os demais itens no gerenciamento de acesso, pois, no processo, de um lado temos as tarefas que podem ser agrupadas em diferentes combinações que o negócio necessita, formando os 
diferentes perfis. De outro lado, temos os usuários e grupos de usuários que recebem os perfis/tarefas necessárias para desempenhar suas atividades. Portanto, as propriedades de Perfil de Acesso e Lista de Tarefas contribuem muito mais do que a definição de Usuários e Grupos no Gerenciamento de Acesso.

o Entendo que aqui a definição de Perfil de Acesso está ligado com a definição de direitos sobre o uso de recursos, certo ?

\section{Item 2 - Desenho de Processos}

Matriz AHP apresentada:

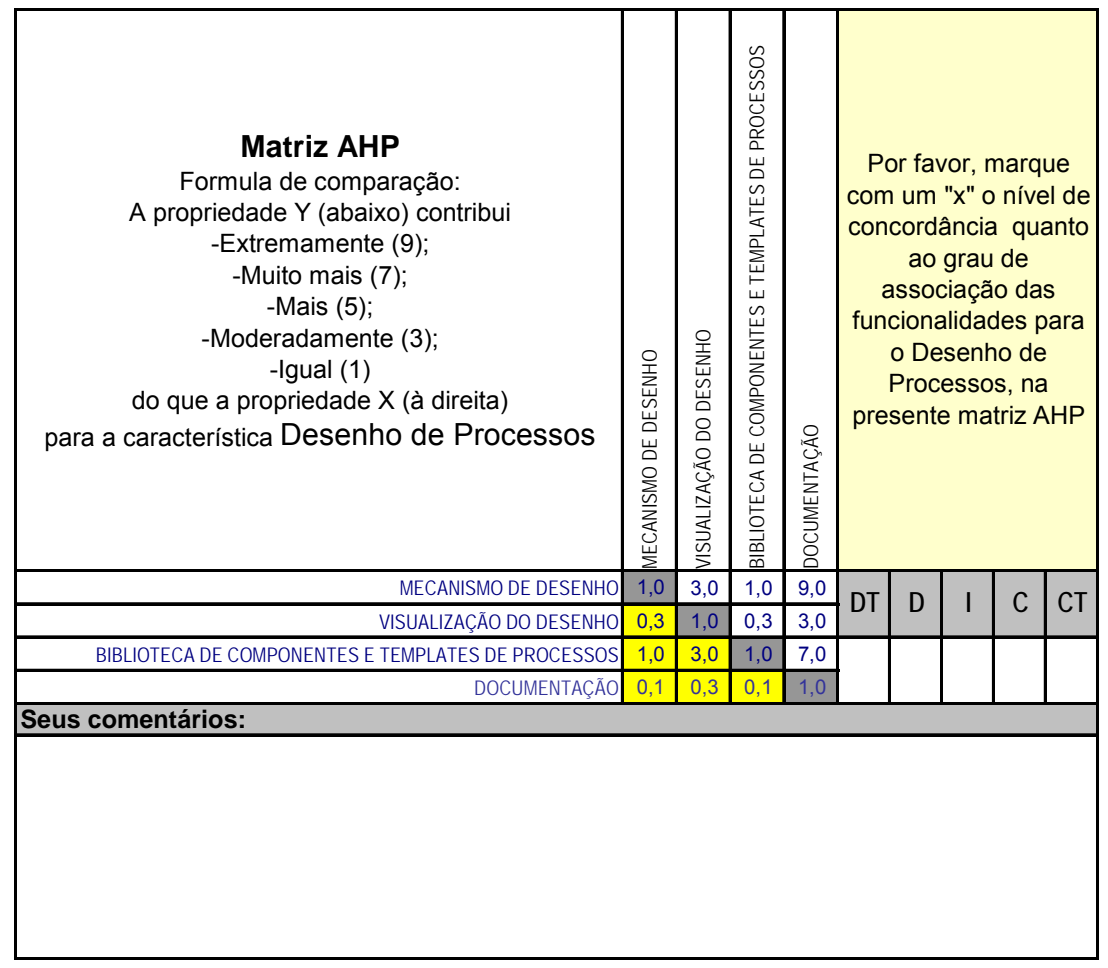

A Avaliação dos Especialistas:
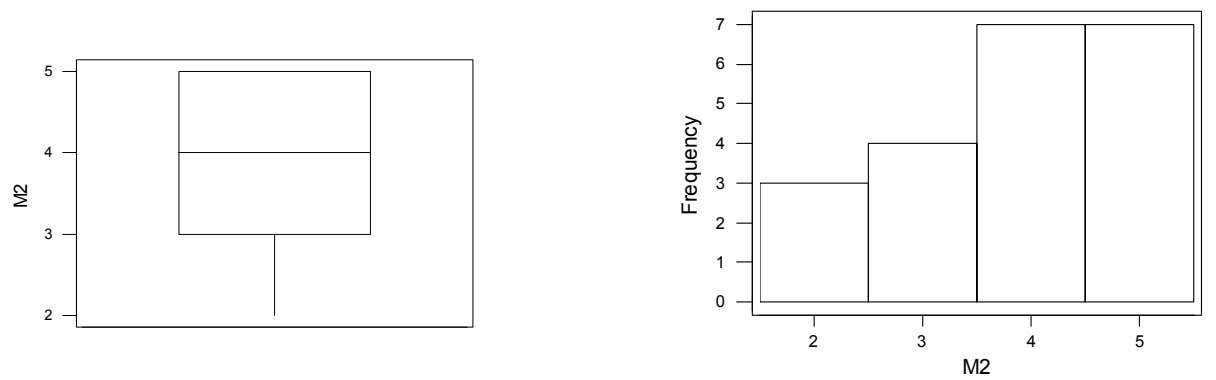
Wilcoxon Signed Rank Test: M2

\begin{tabular}{|c|c|c|c|c|c|}
\hline & & $N$ for & Wilcoxon & & timated \\
\hline & $\mathrm{N}$ & Test & Statistic & $\mathbf{P}$ & Median \\
\hline M2 & 21 & 21 & 133,0 & 0,555 & 4,000 \\
\hline
\end{tabular}

Comentários dos Especialistas:

o O mecanismo de desenho parece mais importante que a biblioteca.

- A propriedade de Visualização do Desenho contribui mais do que o Mecanismo e a Biblioteca, pois é o mesmo que dizer que no Word, o mecanismo e biblioteca contribuem mais do que a visualização na editoração de texto. No BPM, a Visualização do Desenho é fundamental, pois é o processo que você vai ter na operação, por mais simples ou complexo que seja.

\section{Item 3 - Regras do Negócio}

Matriz AHP apresentada:

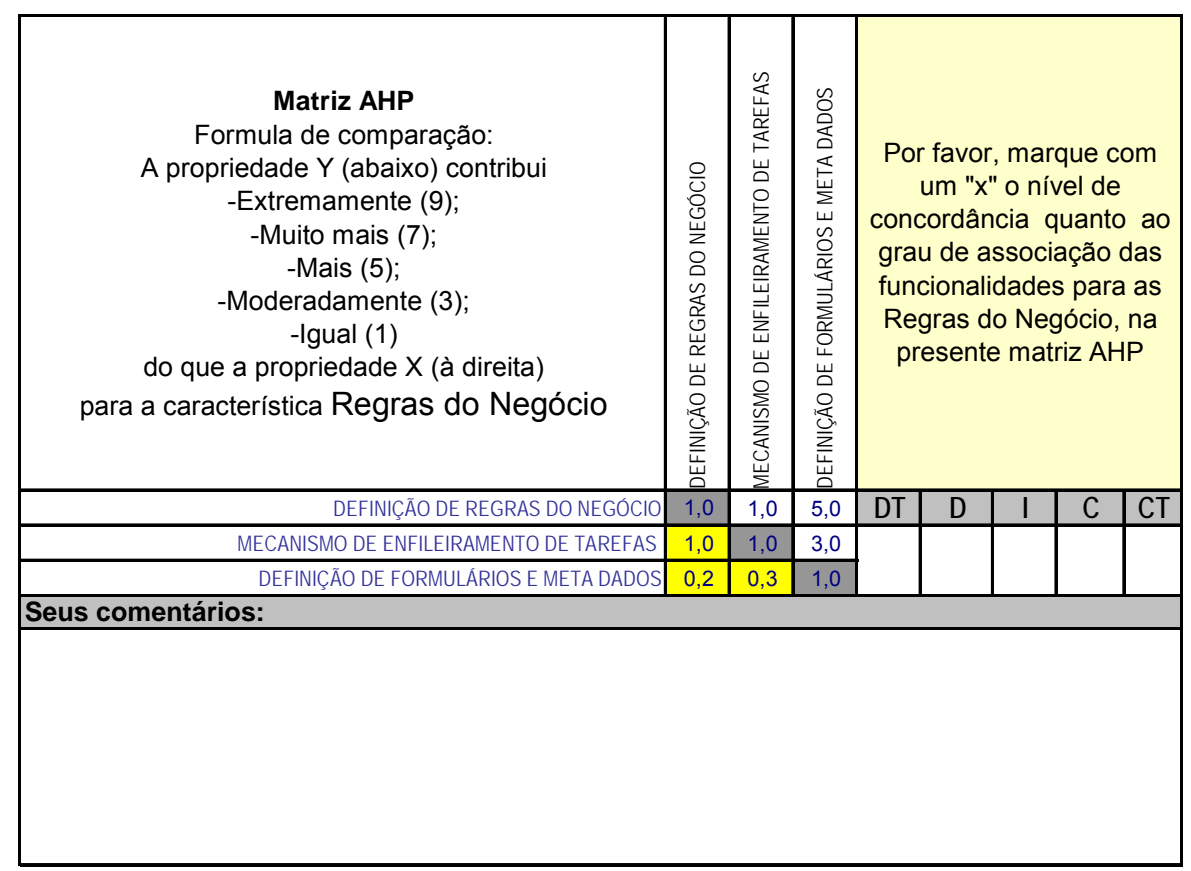


A Avaliação dos Especialistas:
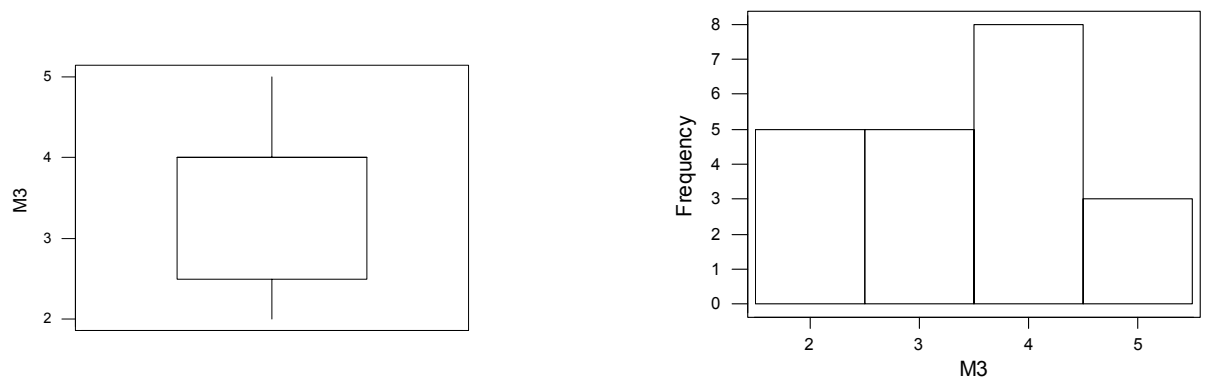

Wilcoxon Signed Rank Test: M3

$$
\begin{aligned}
& \text { Test of median }=3,500 \text { versus median not }=3,500 \\
& \mathrm{~N} \text { for Wilcoxon } \\
& N \text { Test Statistic } \\
& \text { M3 } \\
& 2121 \quad 108,5 \\
& \text { P Median }
\end{aligned}
$$

Comentários dos Especialistas:

o A definicao de regras de negocio é mais importante que o enfileiramento de tarefas.

- Muitas vezes, deixa-se default o enfileiramento de tarefas. O enfileiramento seria para mim a última prioridade.

\section{Item 4 - Integração}

Matriz AHP apresentada:

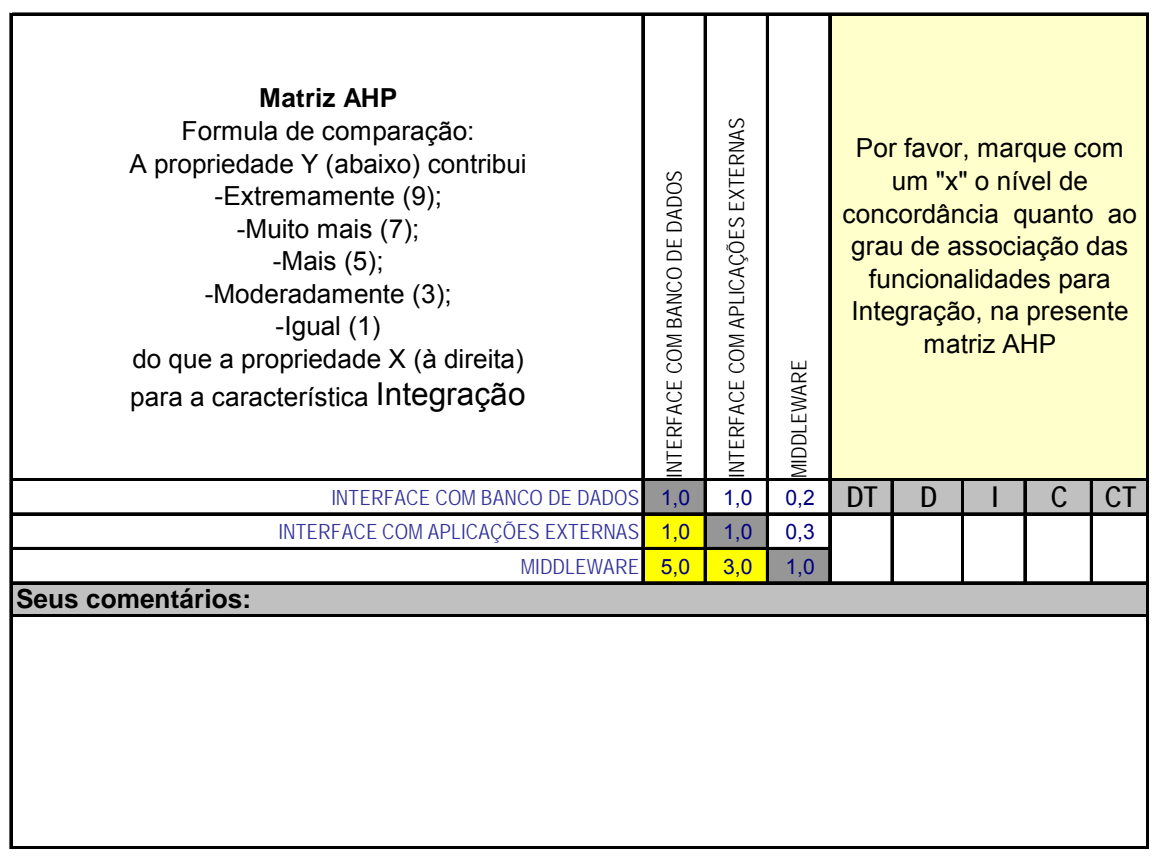


A Avaliação dos Especialistas:
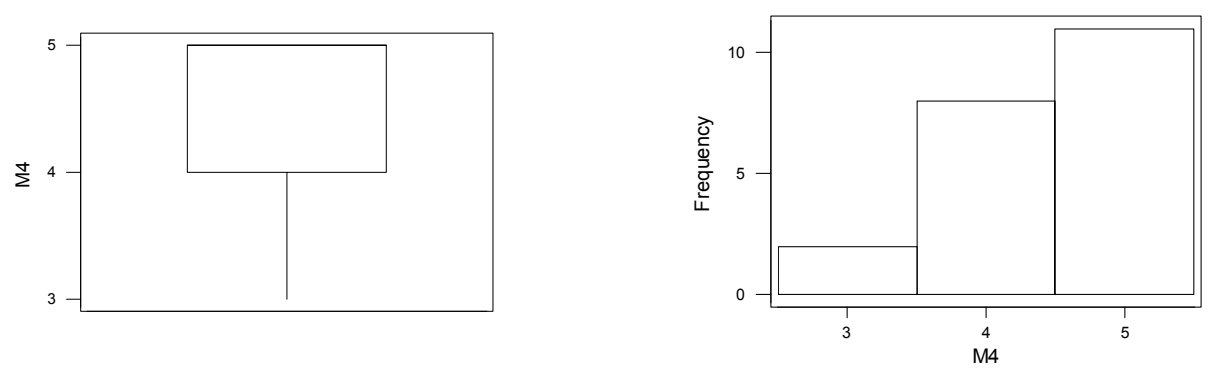

Wilcoxon Signed Rank Test: M4

$$
\begin{aligned}
& \text { Test of median }=4,500 \text { versus median not }=4,500 \\
& \\
& \begin{array}{rrrrr}
\text { N for } & \text { Wilcoxon } & \text { Estimated } \\
\text { M4 } & \text { Test } & \text { Statistic } & \text { P } & \text { Median } \\
21 & 21 & 110,0 & \mathbf{0 , 8 6 2} & 4,500
\end{array}
\end{aligned}
$$

Comentários dos Especialistas:

- A interface com aplicações externas é mais complexa que com banco de dados. Além da dificuldade com os fornecedores do componente.

\section{Item 5 - Mecanismo de Execução}

Matriz AHP apresentada:

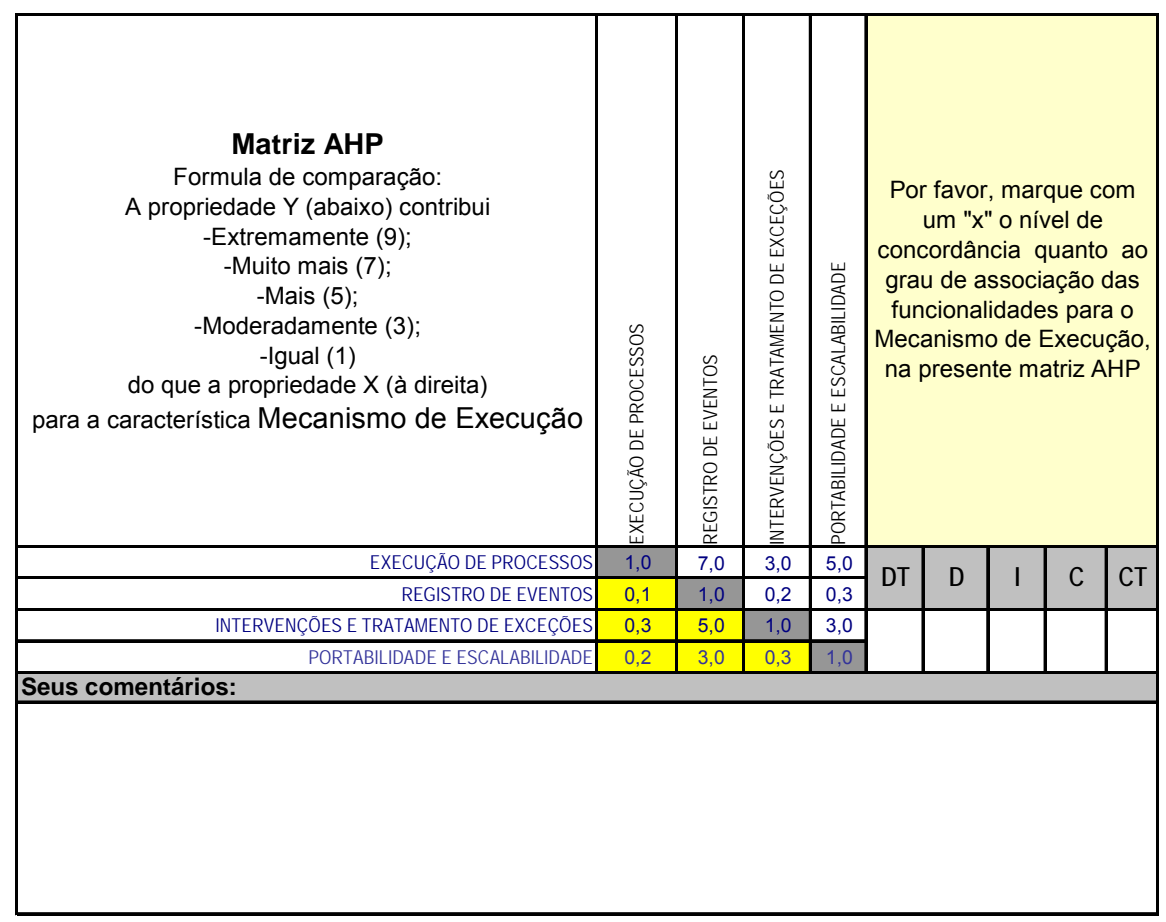


A Avaliação dos Especialistas:
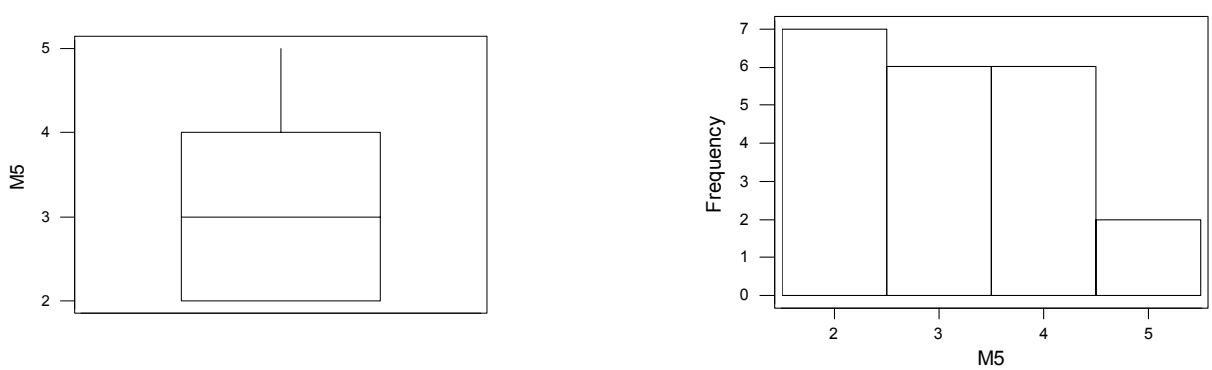

Wilcoxon Signed Rank Test: M5

$$
\begin{aligned}
& \text { Test of median }=3,000 \text { versus median not }=3,000
\end{aligned}
$$

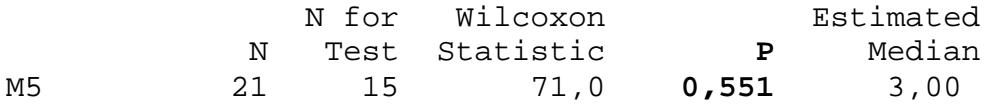

Comentários dos Especialistas:

- Dependendo do cliente a portabilidade e escalabilidade, assim como o registro de eventos podem ser mais importantes. Ou seja, dependerá das características e/ou necessidade do negócio.

o Considerando-se o objetivo da macro funcionalidade Execucao podemos dizer que registro e portabilidade são os menos relevantes.

o Registro de Evento é uma funcionalidade básica. Isto é, toda solução BPM deve possuir.

o Não acho que a propriedade Intervenções e Tratamento de Exceções contribua mais do que a propriedade registro de eventos. Também não concordo que a propriedade tratamento de exceção contribui muito mais que a propriedade registro de eventos.

o Não entendi o porquê a propriedade de Intervenções e Tratamento de Exceções ter mais peso do que o Registro de Eventos e Escalabilidade no mecanismo de execução. Conceitualmente, um processo dever ser algo conhecido, repetitivo e deve ganhar escalabilidade. Caso contrário, analisar melhor a relação custo $\mathrm{x}$ benefício de implementar BPM. 


\section{Item 6 - Monitoramento}

Matriz AHP apresentada:

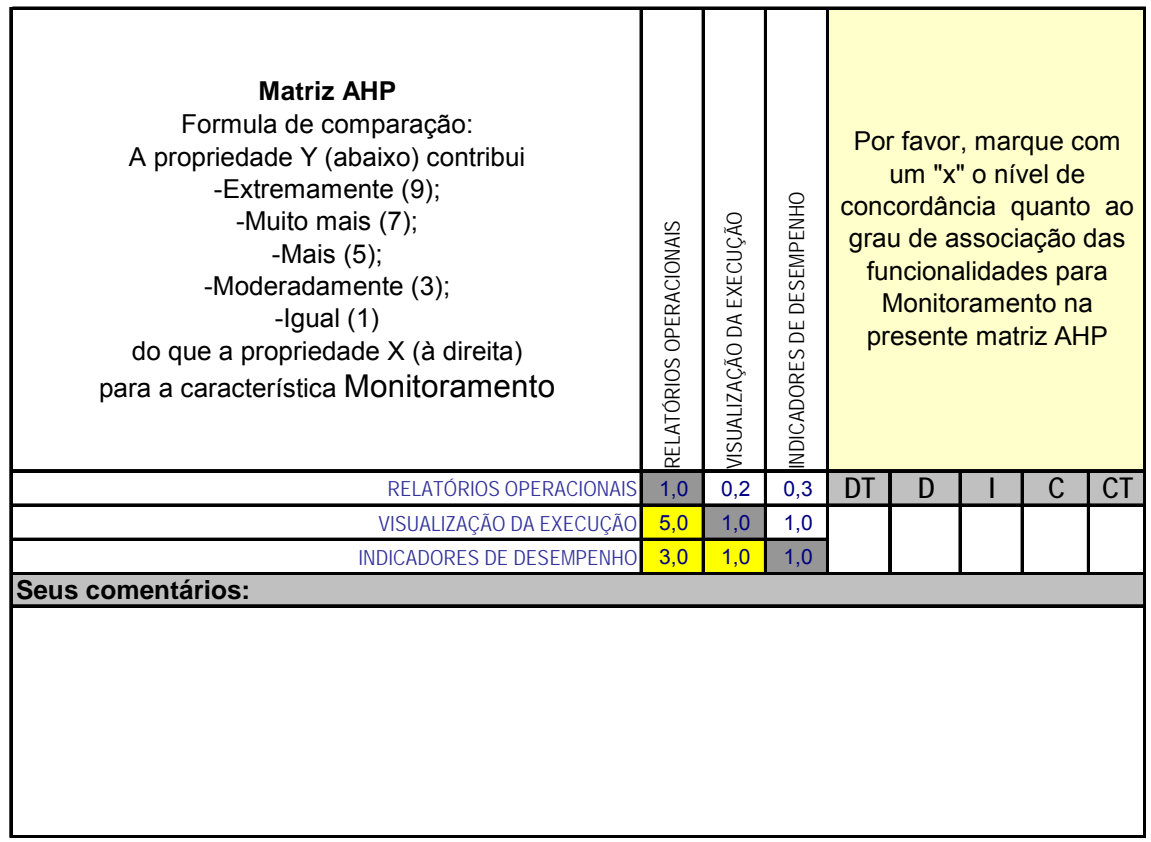

A Avaliação dos Especialistas:
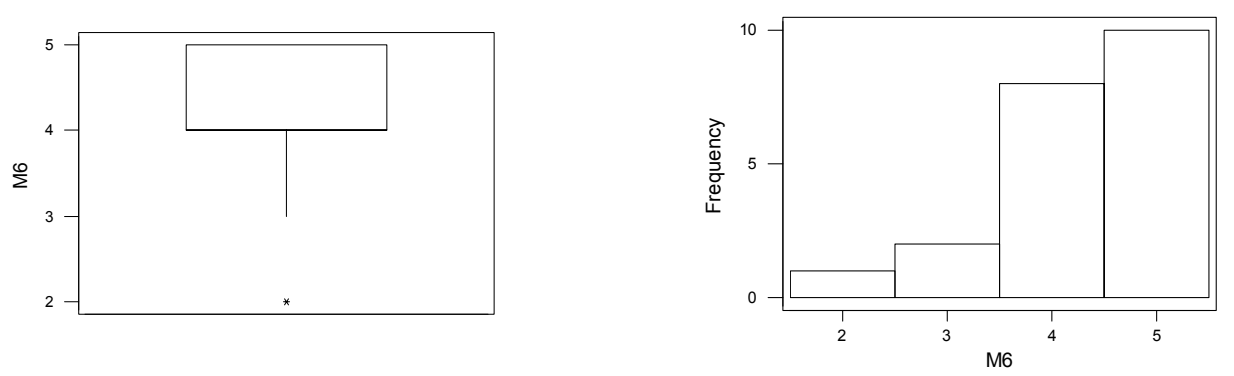

Wilcoxon Signed Rank Test: M6

$$
\begin{aligned}
& \text { Test of median }=4,450 \text { versus median not }=4,450 \\
& \mathrm{~N} \text { for Wilcoxon } \\
& \text { Test Statistic } \\
& \text { M6 } \\
& 21 \quad 21 \quad 135,0 \\
& \begin{array}{rr}
\mathbf{P} & \text { Estimated } \\
\mathbf{0 , 5 0 9} & \text { Median } \\
& 4,500
\end{array}
\end{aligned}
$$

Comentários dos Especialistas:

- Visualizar parece muito interessante. Será que nao estamos valorizando demais?

o Acho que as prioridades variam de negócio a negócio. 
- Apenas deixo a observação que acho que a propriedade de indicadores de desempenho deveria ser 5 em relação a relatórios operacionais. 


\section{Apêndice 6 Agrupamentos das Funcionalidades - Versão 2.Rodada}

Participaram desta $2^{\mathrm{a}}$ rodada da Fase II (Agrupamento das Funcionalidades de uma Solução de BPM) 21 especialistas, cujas avaliações foram coletadas no período de 15/10/05 a 21/10/05. A tabulação dos dados foi realizada por meio do software MiniTab e, são apresentadas a seguir um resumo das estatísticas descritivas e, para cada funcionalidade um gráfico boxplot e um histograma. Como não obtivemos uma convergência adequada para alguns agrupamentos na primeira rodada, foi realizado mais esta rodada com a apresentação dos agrupamentos para os especialistas sob a forma de lista ponderada com os pesos relativos em valores percentuais para cada funcionalidade, resultado das considerações da primeira rodada e aplicação da matriz AHP.

\section{a) Estatísticas Descritivas para cada Agrupamento avaliado:}

\begin{tabular}{|c|c|c|c|c|c|c|}
\hline Variable & $\overline{\mathrm{N}}$ & $\overline{M e a n}$ & Median & TrMean & StDev & SE Mean \\
\hline$\overline{M 1}$ & 21 & 4,381 & 4,000 & 4,368 & 0,498 & 0,109 \\
\hline M2 & 21 & 3,619 & $4,0 \odot \odot$ & 3,632 & 1,203 & 0,263 \\
\hline M3 & 21 & 4,476 & 4,000 & 4,474 & 0,512 & 0,112 \\
\hline M4 & 21 & 4,476 & 5,000 & 4,579 & 0,814 & 0,178 \\
\hline M5 & 21 & 4,381 & 4,000 & 4,421 & 0,590 & 0,129 \\
\hline M6 & 21 & 4,333 & 4,000 & 4,421 & 0,796 & 0,174 \\
\hline
\end{tabular}


b) Avaliação individual de cada Macro-Funcionalidade apresentada:

\section{Item 1 - Gerenciamento de Acesso}

Lista apresentada:

1. Gerenciamento de Acesso

\begin{tabular}{|c|c|c|c|c|c|c|}
\hline Ordem & Peso & DT & D & I & C & CT \\
\hline 1 & $63 \%$ & & & & & \\
\hline 2 & $26 \%$ & & & & & \\
\hline 3 & $11 \%$ & & & & & \\
\hline
\end{tabular}

Avaliação dos Especialistas:
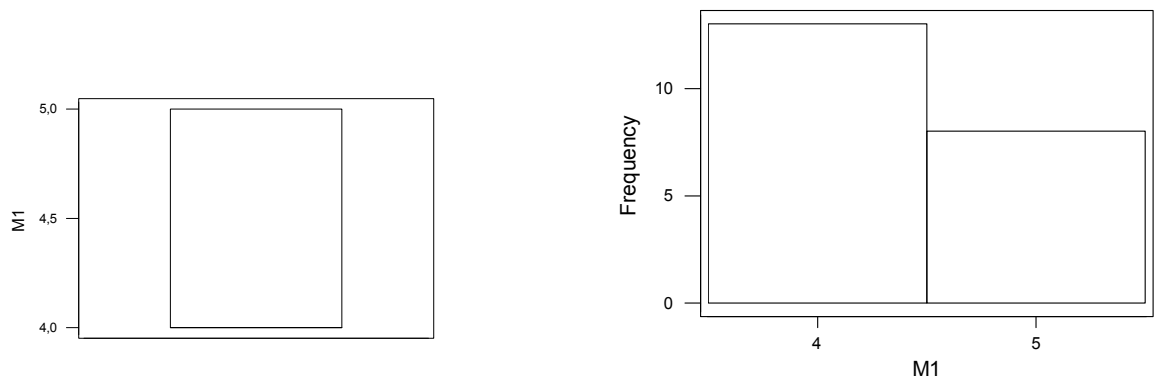

Wilcoxon Signed Rank Test: M1

\begin{tabular}{|c|c|c|c|c|c|}
\hline & & $\mathrm{N}$ for & Wilcoxon & & Estimated \\
\hline & $\mathrm{N}$ & Test & Statistic & $\mathbf{P}$ & Median \\
\hline M1 & 21 & 21 & 140,0 & 0,404 & 4,500 \\
\hline
\end{tabular}

\section{Item 2 - Desenho de Processos}

Lista apresentada:

2. Desenho de Processos

MECANISMO DE DESENHO VISUALIZAÇÃO DO DESENHO BIBLIOTECA DE COMPONENTES E TEMPLATES DE PROCESSOS DOCUMENTAÇÃO

$\begin{array}{cc}\text { Ordem } & \text { Peso } \\ 1 & 52 \% \\ 2 & 27 \% \\ 3 & 16 \% \\ 4 & 5 \%\end{array}$

\begin{tabular}{|l|l|l|l|l|}
\hline DT & D & I & C & CT \\
\hline & & & & \\
& & & & \\
& & & & \\
\hline
\end{tabular}


Avaliação dos Especialistas:
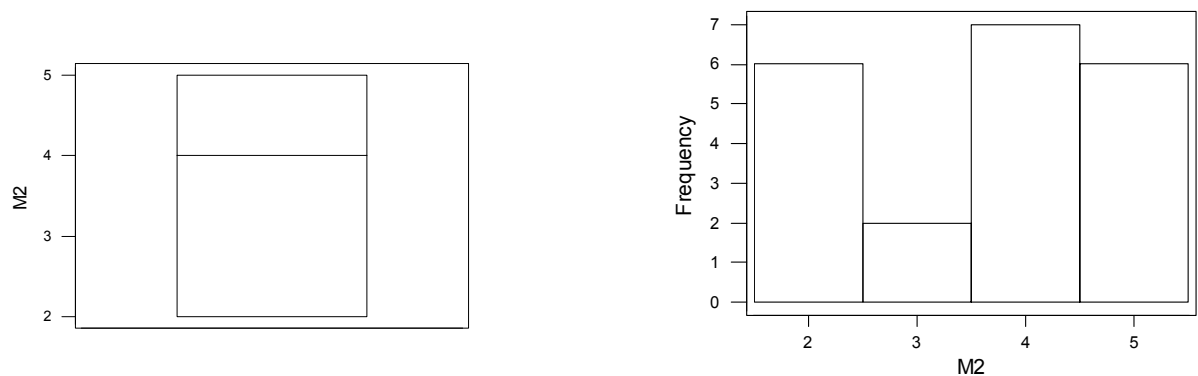

Wilcoxon Signed Rank Test: M2

$$
\begin{aligned}
& \text { Test of median }=3,950 \text { versus median not }=3,950 \\
& \\
& \begin{array}{rrrrr}
\text { N for } & \text { Wilcoxon } & \text { Estimated } \\
\text { M2 } & \text { Test } & \text { Statistic } & \text { Median } \\
21 & 21 & 103,0 & \mathbf{0 , 6 7 7} & 3,500
\end{array}
\end{aligned}
$$

Comentários dos Especialistas:

- O mecanismo de desenho parece mais importante que a biblioteca.

- A propriedade de Visualização do Desenho contribui mais do que o Mecanismo e a Biblioteca, pois é o mesmo que dizer que no Word, o mecanismo e biblioteca contribuem mais do que a visualização na editoração de texto. No BPM, a Visualização do Desenho é fundamental, pois é o processo que você vai ter na operação, por mais simples ou complexo que seja.

\section{Item 3 - Regras do Negócio}

Lista apresentada:

3. Regras do Negócio

DEFINIÇÃO DE REGRAS DO NEGÓCIO DEFINIÇÃO DE FORMULÁRIOS E META DADOS MECANISMO DE ENFILEIRAMENTO DE TAREFAS
Ordem Peso

$163 \%$

$226 \%$

$311 \%$

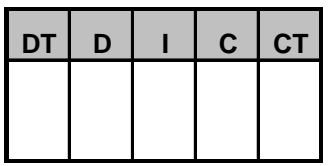


Avaliação dos Especialistas:
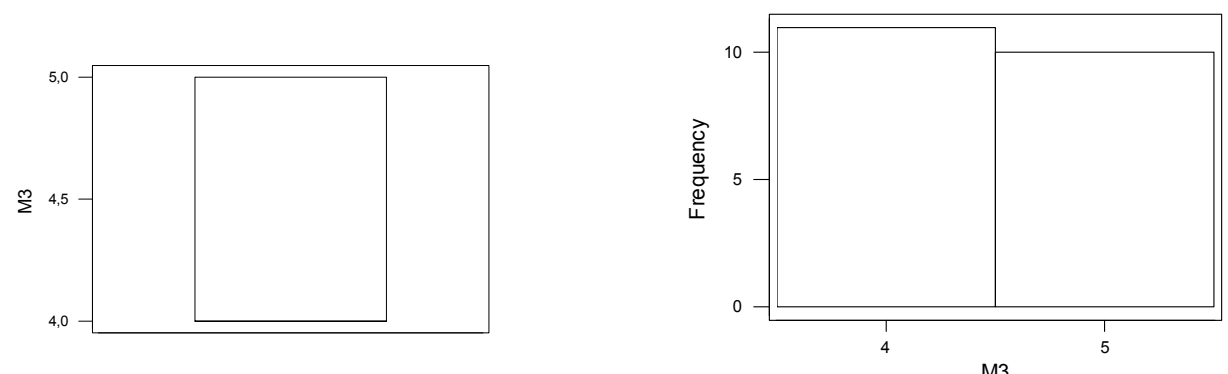

Wilcoxon Signed Rank Test: M3

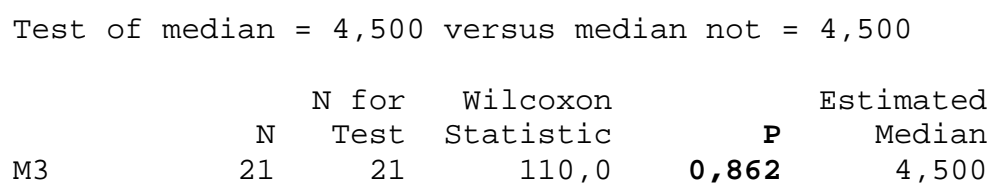

Comentários dos Especialistas:

o A definicao de regras de negocio é mais importante que o enfileiramento de tarefas.

o Muitas vezes, deixa-se default o enfileiramento de tarefas. O enfileiramento seria para mim a última prioridade.

\section{Item 4 - Integração}

Lista apresentada:

4. Integração

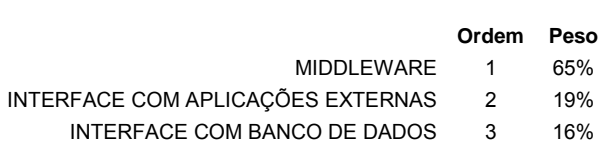

\begin{tabular}{|l|l|l|l|l|}
\hline DT & D & I & C & CT \\
\hline & & & & \\
& & & & \\
\hline
\end{tabular}

Avaliação dos Especialistas:
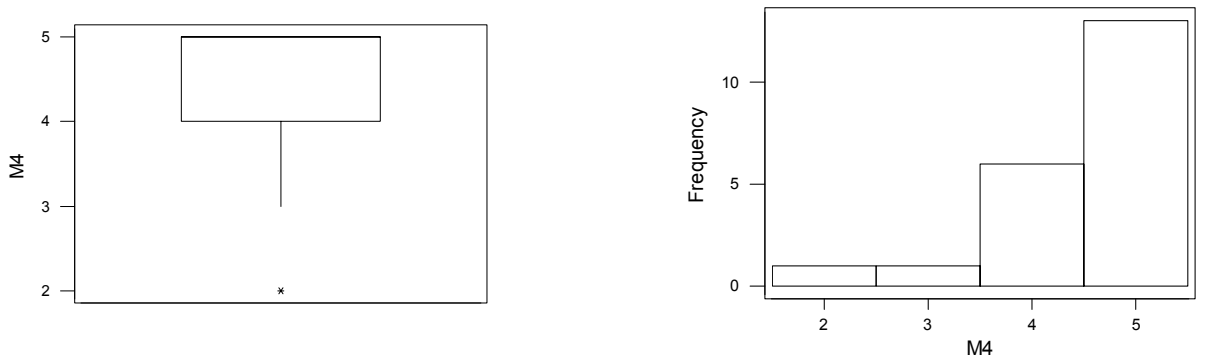

Wilcoxon Signed Rank Test: M4

Test of median $=4,500$ versus median not $=4,500$ 


$\begin{array}{rrrrrr} & & \text { N for } & \text { Wilcoxon } & & \text { Estimated } \\ \text { M4 } & \text { Test } & \text { Statistic } & \mathbf{P} & \text { Median } \\ & 21 & 21 & 130,0 & \mathbf{0 , 6 2 7} & 4,500\end{array}$

Comentários dos Especialistas:

- A interface com aplicações externas é mais complexa que com banco de dados. Além da dificuldade com os fornecedores do componente.

\section{Item 5 - Mecanismo de Execução}

Lista apresentada:

5. Mecanismo de Execução

$\begin{array}{cc}\text { Ordem } & \text { Peso } \\ 1 & 52 \% \\ 2 & 20 \% \\ 3 & 20 \% \\ 4 & 8 \%\end{array}$

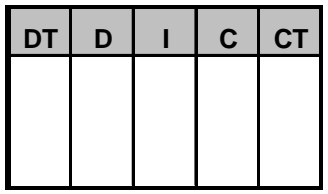

Avaliação dos Especialistas:
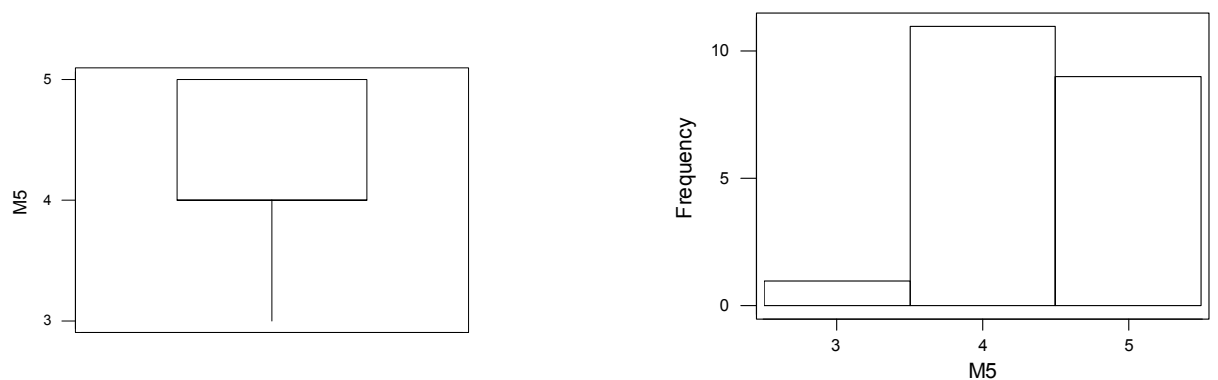

Wilcoxon Signed Rank Test: M5

$$
\begin{aligned}
& \text { Test of median }=4,500 \text { versus median not }=4,500
\end{aligned}
$$

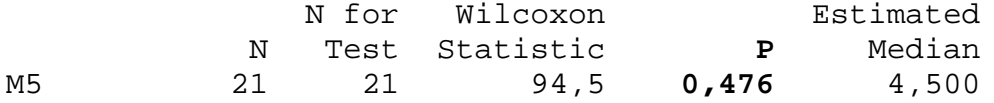

Comentários dos Especialistas:

o Dependendo do cliente a portabilidade e escalabilidade, assim como o registro de eventos podem ser mais importantes. Ou seja, dependerá das características e/ou necessidade do negócio.

o Considerando-se o objetivo da macro funcionalidade Execucao podemos dizer que registro e portabilidade são os menos relevantes.

o Registro de Evento é uma funcionalidade básica. Isto é, toda solução BPM deve possuir. 
o Não acho que a propriedade Intervenções e Tratamento de Exceções contribua mais do que a propriedade registro de eventos. Também não concordo que a propriedade tratamento de exceção contribui muito mais que a propriedade registro de eventos.

o Não entendi o porquê a propriedade de Intervenções e Tratamento de Exceções ter mais peso do que o Registro de Eventos e Escalabilidade no mecanismo de execução. Conceitualmente, um processo dever ser algo conhecido, repetitivo e deve ganhar escalabilidade. Caso contrário, analisar melhor a relação custo $\mathrm{x}$ benefício de implementar BPM.

\section{Item 6 - Monitoramento}

Lista apresentada:

6. Monitoramento
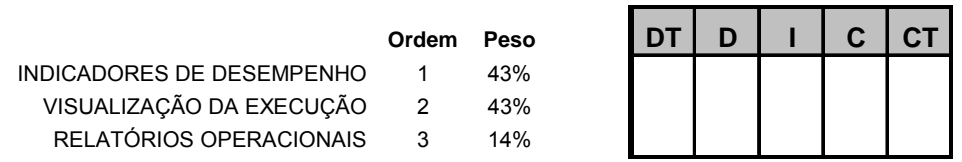

Avaliação dos Especialistas:
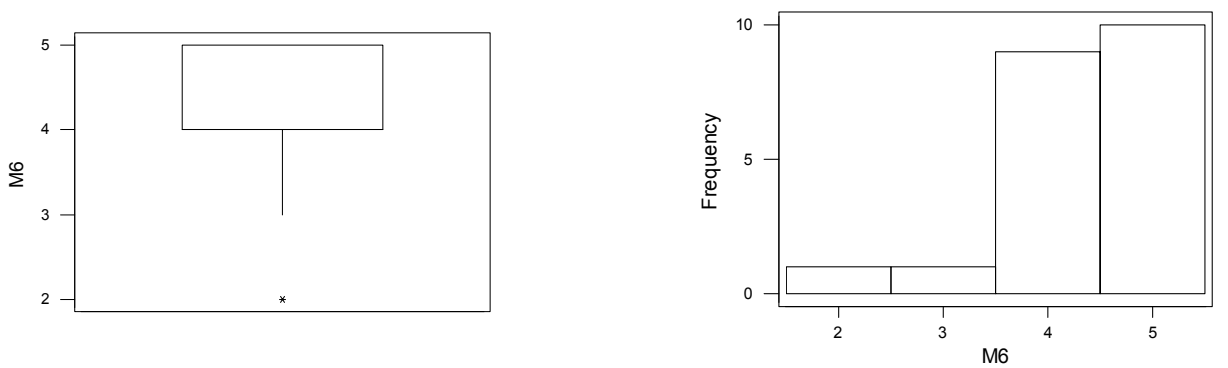

Wilcoxon Signed Rank Test: M6

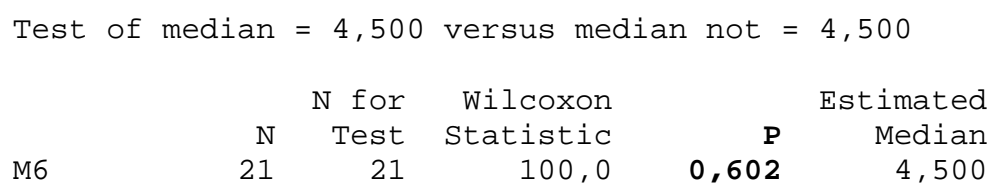

Comentários dos Especialistas:

o Visualizar parece muito interessante. Será que nao estamos valorizando demais?

- Acho que as prioridades variam de negócio a negócio.

- Apenas deixo a observação que acho que a propriedade de indicadores de desempenho deveria ser 5 em relação a relatórios operacionais. 


\section{Apêndice 6 Agrupamentos das Funcionalidades - Versão 3.Rodada}

Participaram desta $3^{a}$ rodada da Fase II (Agrupamento das Funcionalidades de uma Solução de BPM) 18 especialistas, cujas avaliações foram coletadas no período de 22/10/05 a 29/10/05. A tabulação dos dados foi realizada por meio do software MiniTab e, são apresentadas a seguir um resumo das estatísticas descritivas e, para cada funcionalidade um gráfico boxplot e um histograma. Como não obtivemos uma convergência adequada para o agrupamento do item 2 - Desenho de Processos, foi realizado mais esta rodada com a apresentação do respectivo agrupamento para os especialistas sob a forma de lista ponderada com os pesos relativos em valores percentuais para cada funcionalidade, resultado das considerações da rodadas anteriores e aplicação da matriz AHP.

a) Estatísticas Descritivas para o Agrupamento avaliado:

Descriptive Statistics: M2

\begin{tabular}{lrrrrrr}
\hline Variable & $\mathrm{N}$ & Mean & Median & TrMean & StDev & SE Mean \\
\hline M2 & 18 & 4,333 & 4,000 & 4,313 & 0,485 & 0,114 \\
\hline
\end{tabular}

b) Avaliação da Macro-Funcionalidade apresentada:

Item 2 - Desenho de Processos

Lista apresentada:
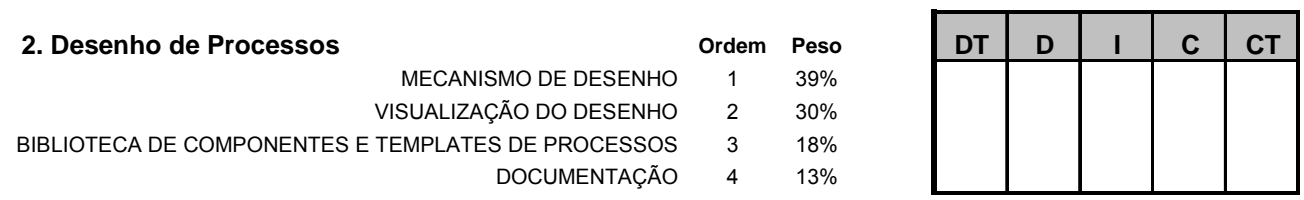

Bibliografia 
Avaliação dos Especialistas:
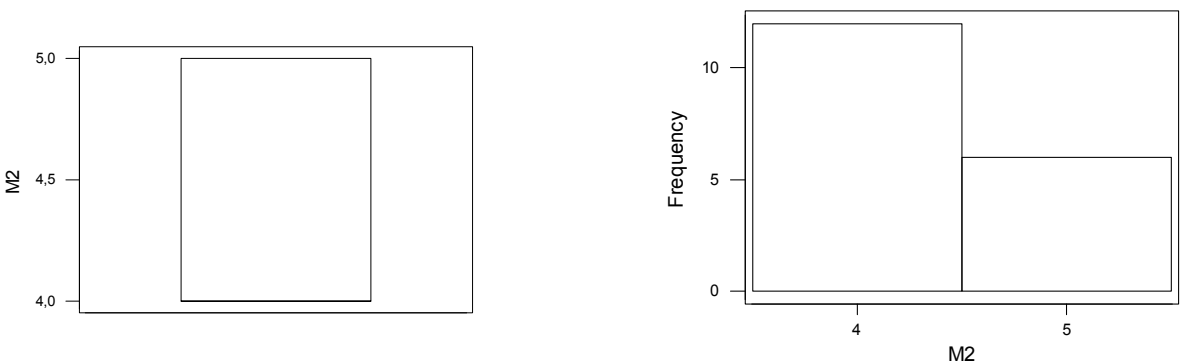

Wilcoxon Signed Rank Test: M2

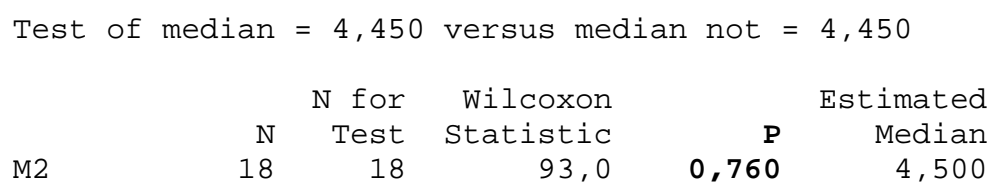




\section{Apêndice 7 \\ Macro-Funcionalidades X Objetivos de Desempenho - 1. Rodada}

Participaram desta Fase III - Primeira Rodada (Agrupamento das Funcionalidades de uma Solução BPM versus Objetivos de Desempenho) 14 especialistas, cujas avaliações foram coletadas no período de 12/11/05 a 05/12/05. A tabulação dos dados foi realizada por meio do software MiniTab e, são apresentadas a seguir um resumo das estatísticas descritivas e, para cada funcionalidade um gráfico boxplot e um histograma. A partir das sugestões de ordem de contribuição dadas pelos especialistas foram obtidas novas sequências com o uso da técnica de grupo nominal.

b) Estatísticas Descritivas para cada Agrupamento avaliado:

\begin{tabular}{|lrrrrrr|}
\hline Variable & $\mathrm{N}$ & Mean & Median & TrMean & \multicolumn{1}{c|}{ StDev } & SE Mean \\
\hline Qualidade & 14 & 3,286 & $3,50 \odot$ & 3,333 & 1,326 & 0,354 \\
\hline Custo & 14 & 3,071 & $3,00 \odot$ & 3,083 & 1,141 & 0,305 \\
\hline Velocidade & 14 & 3,143 & $3,00 \odot$ & 3,167 & 1,406 & 0,376 \\
\hline Flexibilidade & 14 & 3,714 & $4,00 \odot$ & 3,833 & 1,267 & 0,339 \\
\hline Confiabilidade & 14 & 3,429 & $3,50 \odot$ & $3,50 \odot$ & 1,342 & 0,359 \\
\hline
\end{tabular}

c) Avaliação de cada Agrupamento apresentado:

Objetivo: Qualidade

CONTRIBUIÇÃO PARA A QUALIDADE DO
PROCESSO DE NEGÓCIO
GERENCIAMENTO DE ACESSO
DESENHO DE PROCESSOS
DEFINIÇÃO DE REGRAS DO NEGÓCIO
INTEGRAÇÃO
MECANISMO DE EXECUÇÃO
MONITORAMENTO

\begin{tabular}{|c|c|c|c|c|c|c|}
\hline ORDEM & DT & D & I & C & CT & SEU COMENTÁRIO \\
6 & & & & & & \\
3 & & & & & & \\
4 & & & & & & \\
5 & & & & & & \\
1 & & & & & & \\
2 & & & & & & \\
\cline { 2 - 6 }
\end{tabular}
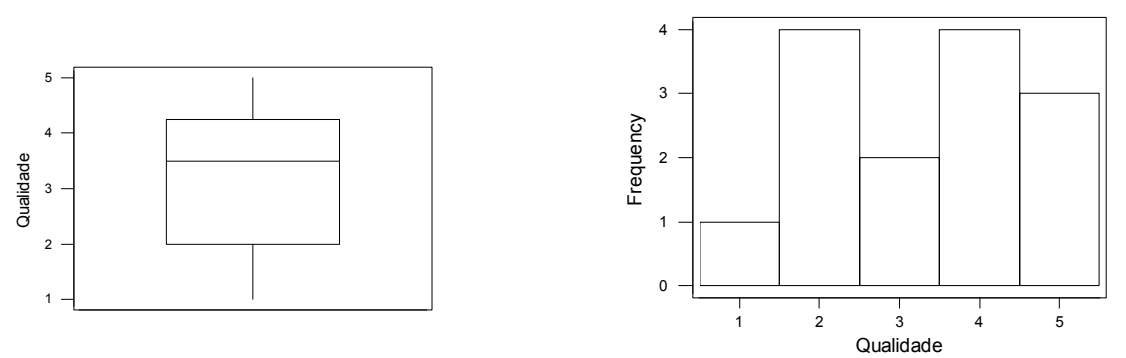

Bibliografia 
Wilcoxon Signed Rank Test: Qualidade

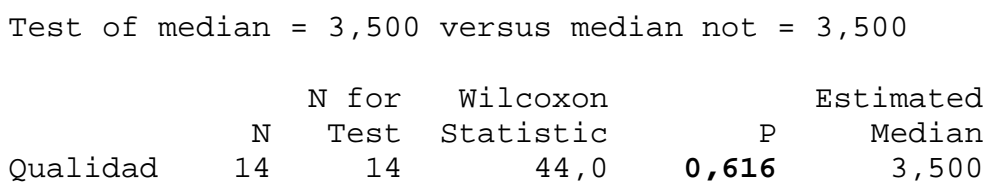

Nova Ordem obtida pela Técnica de Grupo Nominal das sugestões efetuadas:

\begin{tabular}{|l|c|c|c|c|c|c|c|c|c|c|c|c|c|c|c|c|}
\hline $\begin{array}{c}\text { CONTRIBUIÇÃO PARA A QUALIDADE DO } \\
\text { PROCESSO DE NEGÓCIO }\end{array}$ & $\mathbf{R} 1$ & $\mathbf{R 2}$ & $\mathbf{R} 3$ & $\mathbf{R} 4$ & $\mathbf{R 5}$ & $\mathbf{R 6}$ & $\mathbf{R 7}$ & $\mathbf{R 8}$ & $\mathbf{R 9}$ & $\mathbf{R} 10$ & $\mathbf{R} 11$ & $\mathbf{R} 12$ & $\mathbf{R 1 3}$ & $\mathbf{R} 14$ & TNG \\
\hline GERENCIAMENTO DE ACESSO & 3 & & 6 & & 6 & 6 & 6 & 6 & 6 & 5 & 6 & 6 & 6 & 6 & $\mathbf{6}$ \\
\hline DESENHO DE PROCESSOS & 4 & & 1 & 1 & 1 & 2 & 1 & 3 & 1 & 1 & 3 & 1 & 3 & 1 & $\mathbf{1}$ \\
\hline DEFINIÇÃO DE REGRAS DO NEGÓCIO & 5 & & 4 & & 2 & 3 & 2 & 4 & 2 & 2 & 4 & 4 & 4 & 2 & $\mathbf{4}$ \\
\hline INTEGRAÇÃO & 6 & & 5 & & 5 & 4 & 5 & 5 & 5 & 4 & 5 & 5 & 5 & 5 & $\mathbf{5}$ \\
\hline MECANISMO DE EXECUÇÃO & 1 & & 2 & & 3 & 1 & 3 & 1 & 3 & 3 & 2 & 2 & 1 & 3 & $\mathbf{2}$ \\
\hline MONITORAMENTO & 2 & 1 & 3 & & 4 & 5 & 4 & 2 & 4 & 6 & 1 & 3 & 2 & 4 & $\mathbf{3}$ \\
\hline
\end{tabular}

\section{Objetivo: Redução de Custo}

\footnotetext{
CONTRIBUIÇÃO PARA A REDUÇÃO DE CUSTO DO PROCESSO DE NEGÓCIO GERENCIAMENTO DE ACESSO

DESENHO DE PROCESSOS

DEFINIÇÃO DE REGRAS DO NEGÓCIO

INTEGRAÇÃO

MECANISMO DE EXECUÇÃO

MONITORAMENTO
}
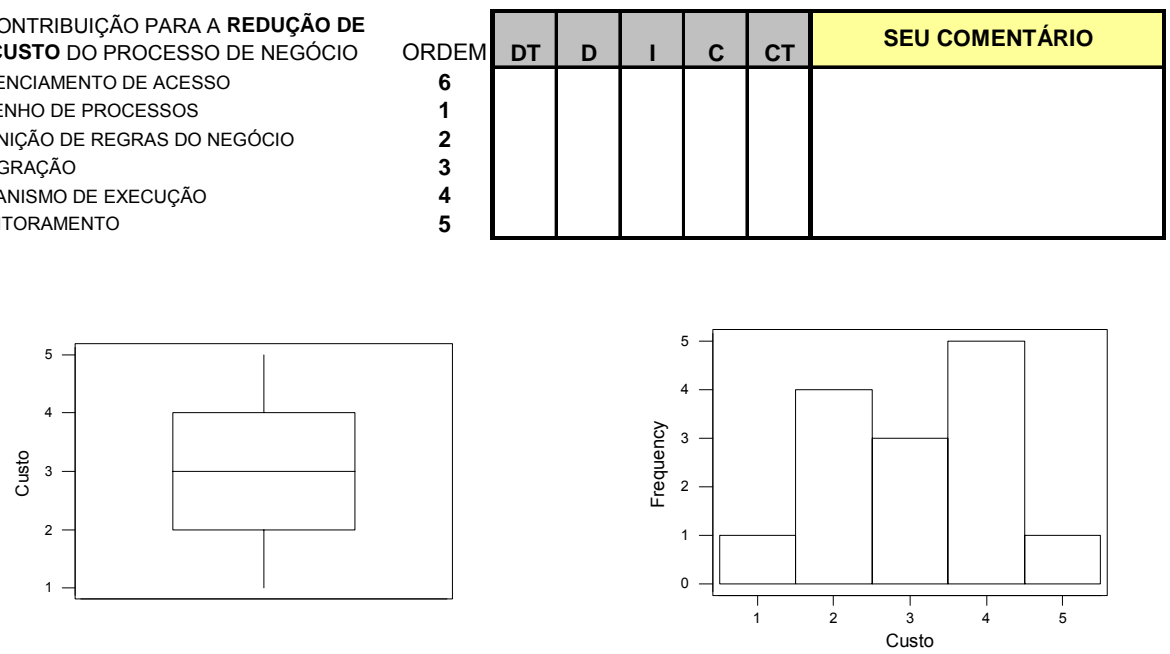

Wilcoxon Signed Rank Test: Custo

\begin{tabular}{|c|c|c|c|c|c|}
\hline & & $\mathrm{N}$ for & Wilcoxon & & timate \\
\hline & $\mathrm{N}$ & Test & Statistic & $\mathrm{P}$ & Media \\
\hline Custo & 14 & 11 & 35,5 & 0,859 & 3,0 \\
\hline
\end{tabular}


Nova Ordem obtida pela Técnica Nominal de Grupo das sugestões efetuadas:

\begin{tabular}{|l|c|c|c|c|c|c|c|c|c|c|c|c|c|c|c|}
\hline $\begin{array}{c}\text { CONTRIBUIÇÃO PARA A REDUÇÃO DE } \\
\text { CUSTO DO PROCESSO DE NEGÓCIO }\end{array}$ & $\mathbf{R} 1$ & $\mathbf{R} 2$ & $\mathbf{R 3}$ & $\mathbf{R} 4$ & $\mathbf{R 5}$ & $\mathbf{R 6}$ & $\mathbf{R 7}$ & $\mathbf{R 8}$ & $\mathbf{R 9}$ & $\mathbf{R} 10$ & $\mathbf{R 1 1}$ & $\mathbf{R} 12$ & $\mathbf{R} 13$ & $\mathbf{R 1 4}$ & TNG \\
\hline GERENCIAMENTO DE ACESSO & 1 & & & 6 & 6 & 6 & 6 & 6 & 6 & 5 & 6 & 6 & 6 & 6 & $\mathbf{6}$ \\
\hline DESENHO DE PROCESSOS & 5 & & & 1 & 3 & 1 & 5 & 2 & 4 & 2 & 5 & 4 & 3 & 1 & $\mathbf{3}$ \\
\hline DEFINIÇÃO DE REGRAS DO NEGÓCIO & 4 & & & 2 & 2 & 2 & 4 & 1 & 3 & 1 & 2 & 2 & 1 & 3 & $\mathbf{1}$ \\
\hline INTEGRAÇÃO & 6 & & & 3 & 1 & 3 & 3 & 3 & 1 & 3 & 1 & 3 & 2 & 2 & $\mathbf{2}$ \\
\hline MECANISMO DE EXECUÇÃO & 2 & 4 & & 4 & 4 & 4 & 2 & 4 & 2 & 4 & 4 & 1 & 4 & 4 & $\mathbf{4}$ \\
\hline MONITORAMENTO & 3 & 3 & 1 & 5 & 5 & 5 & 1 & 5 & 5 & 6 & 3 & 5 & 5 & 5 & $\mathbf{5}$ \\
\hline
\end{tabular}

\section{Objetivo: Velocidade}

CONTRIBUIÇÃO PARA A REDUÇÃO DE CUSTO DO PROCESSO DE NEGÓCIO GERENCIAMENTO DE ACESSO

DESENHO DE PROCESSOS

DEFINIÇÃO DE REGRAS DO NEGÓCIO

INTEGRAÇÃO

MECANISMO DE EXECUÇÃO

MONITORAMENTO
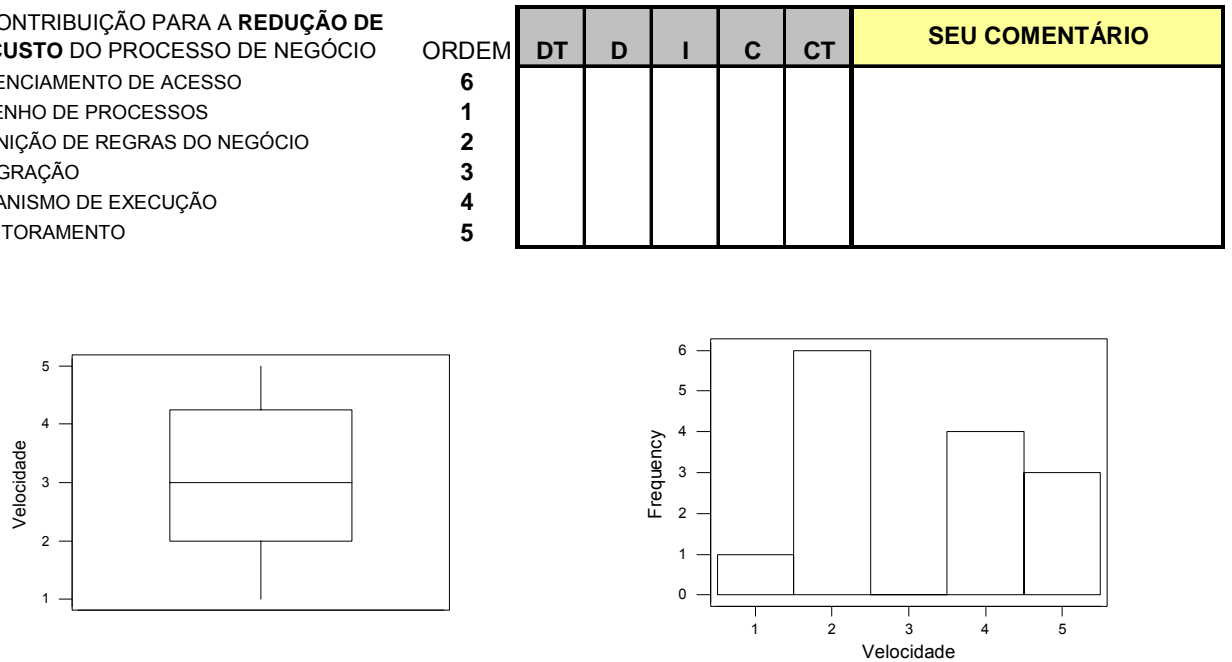

Wilcoxon Signed Rank Test: Velocidade

\begin{tabular}{|c|c|c|c|c|c|}
\hline & & $\mathrm{N}$ for & Wilcoxon & & timated \\
\hline & $\mathrm{N}$ & Test & Statistic & $P$ & Median \\
\hline Velocida & 14 & 14 & 59,5 & 0,683 & 3,000 \\
\hline
\end{tabular}

Nova Ordem obtida pela Técnica de Grupo Nominal das sugestões efetuadas:

\begin{tabular}{|l|c|c|c|c|c|c|c|c|c|c|c|c|c|c|c|}
\hline $\begin{array}{c}\text { CONTRIBUIÇÃO PARA A VELOCIDADE } \\
\text { DO PROCESSO DE NEGÓCIO }\end{array}$ & R1 & R2 & R3 & R4 & R5 & R6 & R7 & R8 & R9 & R10 & R11 & R12 & R13 & R14 & TNG \\
\hline GERENCIAMENTO DE ACESSO & 6 & & 6 & 6 & 6 & 2 & 2 & 6 & 6 & 5 & 5 & 5 & 6 & 5 & $\mathbf{6}$ \\
\hline DESENHO DE PROCESSOS & 3 & 1 & 1 & 3 & 3 & & 6 & 3 & 2 & 1 & 2 & 2 & 2 & 3 & $\mathbf{1}$ \\
\hline DEFINIÇÃO DE REGRAS DO NEGÓCIO & 4 & & 4 & 4 & 4 & 1 & 1 & 4 & 1 & 2 & 4 & 1 & 3 & 2 & $\mathbf{2}$ \\
\hline INTEGRAÇÃO & 5 & & 5 & 5 & 1 & & 4 & 5 & 4 & 3 & 3 & 3 & 1 & 1 & 4 \\
\hline MECANISMO DE EXECUÇÃO & 2 & & 3 & 2 & 2 & & 3 & 1 & 3 & 4 & 1 & 4 & 4 & 4 & $\mathbf{3}$ \\
\hline MONITORAMENTO & 1 & 3 & 2 & 1 & 5 & & 5 & 2 & 5 & 6 & 6 & 6 & 5 & 6 & $\mathbf{5}$ \\
\hline
\end{tabular}




\title{
Objetivo: Flexibilidade
}

\author{
CONTRIBUIÇÃO PARA A FLEXIBILIDADE \\ DO PROCESSO DE NEGÓCIO \\ GERENCIAMENTO DE ACESSO \\ DESENHO DE PROCESSOS \\ DEFINIÇÃO DE REGRAS DO NEGÓCIO \\ INTEGRAÇÃO \\ MECANISMO DE EXECUÇÃO \\ MONITORAMENTO
}

\begin{tabular}{|c|c|c|c|c|c|c|}
\hline ORDEM & DT & D & I & C & CT & SEU COMENTÁRIO \\
\hline 5 & & & & & & \\
\hline 2 & & & & & & \\
\hline 3 & & & & & & \\
\hline 4 & & & & & & \\
\hline 1 & & & & & & \\
\hline 6 & & & & & & \\
\hline
\end{tabular}
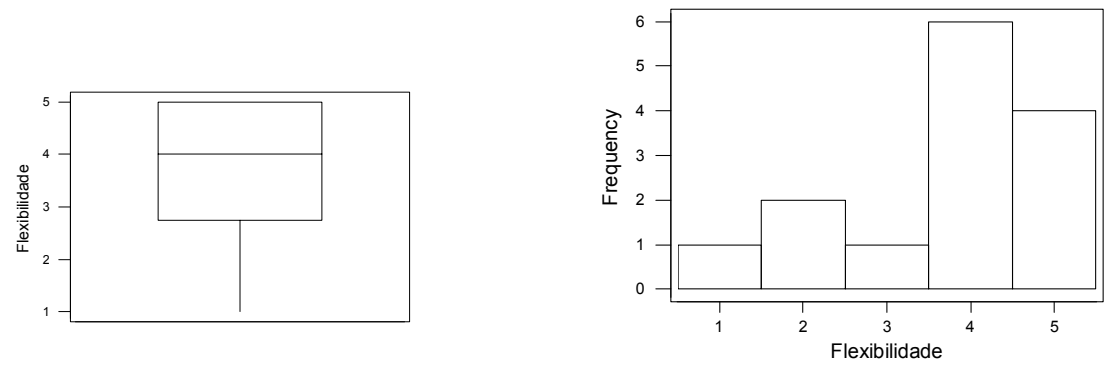

\section{Wilcoxon Signed Rank Test: Flexibilidade}

\begin{tabular}{|c|c|c|c|c|c|}
\hline & & $\mathrm{N}$ for & Wilcoxon & & timate \\
\hline & $\mathrm{N}$ & Test & Statistic & $\mathrm{P}$ & Media \\
\hline Flexibil & 14 & 8 & 12,0 & 0,441 & 4,00 \\
\hline
\end{tabular}

Nova Ordem obtida pela Técnica de Grupo Nominal das sugestões efetuadas:

\begin{tabular}{|l|c|c|c|c|c|c|c|c|c|c|c|c|c|c|c|}
\hline $\begin{array}{c}\text { CONTRIBUIÇÃO PARA A FLEXIBILIDADE } \\
\text { DO PROCESSO DE NEGÓCIO }\end{array}$ & R1 & R2 & R3 & R4 & R5 & R6 & R7 & R8 & R9 & R10 & R11 & R12 & R13 & R14 & TNG \\
\hline GERENCIAMENTO DE ACESSO & 4 & 5 & 1 & 5 & 6 & 5 & 5 & 5 & 5 & 5 & 1 & 5 & 5 & 5 & $\mathbf{5}$ \\
\hline DESENHO DE PROCESSOS & 5 & 2 & & 2 & 1 & 2 & 2 & 4 & 2 & 3 & 4 & 2 & 3 & 2 & $\mathbf{2}$ \\
\hline DEFINIÇÃO DE REGRAS DO NEGÓCIO & 6 & 3 & & 3 & 2 & 3 & 1 & 3 & 1 & 2 & 5 & 3 & 4 & 1 & $\mathbf{3}$ \\
\hline INTEGRAÇÃO & 3 & 4 & & 4 & 3 & 4 & 3 & 2 & 3 & 4 & 3 & 4 & 2 & 4 & 4 \\
\hline MECANISMO DE EXECUÇÃO & 1 & 1 & & 1 & 5 & 1 & 4 & 1 & 4 & 1 & 2 & 1 & 1 & 3 & $\mathbf{1}$ \\
\hline MONITORAMENTO & 2 & 6 & & 6 & 4 & 6 & 6 & 6 & 6 & 6 & 6 & 6 & 6 & 6 & $\mathbf{6}$ \\
\hline
\end{tabular}

\section{Objetivo: Confiabilidade}

\begin{tabular}{|c|c|c|c|c|c|c|c|}
\hline $\begin{array}{l}\text { CONTRIBUIÇÃO PARA A CONFIABILIDADE } \\
\text { DO PROCESSO DE NEGÓCIO }\end{array}$ & ORDEM & DT & D & I & C & CT & SEU COMENTÁRIO \\
\hline GERENCIAMENTO DE ACESSO & 3 & & & & & & \\
\hline DESENHO DE PROCESSOS & 4 & & & & & & \\
\hline DEFINIÇÃO DE REGRAS DO NEGÓCIO & 5 & & & & & & \\
\hline INTEGRAÇÃO & 6 & & & & & & \\
\hline MECANISMO DE EXECUCCÃO & 1 & & & & & & \\
\hline MONITORAMENTO & 2 & & & & & & \\
\hline
\end{tabular}



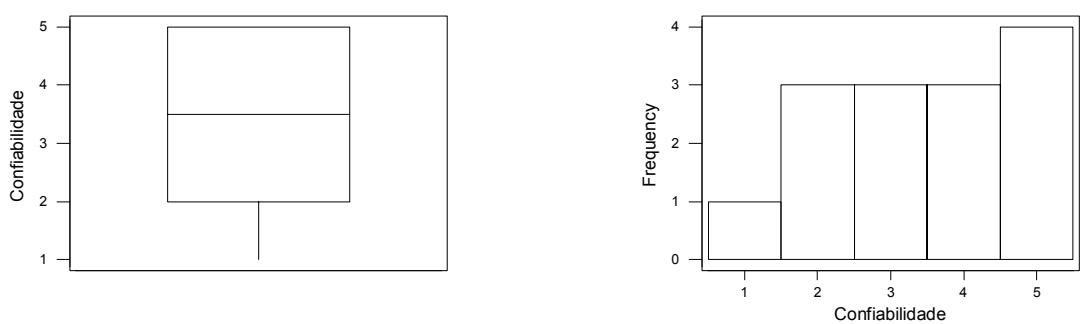

Wilcoxon Signed Rank Test: Confiabilidade
Test of median $=3,500$ versus median not $=3,500$

$\begin{array}{rrrrrr} & & \text { N for } & \text { Wilcoxon } & & \text { Estimated } \\ & N & \text { Test } & \text { Statistic } & P & \text { Median } \\ \text { Confiabi } & 14 & 14 & 50,5 & 0,925 & 3,500\end{array}$

Nova Ordem obtida pela Técnica de Grupo Nominal das sugestões efetuadas:

\begin{tabular}{|c|c|c|c|c|c|c|c|c|c|c|c|c|c|c|c|}
\hline $\begin{array}{c}\text { CONTRIBUIÇÃO PARA A } \\
\text { CONFIABILIDADE DO PROCESSO DE } \\
\text { NEGÓCIO }\end{array}$ & R1 & R2 & R3 & R4 & R5 & R6 & R7 & R8 & R9 & R10 & R11 & R12 & R13 & R14 & TNG \\
\hline GERENCIAMENTO DE ACESSO & 3 & 6 & 4 & & 6 & 3 & 5 & 3 & 6 & 6 & 4 & 4 & 3 & 6 & 4 \\
\hline DESENHO DE PROCESSOS & 4 & 4 & 1 & 1 & 2 & 4 & 3 & 4 & 1 & 4 & 1 & 1 & 2 & 3 & 2 \\
\hline DEFINIÇÃO DE REGRAS DO NEGÓCIO & 5 & 5 & 5 & & 3 & 5 & 4 & 5 & 4 & 5 & 5 & 5 & 5 & 4 & 5 \\
\hline INTEGRAÇÃO & 6 & 3 & 6 & & 4 & 6 & 6 & 6 & 5 & 2 & 6 & 6 & 6 & 5 & 6 \\
\hline MECANISMO DE EXECUÇÃO & 1 & 1 & 2 & & 1 & 1 & 1 & 1 & 2 & 1 & 2 & 1 & 1 & 1 & 1 \\
\hline MONITORAMENTO & 2 & 2 & 3 & & 5 & 2 & 2 & 2 & 3 & 3 & 3 & 3 & 4 & 2 & 3 \\
\hline
\end{tabular}




\section{Apêndice 7 \\ Macro-Funcionalidades X Objetivos de Desempenho - 2. Rodada}

Participaram desta Fase III - Segunda Rodada (Agrupamento das Funcionalidades de uma Solução BPM com os respectivos pesos relativos versus Objetivos de Desempenho) 09 especialistas, cujas avaliações foram coletadas no período de 05/12/05 a 11/12/05. A tabulação dos dados foi realizada por meio do software MiniTab e, são apresentadas a seguir um resumo das estatísticas descritivas e, para cada funcionalidade um gráfico boxplot e um histograma. O consenso na validação da nova ordem de contribuição e dos pesos relativos atribuídos foi possível para a maioria dos Objetivos de Desempenho. A avaliação quanto ao objetivo de desempenho Confiabilidade, dada a convergência como indiferente e os comentários dos especialistas, foi submetida à uma nova rodada.

a) Estatísticas Descritivas para cada Agrupamento avaliado:

\begin{tabular}{|lrrrrrr|}
\hline Variable & N & Mean & Median & TrMean & StDev & SE Mean \\
\hline Qualidadade & 9 & 3,667 & 4,000 & 3,667 & 0,707 & 0,236 \\
\hline Custo & 9 & 3,778 & 4,000 & 3,778 & 0,667 & 0,222 \\
\hline Velocidade & 9 & 3,556 & 4,000 & 3,556 & 0,882 & 0,294 \\
\hline Flexibilidade & 9 & 3,889 & 4,000 & 3,889 & 0,782 & 0,261 \\
\hline Confiabidade & 9 & 3,111 & 3,000 & 3,111 & 0,782 & 0,261 \\
\hline
\end{tabular}

b) Avaliação de cada Agrupamento apresentado:

Objetivo: Qualidade

\begin{tabular}{|l|c|c|c|c|c|c|c|c|}
\hline $\begin{array}{l}\text { CONTRIBUIÇÃO PARA A QUALIDADE } \\
\text { DO PROCESSO DE NEGÓCIO }\end{array}$ & Peso & Ordem & DT & D & I & C & CT & SEU COMENTÁRIO \\
\hline GERENCIAMENTO DE ACESSO & $5 \%$ & 6 & & & & & & \\
\hline DESENHO DE PROCESSOS & $32 \%$ & 1 & & & & & & \\
\hline DEFINIÇÃO DE REGRAS DO NEGÓCIO & $14 \%$ & 4 & & & & & & \\
\cline { 1 - 2 } INTEGRAÇÃO & $6 \%$ & 5 & & & & & & \\
\hline MECANISMO DE EXECUÇÃO & $27 \%$ & 2 & & & & & & \\
\hline MONITORAMENTO & $16 \%$ & 3 & & & & & & \\
\hline
\end{tabular}



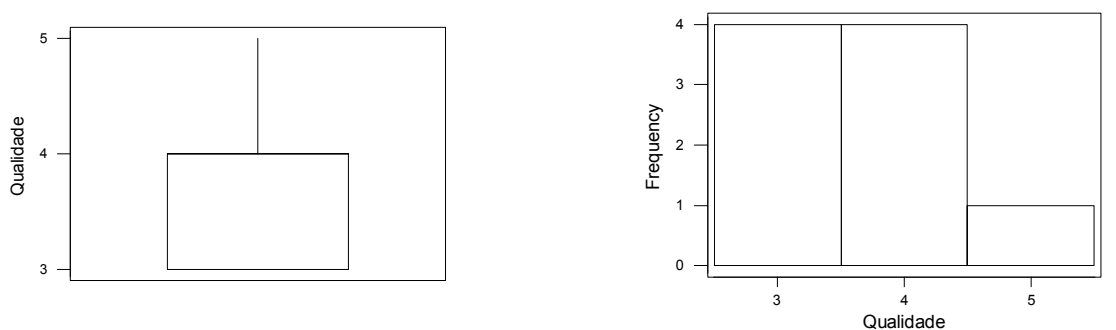

Wilcoxon Signed Rank Test: Qualidade

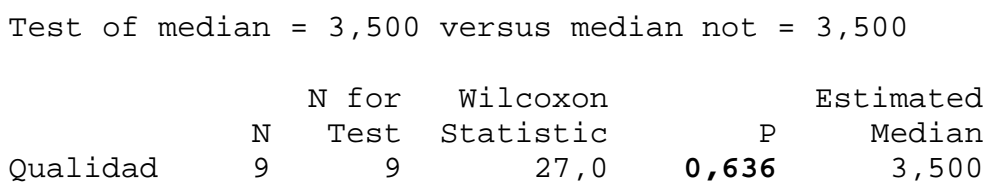

\section{Objetivo: Redução de Custo}

\begin{tabular}{|c|c|c|c|c|c|c|c|c|}
\hline $\begin{array}{l}\text { CONTRIBUIÇÃO PARA A REDUÇÃO DE } \\
\text { CUSTO DO PROCESSO DE NEGÓCIO }\end{array}$ & Peso & Ordem & DT & D & $\mathrm{I}$ & C & CT & SEU COMENTÁRIO \\
\hline GERENCIAMENTO DE ACESSO & $5 \%$ & 6 & & & & & & \\
\hline DESENHO DE PROCESSOS & $14 \%$ & 3 & & & & & & \\
\hline DEFINIÇÃO DE REGRAS DO NEGÓCIO & $31 \%$ & 1 & & & & & & \\
\hline INTEGRAÇÃO & $31 \%$ & 2 & & & & & & \\
\hline MECANISMO DE EXECUÇÃO & $14 \%$ & 4 & & & & & & \\
\hline MONITORAMENTO & $5 \%$ & 5 & & & & & & \\
\hline
\end{tabular}
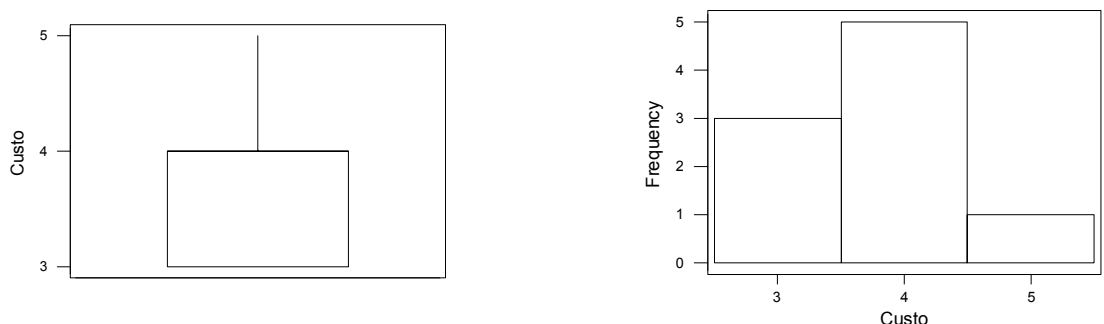

Wilcoxon Signed Rank Test: Custo
Test of median $=4,0 \odot \odot$ versus median not $=4,0 \odot \odot$
Custo
$\begin{array}{rr}N \text { for } & \text { Wilcoxon } \\ \text { Test } & \text { Statistic } \\ 4 & 2,5\end{array}$
$2,5 \quad 0,465$
Estimated
Median
$0,465 \quad 4,0 \odot \odot$ 
Objetivo: Velocidade

\begin{tabular}{|l|c|c|c|c|c|c|c|c|}
\hline $\begin{array}{c}\text { CONTRIBUIÇÃO PARA A VELOCIDADE } \\
\text { DO PROCESSO DE NEGÓCIO }\end{array}$ & Peso & Ordem & DT & D & I & C & CT & SEU COMENTÁRIO \\
\hline GERENCIAMENTO DE ACESSO & $\mathbf{5} \%$ & $\mathbf{6}$ & & & & & & \\
\hline DESENHO DE PROCESSOS & $\mathbf{3 1 \%}$ & $\mathbf{1}$ & & & & & & \\
\hline DEFINIÇÃO DE REGRAS DO NEGÓCIO & $\mathbf{2 5 \%}$ & $\mathbf{2}$ & & & & & & \\
\hline INTEGRAÇÃO & $\mathbf{1 0 \%}$ & $\mathbf{4}$ & & & & & & \\
\hline MECANISMO DE EXECUÇÃO & $\mathbf{2 0 \%}$ & $\mathbf{3}$ & & & & & & \\
\hline MONITORAMENTO & $\mathbf{1 0 \%}$ & $\mathbf{5}$ & & & & & & \\
\hline
\end{tabular}
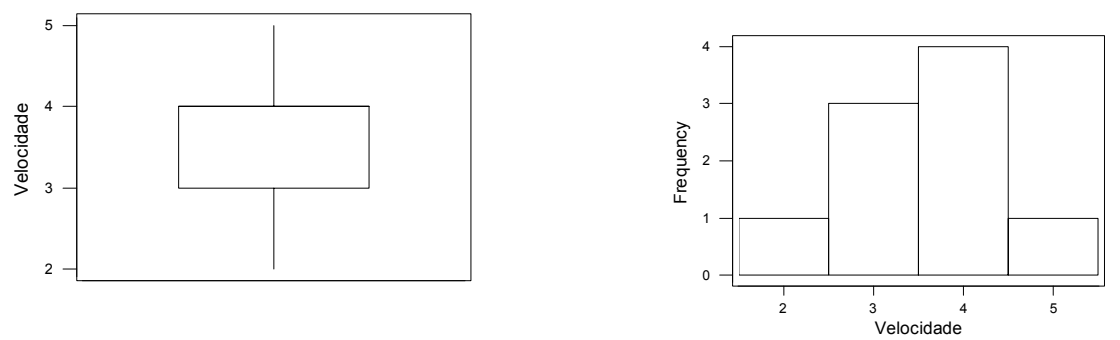

Wilcoxon Signed Rank Test: Velocidade

\begin{tabular}{lrrrrr}
\multicolumn{1}{l}{ Test of median $=3,500$} & versus median not $=3,500$ \\
& & N for & Wilcoxon & & Estimated \\
& $\mathrm{N}$ & Test & Statistic & $\mathrm{P}$ & Median \\
Velocida & 9 & 9 & 24,5 & $\mathbf{0 , 8 5 9}$ & 3,500
\end{tabular}

Objetivo: Flexibilidade

\begin{tabular}{|c|c|c|c|c|c|c|c|c|}
\hline $\begin{array}{c}\text { CONTRIBUIÇÃO PARA A } \\
\text { FLEXIBILIDADE DO PROCESSO DE } \\
\text { NEGÓCIO } \\
\end{array}$ & Peso & Ordem & DT & D & $\mathrm{I}$ & C & CT & SEU COMENTÁRIO \\
\hline GERENCIAMENTO DE ACESSO & $6 \%$ & 5 & & & & & & \\
\hline DESENHO DE PROCESSOS & $27 \%$ & 2 & & & & & & \\
\hline DEFINIÇÃO DE REGRAS DO NEGÓCIO & $18 \%$ & 3 & & & & & & \\
\hline INTEGRAÇÃ̃o & $13 \%$ & 4 & & & & & & \\
\hline MECANISMO DE EXECUÇÃO & $32 \%$ & 1 & & & & & & \\
\hline MONITORAMENTO & $5 \%$ & 6 & & & & & & \\
\hline
\end{tabular}
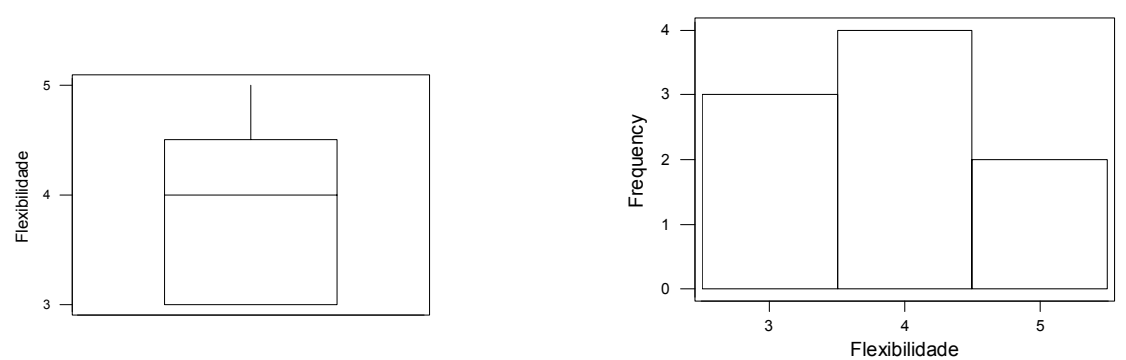


\section{Wilcoxon Signed Rank Test: Flexibilidade}

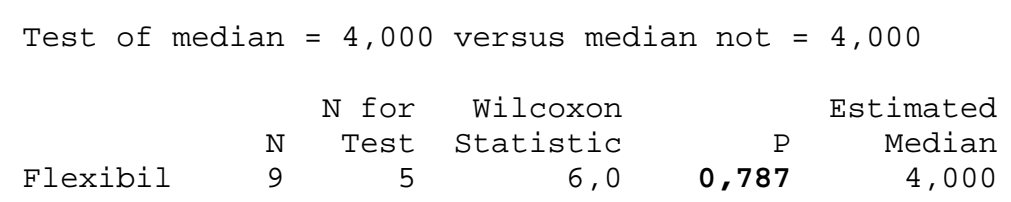

\section{Objetivo: Confiabilidade}

\begin{tabular}{|l|c|c|c|c|c|c|c|c|}
\hline $\begin{array}{c}\text { CONTRIBUIÇÃO PARA A } \\
\text { CONFIABILIDADE DO PROCESSO DE } \\
\text { NEGÓCIO }\end{array}$ & Peso & Ordem & & & & & & SEU COMENTÁRIO \\
\hline GERENCIAMENTO DE ACESSO & $12 \%$ & 4 & & & & & & \\
\hline DESENHO DE PROCESSOS & $24 \%$ & 2 & & & & & & \\
\hline DEFINIÇÃO DE REGRAS DO NEGÓCIO & $7 \%$ & 5 & & & & & & \\
\hline INTEGRAÇÃO & $6 \%$ & 6 & & & & & & \\
\hline MECANISMO DE EXECUÇÃO & $34 \%$ & 1 & & & & & & \\
\hline MONITORAMENTO & $\mathbf{1 7 \%}$ & $\mathbf{3}$ & & & & & & \\
\hline
\end{tabular}
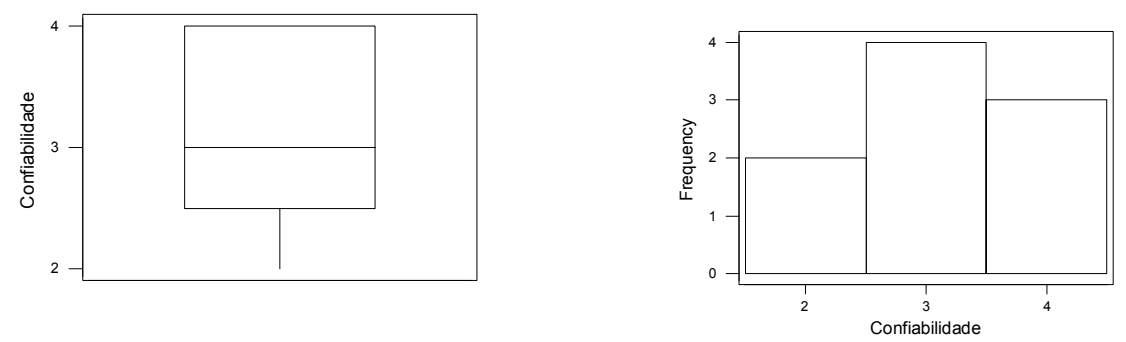

Wilcoxon Signed Rank Test: Confiabilidade

Test of median $=3,000$ versus median not $=3,00 \odot$

Comentários dos Especialistas:

- O Monitoramento é mais importante que o Desenho de Processo;

- O monitoramento é um painel do que já aconteceu, portanto ele dificilmente contribuirá para qualquer uma das dimensões apresentadas. Ele sempre será um item de feedback da dimensão que estamos querendo maximizar;

- A Integração é fundamental para garantir a acuracidade das informações com bases e aplicações legadas;

- Não acredito que o Desenho de Processos tenha um peso tão grande para este Objetivo. 


\section{Apêndice 7 \\ Macro-Funcionalidades X Objetivos de Desempenho - 3. Rodada}

Participaram desta Fase III - Terceira Rodada (Agrupamento das Funcionalidades de uma Solução BPM com os respectivos pesos relativos versus Objetivos de Desempenho) 08 especialistas, cujas avaliações foram coletadas no período de 12/12/05 a 19/12/05. A tabulação dos dados foi realizada por meio do software MiniTab e, são apresentadas a seguir um resumo das estatísticas descritivas, um gráfico boxplot e um histograma.

a) Estatística Descritiva para o Agrupamento avaliado:

\begin{tabular}{|lrrrrrc|}
\hline Variable & N & Mean & Median & TrMean & StDev & SE Mean \\
\hline Confiabilidade & $\mathbf{8}$ & 4,000 & 4,000 & 4,000 & 1,069 & 0,378 \\
\hline
\end{tabular}

b) Avaliação do Agrupamento apresentado:

Objetivo: Confiabilidade

\begin{tabular}{|l|c|c|c|c|c|c|c|c|}
\hline $\begin{array}{c}\text { CONTRIBUIÇÃO PARA A } \\
\text { CONFIABILIDADE DO PROCESSO DE } \\
\text { NEGÓCIO }\end{array}$ & Peso & Ordem & & & & & & SEU COMENTÁRIO \\
\hline GERENCIAMENTO DE ACESSO & $9 \%$ & 5 & & & & & & \\
\hline DESENHO DE PROCESSOS & $19 \%$ & 2 & & & & & & \\
\hline DEFINIÇÃO DE REGRAS DO NEGÓCIO & $16 \%$ & 3 & & & & & & \\
\hline INTEGRAÇÃO & $12 \%$ & 4 & & & & & & \\
\hline MECANISMO DE EXECUÇÃO & $39 \%$ & 1 & & & & & & \\
\hline MONITORAMENTO & $5 \%$ & 6 & & & & & & \\
\hline
\end{tabular}
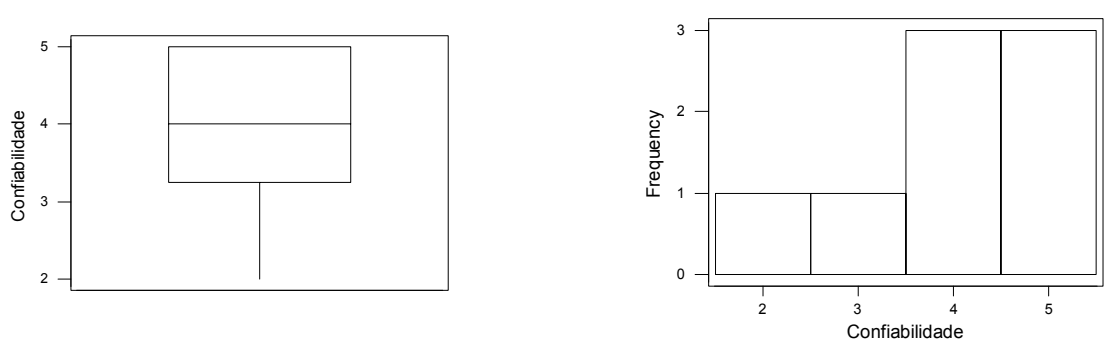

Wilcoxon Signed Rank Test: Confiabilidade

$\begin{array}{lrrrrr}\text { Test of median }= & 4,000 & \text { versus median not }=4,00 \odot \\ & & \text { N for } & \text { Wilcoxon } & \text { Estimated } \\ \text { Confiabi } & \mathrm{N} & \text { Test } & \text { Statistic } & \text { P } & \text { Median } \\ \text { T } & 8 & 5 & 7,5 & \mathbf{1 , 0 0 0} & 4,00\end{array}$




\section{Apêndice 8 \\ Macro-Funcionalidades $X$ Objetivos de Desempenho - Matrizes AHP}

\section{Objetivo Flexibilidade:}

Matriz AHP

\begin{tabular}{|c|c|c|c|c|c|c|}
\hline $\begin{array}{l}\text { Formula de comparação: } \\
\text { A propriedade Y (abaixo) contribui } \\
\text {-Extremamente (9); } \\
\text {-Muito mais (7); } \\
\text {-Mais (5); } \\
\text {-Moderadamente (3); } \\
\text {-Igual (1) } \\
\text { do que a propriedade X (à direita) } \\
\text { para a dimensão competitiva } \\
\text { Flexibilidade }\end{array}$ & 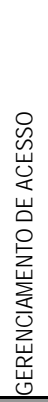 & 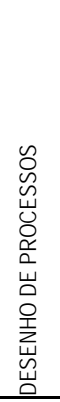 & 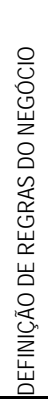 & 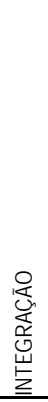 & 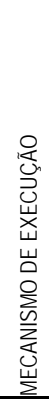 & 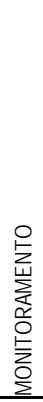 \\
\hline GERENCIAMENTO DE ACESSO & 1,0 & 0,2 & 0,2 & 0,3 & 0,2 & 3,0 \\
\hline DESENHO DE PROCESSOS & 5,0 & 1,0 & 1,0 & 3,0 & 1,0 & 5,0 \\
\hline DEFINIÇÃO DE REGRAS DO NEGÓCIO & 5,0 & 1,0 & 1,0 & 1,0 & 0,3 & 3,0 \\
\hline INTEGRAÇÃO & 3,0 & 0,3 & 1,0 & 1,0 & 0,3 & 3,0 \\
\hline MECANISMO DE EXECUÇÃO & 5,0 & 1,0 & 3,0 & 3,0 & 1,0 & 5,0 \\
\hline MONITORAMENTO & 0,3 & 0,2 & 0,3 & 0,3 & 0,2 & 1,0 \\
\hline
\end{tabular}

\section{Matriz Normalizada}

\begin{tabular}{|c|c|c|c|c|c|c|c|}
\hline $\begin{array}{l}\text { Formula de comparação: } \\
\text { A propriedade Y (abaixo) contribui } \\
\text {-Extremamente (9); } \\
\text {-Muito mais (7); } \\
\text {-Mais (5); } \\
\text {-Moderadamente (3); } \\
\text {-Igual (1) } \\
\text { do que a propriedade X (à direita) } \\
\text { para a dimensão competitiva } \\
\text { Flexibilidade }\end{array}$ & 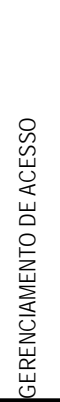 & 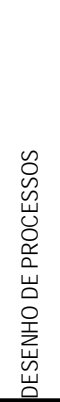 & 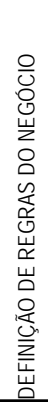 & 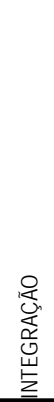 & 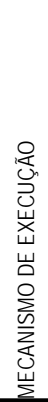 & 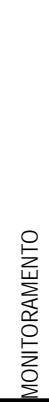 & \\
\hline GERENCIAMENTO DE ACESSO & 0,1 & 0,1 & 0,0 & 0,0 & 0,1 & 0,2 & 0,0649 \\
\hline DESENHO DE PROCESSOS & 0,3 & 0,3 & 0,2 & 0,3 & 0,3 & 0,3 & 0,2670 \\
\hline DEFINIÇÃO DE REGRAS DO NEGÓCIO & 0,3 & 0,3 & 0,2 & 0,1 & 0,1 & 0,2 & 0,1756 \\
\hline INTEGRAÇÃO & 0,2 & 0,1 & 0,2 & 0,1 & 0,1 & 0,2 & 0,1286 \\
\hline MECANISMO DE EXECUÇÃO & 0,3 & 0,3 & 0,5 & 0,3 & 0,3 & 0,3 & 0,3180 \\
\hline MONITORAMENTO & 0,0 & 0,1 & 0,1 & 0,0 & 0,1 & 0,1 & 0,0459 \\
\hline
\end{tabular}

$\begin{array}{cc}\text { IC } & 0,0815 \\ \text { IR } & 1,3200 \\ \text { RC } & 0,0617\end{array}$




\section{Objetivo Qualidade:}

\section{Matriz AHP}

\begin{tabular}{|c|c|c|c|c|c|c|}
\hline 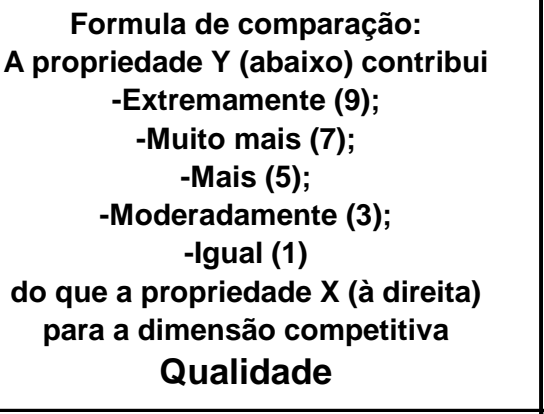 & 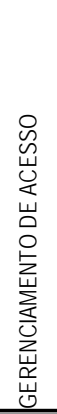 & 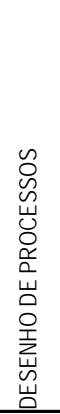 & 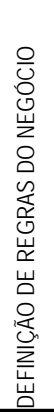 & 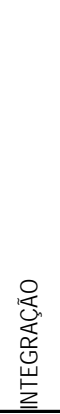 & 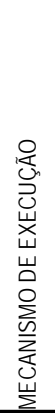 & 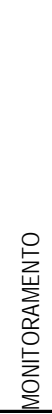 \\
\hline GERENCIAMENTO DE ACESSO & 1,0 & 0,1 & 0,3 & 1,0 & 0,2 & 0,2 \\
\hline DESENHO DE PROCESSOS & 7,0 & 1,0 & 3,0 & 5,0 & 1,0 & 3,0 \\
\hline DEFINIÇÃO DE REGRAS DO NEGÓCIO & 3,0 & 0,3 & 1,0 & 1,0 & 0,3 & 3,0 \\
\hline INTEGRAÇÃO & 1,0 & 0,2 & 1,0 & 1,0 & 0,2 & 0,3 \\
\hline MECANISMO DE EXECUÇÃO & 5,0 & 1,0 & 3,0 & 5,0 & 1,0 & 1,0 \\
\hline MONITORAMENTO & 5,0 & 0,3 & 0,3 & 3,0 & 1,0 & 1,0 \\
\hline
\end{tabular}

\section{Matriz Normalizada}

Formula de comparação:

A propriedade $Y$ (abaixo) contribui

-Extremamente (9);

-Muito mais (7);

-Mais (5);

-Moderadamente (3);

-Igual (1)

do que a propriedade $X$ (à direita)

para a dimensão competitiva

Qualidade

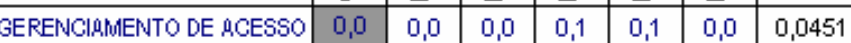

\begin{tabular}{|c|c|c|c|c|c|c|c|} 
DESENHO DE PROCESSOS & 0,3 & 0,3 & 0,3 & 0,3 & 0,3 & 0,4 & 0,3214 \\
\hline
\end{tabular}

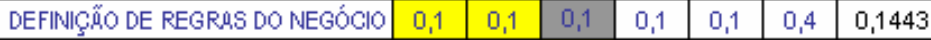

\begin{tabular}{|c|c|c|c|c|c|c|c|} 
INTEGRGÇ,̃̂́O & 0,0 & 0,1 & 0,1 & 0,1 & 0,1 & 0,0 & 0,0637 \\
\hline
\end{tabular}

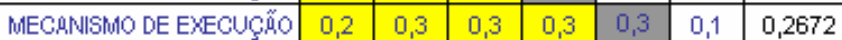

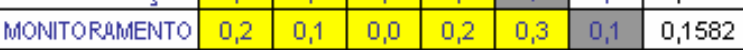

\begin{tabular}{ccc} 
IC & 0,1157 \\
IR & 1,3200 \\
RC & 0,0876 \\
\hline
\end{tabular}




\section{Objetivo Custo:}

Matriz AHP

\begin{tabular}{|c|c|c|c|c|c|c|}
\hline 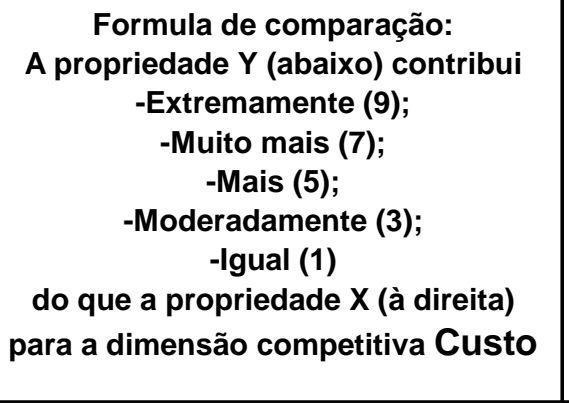 & 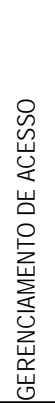 & 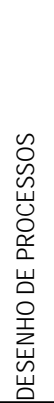 & 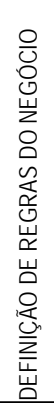 & 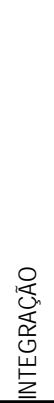 & 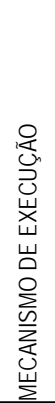 & 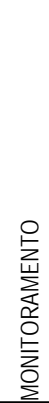 \\
\hline GERENCIAMENTO DE ACESSO & 1,0 & 0,2 & 0,2 & 0,2 & 0,3 & 1,0 \\
\hline DESENHO DE PROCESSOS & 5,0 & 1,0 & 0,3 & 0,3 & 1,0 & 3,0 \\
\hline DEFINIÇÃO DE REGRAS DO NEGÓCIO & 5,0 & 3,0 & 1,0 & 1,0 & 3,0 & 5,0 \\
\hline INTEGRAÇÃO & 5,0 & 3,0 & 1,0 & 1,0 & 3,0 & 5,0 \\
\hline MECANISMO DE EXECUÇÃO & 3,0 & 1,0 & 0,3 & 0,3 & 1,0 & 5,0 \\
\hline MONITORAMENTO & 1,0 & 0,3 & 0,2 & 0,2 & 0,2 & 1,0 \\
\hline
\end{tabular}

\section{Matriz Normalizada}

\begin{tabular}{|c|c|c|c|c|c|c|c|}
\hline $\begin{array}{c}\text { Formula de comparação: } \\
\text { A propriedade Y (abaixo) contribui } \\
\text {-Extremamente (9); } \\
\text {-Muito mais (7); } \\
\text {-Mais (5); } \\
\text {-Moderadamente (3); } \\
\text {-Igual (1) } \\
\text { do que a propriedade X (à direita) } \\
\text { para a dimensão competitiva Custo }\end{array}$ & 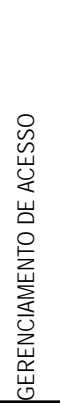 & 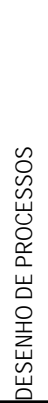 & 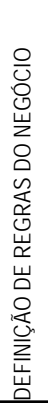 & 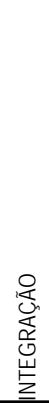 & 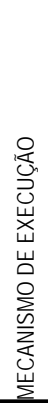 & 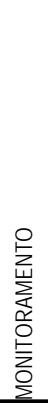 & \\
\hline GERENCIAMENTO DE ACESSO & 0,1 & 0,0 & 0,1 & 0,1 & 0,0 & 0,1 & 0,0488 \\
\hline DESENHO DE PROCESSOS & 0,3 & 0,1 & 0,1 & 0,1 & 0,1 & 0,2 & 0,1420 \\
\hline DEFINIÇÃO DE REGRAS DO NEGÓCIO & 0,3 & 0,4 & 0,3 & 0,3 & 0,4 & 0,3 & 0,3092 \\
\hline INTEGRAÇÃO & 0,3 & 0,4 & 0,3 & 0,3 & 0,4 & 0,3 & 0,3092 \\
\hline MECANISMO DE EXECUÇÃO & 0,2 & 0,1 & 0,1 & 0,1 & 0,1 & 0,3 & 0,1420 \\
\hline MONITORAMENTO & 0,1 & 0,0 & 0,1 & 0,1 & 0,0 & $\overline{0,1}$ & 0,0488 \\
\hline
\end{tabular}

$\begin{array}{ll}\text { IC } & 0,0544 \\ \text { IR } & 1,3200 \\ \text { RC } & 0,0412\end{array}$




\section{Objetivo Velocidade:}

Matriz AHP

\begin{tabular}{|c|c|c|c|c|c|c|}
\hline $\begin{array}{l}\text { Formula de comparação: } \\
\text { A propriedade Y (abaixo) contribui } \\
\text {-Extremamente (9); } \\
\text {-Muito mais (7); } \\
\text {-Mais (5); } \\
\text {-Moderadamente (3); } \\
\text {-Igual (1) } \\
\text { do que a propriedade X (à direita) } \\
\text { para a dimensão competitiva } \\
\text { Velocidade }\end{array}$ & 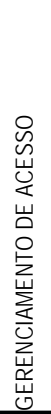 & 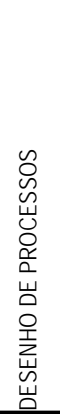 & 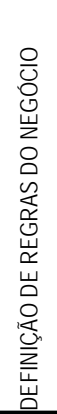 & 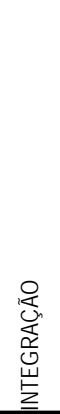 & 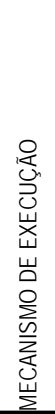 & 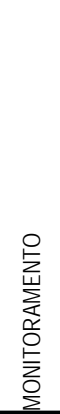 \\
\hline GERENCIAMENTO DE ACESSO & 1,0 & 0,2 & 0,2 & 0,3 & 0,3 & 0,3 \\
\hline DESENHO DE PROCESSOS & 5,0 & 1,0 & 1,0 & 3,0 & 3,0 & 3,0 \\
\hline DEFINIÇÃO DE REGRAS DO NEGÓCIO & 5,0 & 1,0 & 1,0 & 3,0 & 1,0 & 3,0 \\
\hline INTEGRAÇÃO & 3,0 & 0,3 & 0,3 & 1,0 & 0,3 & 1,0 \\
\hline MECANISMO DE EXECUÇÃO & 3,0 & 0,3 & 1,0 & 3,0 & 1,0 & 3,0 \\
\hline MONITORAMENTO & 3,0 & 0,3 & 0,3 & 1,0 & 0,3 & 1,0 \\
\hline
\end{tabular}

\section{Matriz Normalizada}

\begin{tabular}{|c|c|c|c|c|c|c|c|}
\hline $\begin{array}{l}\text { Formula de comparação: } \\
\text { A propriedade Y (abaixo) contribui } \\
\text {-Extremamente (9); } \\
\text {-Muito mais (7); } \\
\text {-Mais (5); } \\
\text {-Moderadamente (3); } \\
\text {-Igual (1) } \\
\text { do que a propriedade X (à direita) } \\
\text { para a dimensão competitiva } \\
\text { Velocidade }\end{array}$ & 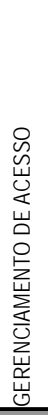 & 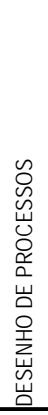 & 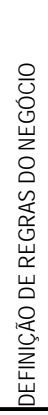 & 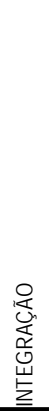 & 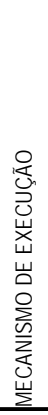 & 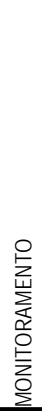 & \\
\hline GERENCIAMENTO DE ACESSO & 0,1 & 0,1 & 0,1 & 0,0 & 0,1 & 0,0 & 0,0464 \\
\hline DESENHO DE PROCESSOS & 0,3 & 0,3 & 0,3 & 0,3 & 0,5 & 0,3 & 0,3084 \\
\hline DEFINIÇÃO DE REGRAS DO NEGÓCIO & 0,3 & 0,3 & 0,3 & 0,3 & 0,2 & 0,3 & 0,2529 \\
\hline INTEGRAÇÃO & 0,2 & 0,1 & 0,1 & 0,1 & 0,1 & 0,1 & 0,0954 \\
\hline MECANISMO DE EXECUÇÃO & 0,2 & 0,1 & 0,3 & 0,3 & 0,2 & 0,3 & 0,2015 \\
\hline MONITORAMENTO & 0,2 & 0,1 & 0,1 & 0,1 & 0,1 & 0,1 & 0,0954 \\
\hline
\end{tabular}

$\begin{array}{cc}\text { IC } & 0,0529 \\ \text { IR } & 1,3200 \\ \text { RC } & 0,0401\end{array}$




\section{Objetivo Confiabilidade:}

Matriz AHP

\begin{tabular}{|c|c|c|c|c|c|c|}
\hline $\begin{array}{l}\text { Formula de comparação: } \\
\text { A propriedade Y (abaixo) contribui } \\
\text {-Extremamente (9); } \\
\text {-Muito mais (7); } \\
\text {-Mais (5); } \\
\text {-Moderadamente (3); } \\
\text {-Igual (1) } \\
\text { do que a propriedade X (à direita) } \\
\text { para a dimensão competitiva } \\
\text { Confiabilidade }\end{array}$ & 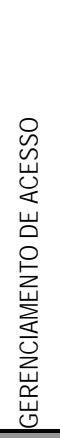 & 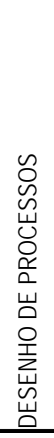 & 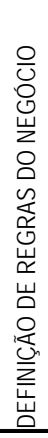 & 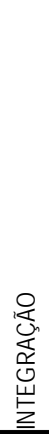 & 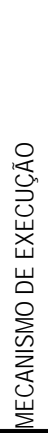 & 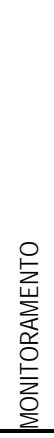 \\
\hline GERENCIAMENTO DE ACESSO & 1,0 & 0,3 & 0,3 & 1,0 & 0,2 & 3,0 \\
\hline DESENHO DE PROCESSOS & 3,0 & 1,0 & 1,0 & 3,0 & 0,3 & 3,0 \\
\hline DEFINIÇÃO DE REGRAS DO NEGÓCIO & 3,0 & 1,0 & 1,0 & 1,0 & 0,3 & 3,0 \\
\hline INTEGRAÇÃO & 1,0 & 0,3 & 1,0 & 1,0 & 0,3 & 3,0 \\
\hline MECANISMO DE EXECUÇÃO & 5,0 & 3,0 & 3,0 & 3,0 & 1,0 & 5,0 \\
\hline MONITORAMENTO & 0,3 & 0,3 & 0,3 & 0,3 & 0,2 & 1,0 \\
\hline
\end{tabular}

\section{Matriz Normalizada}

Formula de comparação:

A propriedade $\mathrm{Y}$ (abaixo) contribui

-Extremamente (9);

-Muito mais (7);

-Mais (5);

-Moderadamente (3);

-Igual (1)

do que a propriedade $X$ (à direita)

para a dimensão competitiva

Confiabilidade

GERENCIAMENTO DE ACESSO 0,1

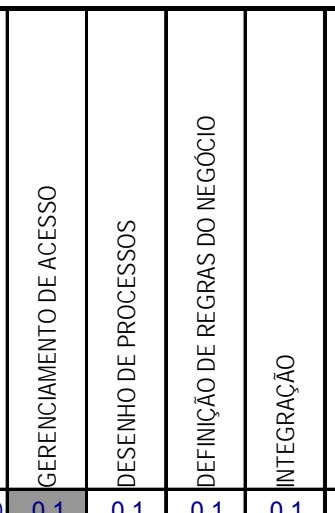

\begin{tabular}{|c|c|c|}
\hline 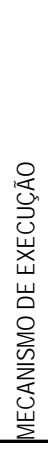 & 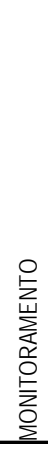 & \\
\hline 0,1 & 0,2 & 0,0896 \\
\hline 0,1 & 0,2 & 0,1948 \\
\hline 0,1 & 0,2 & 0,1591 \\
\hline 0,1 & 0,2 & 0,1155 \\
\hline 0,4 & 0,3 & 0,3901 \\
\hline 0,1 & $\overline{0,1}$ & 0,0509 \\
\hline
\end{tabular}

\begin{tabular}{ll} 
IC & 0,0708 \\
IR & 1,3200 \\
RC & 0,0537 \\
\hline
\end{tabular}




\section{Apêndice 9 \\ Tabulações do Delphi Eletrônico}

Fase I - Primeira Rodada:

\begin{tabular}{|c|c|c|c|c|c|c|c|c|c|c|c|c|c|c|c|c|c|c|c|c|}
\hline $\mathbf{R}$ & Q11 & Q12 & Q13 & Q21 & Q22 & Q23 & Q24 & Q31 & Q32 & Q33 & Q41 & Q42 & Q43 & Q51 & Q52 & Q53 & Q54 & Q61 & Q62 & Q63 \\
\hline $\mathrm{R} 1$ & 5 & 5 & 5 & 5 & 3 & 4 & 5 & 5 & 3 & 5 & 5 & 4 & 5 & 5 & 4 & 3 & 5 & 5 & 5 & 3 \\
\hline R2 & 5 & 5 & 5 & 5 & 5 & 5 & 5 & 5 & 5 & 5 & 5 & 5 & 5 & 5 & 5 & 5 & 5 & 5 & 5 & 5 \\
\hline R3 & 5 & 5 & 5 & 5 & 5 & 5 & 5 & 5 & 5 & 5 & 5 & 5 & 5 & 5 & 5 & 5 & 5 & 5 & 5 & 5 \\
\hline R4 & 5 & 5 & 5 & 4 & 5 & 5 & 5 & 4 & 5 & 5 & 5 & 4 & 5 & 5 & 5 & 5 & 5 & 5 & 5 & 5 \\
\hline R5 & 5 & 5 & 5 & 5 & 4 & 5 & 5 & 4 & 5 & 5 & 5 & 5 & 5 & 2 & 5 & 2 & 5 & 5 & 5 & 5 \\
\hline R6 & 4 & 5 & 4 & 5 & 3 & 4 & 4 & 4 & 5 & 3 & 5 & 4 & 4 & 4 & 3 & 3 & 5 & 5 & 4 & 4 \\
\hline R7 & 4 & 3 & 2 & 3 & 3 & 3 & 3 & 1 & 2 & 2 & 1 & 2 & 1 & 2 & 2 & 3 & 3 & 3 & 2 & 3 \\
\hline R8 & 5 & 5 & 5 & 5 & 5 & 5 & 5 & 5 & 5 & 5 & 5 & 5 & 5 & 5 & 5 & 5 & 5 & 5 & 5 & 5 \\
\hline R9 & 4 & 4 & 3 & 5 & 4 & 5 & 4 & 2 & 4 & 4 & 5 & 5 & 4 & 3 & 4 & 2 & 5 & 5 & 4 & 4 \\
\hline R10 & 3 & 4 & 4 & 4 & 5 & 4 & 4 & 4 & 4 & 4 & 4 & 4 & 4 & 4 & 4 & 4 & 4 & 4 & 4 & 4 \\
\hline R11 & 4 & 4 & 4 & 4 & 3 & 3 & 3 & 4 & 4 & 4 & 4 & 4 & 4 & 4 & 4 & 4 & 4 & 4 & 4 & 4 \\
\hline R12 & 4 & 4 & 4 & 2 & 4 & 4 & 4 & 4 & 3 & 4 & 3 & 4 & 4 & 4 & 4 & 4 & 3 & 4 & 4 & 4 \\
\hline R13 & 5 & 5 & 5 & 5 & 3 & 4 & 5 & 5 & 3 & 5 & 5 & 4 & 5 & 5 & 4 & 3 & 5 & 5 & 5 & 3 \\
\hline R14 & 5 & 5 & 5 & 5 & 5 & 5 & 5 & 5 & 5 & 5 & 5 & 5 & 5 & 5 & 5 & 5 & 5 & 5 & 5 & 5 \\
\hline R15 & 5 & 5 & 5 & 5 & 5 & 5 & 5 & 5 & 5 & 5 & 5 & 5 & 5 & 5 & 5 & 5 & 5 & 5 & 5 & 5 \\
\hline R16 & 5 & 5 & 5 & 4 & 5 & 5 & 5 & 4 & 5 & 5 & 5 & 4 & 5 & 5 & 5 & 5 & 5 & 5 & 5 & 5 \\
\hline R17 & 5 & 5 & 5 & 5 & 4 & 5 & 5 & 4 & 5 & 5 & 5 & 5 & 5 & 2 & 5 & 2 & 5 & 5 & 5 & 5 \\
\hline R18 & 4 & 5 & 4 & 5 & 3 & 4 & 4 & 4 & 5 & 3 & 5 & 4 & 4 & 4 & 3 & 3 & 5 & 5 & 4 & 4 \\
\hline R19 & 5 & 5 & 5 & 5 & 3 & 4 & 5 & 5 & 3 & 5 & 5 & 4 & 5 & 5 & 4 & 3 & 5 & 5 & 5 & 3 \\
\hline R20 & 5 & 5 & 5 & 5 & 5 & 5 & 5 & 5 & 5 & 5 & 5 & 5 & 5 & 5 & 5 & 5 & 5 & 5 & 5 & 5 \\
\hline \begin{tabular}{|l} 
R21 \\
\end{tabular} & 5 & 5 & 5 & 5 & 5 & 5 & 5 & 5 & 5 & 5 & 5 & 5 & 5 & 5 & 5 & 5 & 5 & 5 & 5 & 5 \\
\hline \begin{tabular}{|l} 
R22 \\
\end{tabular} & 5 & 5 & 5 & 4 & 5 & 5 & 5 & 4 & 5 & 5 & 5 & 4 & 5 & 5 & 5 & 5 & 5 & 5 & 5 & 5 \\
\hline R23 & 4 & 4 & 4 & 2 & 4 & 4 & 4 & 4 & 3 & 4 & 3 & 4 & 4 & 4 & 4 & 4 & 3 & 4 & 4 & 4 \\
\hline R24 & 5 & 5 & 5 & 5 & 4 & 5 & 5 & 4 & 5 & 5 & 5 & 5 & 5 & 2 & 5 & 2 & 5 & 5 & 5 & 5 \\
\hline R25 & 4 & 5 & 4 & 5 & 3 & 4 & 4 & 4 & 5 & 3 & 5 & 4 & 4 & 4 & 3 & 3 & 5 & 5 & 4 & 4 \\
\hline R26 & 5 & 5 & 5 & 5 & 5 & 5 & 5 & 5 & 5 & 5 & 5 & 5 & 5 & 5 & 5 & 5 & 5 & 5 & 5 & 5 \\
\hline R27 & 4 & 4 & 3 & 5 & 4 & 5 & 4 & 2 & 4 & 4 & 5 & 5 & 4 & 3 & 4 & 2 & 5 & 5 & 4 & 4 \\
\hline R28 & 3 & 4 & 4 & 4 & 5 & 4 & 4 & 4 & 4 & 4 & 4 & 4 & 4 & 4 & 4 & 4 & 4 & 4 & 4 & 4 \\
\hline R29 & 4 & 4 & 4 & 4 & 3 & 3 & 3 & 4 & 4 & 4 & 4 & 4 & 4 & 4 & 4 & 4 & 4 & 4 & 4 & 4 \\
\hline R30 & 5 & 5 & 5 & 5 & 5 & 5 & 5 & 5 & 5 & 5 & 5 & 5 & 5 & 5 & 5 & 5 & 5 & 5 & 5 & 5 \\
\hline R31 & 4 & 4 & 3 & 5 & 4 & 5 & 4 & 2 & 4 & 4 & 5 & 5 & 4 & 3 & 4 & 2 & 5 & 5 & 4 & 4 \\
\hline R32 & 3 & 4 & 4 & 4 & 5 & 4 & 4 & 4 & 4 & 4 & 4 & 4 & 4 & 4 & 4 & 4 & 4 & 4 & 4 & 4 \\
\hline R33 & 4 & 4 & 4 & 4 & 3 & 3 & 3 & 4 & 4 & 4 & 4 & 4 & 4 & 4 & 4 & 4 & 4 & 4 & 4 & 4 \\
\hline R34 & 4 & 4 & 4 & 2 & 4 & 4 & 4 & 4 & 3 & 4 & 3 & 4 & 4 & 4 & 4 & 4 & 3 & 4 & 4 & 4 \\
\hline
\end{tabular}


Fase II - Primeira Rodada:

\begin{tabular}{|l|c|c|c|c|c|c|}
\hline & M1 & M2 & M3 & M4 & M5 & M6 \\
\hline R1 & 4 & 5 & 4 & 5 & 4 & 5 \\
\hline R2 & 4 & 5 & 4 & 5 & 2 & 4 \\
\hline R3 & 5 & 5 & 5 & 5 & 5 & 5 \\
\hline R4 & 3 & 4 & 2 & 3 & 3 & 5 \\
\hline R5 & 1 & 2 & 4 & 5 & 2 & 5 \\
\hline R6 & 4 & 4 & 2 & 4 & 2 & 4 \\
\hline R7 & 4 & 2 & 3 & 4 & 4 & 2 \\
\hline R8 & 5 & 4 & 5 & 5 & 4 & 5 \\
\hline R9 & 5 & 4 & 5 & 4 & 4 & 5 \\
\hline R10 & 4 & 5 & 4 & 5 & 4 & 4 \\
\hline R11 & 4 & 3 & 2 & 3 & 3 & 4 \\
\hline R12 & 2 & 4 & 4 & 5 & 2 & 4 \\
\hline R13 & 3 & 3 & 3 & 4 & 3 & 3 \\
\hline R14 & 1 & 2 & 2 & 4 & 3 & 4 \\
\hline R15 & 4 & 4 & 3 & 4 & 3 & 4 \\
\hline R16 & 5 & 5 & 4 & 4 & 2 & 5 \\
\hline R17 & 4 & 5 & 4 & 5 & 5 & 5 \\
\hline R18 & 4 & 5 & 2 & 4 & 3 & 5 \\
\hline R19 & 3 & 3 & 4 & 5 & 4 & 5 \\
\hline R20 & 3 & 4 & 3 & 5 & 2 & 4 \\
\hline R21 & 3 & 3 & 3 & 5 & 2 & 3 \\
\hline
\end{tabular}

Fase II - Segunda Rodada:

\begin{tabular}{|l|r|r|r|r|r|r|}
\hline & M1 & M2 & \multicolumn{1}{|c|}{ M3 } & M4 & M5 & \multicolumn{1}{|c|}{ M6 } \\
\hline R1 & 4 & 5 & 4 & 5 & 4 & 5 \\
\hline R2 & 4 & 5 & 4 & 5 & 5 & 4 \\
\hline R3 & 5 & 5 & 5 & 5 & 5 & 5 \\
\hline R4 & 5 & 4 & 5 & 5 & 5 & 5 \\
\hline R5 & 4 & 2 & 4 & 5 & 4 & 5 \\
\hline R6 & 5 & 5 & 5 & 5 & 5 & 4 \\
\hline R7 & 4 & 2 & 4 & 4 & 4 & 2 \\
\hline R8 & 4 & 2 & 5 & 2 & 4 & 4 \\
\hline R9 & 5 & 5 & 5 & 4 & 5 & 5 \\
\hline R10 & 4 & 4 & 4 & 5 & 4 & 5 \\
\hline R11 & 4 & 5 & 5 & 5 & 5 & 5 \\
\hline R12 & 5 & 4 & 5 & 5 & 4 & 5 \\
\hline R13 & 4 & 2 & 4 & 4 & 4 & 4 \\
\hline R14 & 4 & 4 & 4 & 4 & 4 & 4 \\
\hline R15 & 4 & 2 & 5 & 4 & 5 & 3 \\
\hline R16 & 5 & 2 & 4 & 5 & 3 & 4 \\
\hline R17 & 4 & 3 & 4 & 4 & 4 & 4 \\
\hline R18 & 4 & 3 & 4 & 3 & 4 & 4 \\
\hline R19 & 5 & 4 & 4 & 5 & 5 & 4 \\
\hline R20 & 5 & 4 & 5 & 5 & 4 & 5 \\
\hline R21 & 4 & 4 & 5 & 5 & 5 & 5 \\
\hline
\end{tabular}


Fase II - Terceira Rodada:

\begin{tabular}{|c|c|}
\hline & M2 \\
\hline R1 & 4 \\
\hline R2 & 4 \\
\hline R3 & 4 \\
\hline R4 & 5 \\
\hline R5 & 5 \\
\hline R6 & 5 \\
\hline R7 & 4 \\
\hline R8 & 5 \\
\hline R9 & 4 \\
\hline R10 & 5 \\
\hline R11 & 4 \\
\hline R12 & 4 \\
\hline R13 & 5 \\
\hline R14 & 4 \\
\hline R15 & 4 \\
\hline R16 & 4 \\
\hline R17 & 4 \\
\hline R18 & 4 \\
\hline
\end{tabular}

Fase III - Primeira Rodada:

\begin{tabular}{|l|c|c|c|c|c|}
\hline & Qualidade & Custo & Velocidade & Flexibilidade & Confiabilidade \\
\hline R1 & 3 & 3 & 5 & 4 & 5 \\
\hline R2 & 2 & 4 & 4 & 4 & 2 \\
\hline R3 & 4 & 2 & 4 & 5 & 4 \\
\hline R4 & 4 & 4 & 4 & 4 & 5 \\
\hline R5 & 2 & 4 & 4 & 5 & 4 \\
\hline R6 & 1 & 1 & 1 & 5 & 5 \\
\hline R7 & 4 & 5 & 5 & 5 & 5 \\
\hline R8 & 5 & 2 & 2 & 4 & 3 \\
\hline R9 & 4 & 4 & 2 & 4 & 2 \\
\hline R10 & 2 & 2 & 2 & 2 & 2 \\
\hline R11 & 5 & 3 & 2 & 5 & 3 \\
\hline R12 & 3 & 2 & 2 & 3 & 4 \\
\hline R13 & 5 & 3 & 2 & 2 & 3 \\
\hline R14 & 2 & 4 & 5 & & \\
\hline
\end{tabular}


Fase III - Segunda Rodada:

\begin{tabular}{|l|c|c|c|c|c|}
\hline & Qualidade & Custo & Velocidade & Flexibilidade & Confiabilidade \\
\hline R1 & 3 & 3 & 2 & 3 & 2 \\
\hline R2 & 4 & 4 & 3 & 3 & 3 \\
\hline R3 & 3 & 3 & 3 & 3 & 2 \\
\hline R4 & 4 & 4 & 4 & 4 & 4 \\
\hline R5 & 3 & 4 & 3 & 4 & 3 \\
\hline R6 & 3 & 4 & 4 & 5 & 3 \\
\hline R7 & 4 & 4 & 5 & 4 & 4 \\
\hline R8 & 5 & 3 & 4 & 4 & 3 \\
\hline R9 & 4 & 5 & 4 & 5 & 4 \\
\hline
\end{tabular}

Fase III - Terceira Rodada:

\begin{tabular}{|l|c|}
\hline & Confiabilidade \\
\hline R1 & 3 \\
\hline R2 & 4 \\
\hline R3 & 2 \\
\hline R4 & 5 \\
\hline R5 & 4 \\
\hline R6 & 5 \\
\hline R7 & 4 \\
\hline R8 & 5 \\
\hline
\end{tabular}




\section{-Anexos}

\section{Anexo 1 Lista de Especialistas}

Lista de especialistas selecionados da Base de Dados Lattes encontrados com o uso da palavra chave Business Process Management.

\begin{tabular}{|c|c|c|c|c|}
\hline$\#$ & NOME & NIVEL & ATUAÇÃo & E-MAIL \\
\hline 1 & Henrique Rozenfeld & $\begin{array}{l}\text { Maior nivel de formação: Doutorado } \\
\text { (Livre Docência) }\end{array}$ & $\begin{array}{l}\text { Primeira área de atuação: } \\
\text { Engenharias - Engenharia de } \\
\text { Producaão }\end{array}$ & roz@sc.usp.br \\
\hline 2 & Marcos Fava Neves & $\begin{array}{l}\text { Primeira área de atuação: Ciências } \\
\text { Sociais Aplicadas - Multidisciplinar }\end{array}$ & $\begin{array}{l}\text { Instituição: Universidade de São } \\
\text { Paulo }\end{array}$ & mfaneves@usp.br \\
\hline 3 & Sergio Luis da Silva & Maior nivel de formação: Doutorado & $\begin{array}{l}\text { Primeira área de atuação: } \\
\text { Engenharias - Engenharia de } \\
\text { Produção }\end{array}$ & sergiol@power.ufscar.br \\
\hline 4 & Carlos José Pereira de Lucena & $\begin{array}{l}\text { Maior nivel de formação: Doutorado } \\
\text { (Pós-Doutorado) }\end{array}$ & $\begin{array}{l}\text { Primeira área de atuaçâa: Ciências } \\
\text { Exatas e da Terra - Ciência da } \\
\text { Computacão }\end{array}$ & lucena@inf.puc-rio.br \\
\hline 5 & Luís Gonzaga Trabasso & Maior nível de formação: Doutorado & $\begin{array}{l}\text { Primeira área de atuação: } \\
\text { Engenharias - Engenharia Mecânica }\end{array}$ & gonzaga@ita.br \\
\hline 6 & Luiz Marcio Spinosa & Maior nivel de formação: Doutorado & $\begin{array}{l}\text { Primeira área de atuação: } \\
\text { Engenharias - Multidisciplinar }\end{array}$ & m.spinosa@pucpr.br \\
\hline .7 & Marcos Roberto da Silva Borges & $\begin{array}{l}\text { Maior nível de formação: Doutorado } \\
\text { (Pós-Doutorado) }\end{array}$ & $\begin{array}{l}\text { Primeira área de atuaçâa: Ciências } \\
\text { Exatas e da Terra - Ciência da } \\
\text { Computacão }\end{array}$ & MBORGES@NCE.UFRJ.BR \\
\hline 8 & Hugo Cesar Hoeschl & $\begin{array}{l}\text { Maior nível de formação: Doutorado } \\
\text { (Pós-Doutorado) }\end{array}$ & $\begin{array}{l}\text { Primeira área de atuação: Ciências } \\
\text { Sociais Aplicadas - Multidisciplinar }\end{array}$ & hugo@wbsa.com.br \\
\hline 9 & Marcos Cortez Campomar & $\begin{array}{l}\text { Maior nivel de formação: Doutorado } \\
\text { (Livre Docência) }\end{array}$ & $\begin{array}{l}\text { Primeira área de atuação: Ciências } \\
\text { Sociais Aplicadas - Multidisciplinar - } \\
\text { USP }\end{array}$ & campomar@usp.br \\
\hline 10 & $\begin{array}{l}\text { Teresia Diana Lewe van Aduard de Macedo- } \\
\text { Soares }\end{array}$ & Maior nível de formação: Doutorado & $\begin{array}{l}\text { Primeira área de atuação: Ciências } \\
\text { Sociais Aplicadas - Multidisciplinar }\end{array}$ & dianams@iag.puc-rio.br \\
\hline 11 & Jorge Luis Nicolas Audy & Maior nivel de formação: Doutorado & $\begin{array}{l}\text { Primeira área de atuação: Ciências } \\
\text { Exatas e da Terra - Ciência da } \\
\text { Computacão }\end{array}$ & audy@inf.pucrs.br \\
\hline 12 & Paulo Augusto Cauchick Miguel & $\begin{array}{l}\text { Maior nivel de formação: Doutorado } \\
\text { (Pós-Doutorado) }\end{array}$ & $\begin{array}{l}\text { Primeira área de atuação: } \\
\text { Engenharias - Engenharia de } \\
\text { Produção }\end{array}$ & pamiguel@unimep.br \\
\hline 13 & Claudia Maria Lima Werner & Maior nível de formação: Doutorado & $\begin{array}{l}\text { Primeira área de atuação: Ciências } \\
\text { Exatas e da Terra - Ciência da } \\
\text { Computacão }\end{array}$ & werner@cos.ufri.br \\
\hline 14 & Ricardo Miranda Barcia & Maior nivel de formação: Doutorado & $\begin{array}{l}\text { Primeira área de atuação: } \\
\text { Engenharias - Multidisciplinar }\end{array}$ & rbarcia@vias.org.br \\
\hline 15 & Celson Pantoja Lima & Maior nivel de formação: Doutorado & $\begin{array}{l}\text { Primeira área de atuação: Ciências } \\
\text { Exatas e da Terra - Multidisciplinar }\end{array}$ & celson lima@yahoo.com \\
\hline 16 & Edgard Jamhour & Maior nivel de formação: Doutorado & $\begin{array}{l}\text { Primeira área de atuação: Ciências } \\
\text { Exatas e da Terra - Ciência da } \\
\text { Computacãa }\end{array}$ & jamhour@ppgia.pucpr.br \\
\hline 17 & Fernando Augusto Silva Marins & $\begin{array}{l}\text { Maior nível de formação: Doutorado } \\
\text { (Pós-Doutorado) }\end{array}$ & $\begin{array}{l}\text { Primeira área de atuação: } \\
\text { Engenharias - Engenharia de } \\
\text { Produção }\end{array}$ & fmarins@feg.unesp.br \\
\hline 18 & Luiz Carlos Di Serio & Maior nivel de formação: Doutorado & $\begin{array}{l}\text { Primeira área de atuação: } \\
\text { Engenharias - Engenharia de } \\
\text { Produção }\end{array}$ & Idiserio@fgvsp.br \\
\hline 19 & Fernando José Barbin Laurindo & $\begin{array}{l}\text { Maior nivel de formação: Doutorado } \\
\text { (Pós-Doutorado) }\end{array}$ & $\begin{array}{l}\text { Primeira área de atuação: } \\
\text { Engenharias - Multidisciplinar }\end{array}$ & fiblau@usp.br \\
\hline 20 & Paulo Cesar Masiero & $\begin{array}{l}\text { Maior nível de formação: Doutorado } \\
\text { (Pós-Doutorado) }\end{array}$ & $\begin{array}{l}\text { Primeira área de atuação: Ciências } \\
\text { Exatas e da Terra - Ciência da } \\
\text { Computacão }\end{array}$ & masiero@icmc.usp.br \\
\hline
\end{tabular}




\begin{tabular}{|c|c|c|c|c|}
\hline 21 & Rosana Teresinha Vaccare Braga & Maior nivel de formação: Doutorado & $\begin{array}{l}\text { Primeira área de atuaçẫo: Ciências } \\
\text { Exatas e da Terra - Ciência da } \\
\text { Computacão }\end{array}$ & rtvb@icmc.usp.br \\
\hline 22 & Cirano lochpe & Maior nível de formação: Doutorado & $\begin{array}{l}\text { Primeira área de atuaçāo: Ciências } \\
\text { Exatas e da Terra - Ciência da } \\
\text { Computação - UFRGS }\end{array}$ & ciochpe@inf.ufrgs.br \\
\hline 23 & Jano Moreira de Souza & Maior nível de formação: Doutorado & $\begin{array}{l}\text { Primeira área de atuaçāo: Ciências } \\
\text { Exatas e da Terra - Ciência da } \\
\text { Computação }\end{array}$ & jano@cos.ufr.br \\
\hline 24 & Rosemary Barber-Madden & Maior nível de formação: Doutorado & $\begin{array}{l}\text { Primeira área de atuação: Ciências } \\
\text { da Saúde - Saúde Coletiva }\end{array}$ & rbarber madden@yahoo.com \\
\hline 25 & Isak Kruglianskas & $\begin{array}{l}\text { Maior nivel de formação: Doutorado } \\
\text { (Livre Docência) }\end{array}$ & $\begin{array}{l}\text { Primeira área de atuação: Ciências } \\
\text { Sociais Aplicadas - Administração }\end{array}$ & IKRUGLIA@USP.BR \\
\hline 26 & Anna Goussevskaia & Maior nível de formação: Doutorado & 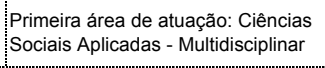 & Anna.Goussevskaia@wbs.ac.uk \\
\hline 27 & Luiz Flavio Autran Monteiro Gomes & $\begin{array}{l}\text { Maior nível de formação: Doutorado } \\
\text { (Pós-Doutorado) }\end{array}$ & $\begin{array}{l}\text { Primeira área de atuação: } \\
\text { Engenharias - Engenharia de } \\
\text { Produção }\end{array}$ & luiz.autran.gomes@terra.com.br \\
\hline 28 & Donizeti de Andrade & Maior nível de formação: Doutorado & $\begin{array}{l}\text { Primeira área de atuação: } \\
\text { Engenharias - Engenharia } \\
\text { Aeroespacial }\end{array}$ & donizetideandrade@terra.com.br \\
\hline 29 & José Celso Contador & $\begin{array}{l}\text { Maior nivel de formação: Doutorado } \\
\text { (Livre Docência) }\end{array}$ & $\begin{array}{l}\text { Primeira área de atuação: Ciências } \\
\text { Sociais Aplicadas - Multidisciplinar }\end{array}$ & celsocontador@terra.com.br \\
\hline 30 & Antonio Freitas Rentes & $\begin{array}{l}\text { Maior nivel de formaçāo: Doutorado } \\
\text { (Livre Docência) }\end{array}$ & $\begin{array}{l}\text { Primeira área de atuaçấo: } \\
\text { Engenharias - Multidisciplinar }\end{array}$ & rentes@sc.usp.br \\
\hline 31 & Maria Luiza Machado Campos & Maior nível de formação: Doutorado & $\begin{array}{l}\text { Primeira área de atuaçẫo: Ciências } \\
\text { Exatas e da Terra - Ciência da } \\
\text { Computação }\end{array}$ & mluiza@nce.ufri.br \\
\hline 32 & Heitor Luiz Murat de Meirelles Quintella & $\begin{array}{l}\text { Maior nível de formação: Doutorado } \\
\text { (Pós-Doutorado) }\end{array}$ & $\begin{array}{l}\text { Primeira área de atuaçāo: } \\
\text { Engenharias - Engenharia de } \\
\text { Produção }\end{array}$ & hquintel@unisys.com.br \\
\hline 33 & Marly Monteiro de Carvalho & $\begin{array}{l}\text { Maior nível de formação: Doutorado } \\
\text { (Pós-Doutorado) }\end{array}$ & $\begin{array}{l}\text { Primeira área de atuação: } \\
\text { Engenharias - Multidisciplinar }\end{array}$ & marlymc@usp.br \\
\hline 34 & Hercules Antonio do Prado & Maior nivel de formação: Doutorado & $\begin{array}{l}\text { Primeira área de atuação: Ciências } \\
\text { Exatas e da Terra - Multidisciplinar }\end{array}$ & hercules@ctaa.embrapa.br \\
\hline 36 & Alexandra Augusta Pereira Klen & $\begin{array}{l}\text { Maior nível de formaçãa: Doutorado } \\
\text { (Pós-Doutorado) }\end{array}$ & $\begin{array}{l}\text { Primeira área de atuação: } \\
\text { Engenharias - Multidisciplinar }\end{array}$ & klen@gsigma.ufsc.br \\
\hline 37 & Ricardo José Rabelo & Maior nivel de formação: Doutorado & $\begin{array}{l}\text { Primeira área de atuação: } \\
\text { Engenharias - Engenharia de } \\
\text { Produção }\end{array}$ & rabelo@das.ufsc.br \\
\hline 38 & Suzana Braga Rodrigues & $\begin{array}{l}\text { Maior nível de formação: Doutorado } \\
\text { (Pós-Doutorado) }\end{array}$ & $\begin{array}{l}\text { Primeira área de atuação: Ciências } \\
\text { Sociais Aplicadas - Administração - } \\
\text { UFMG }\end{array}$ & sbrodrigues@task.com.br \\
\hline 39 & Rolando Vargas Vallejos & Maior nível de formação: Mestrado & $\begin{array}{l}\text { Primeira área de atuaçāo: } \\
\text { Engenharias - Multidisciplinar }\end{array}$ & rvvallej@ucs.br \\
\hline 40 & Osvaldo Luiz Gonçalves Quelhas & $\begin{array}{l}\text { Primeira área de atuação: } \\
\text { Engenharias - Engenharia de } \\
\text { Producão }\end{array}$ & $\begin{array}{l}\text { Instituição: Universidade Federal } \\
\text { Fluminense }\end{array}$ & guelhas@latec.uff.br \\
\hline 41 & Luiz Cesar Ribeiro Carpinetti & $\begin{array}{l}\text { Maior nível de formação: Doutorado } \\
\text { (Livre Docência) }\end{array}$ & $\begin{array}{l}\text { Primeira área de atuação: } \\
\text { Engenharias - Multidisciplinar }\end{array}$ & carpinet@prod.eesc.usp.br \\
\hline 42 & Luiz Alex Silva Saraiva & Maior nível de formação: Mestrado & $\begin{array}{l}\text { Primeira área de atuação: Ciências } \\
\text { Sociais Aplicadas - Multidisciplinar }\end{array}$ & lassaraiva@uol.com.br \\
\hline 43 & Manfred Fehr & $\begin{array}{l}\text { Maior nivel de formaçẫo: Doutorado } \\
\text { (Pós-Doutorado) }\end{array}$ & $\begin{array}{l}\text { Primeira área de atuaçẫo: } \\
\text { Engenharias - Multidisciplinar }\end{array}$ & prosec22@yahoo.com \\
\hline 44 & Rogerio Atem de Carvalho & Maior nivel de formação: Doutorado & $\begin{array}{l}\text { Primeira área de atuação: Ciências } \\
\text { Exatas e da Terra - Ciência da } \\
\text { Computação }\end{array}$ & ratem@cefetcampos.br \\
\hline 45 & Neusa Maria Bastos Fernandes dos Santos & $\begin{array}{l}\text { Maior nivel de formação: Doutorado } \\
\text { (Pós-Doutorado) }\end{array}$ & $\begin{array}{l}\text { Primeira área de atuação: Não } \\
\text { informada }\end{array}$ & admneusa@pucsp.br \\
\hline 46 & George Wagner Leão e Sousa & $\begin{array}{l}\text { Primeira área de atuação: } \\
\text { Engenharias - Engenharia de } \\
\text { Producão }\end{array}$ & $\begin{array}{l}\text { Instituição: Pontifícia Universidade } \\
\text { Católica do Paraná }\end{array}$ & george.sousa@pucpr.br \\
\hline 47 & Maria Angela Campelo de Melo & $\begin{array}{l}\text { Maior nível de formação: Doutorado } \\
\text { (Pós-Doutorado) }\end{array}$ & $\begin{array}{l}\text { Primeira área de atuação: } \\
\text { Engenharias - Engenharia de } \\
\text { Produção }\end{array}$ & macm@ind.puc-rio.br \\
\hline 48 & Sérgio Roberto Pereira & Maior nível de formação: Mestrado & $\begin{array}{l}\text { Primeira área de atuação: } \\
\text { Engenharias - Multidisciplinar }\end{array}$ & sergiop@cpgd.com.br \\
\hline 49 & Luiz Carlos Duclós & Maior nível de formação: Doutorado & $\begin{array}{l}\text { Primeira área de atuação: Ciências } \\
\text { Sociais Aplicadas - Multidisciplinar }\end{array}$ & luiz.duclos@pucpr.br \\
\hline 50 & Hugo Fuks & Maior nivel de formação: Doutorado & $\begin{array}{l}\text { Primeira área de atuação: Ciências } \\
\text { Exatas e da Terra - Multidisciplinar - } \\
\text { PUC RJ }\end{array}$ & hugo@inf.puc-rio.br \\
\hline
\end{tabular}




\begin{tabular}{|c|c|c|c|c|}
\hline 52 & José Amaro dos Santos & Maior nível de formação: Doutorado & $\begin{array}{l}\text { Primeira área de atuação: Ciências } \\
\text { Sociais Aplicadas - Administração }\end{array}$ & amaro@ufpr.br \\
\hline 53 & Eduardo Pinheiro Gondim de Vasconcellos & $\begin{array}{l}\text { Maior nível de formação: Doutorado } \\
\text { (Livre Docência) }\end{array}$ & $\begin{array}{l}\text { Primeira área de atuação: Ciências } \\
\text { Sociais Aplicadas - Multidisciplinar }\end{array}$ & epgdvasc@usp.br \\
\hline 54 & Heliana Comin Vargas & $\begin{array}{l}\text { Primeira área de atuaçẫo: Ciências } \\
\text { Sociais Aplicadas - Planejamento } \\
\text { Urbano e Regional }\end{array}$ & $\begin{array}{l}\text { Instituição: Universidade de São } \\
\text { Paulo }\end{array}$ & hcvargas@usp.br \\
\hline 55 & Alexandre Marcos Lins de Vasconcelos & Maior nível de formação: Doutorado & $\begin{array}{l}\text { Primeira área de atuação: Ciências } \\
\text { Exatas e da Terra - Multidisciplinar }\end{array}$ & amlv@cin.ufpe.br \\
\hline 56 & Wilson Vicente Ruggiero & $\begin{array}{l}\text { Maior nível de formação: Doutorado } \\
\text { (Livre Docência) }\end{array}$ & $\begin{array}{l}\text { Primeira área de atuação: } \\
\text { Engenharias - Multidisciplinar }\end{array}$ & wilson@larc.usp.br \\
\hline 57 & Vanessa Gomes da Silva & Maior nível de formação: Doutorado & $\begin{array}{l}\text { Primeira área de atuaçẫo: } \\
\text { Engenharias - Multidisciplinar }\end{array}$ & vangomes@fec.unicamp.br \\
\hline 58 & Marie Anne Macadar Moron & Maior nível de formação: Doutorado & $\begin{array}{l}\text { Primeira área de atuação: Ciências } \\
\text { Sociais Aplicadas - Multidisciplinar }\end{array}$ & macadar@via-rs.net \\
\hline 59 & Michitoshi Oishi & $\begin{array}{l}\text { Maior nivel de formação: Doutorado } \\
\text { (Pós-Doutorado) }\end{array}$ & $\begin{array}{l}\text { Primeira área de atuação: Ciências } \\
\text { Sociais Aplicadas - Administração }\end{array}$ & oishi@brturbo.com.br \\
\hline 60 & Rafael Prikladnicki & Maior nivel de formação: Mestrado & $\begin{array}{l}\text { Primeira área de atuação: Ciências } \\
\text { Exatas e da Terra - Ciência da } \\
\text { Computação }\end{array}$ & rafael@inf.pucrs.br \\
\hline 61 & Tânia Cristina D'Agostini Bueno & Maior nível de formação: Doutorado & $\begin{array}{l}\text { Primeira área de atuação: } \\
\text { Engenharias - Multidisciplinar }\end{array}$ & tania@linhalivre.net \\
\hline 62 & Jose Luis Duarte Ribeiro & $\begin{array}{l}\text { Maior nivel de formação: Doutorado } \\
\text { (Pós-Doutorado) }\end{array}$ & $\begin{array}{l}\text { Primeira área de atuação: } \\
\text { Engenharias - Engenharia de } \\
\text { Producão }\end{array}$ & ribeiro@ufrgs.br \\
\hline 63 & Leonardo Ensslin & $\begin{array}{l}\text { Maior nivel de formação: Doutorado } \\
\text { (Pós-Doutorado) }\end{array}$ & $\begin{array}{l}\text { Primeira área de atuação: } \\
\text { Engenharias - Engenharia de } \\
\text { Producão }\end{array}$ & ensslin@eps.ufsc.br \\
\hline 64 & Edson Pinheiro de Lima & Maior nível de formação: Doutorado & $\begin{array}{l}\text { Primeira área de atuação: Nâo } \\
\text { informada }\end{array}$ & e.pinheiro@pucpr.br \\
\hline 65 & Klaus Schützer & Maior nível de formação: Doutorado & $\begin{array}{l}\text { Primeira área de atuação: } \\
\text { Engenharias - Engenharia Mecânica }\end{array}$ & schuetzer@unimep.br \\
\hline 66 & Calebe de Paula Bianchini & Maior nível de formação: Mestrado & $\begin{array}{l}\text { Primeira área de atuação: Ciências } \\
\text { Exatas e da Terra - Ciência da } \\
\text { Computacãa }\end{array}$ & calebe@netsite.com.br \\
\hline 67 & Antonio Artur de Souza & Maior nível de formação: Doutorado & $\begin{array}{l}\text { Primeira área de atuação: Ciências } \\
\text { Sociais Aplicadas - Administração }\end{array}$ & artur@face.ufmg.br \\
\hline 68 & Sergio Eduardo Gouvea da Costa & Maior nível de formação: Doutorado & $\begin{array}{l}\text { Primeira área de atuação: } \\
\text { Engenharias - Engenharia Elétrica }\end{array}$ & s.gouvea@pucpr.br \\
\hline 69 & Wilson Toshiro Nakamura & Maior nível de formação: Doutorado & $\begin{array}{l}\text { Primeira área de atuação: Ciências } \\
\text { Sociais Aplicadas - Administração }\end{array}$ & wtnakamura@uol.com.br \\
\hline 70 & Edson Alves de Oliveira Junior & Maior nível de formação: Mestrado & $\begin{array}{l}\text { Primeira área de atuaçâo: Ciências } \\
\text { Exatas e da Terra - Ciência da } \\
\text { Computacão }\end{array}$ & edson.junior@pop.com.br \\
\hline 71 & Milena Bodmer & $\begin{array}{l}\text { Maior nivel de formação: Doutorado } \\
\text { (Pós-Doutorado) }\end{array}$ & $\begin{array}{l}\text { Primeira área de atuaçẫo: } \\
\text { Engenharias - Engenharia de } \\
\text { Transportes }\end{array}$ & milenium@infolink.com.br \\
\hline 72 & Fabricio Alves Barbosa da Silva & $\begin{array}{l}\text { Maior nível de formação: Doutorado } \\
\text { (Pós-Doutorado) }\end{array}$ & $\begin{array}{l}\text { Primeira área de atuaçâo: Ciências } \\
\text { Exatas e da Terra - Ciência da } \\
\text { Computacão }\end{array}$ & fabricio@unisantos.br \\
\hline 73 & Renata Mendes de Araujo & $\begin{array}{l}\text { Maior nível de formação: Doutorado } \\
\text { (Pós-Doutorado) }\end{array}$ & $\begin{array}{l}\text { Primeira área de atuaçâo: Ciências } \\
\text { Exatas e da Terra - Ciência da } \\
\text { Computação }\end{array}$ & renata.araujo@uniriotec.br \\
\hline 74 & Mauro de Mesquita Spinola & Maior nível de formação: Doutorado & $\begin{array}{l}\text { Primeira área de atuação: Ciências } \\
\text { Exatas e da Terra - Ciência da } \\
\text { Computacão }\end{array}$ & mauro.spinola@poli.usp.br \\
\hline 75 & Jose Carlos de Toledo & Maior nível de formação: Doutorado & $\begin{array}{l}\text { Primeira área de atuação: } \\
\text { Engenharias - Engenharia de } \\
\text { Produção - UFSCAR }\end{array}$ & toledo@power.ufscar.br \\
\hline 76 & Walace Sartori Bonfim & Maior nivel de formação: Mestrado & $\begin{array}{l}\text { Primeira área de atuação: Ciências } \\
\text { Exatas e da Terra - Multidisciplinar }\end{array}$ & walace@ec3.com.br \\
\hline 77 & Dario Henrique Alliprandini & $\begin{array}{l}\text { Maior nível de formação: Doutorado } \\
\text { (Pós-Doutorado) }\end{array}$ & $\begin{array}{l}\text { Primeira área de atuação: } \\
\text { Engenharias - Engenharia de } \\
\text { Producão - UFSCAR }\end{array}$ & dha@power.ufscar.br \\
\hline 78 & Antonio Nelson Rodrigues da Silva & $\begin{array}{l}\text { Maior nivel de formação: Doutorado } \\
\text { (Livre Docência) }\end{array}$ & $\begin{array}{l}\text { Primeira área de atuação: } \\
\text { Engenharias - Engenharia de } \\
\text { Transportes }\end{array}$ & anelson@sc.usp.br \\
\hline 79 & Paulo Mauricio Selig & Maior nível de formação: Doutorado & $\begin{array}{l}\text { Primeira área de atuação: } \\
\text { Engenharias - Multidisciplinar - } \\
\text { UFSC }\end{array}$ & selig@deps.ufsc.br \\
\hline 80 & Fabio Frezatti & $\begin{array}{l}\text { Maior nivel de formação: Doutorado } \\
\text { (Livre Docência) }\end{array}$ & $\begin{array}{l}\text { Primeira área de atuação: Ciências } \\
\text { Sociais Aplicadas - Administração }\end{array}$ & frezatti@usp.br \\
\hline 81 & Miguel Fiod Neto & Maior nível de formação: Doutorado & $\begin{array}{l}\text { Primeira área de atuação: } \\
\text { Engenharias - Engenharia de } \\
\text { Producãa. }\end{array}$ & miguelfiod@deps.ufsc.br \\
\hline 82 & Antonio Carlos Tonini & Maior nível de formação: Mestrado & $\begin{array}{l}\text { Primeira área de atuação: Ciências } \\
\text { Sociais Aplicadas - Administração }\end{array}$ & actonini@uol.com.br \\
\hline
\end{tabular}




\begin{tabular}{|c|c|c|c|c|}
\hline 83 & Pedro Rafael Falcone Sampaio & $\begin{array}{l}\text { Maior nivel de formação: Doutorado } \\
\text { (Pós-Doutorado) }\end{array}$ & $\begin{array}{l}\text { Primeira área de atuaçâo: Ciências } \\
\text { Exatas e da Terra - Ciência da } \\
\text { Computacão }\end{array}$ & p.sampaio@manchester.ac.uk \\
\hline 84 & Vera Lúcia Lopes Cristovão & Maior nível de formação: Doutorado & $\begin{array}{l}\text { Primeira área de atuação: } \\
\text { Lingǘstica, Letras e Artes - } \\
\text { Multidisciplinar }\end{array}$ & cristova@uel.br \\
\hline 85 & Geraldina Porto Witter & $\begin{array}{l}\text { Maior nivel de formaçāo: Doutorado } \\
\text { (Livre Docência) }\end{array}$ & $\begin{array}{l}\text { Primeira área de atuaçâo: Ciências } \\
\text { Humanas - Psicologia }\end{array}$ & witter@uol.com.br \\
\hline 86 & Hélène Bertrand & Maior nível de formação: Doutorado & $\begin{array}{l}\text { Primeira área de atuação: Ciências } \\
\text { Sociais Aplicadas - Multidisciplinar - } \\
\text { PUC RJ }\end{array}$ & bertrand@iag.puc-rio.br \\
\hline 87 & Mírian Oliveira & Maior nível de formação: Doutorado & $\begin{array}{l}\text { Primeira área de atuação: Ciências } \\
\text { Sociais Aplicadas - Multidisciplinar }\end{array}$ & miriano@pucrs.br \\
\hline 88 & Cristian Tristão & Maior nível de formação: Graduação & $\begin{array}{l}\text { Primeira área de atuaçẫo: Ciências } \\
\text { Exatas e da Terra - Ciência da } \\
\text { Computacão }\end{array}$ & ctristao@inf.pucrs.br \\
\hline 89 & Duncan Dubugras Alcoba Ruiz & $\begin{array}{l}\text { Primeira área de atuaçẫo: Ciências } \\
\text { Exatas e da Terra - Ciência da } \\
\text { Computacão }\end{array}$ & $\begin{array}{l}\text { Instituição: PONTIFICIA } \\
\text { UNIVERSIDADE CATOLICA DO } \\
\text { RIO GRANDE DO SUL }\end{array}$ & duncan@inf.pucrs.br \\
\hline 90 & Armando de Azevedo Caldeira Pires & $\begin{array}{l}\text { Maior nível de formação: Doutorado } \\
\text { (Pós-Doutorado) }\end{array}$ & $\begin{array}{l}\text { Primeira área de atuaçâo: Ciências } \\
\text { Exatas e da Terra - Ciência da } \\
\text { Computacão }\end{array}$ & armandcp@unb.br \\
\hline 91 & Carlos Alberto Costa & Maior nível de formação: Doutorado & $\begin{array}{l}\text { Primeira área de atuação: } \\
\text { Engenharias - Engenharia Mecânica }\end{array}$ & cacosta@ucs.br \\
\hline 92 & Henrique Mello Rodrigues de Freitas & $\begin{array}{l}\text { Maior nível de formação: Doutorado } \\
\text { (Pós-Doutorado) }\end{array}$ & $\begin{array}{l}\text { Primeira área de atuação: Ciências } \\
\text { Sociais Aplicadas - Multidisciplinar }\end{array}$ & hf@ea.ufrgs.br \\
\hline 93 & Maria Aparecida Gouvea & Maior nível de formação: Doutorado & $\begin{array}{l}\text { Primeira área de atuação: Ciências } \\
\text { Sociais Aplicadas - Administração }\end{array}$ & magouvea@usp.br \\
\hline 94 & Asher Kiperstok & Maior nível de formação: Doutorado & $\begin{array}{l}\text { Primeira área de atuaçẫo: } \\
\text { Engenharias - Multidisciplinar }\end{array}$ & asher@ufba.br \\
\hline 95 & Manuel de Jesus Mendes & $\begin{array}{l}\text { Maior nível de formação: Doutorado } \\
\text { (Pós-Doutorado) }\end{array}$ & $\begin{array}{l}\text { Primeira área de atuação: } \\
\text { Engenharias - Multidisciplinar }\end{array}$ & mendes@dca.fee.unicamp.br \\
\hline 96 & Marco Antônio Paludo & Maior nivel de formação: Mestrado & $\begin{array}{l}\text { Primeira área de atuaçẫo: Ciências } \\
\text { Exatas e da Terra - Ciência da } \\
\text { Computacão }\end{array}$ & m.paludo@sul.com.br \\
\hline 97 & Clovis Luiz Machado-da-Silva & Maior nível de formação: Doutorado & $\begin{array}{l}\text { Primeira área de atuação: Ciências } \\
\text { Sociais Aplicadas - Administração }\end{array}$ & clms@terra.com.br \\
\hline 98 & Robert Carlisle Burnett & Maior nível de formação: Doutorado & $\begin{array}{l}\text { Primeira área de atuaçâo: Ciências } \\
\text { Exatas e da Terra - Ciência da } \\
\text { Computacãa }\end{array}$ & robert.burnett@pucpr.br \\
\hline 99 & João Luiz Becker & Maior nível de formação: Doutorado & $\begin{array}{l}\text { Primeira área de atuação: Ciências } \\
\text { Sociais Aplicadas - Multidisciplinar }\end{array}$ & jbecker@ea.ufrgs.br \\
\hline 100 & Wagner Meira Junior & Maior nível de formação: Doutorado & $\begin{array}{l}\text { Primeira área de atuaçâo: Ciências } \\
\text { Exatas e da Terra - Ciência da } \\
\text { Computacão }\end{array}$ & MEIRA@DCC.UFMG.BR \\
\hline 101 & Eduardo Amaral Haddad & $\begin{array}{l}\text { Maior nível de formação: Doutorado } \\
\text { (Livre Docência) }\end{array}$ & $\begin{array}{l}\text { Primeira área de atuação: Ciências } \\
\text { Sociais Aplicadas - Economia }\end{array}$ & ehaddad@usp.br \\
\hline 102 & Rafael Paim Cunha Santos & Maior nível de formação: Mestrado & $\begin{array}{l}\text { Primeira área de atuação: } \\
\text { Engenharias - Engenharia de } \\
\text { Producão }\end{array}$ & rafael@gpi.ufri.br \\
\hline 103 & Ana Cristina Vieira de Melo & Maior nível de formação: Doutorado & $\begin{array}{l}\text { Primeira área de atuação: Ciências } \\
\text { Exatas e da Terra - Ciência da } \\
\text { Computação- USP }\end{array}$ & acvm@ime.usp.br \\
\hline 104 & Paulo Henrique Muller Prado & $\begin{array}{l}\text { Primeira área de atuação: Ciências } \\
\text { Sociais Aplicadas - Administração }\end{array}$ & $\begin{array}{l}\text { Instituição: Universidade Federal do } \\
\text { Paraná }\end{array}$ & pprado@ufpr.br \\
\hline 105 & Sérgio Carvalho Benício de Mello & Maior nível de formação: Doutorado & $\begin{array}{l}\text { Primeira área de atuação: Ciências } \\
\text { Sociais Aplicadas - Administração }\end{array}$ & scbm@elogica.com.br \\
\hline 106 & Marcia Marques Gomes & Maior nível de formação: Doutorado & $\begin{array}{l}\text { Primeira área de atuação: } \\
\text { Engenharias - Engenharia Sanitária }\end{array}$ & marcia@marques.pro.br \\
\hline 107 & Dario Ikuo Miyake & $\begin{array}{l}\text { Maior nivel de formação: Doutorado } \\
\text { (Pós-Doutorado) }\end{array}$ & $\begin{array}{l}\text { Primeira área de atuação: } \\
\text { Engenharias - Engenharia de } \\
\text { Producão }\end{array}$ & dariomiy@usp.br \\
\hline 108 & Maurício Fernandes Pereira & $\begin{array}{l}\text { Primeira área de atuação: Ciências } \\
\text { Sociais Aplicadas - Administração }\end{array}$ & $\begin{array}{l}\text { Instituição: Universidade Federal de } \\
\text { Santa Catarina }\end{array}$ & mpereira@cse.ufsc.br \\
\hline 109 & Dagoberto Alves de Almeida & Maior nível de formação: Doutorado & $\begin{array}{l}\text { Primeira área de atuação: } \\
\text { Engenharias - Multidisciplinar }\end{array}$ & dagoberto@unifei.edu.br \\
\hline 110 & Vania Ribas Ulbricht & Maior nível de formação: Doutorado & $\begin{array}{l}\text { Primeira área de atuação: Ciências } \\
\text { Humanas - Educacão }\end{array}$ & ulbricht@floripa.com.br \\
\hline 111 & Roberto Sbragia & $\begin{array}{l}\text { Maior nível de formação: Doutorado } \\
\text { (Pós-Doutorado) }\end{array}$ & $\begin{array}{l}\text { Primeira área de atuação: Ciências } \\
\text { Sociais Aplicadas - Administração }\end{array}$ & rsbragia@usp.br \\
\hline 112 & Cláudio Rodrigues Muniz da Silva & Maior nível de formação: Doutorado & $\begin{array}{l}\text { Primeira área de atuaçâo: Ciências } \\
\text { Exatas e da Terra - Ciência da } \\
\text { Computacão }\end{array}$ & crmsilva@terra.com.br \\
\hline 113 & Aline França de Abreu & Maior nível de formação: Doutorado & $\begin{array}{l}\text { Primeira área de atuaçâo: Ciências } \\
\text { Exatas e da Terra - Ciência da } \\
\text { Computacão- UFSC }\end{array}$ & aline@deps.ufsc.br \\
\hline
\end{tabular}




\begin{tabular}{|c|c|c|c|c|}
\hline 114 & Peter Kevin Spink & $\begin{array}{l}\text { Maior nível de formação: Doutorado } \\
\text { (Pós-Doutorado) }\end{array}$ & $\begin{array}{l}\text { Primeira área de atuação: Ciências } \\
\text { Humanas - Psicologia }\end{array}$ & spink@fgvsp.br \\
\hline 115 & Filipe Teixeira Marques & Maior nível de formação: Graduação & $\begin{array}{l}\text { Primeira área de atuação: Ciências } \\
\text { Exatas e da Terra - Multidisciplinar }\end{array}$ & filipetm@gmail.com \\
\hline 116 & Angela Maria Cavalcanti da Rocha & Maior nível de formação: Doutorado & $\begin{array}{l}\text { Primeira área de atuação: Ciências } \\
\text { Sociais Aplicadas - Administração }\end{array}$ & angela@coppead.ufri.br \\
\hline 117 & Cristina Muccioli & $\begin{array}{l}\text { Maior nivel de formação: Doutorado } \\
\text { (Livre Docência) }\end{array}$ & $\begin{array}{l}\text { Primeira área de atuação: Ciências } \\
\text { da Saúde - Medicina - UNIFESP }\end{array}$ & cmucciol@uol.com.br \\
\hline 118 & Rogerio Hermida Quintella & Maior nível de formação: Doutorado & $\begin{array}{l}\text { Primeira área de atuação: Ciências } \\
\text { Sociais Aplicadas - Administração }\end{array}$ & rogerio@ufba.br \\
\hline 119 & Julia Celia Mercedes Strauch & Maior nível de formação: Doutorado & $\begin{array}{l}\text { Primeira área de atuação: Ciências } \\
\text { Exatas e da Terra - Multidisciplinar }\end{array}$ & juliast@ibge.gov.br \\
\hline 120 & Jorge Antonio Martins & Maior nível de formação: Doutorado & $\begin{array}{l}\text { Primeira área de atuação: } \\
\text { Engenharias - Engenharia de } \\
\text { Transportes }\end{array}$ & jmartinsxxi@hotmail.com \\
\hline 121 & Edmilson Rampazzo Klen & $\begin{array}{l}\text { Primeira área de aluação: } \\
\text { Engenharias - Multidisciplinar }\end{array}$ & $\begin{array}{l}\text { Instituiçãa: Universidade Federal de } \\
\text { Santa Catarina }\end{array}$ & erklen@gsigma-grucon.ufsc.br \\
\hline 122 & Geraldo Luciano Toledo & $\begin{array}{l}\text { Maior nivel de formação: Doutorado } \\
\text { (Livre Docência) }\end{array}$ & $\begin{array}{l}\text { Primeira área de atuação: Ciências } \\
\text { Sociais Aplicadas - Administração }\end{array}$ & GLTOLEDO@USP.BR \\
\hline 123 & Nelio Domingues Pizzolato & $\begin{array}{l}\text { Maior nível de formação: Doutorado } \\
\text { (Pós-Doutorado) }\end{array}$ & $\begin{array}{l}\text { Primeira área de atuação: } \\
\text { Engenharias - Engenharia de } \\
\text { Producão- - PUCRJ }\end{array}$ & ndp@ind.puc-rio.br \\
\hline 124 & Carlos Alberto Gonçalves & Maior nível de formação: Doutorado & $\begin{array}{l}\text { Primeira área de atuação: Ciências } \\
\text { Sociais Aplicadas - Administração }\end{array}$ & carlos@face.ufmg.br \\
\hline 125 & Tania Fatima Calvi Tait & Maior nível de formação: Doutorado & $\begin{array}{l}\text { Primeira área de atuaçẫo: Ciências } \\
\text { Exatas e da Terra - Ciência da } \\
\text { Computação }\end{array}$ & tait@din.uem.br \\
\hline 126 & Geraldo Nunes Corrêa & Maior nível de formação: Doutorado & $\begin{array}{l}\text { Primeira área de atuação: Ciências } \\
\text { Exatas e da Terra - Ciência da } \\
\text { Computação }\end{array}$ & geraldo@saoluis.br \\
\hline 127 & Maurício Manoel Ribeiro dos Santos & Maior nível de formação: Graduação & $\begin{array}{l}\text { Primeira área de atuação: } \\
\text { Engenharias - Engenharia de } \\
\text { Produção }\end{array}$ & mribeiro@accio.com.br \\
\hline 128 & Luiz Dourado Dias Junior & Maior nível de formação: Graduação & $\begin{array}{l}\text { Primeira área de atuação: Ciências } \\
\text { Exatas e da Terra - Ciência da } \\
\text { Computação }\end{array}$ & Idourado1980@globo.com \\
\hline 129 & Luiz Camolesi Júnior & Maior nível de formação: Doutorado & $\begin{array}{l}\text { Primeira área de atuação: Ciências } \\
\text { Exatas e da Terra - Ciência da } \\
\text { Computacão }\end{array}$ & Icamoles@unimep.br \\
\hline 130 & Filipe Corrêa da Costa & $\begin{array}{l}\text { Maior nivel de formação: } \\
\text { Especialização }\end{array}$ & $\begin{array}{l}\text { Primeira área de atuação: Ciências } \\
\text { Sociais Aplicadas - Direito }\end{array}$ & filipe@ijuris.org \\
\hline$\ldots 131$ & Nicolau Reinhard & $\begin{array}{l}\text { Maior nível de formação: Doutorado } \\
\text { (Livre Docência) }\end{array}$ & $\begin{array}{l}\text { Primeira área de atuaçẫo: Ciências } \\
\text { Sociais Aplicadas - Multidisciplinar - } \\
\text { USP }\end{array}$ & reinhard@usp.br \\
\hline 132 & Guillermo José Asper y Valdés & Maior nível de formação: Doutorado & $\begin{array}{l}\text { Primeira área de atuação: Ciências } \\
\text { Sociais Aplicadas - Multidisciplinar }\end{array}$ & asper@unb.br \\
\hline 133 & Marcus Costa Sampaio & Maior nível de formação: Doutorado & $\begin{array}{l}\text { Primeira área de atuaçẫo: Ciências } \\
\text { Exatas e da Terra - Ciência da } \\
\text { Computacão }\end{array}$ & costasampaio@uol.com.br \\
\hline 134 & Alexandre Reis Graeml & Maior nível de formação: Doutorado & $\begin{array}{l}\text { Primeira área de atuação: Ciências } \\
\text { Sociais Aplicadas - Multidisciplinar }\end{array}$ & graeml@fulbrightweb.org \\
\hline 135 & Geilson Loureiro & Maior nível de formação: Doutorado & $\begin{array}{l}\text { Primeira área de atuaçâo: } \\
\text { Engenharias - Engenharia de } \\
\text { Producão }\end{array}$ & geilson@directnet.com.br \\
\hline 136 & Claudia Cristina Bitencourt & Maior nível de formação: Doutorado & $\begin{array}{l}\text { Primeira área de atuação: Ciências } \\
\text { Sociais Aplicadas - Administração }\end{array}$ & claudiab.ez@terra.com.br \\
\hline 137 & Francisco José Kliemann Neto & Maior nível de formação: Doutorado & $\begin{array}{l}\text { Primeira área de atuaçâo: Nâo } \\
\text { informada }\end{array}$ & Kliemann@producao.ufrgs.br \\
\hline 138 & Mirian Palmeira & Maior nível de formação: Doutorado & $\begin{array}{l}\text { Primeira área de atuação: Ciências } \\
\text { Sociais Aplicadas - Administração }\end{array}$ & mirianpalmeira@ufpr.br \\
\hline 139 & Marcos Antonio Pedlowski & Maior nivel de formação: Doutorado & $\begin{array}{l}\text { Primeira área de atuação: Ciências } \\
\text { Humanas - Geografia }\end{array}$ & pedlowma@uenf.br \\
\hline 140 & Yeda Swirski de Souza & Maior nível de formação: Doutorado & $\begin{array}{l}\text { Primeira área de atuação: Ciências } \\
\text { Sociais Aplicadas - Administração }\end{array}$ & yedasou@portoweb.com.br \\
\hline 141 & Alex Coltro & $\begin{array}{l}\text { Maior nivel de formação: Doutorado } \\
\text { (Pós-Doutorado) }\end{array}$ & $\begin{array}{l}\text { Primeira área de atuação: Ciências } \\
\text { Sociais Aplicadas - Multidisciplinar }\end{array}$ & alcoltro@usp.br \\
\hline 142 & Matheus Alberto Consoli & Maior nível de formação: Graduação & $\begin{array}{l}\text { Primeira área de atuação: Ciências } \\
\text { Sociais Aplicadas - Multidisciplinar }\end{array}$ & consoli@usp.br \\
\hline 143 & Rodrigo Fernandes de Mello & $\begin{array}{l}\text { Primeira área de atuação: Ciências } \\
\text { Exatas e da Terra - Ciência da } \\
\text { Computação }\end{array}$ & $\begin{array}{l}\text { Instituição: Universidade de São } \\
\text { Paulo }\end{array}$ & mello@icmc.usp.br \\
\hline
\end{tabular}




\begin{tabular}{|c|c|c|c|c|}
\hline 144 & Mário Aquino Alves & Maior nivel de formação: Doutorado & $\begin{array}{l}\text { Primeira área de atuação: Ciências } \\
\text { Sociais Aplicadas - Administração }\end{array}$ & maalves@fgvsp.br \\
\hline 145 & Sergio Palma da Justa Medeiros & Maior nível de formação: Doutorado & $\begin{array}{l}\text { Primeira ára de atuaçẫo: Ciências } \\
\text { Exatas e da Terra - Ciência da } \\
\text { Computacão }\end{array}$ & palma@cos.ufri.br \\
\hline 146 & Guilherme Ary Plonski & $\begin{array}{l}\text { Maior nivel de formação: Doutorado } \\
\text { (Pós-Doutorado) }\end{array}$ & $\begin{array}{l}\text { Primeira área de atuação: Ciências } \\
\text { Sociais Aplicadas - Administração }\end{array}$ & plonski2@usp.br \\
\hline 147 & Ângela de Moura Ferreira Danilevicz & Maior nível de formação: Mestrado & $\begin{array}{l}\text { Primeira área de atuação: } \\
\text { Engenharias - Multidisciplinar }\end{array}$ & angelamfd@ppgep.ufrgs.br \\
\hline 148 & Renato José Carneiro Neto & Maior nivel de formação: Doutorado & $\begin{array}{l}\text { Primeira área de atuação: Ciências } \\
\text { Sociais Aplicadas - Administração }\end{array}$ & rcarneironeto@terra.com.br \\
\hline 149 & André Rego Macieira & Maior nivel de formação: Mestrado & $\begin{array}{l}\text { Primeira área de atuação: } \\
\text { Engenharias - Multidisciplinar }\end{array}$ & andremacieira@yahoo.com \\
\hline 150 & Jairo Laser Procianoy & Maior nível de formação: Doutorado & $\begin{array}{l}\text { Primeira área de atuação: Ciências } \\
\text { Sociais Aplicadas - Administração }\end{array}$ & Jprocianoy@ea.ufrgs.br \\
\hline 151 & Sylvia Constant Vergara & Maior nível de formação: Doutorado & $\begin{array}{l}\text { Primeira área de atuação: Ciências } \\
\text { Sociais Aplicadas - Administração }\end{array}$ & VERGARA@fgv.br \\
\hline 152 & Maurício Barcellos Almeida & Maior nivel de formação: Mestrado & $\begin{array}{l}\text { Primeira área de atuação: Ciências } \\
\text { Exatas e da Terra - Ciência da } \\
\text { Computação }\end{array}$ & mba@mbalmeida.pro.br \\
\hline 153 & Vanderli Correia Prieto & $\begin{array}{l}\text { Primeira área de atuação: Nẫo } \\
\text { informada }\end{array}$ & $\begin{array}{l}\text { Instituição: Universidade de São } \\
\text { Paulo }\end{array}$ & vanderli.prieto@poli.usp.br \\
\hline 154 & Paulo Afonso Lopes da Silva & Maior nível de formação: Doutorado & $\begin{array}{l}\text { Primeira área de atuaçẫo: Ciências } \\
\text { Exatas e da Terra - Probabilidade e } \\
\text { Estatística }\end{array}$ & estatistica@estatistica.eng.br \\
\hline 155 & Francisco Antonio Serralvo & $\begin{array}{l}\text { Primeira área de atuação: Ciências } \\
\text { Sociais Aplicadas - Administração }\end{array}$ & $\begin{array}{l}\text { Instituição: Pontifícia Universidade } \\
\text { Católica de São Paulo }\end{array}$ & serralvo@pucsp.br \\
\hline 156 & Fernanda Araujo Baião & Maior nível de formação: Doutorado & $\begin{array}{l}\text { Primeira área de atuaçẫo: Ciências } \\
\text { Exatas e da Terra - Ciência da } \\
\text { Computacão }\end{array}$ & fernanda.baiao@uniriotec.br \\
\hline 157 & Carmen Pires Migueles & Maior nivel de formação: Doutorado & $\begin{array}{l}\text { Primeira área de atuação: Ciências } \\
\text { Sociais Aplicadas - Administração }\end{array}$ & cmigueles@ig.com.br \\
\hline 158 & Vitor Brandi Junior & Maior nível de formação: Mestrado & $\begin{array}{l}\text { Primeira área de atuaçâa: Ciências } \\
\text { Exatas e da Terra - Ciência da } \\
\text { Computacão }\end{array}$ & vbrandi@unimep.br \\
\hline 159 & Denise Lima Fleck & Maior nível de formação: Doutorado & $\begin{array}{l}\text { Primeira área de atuação: Ciências } \\
\text { Sociais Aplicadas - Administração }\end{array}$ & denise@coppead.ufri.br \\
\hline 160 & Jose Carlos Assis Dornelas & $\begin{array}{l}\text { Maior nível de formação: Doutorado } \\
\text { (Pós-Doutorado) }\end{array}$ & $\begin{array}{l}\text { Primeira área de atuação: Ciências } \\
\text { Sociais Aplicadas - Multidisciplinar }\end{array}$ & dornelas@empreende.com.br \\
\hline 161 & Rebecca Arkader & Maior nível de formação: Doutorado & $\begin{array}{l}\text { Primeira área de atuação: Ciências } \\
\text { Sociais Aplicadas - Administração }\end{array}$ & rebecca@coppead.ufri.br \\
\hline 162 & José Ricardo Formagio Bueno & Maior nivel de formação: MBA & $\begin{array}{l}\text { Primeira área de atuação: } \\
\text { Engenharias - Engenharia Elétrica }\end{array}$ & formagio@cpgd.com.br \\
\hline 163 & Edgar Toshiro Yano & Maior nivel de formação: Doutorado & $\begin{array}{l}\text { Primeira área de atuação: Ciências } \\
\text { Exatas e da Terra - Multidisciplinar }\end{array}$ & yano@comp.ta.br \\
\hline 164 & Luiz Artur Ledur Brito & $\begin{array}{l}\text { Primeira área de atuação: Ciências } \\
\text { Sociais Aplicadas - Administração }\end{array}$ & $\begin{array}{l}\text { Instituição: Escola de Administração } \\
\text { de Empresas de São Paulo }\end{array}$ & brito@fgvsp.br \\
\hline 165 & Alexandre de Almeida Faria & Maior nivel de formação: Doutorado & $\begin{array}{l}\text { Primeira área de atuação: Ciências } \\
\text { Sociais Aplicadas - Administração }\end{array}$ & afaria@fgv.br \\
\hline 166 & Ricardo Rodrigo Stark Bernard & Maior nível de formação: Mestrado & $\begin{array}{l}\text { Primeira área de atuação: Ciências } \\
\text { Sociais Aplicadas - Administração }\end{array}$ & bernard@cse.ufsc.br \\
\hline 167 & Edson José Dalto & Maior nivel de formação: Doutorado & $\begin{array}{l}\text { Primeira área de atuação: Ciências } \\
\text { Sociais Aplicadas - Multidisciplinar }\end{array}$ & edalto@ibmecri.br \\
\hline 168 & Alberto Sanyuan Suen & $\begin{array}{l}\text { Primeira área de atuação: Ciências } \\
\text { Sociais Aplicadas - Administração }\end{array}$ & $\begin{array}{l}\text { Instituição: Escola de Administração } \\
\text { de Empresas de São Paulo }\end{array}$ & albertosuen@fgvsp.br \\
\hline 169 & Henrique Luiz Correa & $\begin{array}{l}\text { Primeira área de atuaçâo: } \\
\text { Engenharias - Engenharia de } \\
\text { Producão }\end{array}$ & $\begin{array}{l}\text { Instituição: Escola de Administração } \\
\text { de Empresas de São Paulo }\end{array}$ & hcorrea@fgvsp.br \\
\hline 170 & Carlos Machado de Oliveira & Maior nível de formação: Doutorado & $\begin{array}{l}\text { Primeira área de atuação: } \\
\text { Engenharias - Engenharia de } \\
\text { Producão }\end{array}$ & cmachado br@yahoo.com \\
\hline 171 & Ronaldo Soares de Andrade & $\begin{array}{l}\text { Maior nivel de formação: Doutorado } \\
\text { (Pós-Doutorado) }\end{array}$ & $\begin{array}{l}\text { Primeira área de atuação: } \\
\text { Engenharias - Engenharia de } \\
\text { Produção }\end{array}$ & ronaldo.andrade@ufrj.br \\
\hline 172 & José Alcides Gobbo Junior & Maior nivel de formação: Doutorado & $\begin{array}{l}\text { Primeira área de atuação: Ciências } \\
\text { Sociais Aplicadas - Administração }\end{array}$ & gobbo@feb.unesp.br \\
\hline 173 & Jose Antao Beltrao Moura & Maior nível de formação: Doutorado & $\begin{array}{l}\text { Primeira área de atuação: Ciências } \\
\text { Exatas e da Terra - Ciência da } \\
\text { Computacão }\end{array}$ & antao@dsc.ufcg.edu.br \\
\hline
\end{tabular}




\begin{tabular}{|c|c|c|c|c|}
\hline 174 & José Afonso Mazzon & $\begin{array}{l}\text { Primeira área de atuação: Ciências } \\
\text { Sociais Aplicadas - Administração }\end{array}$ & $\begin{array}{l}\text { Instituição: Universidade de São } \\
\text { Paulo }\end{array}$ & jamazzon@usp.br \\
\hline 175 & Filipe Lopes & Maior nível de formação: Mestrado & $\begin{array}{l}\text { Primeira área de atuação: Ciências } \\
\text { Exatas e da Terra - Multidisciplinar }\end{array}$ & flopes5@mail.pt \\
\hline 176 & Rogério Tadeu da Silva & Maior nível de formação: Mestrado & $\begin{array}{l}\text { Primeira área de atuação: Ciências } \\
\text { Sociais Aplicadas - Administração }\end{array}$ & rogeriotadeusilva@gmail.com \\
\hline 177 & Marta de Campos Maia & Maior nivel de formação: Doutorado & $\begin{array}{l}\text { Primeira área de atuação: Ciências } \\
\text { Sociais Aplicadas - Multidisciplinar }\end{array}$ & mmaia@fgusp.br \\
\hline 178 & William Gurdon Tyler & $\begin{array}{l}\text { Maior nível de formação: Doutorado } \\
\text { (Pós-Doutorado) }\end{array}$ & $\begin{array}{l}\text { Primeira área de atuação: Ciências } \\
\text { Sociais Aplicadas - Economia }\end{array}$ & WTyler@attglobal.net \\
\hline 179 & Valter de Assis Moreno Jr & Maior nível de formação: Doutorado & $\begin{array}{l}\text { Primeira área de atuação: Ciências } \\
\text { Exatas e da Terra - Ciência da } \\
\text { Computacão }\end{array}$ & vmoreno@ibmecri.br \\
\hline 181 & Jorge Luis Risco Becerra & Maior nivel de formação: Doutorado & $\begin{array}{l}\text { Primeira área de atuação: } \\
\text { Engenharias - Engenharia Elétrica }\end{array}$ & jorge.becerra@poli.usp.br \\
\hline 182 & Marcelo Alves de Barros & $\begin{array}{l}\text { Maior nível de formação: Doutorado } \\
\text { (Pós-Doutorado) }\end{array}$ & $\begin{array}{l}\text { Primeira área de atuação: Ciências } \\
\text { Exatas e da Terra - Ciência da } \\
\text { Computacão }\end{array}$ & barros@dsc.ufcg.edu.br \\
\hline 183 & João Eduardo Ferreira & $\begin{array}{l}\text { Primeira área de atuação: Ciências } \\
\text { Exatas e da Terra - Ciência da } \\
\text { Computacão }\end{array}$ & $\begin{array}{l}\text { Instituição: Universidade de São } \\
\text { Paulo }\end{array}$ & jef@ime.usp.br \\
\hline 184 & Heitor Mansur Caulliraux & Maior nível de formação: Doutorado & $\begin{array}{l}\text { Primeira área de atuação: } \\
\text { Engenharias - Engenharia de } \\
\text { Produção }\end{array}$ & heitor@gpi.ufrj.br \\
\hline
\end{tabular}




\section{Anexo 2 \\ BPMN - Business Process Modeling Notation}




\title{
Introduction to BPMN
}

\author{
Stephen A. White, IBM Corporation
}

\begin{abstract}
This paper is intended to provide a high-level overview and introduction to the Business Process Modeling Notation (BPMN). The context and general uses for BPMN will be provided as a supplement to the technical details defined the BPMN 1.0 Specification, which has been recently completed and released to the public. The basics of the BPMN notation will be discribed-that is, the types of graphical objects that comprise the notation and how they work together as part of a Business Process Diagram. Also discussed will be the different uses of BPMN, including how levels of precision affect what a modeler will include in a diagram. Finally, the value in using BPMN as a standard notation will be defined and the future of BPMN outlined.
\end{abstract}

\section{What Is BPMN?}

The Business Process Management Initiative (BPMI) has developed a standard Business Process Modeling Notation (BPMN). The BPMN 1.0 specification was released to the public in May, 2004. This specification represents more than two years of effort by the BPMI Notation Working Group. The primary goal of the BPMN effort was to provide a notation that is readily understandable by all business users, from the business analysts that create the initial drafts of the processes, to the technical developers responsible for implementing the technology that will perform those processes, and finally, to the business people who will manage and monitor those processes. BPMN will also be supported with an internal model that will enable the generation of executable BPEL4WS. Thus, BPMN creates a standardized bridge for the gap between the business process design and process implementation.

BPMN defines a Business Process Diagram (BPD), which is based on a flowcharting technique tailored for creating graphical models of business process operations. A Business Process Model, then, is a network of graphical objects, which are activities (i.e., work) and the flow controls that define their order of performance.

\section{BPMN Basics}

A BPD is made up of a set of graphical elements. These elements enable the easy development of simple diagrams that will look familiar to most business analysts (e.g., a flowchart diagram). The elements were chosen to be distinguishable from each other and to utilize shapes that are familiar to most modelers. For example, activities are rectangles and decisions are diamonds. It should be emphasized that one of the drivers for the development of BPMN is to create a simple mechanism for creating business process models, while at the same time being able to handle the complexity inherent to business processes. The approach taken to handle these two conflicting requirements was to organize the graphical aspects of the notation into specific categories. This provides a small set of notation categories so that the reader of a BPD can easily recognize the basic types of 
elements and understand the diagram. Within the basic categories of elements, additional variation and information can be added to support the requirements for complexity without dramatically changing the basic look-and-feel of the diagram. The four basic categories of elements are:

- Flow Objects

- Connecting Objects

- Swimlanes

- Artifacts

\section{Flow Objects}

A BPD has a small set of (three) core elements, which are the Flow Objects, so that modelers do not have to learn and recognize a large number of different shapes. The three Flow Objects are:

Event

Activity

Gateway
An Event is represented by a circle and is something that "happens" during the course of a business process. These Events affect the flow of the process and usually have a cause (trigger) or an impact (result). Events are circles with open centers to allow internal markers to differentiate different triggers or results. There are three types of Events, based on when they affect the flow: Start, Intermediate, and End (see the figures to the right, respectively).

An Activity is represented by a rounded-corner rectangle (see the figure to the right) and is a generic term for work that company performs. An Activity can be atomic or nonatomic (compound). The types of Activities are: Task and Sub-Process. The Sub-Process is distinguished by a small plus sign in the bottom center of the shape.

A Gateway is represented by the familiar diamond shape (see the figure to the right) and is used to control the divergence and convergence of Sequence Flow. Thus, it will determine traditional decisions, as well as the forking, merging, and joining of paths. Internal Markers will indicate the type of behavior control.

Table 1: Core BPD Flow Objects
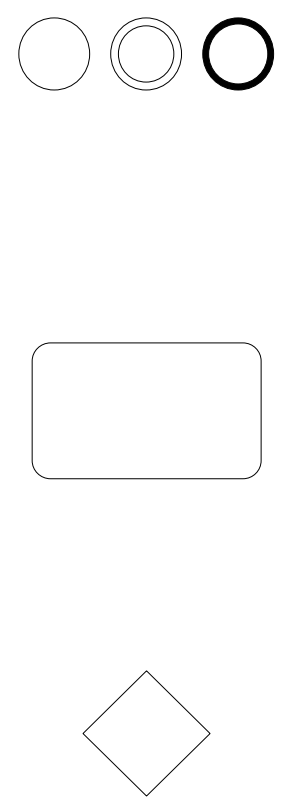


\section{Connecting Objects}

The Flow Objects are connected together in a diagram to create the basic skeletal structure of a business process. There are three Connecting Objects that provide this function. These connectors are:

Sequence Flow

Message Flow

Association
A Sequence Flow is represented by a solid line with a solid arrowhead (see the figure to the right) and is used to show the order (the sequence) that activities will be performed in a Process. Note that the term "control flow" is generally not used in BPMN.

A Message Flow is represented by a dashed line with an open arrowhead (see the figure to the right) and is used to show the flow of messages between two separate Process Participants (business entities or business roles) that send and receive them. In BPMN, two separate Pools in the Diagram will represent the two Participants.

An Association is represented by a dotted line with a line arrowhead (see the figure to the right) and is used to associate data, text, and other Artifacts with flow objects. Associations are used to show the inputs and outputs of activities.

Table 2: BPD Connecting Elements

For modelers who require or desire a low level of precision to create process models for documentation and communication purposes, the core elements plus the connectors will provide the ability to easily create understandable diagrams (see Figure 1).

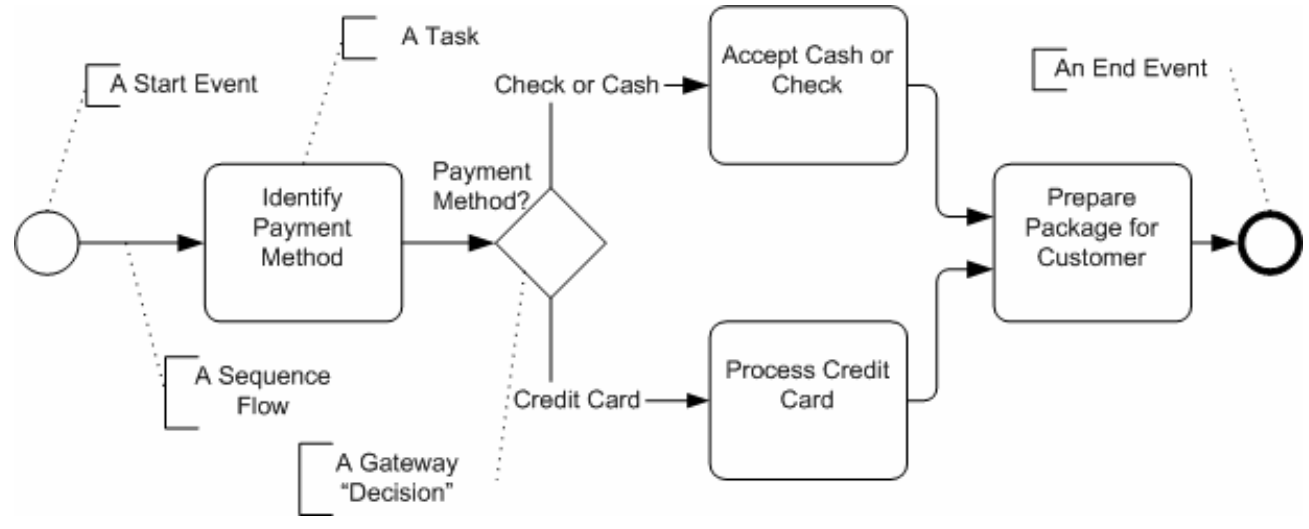

Figure 1: An Example of a Simple Business Process

For modelers who require a higher level of precision to create process models, which will be subject to detailed analysis or will be managed by Business Process Management System (BPMS), additional details can be added to the core elements and shown through internal markers (see Figure 2). 


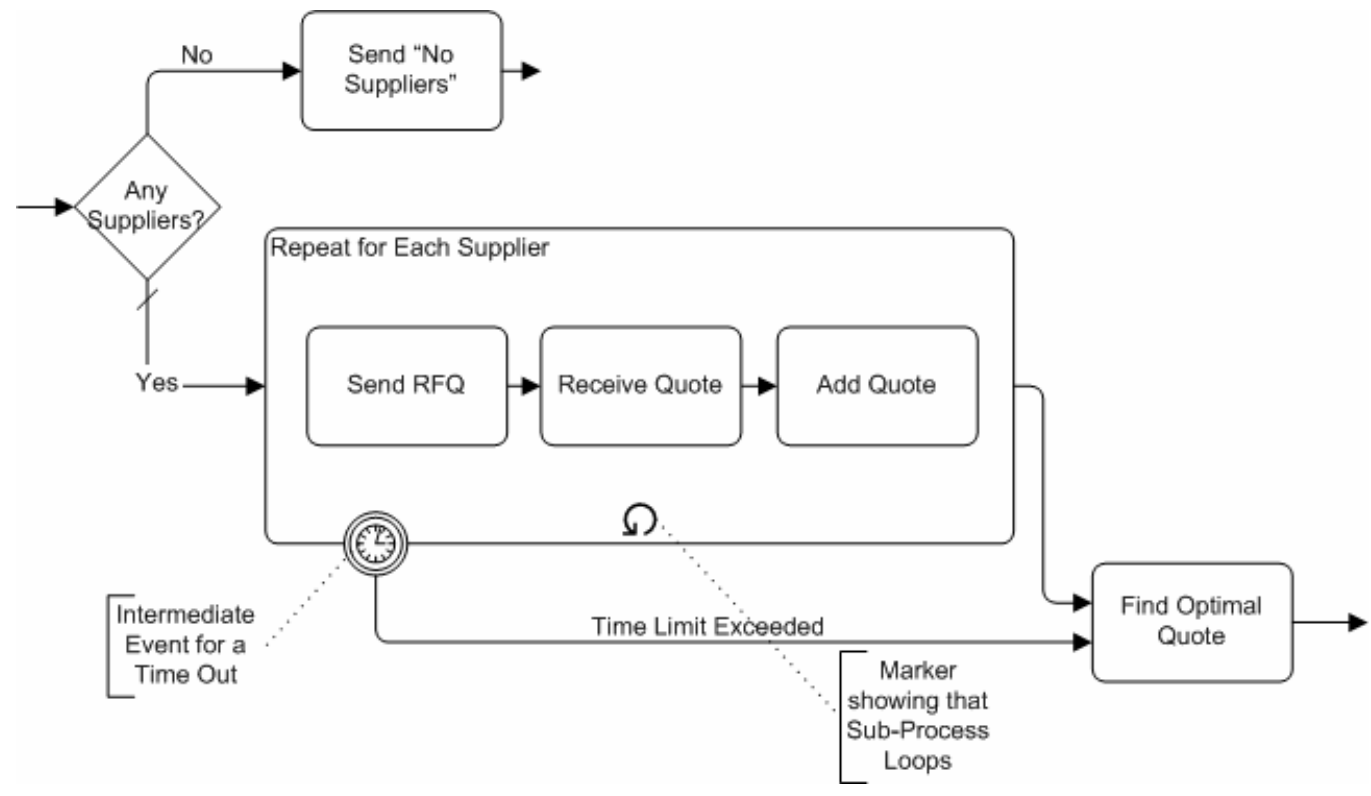

Figure 2: A Segment of a Process with more Details

\section{Swimlanes}

Many process modeling methodologies utilizes the concept of swimlanes as a mechanism to organize activities into separate visual categories in order to illustrate different functional capabilities or responsibilities. BPMN supports swimlanes with two main constructs. The two types of BPD swimlane objects are:

\section{A Pool represents a Participant in a Process. It is also acts as a graphical container for partitioning}

Pool a set of activities from other Pools (see the figure to the right), usually in the context of B2B

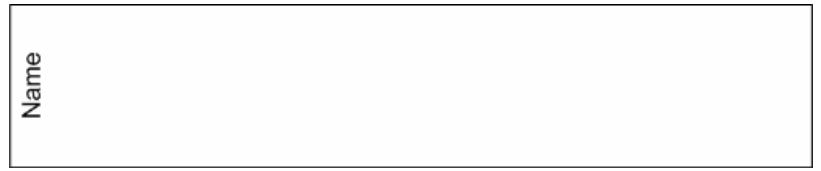
situations.

A Lane is a sub-partition within a Pool and will extend the entire Lane length of the Pool, either vertically or horizontally (see the figure to the right). Lanes are used to organize and categorize activities.

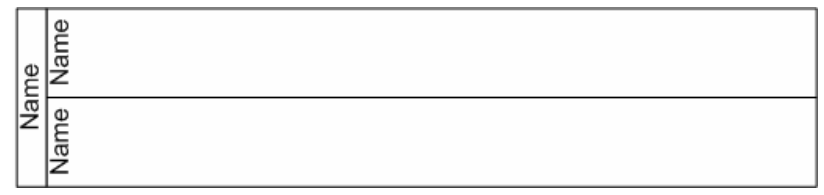

Table 3: BPD Swimlane Objects

Pools are used when the diagram involves two separate business entities or participants (see Figure 3) and are physically separated in the diagram. The activities within separate Pools are considered self-contained Processes. Thus, the Sequence Flow may not cross the boundary of a Pool. Message Flow is defined as being the mechanism to show the communication between two participants, and, thus, must connect between two Pools (or the objects within the Pools). 


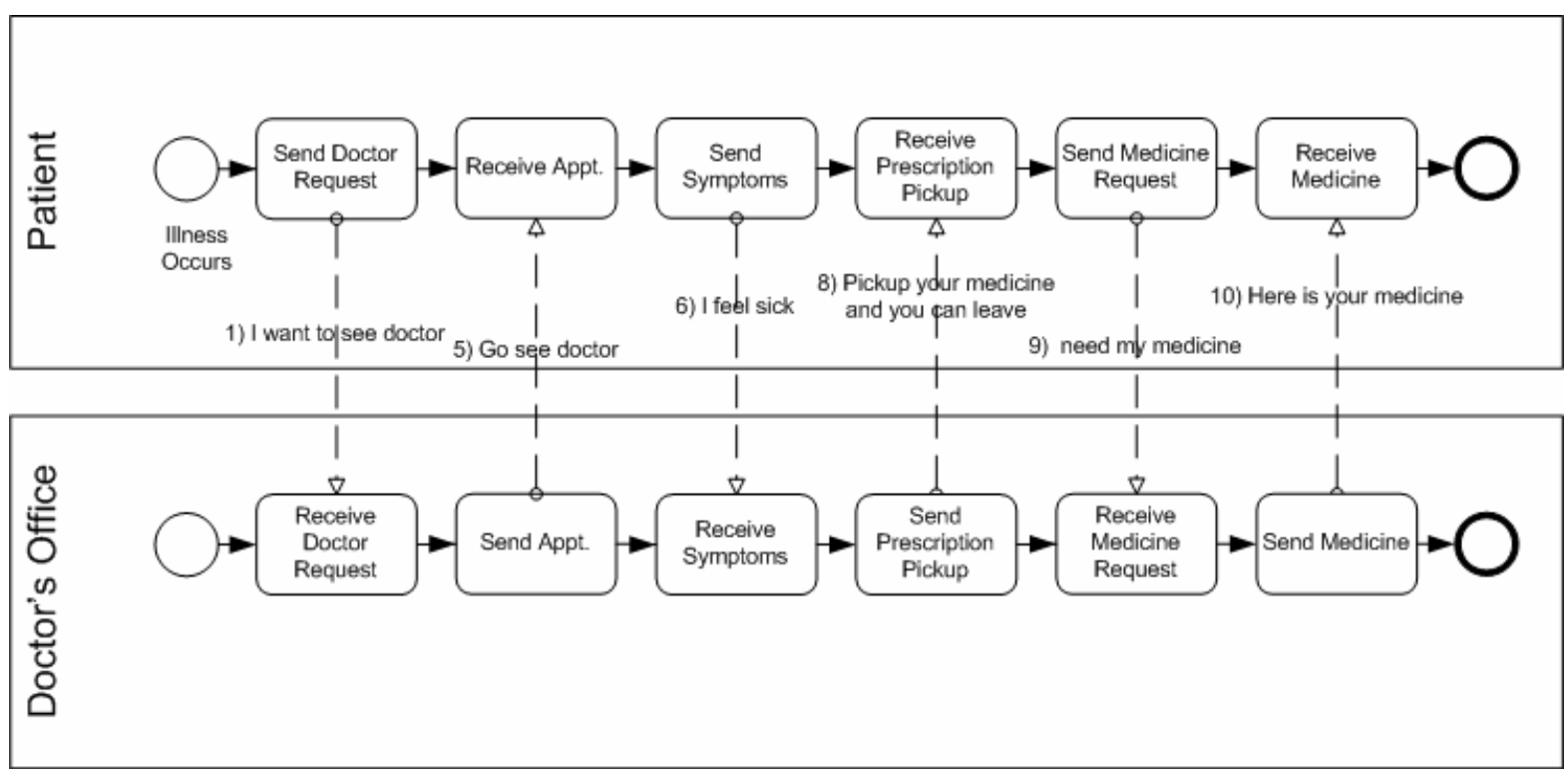

Figure 3: An Example of a BPD with Pools

Lanes are more closely related to the traditional swimlane process modeling methodologies. Lanes are often used to separate the activities associated with a specific company function or role (see Figure 4). Sequence Flow may cross the boundaries of Lanes within a Pool, but Message Flow may not be used between Flow Objects in Lanes of the same Pool.

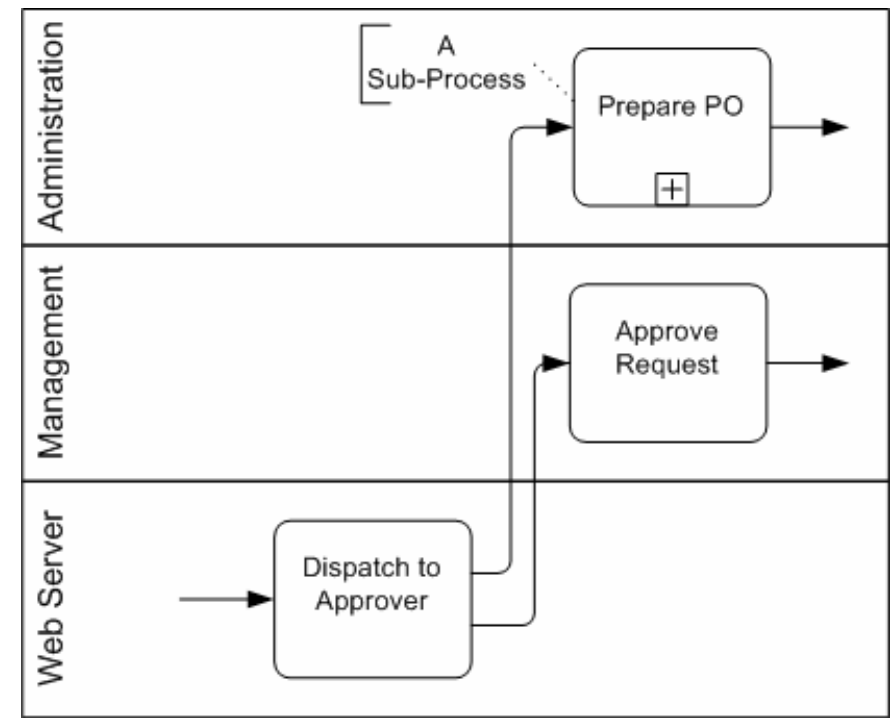

Figure 4: A Segment of a Process with Lanes 


\section{Artifacts}

BPMN was designed to allow modelers and modeling tools some flexibility in extending the basic notation and in providing the ability to additional context appropriate to a specific modeling situation, such as for a vertical market (e.g., insurance or banking). Any number of Artifacts can be added to a diagram as appropriate for the context of the business processes being modeled. The current version of the BPMN specification pre-defines only three types of BPD Artifacts, which are:

Data Object data is required or produced by activities. They are connected to activities through Associations.

A Group is represented by a rounded corner

Group rectangle drawn with a dashed line (see the figure to the right). The grouping can be used for documentation or analysis purposes, but does not affect the Sequence Flow.

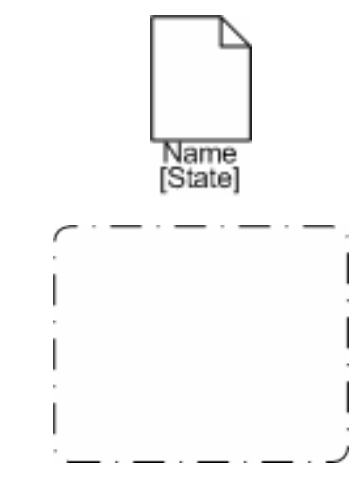

Annotations are a mechanism for a modeler

Annotation to provide additional text information for the reader of a BPMN Diagram (see the figure to the right).

Table 4: BPD Artifact Elements

Modelers can create their own types of Artifacts, which add more details about how the process is performed — quite often to show the inputs and outputs of activities in the Process. However, the basic structure of the process, as determined by the Activities, Gateways, and Sequence Flow, are not changed with the addition of Artifacts in the diagram; as you can see by comparing Figure 4 and Figure 5. 


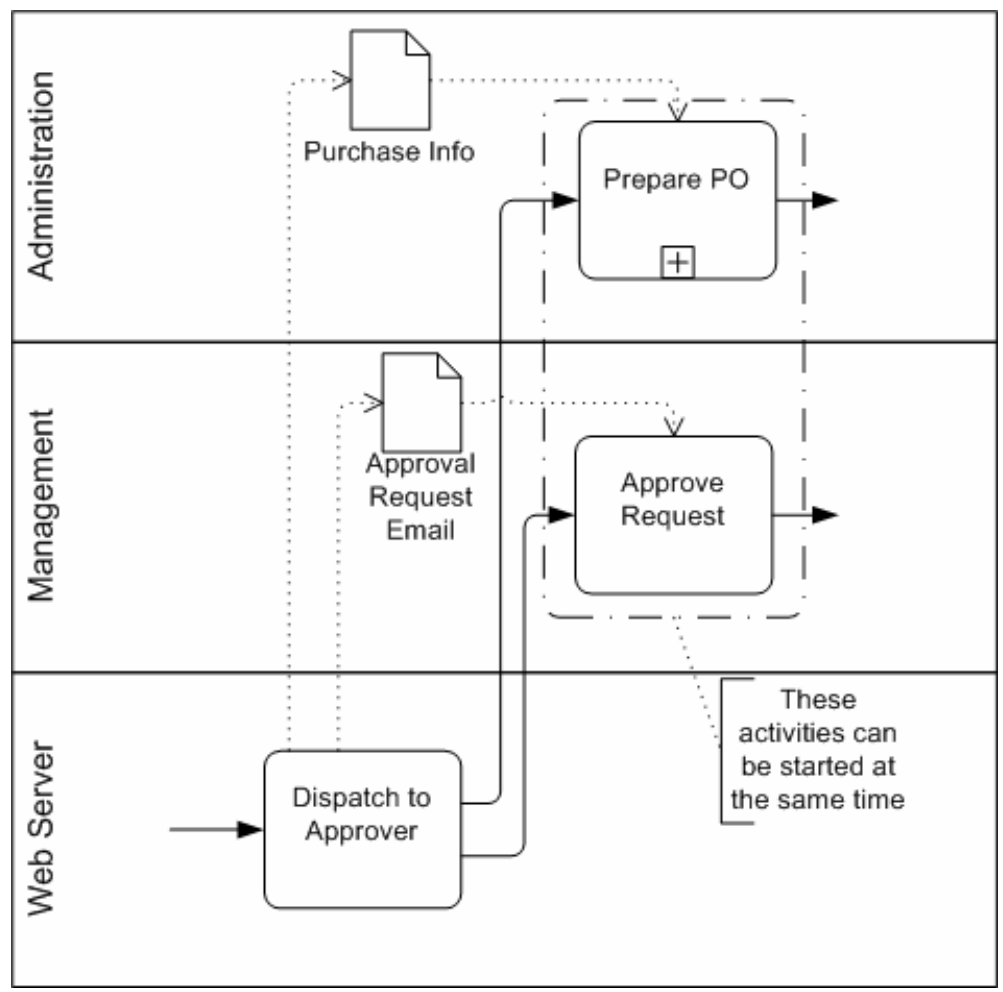

Figure 5: A Segment of a Process with Data Objects, Groups, and Annotations

\section{General uses of BPMN}

Business process modeling is used to communicate a wide variety of information to different audiences. BPMN is designed to cover many types of modeling and allows the creation of process segments as well as end-to-end business processes, at different levels of fidelity. Within the variety of process modeling objectives, there are two basic types of models that can be created with a BPD:

- Collaborative (Public) B2B Processes

- Internal (Private) Business Processes

\section{Collaborative B2B Processes}

A collaborative $B 2 B$ process depicts the interactions between two or more business entities. The diagrams for these types of processes are generally from a global point of view. That is, they do not take the view of any particular participant, but show the interactions between the participants. The interactions are depicted as a sequence of activities and the message exchange patterns between the participants. The activities for the collaboration participants can be considered the "touch-points" between the participants; thus, the process defines the interactions that are visible to the public for each participant. When looking at the process shown in only one Pool (i.e., for one participant), public process is also called an abstract process. The actual (internal) processes are likely to have more activities and detail than what is shown in the collaborative B2B processes.

Figure 3, above, is repeated in Figure 6 to show an example of a collaborative B2B process. 


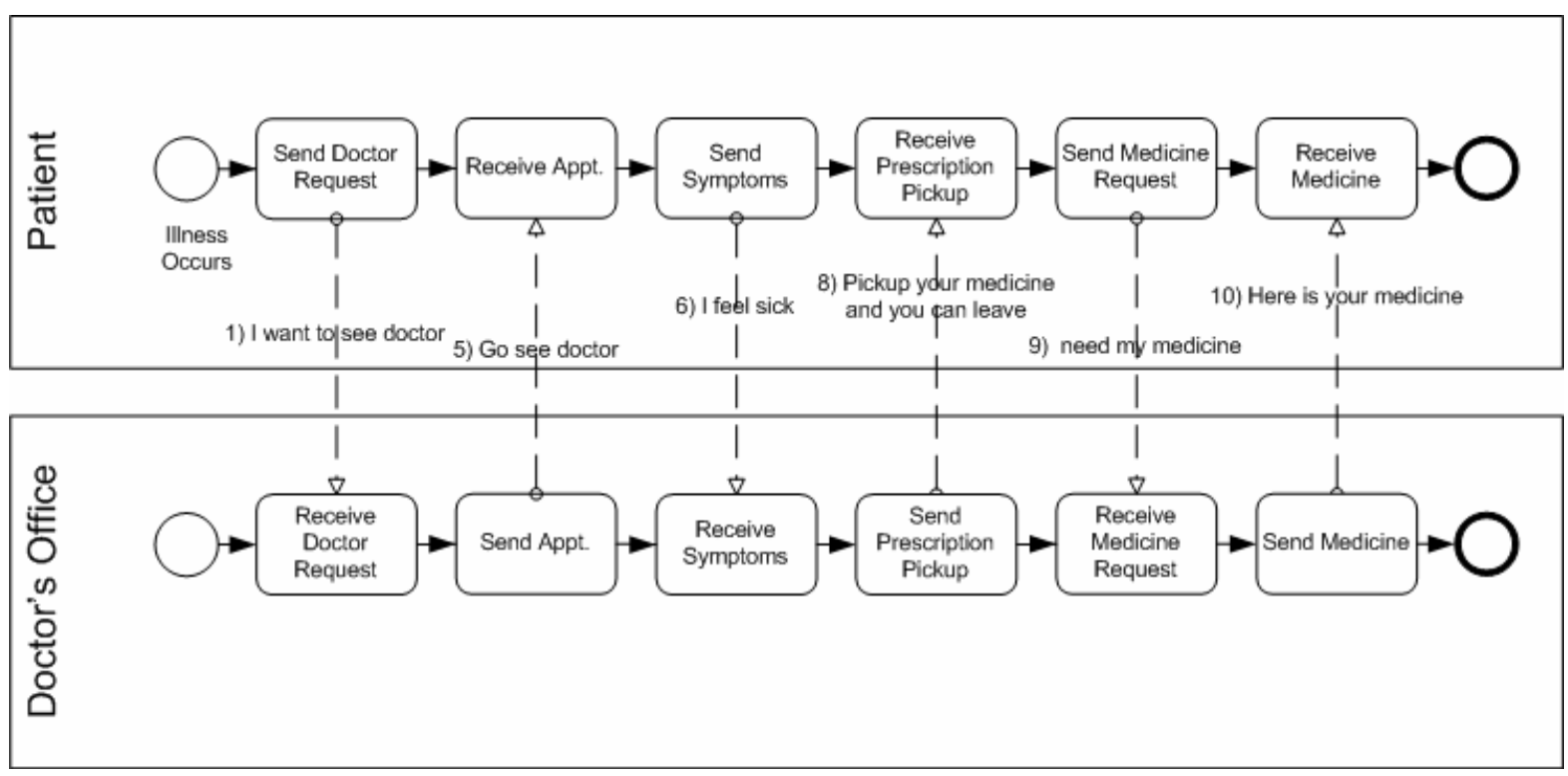

Figure 6: An Example of a Collaborative B2B Process

\section{Internal business processes}

An internal business process will generally focus on the point of view of a single business organization. Although internal processes often show interactions with external participants, they define the activities that are not generally visible to the public and are, therefore, private activities. If swimlanes are used then an internal business process will be contained within a single Pool. The Sequence Flow of the Process is therefore contained within the Pool and cannot cross the boundaries of the Pool. Message Flow can cross the Pool boundary to show the interactions that exist between separate internal business processes. Thus, a single Business Process Diagram may show multiple private business processes.

\section{Different Purposes - Different levels of precision}

The modeling of business processes often starts with capturing high-level activities and then drilling down to lower levels of detail within separate diagrams. There may be multiple levels of diagrams, depending on the methodology used for model development. However, BPMN is independent of any specific process modeling methodology.

Figure 7 shows an example of a high level process, captured for a BPMN case study, which is basically a series of Sub-Processes with three decision points in the Process.

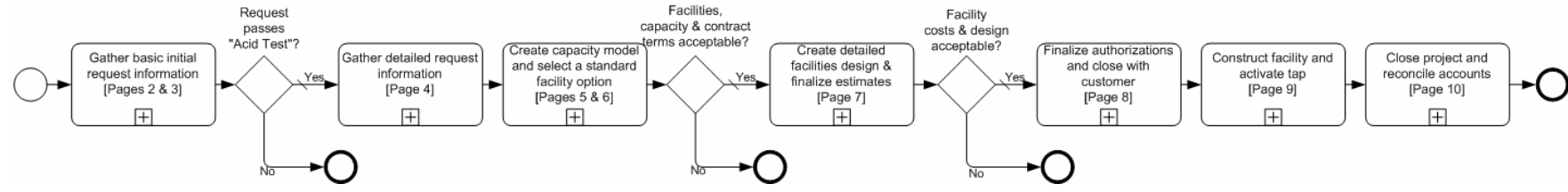

Figure 7: High-level Business Process Example

Figure 8 shows the details of the first Sub-Process of Figure 7. This diagram employs two (2) Pools; one for the customer and one for the company providing the service. Note that this diagram shows the internal business process for the company and shows an abstract process for the customer (i.e., 
the customer process only includes the activities used for communicating through Message Flow to the company). The activities within the company are partitioned by Lanes to show the departments or roles responsible for their performance (e.g., System Coordinator, Business Development, Legal, and Retail).

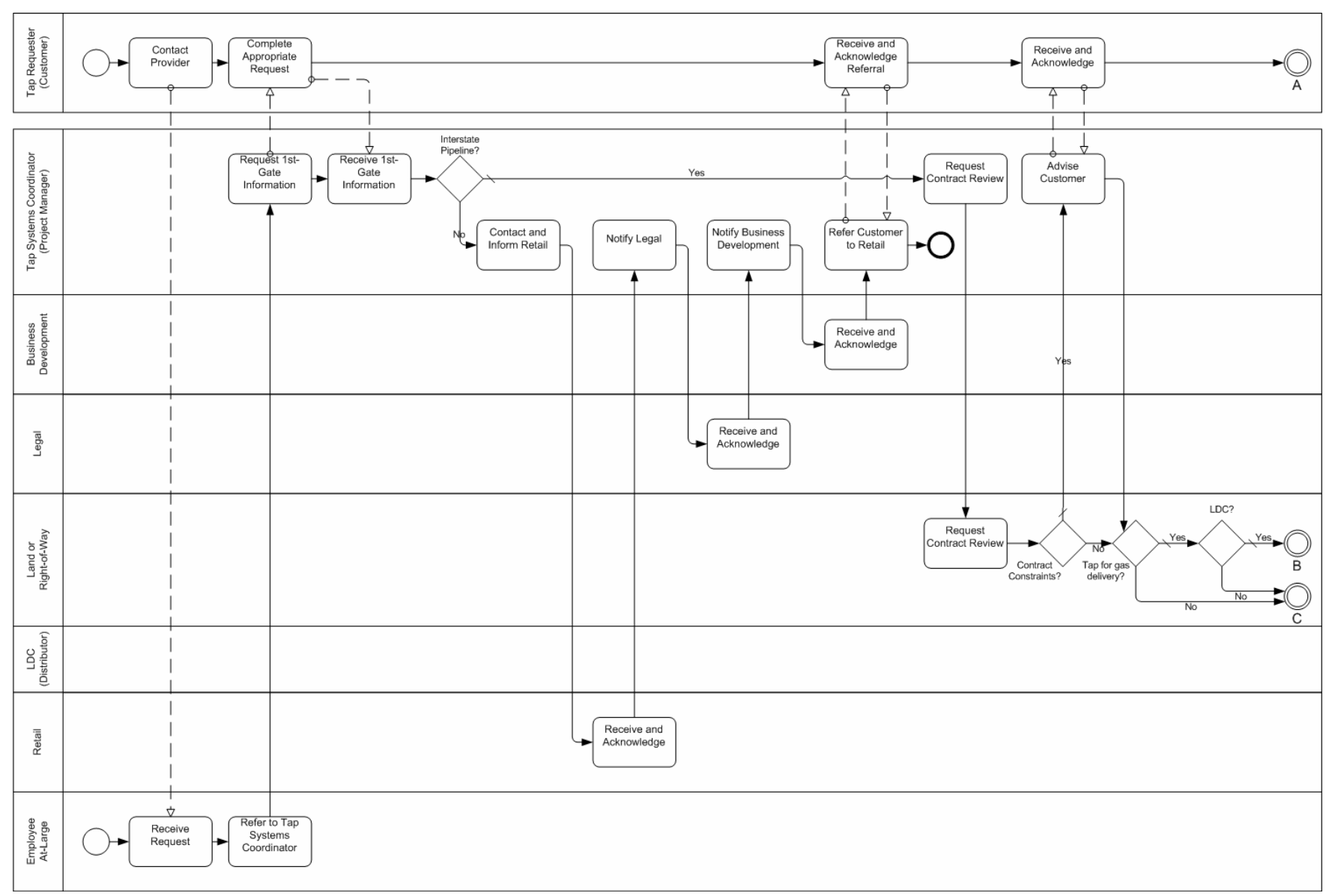

Figure 8: Lower-level Business Process for the High-Level Example

\section{What is the Value of modeling in BPMN?}

The membership of the BPMI Notation Working Group represents a large segment of the business process modeling community and they have come to a consensus and present BPMN as the standard business process modeling notation. The development of BPMN is an important step in reducing the fragmentation that exists with the myriad of process modeling tools and notations. The BPMI Notation Working Group has brought forth expertise and experience with many existing notations and has sought to consolidate the best ideas from these divergent notations into a single standard notation. Examples of other notations or methodologies that were reviewed are: UML Activity Diagram, UML EDOC Business Processes, IDEF, ebXML BPSS, Activity-Decision Flow (ADF) Diagram, RosettaNet, LOVeM, and Event-Process Chains (EPCs). This fragmentation has hampered the wide-spread adoption of inter-operable business process management systems. A well-supported standard modeling notation will reduce confusion among business and IT end-users. 
Another factor that drove the development of BPMN is that, historically, business process models developed by business people have been technically separated from the process representations required by systems designed to implement and execute those processes. Thus, there was a need to manually translate the original business process models to the execution models. Such translations are subject to errors and make it difficult for the process owners to understand the evolution and the performance of the processes they developed.

\section{Mapping a BPMN Diagram to BPEL4WS}

To help alleviate the modeling technical gap, a key goal in the effort to develop BPMN was to create a bridge from the business-oriented process modeling notation to IT-oriented execution languages that will implement the processes within a business process management system. The graphical objects of BPMN, supported by a rich set of object attributes, have been mapped to the Business Process Execution Language for Web Services (BPEL4WS v1.1), the defacto standard for process execution. Figure 9 provides an example of a segment of a business process and marks the mapping to the BPEL4WS execution elements.

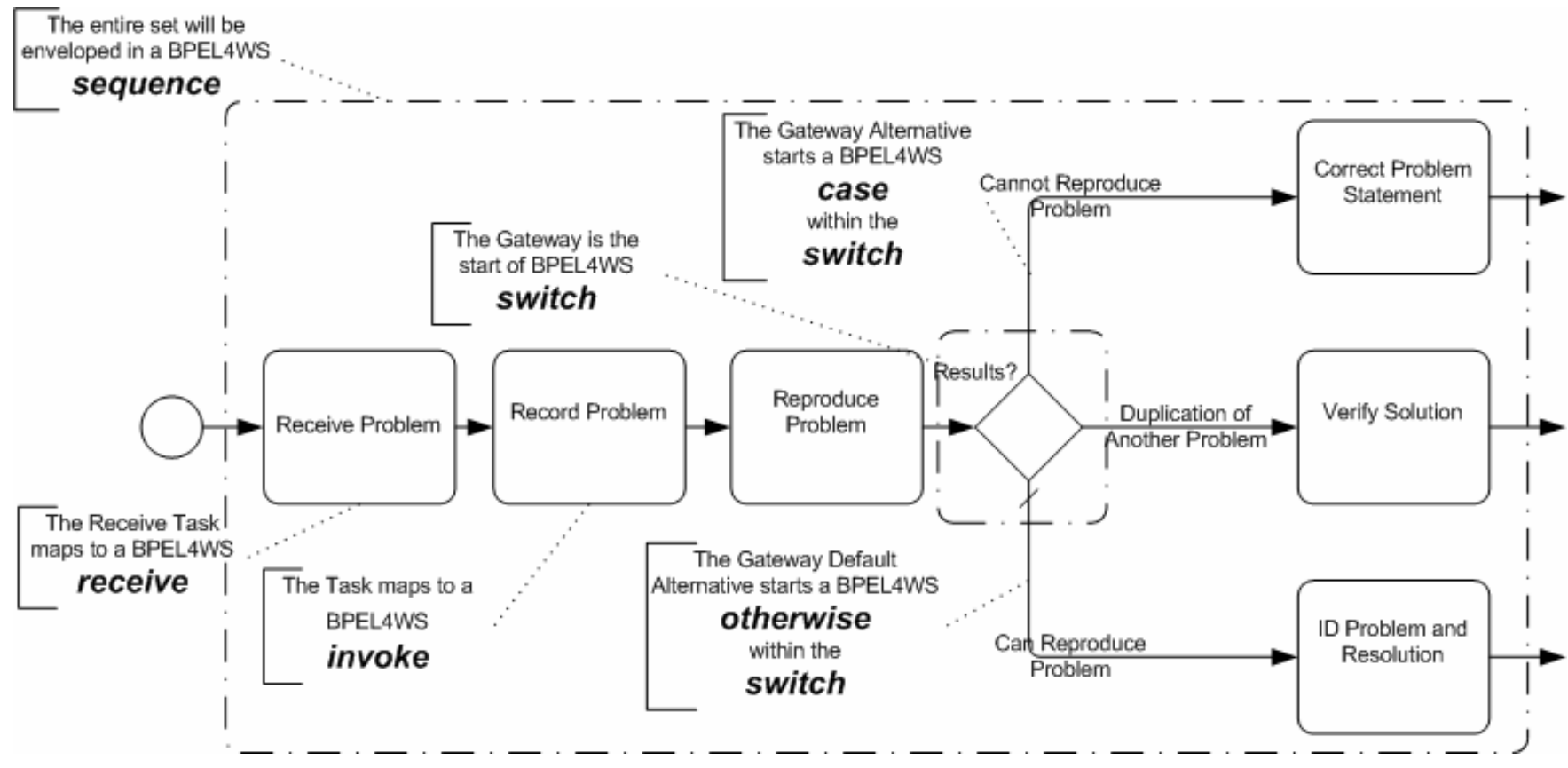

Figure 9: A BPD with Annotations to Show the Mapping to BPEL4WS 


\section{Future of BPMN}

Even though the BPMN specification is currently at a version 1.0, many companies have committed to supporting and implementing the specification (see the BPMI press release, dated March 2, 2004: http://www.bpmi.org/PR.esp?id=301). The near future will provide a great deal of vendor and end-user experience with BPMN. Such experience will provide valuable feedback for fine-tuning the details of the BPMN specification, particularly concerning the mapping to BPEL4WS. While a major revision of BPMN is not expected soon, a maintenance version (e.g., version 1.1) can be expected to be completed in about 9 to 12 months. In addition to a maintenance release, there is likely to be efforts within BPMI to standardize sets of Artifacts to support general business modeling and vertical business domains (e.g., insurance, manufacturing, and finance). In addition, there is likely to be efforts to fit BPMN into a larger context of higher-level business modeling, which includes, for example, the modeling of business rules and business strategy.

BPMI is not a formal standards organization; rather, BPMI is an organization that innovates and incubates key specifications to support the development of BPM systems. Therefore, BPMN will eventually be passed on to an organization to formalize its status as standard. The OMG is a likely candidate to eventually take in the BPMN standards and there have been discussions between BPMI and the OMG to facilitate this transfer in the future. Considering that the OMG is currently developing UML, which includes Activity Diagrams, it is possible that a consolidation of BPMN Business Process Diagrams and UML Activity Diagrams will take place. 